ROBERTO ROMANO

DESENVOLVIMENTO DE UM ATUADOR DE POSIÇÃO BASEADO EM LIGA DE MEMÓRIA DE FORMA COM RESFRIAMENTO FORÇADO 


\title{
DESENVOLVIMENTO DE UM ATUADOR DE POSIÇÃO BASEADO EM LIGA DE MEMÓRIA DE FORMA COM RESFRIAMENTO FORÇADO
}

\author{
Dissertação apresentada à Escola \\ Politécnica da Universidade de São \\ Paulo para obtenção do título de \\ Mestre em Engenharia Elétrica \\ Área de Concentração: \\ Engenharia de Sistemas
}

Orientador:

Prof. Dr. Eduardo Aoun Tannuri 
FICHA CATALOGRÁFICA

\section{Romano, Roberto}

Desenvolvimento de um atuador de posição baseado em liga de memória de forma com resfriamento forçado / R. Romano. -São Paulo, 2006.

$127 \mathrm{p}$.

Dissertação (Mestrado) - Escola Politécnica da Universidade de São Paulo. Departamento de Engenharia de Telecomunicações e Controle.

1.Desenvolvimento de tecnologia 2.Sistemas de controle 3.Sistemas não-lineares I.Universidade de São Paulo. Escola Politécnica. Departamento de Engenharia de Telecomunicações e Controle II.t. 
Dedico este trabalho a minha mãe (em memória), meu pai, minha esposa e minhas filhas. 


\section{AGRADECIMENTOS}

Agradeço a Deus por ter me iluminado, dado forças e saúde para concluir este trabalho.

À minha mãe Maria e ao meu pai Nelson os ensinamentos para o caminho para uma vida digna com seus bons conselhos.

À minha esposa Virley e às minhas filhas, Karoline e Priscilla, a força e incentivo moral e espiritual nas horas difíceis na execução deste trabalho.

Aos meus irmãos Silvana e Carlos o constante incentivo e apoio.

Ao meu orientador Eduardo, que muito me incentivou e principalmente muito me ajudou na execução deste trabalho, sem o qual este não seria possível de ser realizado.

Ao meu amigo Rynaldo, que muito me ajudou nas minhas inúmeras dúvidas.

A todos os meus amigos que direta e indiretamente me ajudaram durante a execução deste trabalho.

Ao Instituto de Pesquisas Tecnológicas do Estado de São Paulo que me proporcionou os meios para realizar os experimentos em suas instalações e utilizar seus recursos. 


\section{RESUMO}

As ligas com memória de forma (Shape Memory Alloy - SMA) consistem em um grupo de materiais metálicos que possuem a habilidade de retornar a um formato ou tamanho previamente definido quando submetidas a um ciclo térmico adequado, devido a alterações em sua estrutura cristalina. Esta mudança não é um processo termodinamicamente reversível, apresentando, conseqüentemente, histerese. Portanto, a característica principal destes materiais é a habilidade de sofrer grandes deformações e, em seguida, recuperar sua forma original quando a carga é removida ou o material é aquecido. Assim, pode-se utilizar esse fenômeno para construir atuadores leves e silenciosos, como verdadeiros músculos metálicos. O desenvolvimento de atuadores com as SMAs apresenta grande atrativo para diversos campos da engenharia, principalmente na área de robótica, substituindo os atuadores convencionais de grande peso e ruidosos, como motores, válvulas solenóides, etc. Entretanto, para o bom desempenho de atuadores SMA requer-se um complexo sistema de controle e resfriamento, reduzindo-se o tempo de resposta do atuador e minimizando-se os efeitos da histerese.

Neste trabalho, propõe-se um inovador sistema de resfriamento, baseado em pastilha termo-elétrica (efeito Seebeck-Peltier). Este método possui a vantagem de ser mais compacto e simples que outros métodos de resfriamento forçado. Um modelo matemático completo foi também desenvolvido, e um protótipo experimental foi construído. Diversos experimentos foram utilizados para a validação do modelo e para a identificação de todos seus parâmetros.

Analisou-se então a aplicabilidade de um controle de posição baseado em algoritmo PID, utilizando-se diversos métodos de ajuste de ganhos. Verificou-se um desempenho razoável, com uma largura de banda em malha fechada de aproximadamente $0,37 \mathrm{~Hz}$. Em seguida, desenvolveu-se um sistema de controle de posição baseado em teoria de modos deslizantes (sliding mode control), que utiliza o modelo matemático do sistema e leva em conta as não linearidades existentes. Embora matematicamente mais complexo, obteve-se um desempenho superior ao PID, com largura de banda de $0,69 \mathrm{~Hz}$. Diversos experimentos confirmaram também a robustez deste controlador e seu bom desempenho na presença de distúrbios.

Palavras Chaves: Atuadores de posição, Liga de memória de forma, Controle por modos deslizantes, Robótica 


\begin{abstract}
Shape Memory Alloys (SMA) consist of a group of metallic materials that demonstrate the ability to return to some previously defined shape when subjected to the appropriate thermal cycle, due to shift in the materials crystalline structure. The change that occurs within SMAs crystalline structure is not a thermodynamically reversible process and results in hysteresis behavior. The key feature of these materials is the ability to undergo large plastic strains and subsequently recover these strains when a load is removed or the material is heated. Such property can be used to build silent and light actuators, similar to a mechanical muscular fiber. SMA actuators have several advantages in several engineering fields, mainly in robotics, replacing the conventional actuators like motors or solenoids. However, the good performance of the SMA actuator depends on a complex control and cooling systems, reducing the time constant and minimizing the effects of hysteresis.

In the present work, a novel cooling system is proposed, based on thermo-electric effect (Seebeck-Peltier effect). Such method has the advantage of reduced weight and requires a simpler control strategy compared to other forced cooling systems. A complete mathematical model of the actuator was also derived, and an experimental prototype was implemented. Several experiments were used to validate the model and to identify all parameters.
\end{abstract}

A PID position control system was developed and implemented in the prototype, using several tuning methods. A good performance was obtained, with a cut-off frequency of $0.37 \mathrm{~Hz}$. A position controller based on sliding mode theory was then developed, using the mathematical model of the system and taking into account the non-linear effects. Although such controller presents a more complex mathematical derivation, a better performance was obtained, with a cut-off frequency of $0.69 \mathrm{~Hz}$. Several experiments confirmed the robustness and disturbance filtering properties of the sliding mode controller.

Keywords: Position's actuators, Shape memory alloy, Sliding mode control, Robotic. 


\section{LISTA DE ILUSTRAÇÕES}

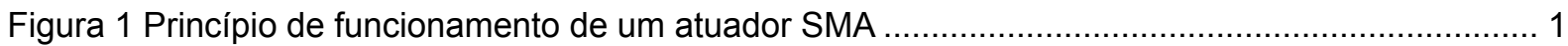

Figura 2 Mecanismo do atuador SMA proposto por Tanaka e Yamada (1991) ............................. 5

Figura 3 Sistema de controle atuador SMA proposto por Tanaka e Yamada (1991) .......................... 7

Figura 4 Atuador SMA proposto por Golbert e Russel (1995) ................................................ 9

Figura 5 Sistema de atuação e controle do atuador SMA proposto por Golbert e Russel (1995) ....... 10

Figura 6 Resposta em malha fechada do atuador SMA com refrigeração por condução (adaptado de

Golbert e Russel (1995).

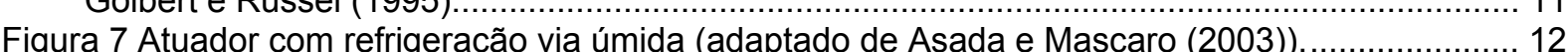

Figura 8 Esquema simplificado do atuador SMA úmido (adaptado de Asada e Mascaro (2002)) ....... 13

Figura 9 Dados experimentais do SMA úmido (adaptado de Asada e Mascaro (2003)) ................... 14

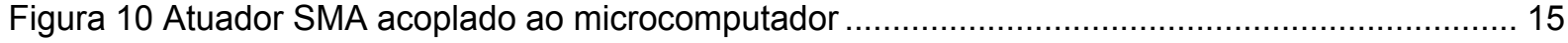

Figura 11 Atuador SMA interligado ao circuito condicionador e microcomputador ......................... 16

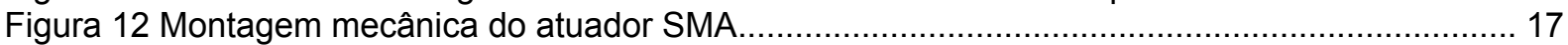

Figura 13 Atuador SMA refrigerado com pastilha termoelétrica ............................................ 18

Figura 14 Detalhes de montagem da pastilha termoelétrica ............................................... 19

Figura 15 Pastilha termoelétrica em contato com o fio de SMA e sistema dissipador de calor .......... 20

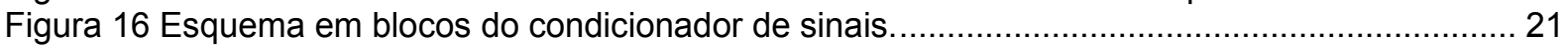

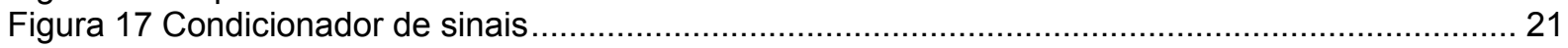

Figura 18- Placa A/D, D/A instalada dentro do gabinete do microcomputador Pentium $100 \ldots \ldots \ldots \ldots . . . . .22$

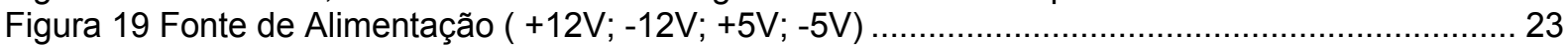

Figura 20-Sensor de posição com potenciômetro interligado ao eixo do atuador...........................23

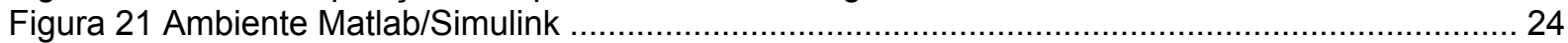

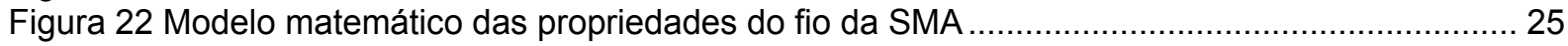

Figura 23 Fio de SMA em contato com a pastilha termoelétrica ........................................... 26

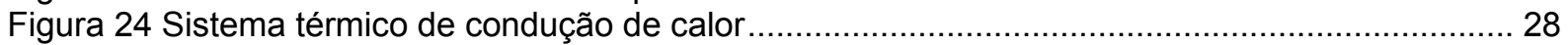

Figura 25 Curva de histerese do fio SMA $\xi$ versus temperatura (adaptado de Mavroidis; Pfeiffer e

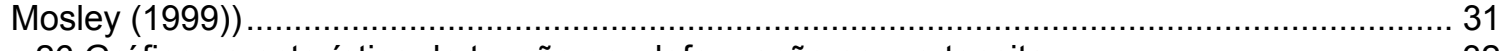

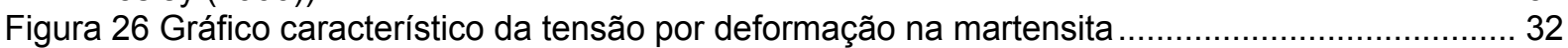

Figura 27 Esquema simplificado da montagem mecânica do experimento ................................... 33

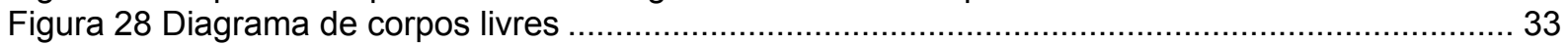

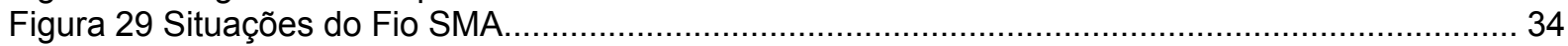

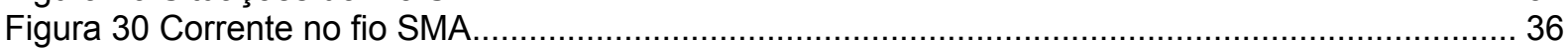

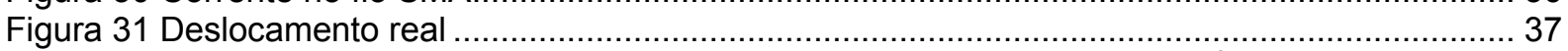

Figura 32 Deslocamento real e do modelo com parâmetros originais $\left(C=0,4 \mathrm{~W} /{ }^{\circ} \mathrm{C} / \mathrm{m} ; h=6,55\right.$ $\left.\mathrm{W} / \mathrm{m}^{2 \circ} \mathrm{C} / \mathrm{m}\right)$

Figura 33 Temperatura no fio de SMA, obtida pelo modelo matemático originais $\left(\mathrm{C}=0,4 \mathrm{~W} /{ }^{\circ} \mathrm{C} / \mathrm{m}\right.$;

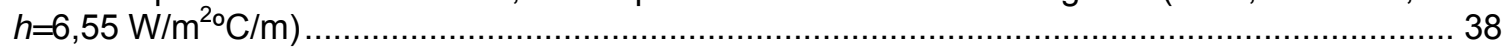

Figura 34 Gráfico do deslocamento após a correção dos parâmetros ........................................ 39

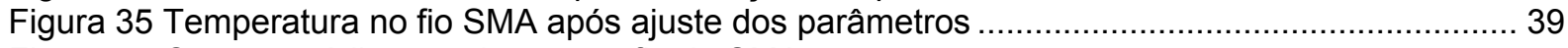

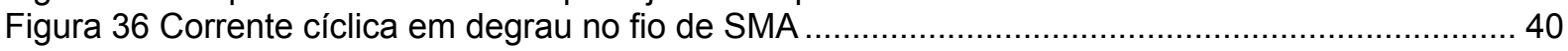

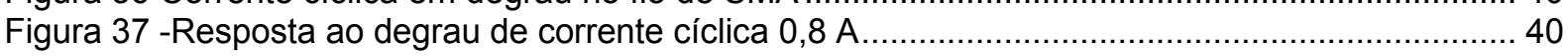

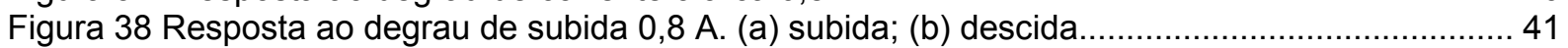

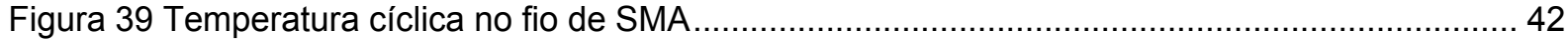

Figura 40 Resposta para corrente cíclica com várias amplitudes de degrau ....................................42

Figura 41 Sistema de controle em malha fechada acoplado ao atuador SMA............................. 45

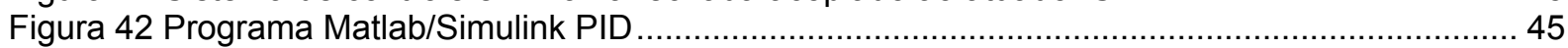

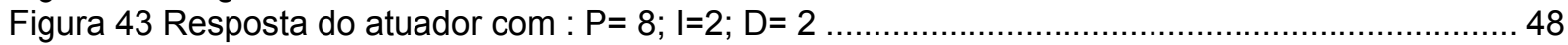

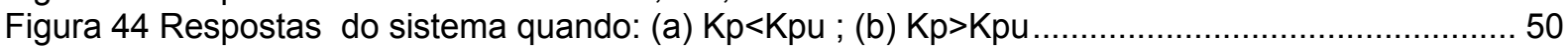

Figura 45 Diagrama em blocos utilizado na auto-sintonia ................................................. 51

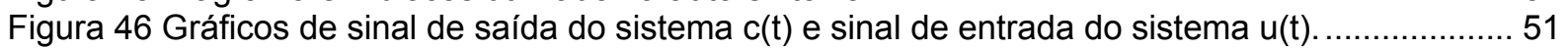

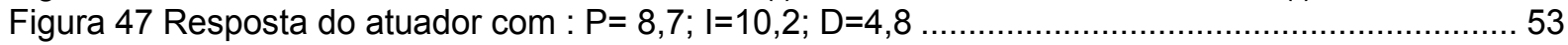

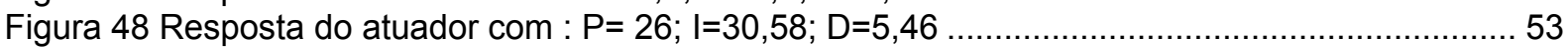

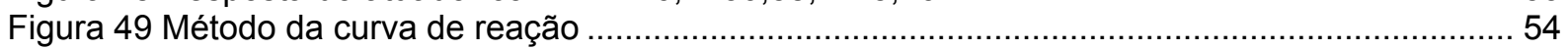

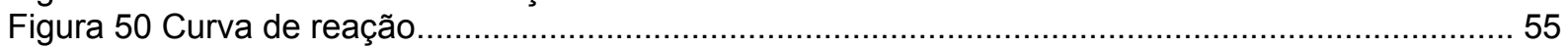

Figura 51 Determinação de $t_{a}$ e $t_{b}$ em função das amplitudes da curva de reação. ......................... 56

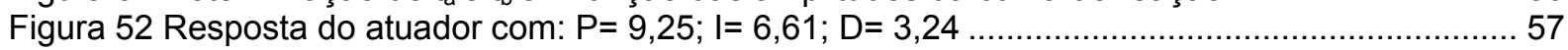




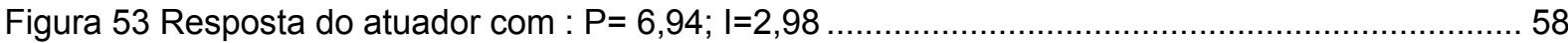

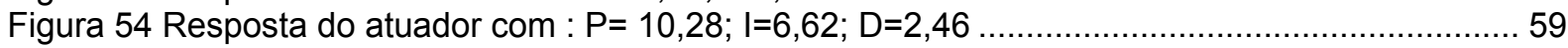

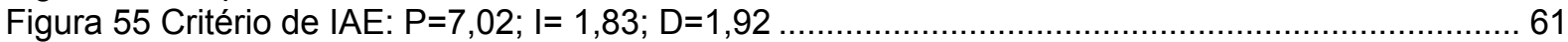

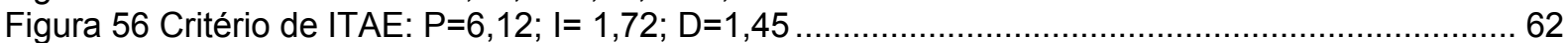

Figura 57 Mudança do valor do sinal de referência para $1 \mathrm{~V}$ com $P=6,12, \mathrm{I}=1,72, \mathrm{D}=1,45$ (ITAE) ..... 63

Figura 58 Critério de ITAE: $P=6,12 ; I=1,72 ; D=1,45$ (sinal senoidal $1 \mathrm{~V} T=20$ s) …........................... 64

Figura 59 Critério de ITAE : $P=6,12 ; I=1,72 ; D=1,45$ (sinal senoidal $2 \mathrm{~V} \mathrm{T=20s)} \mathrm{….........................} 65$

Figura 60 Critério de ITAE : $P=6,12 ; I=1,72 ; D=1,45$ (sinal senoidal $3 V \quad T=10$ s) …........................... 65

Figura 61 Critério de ITAE: $P=6,12 ; \mathrm{I}=1,72 ; \mathrm{D}=1,45$ (sinal senoidal $4 \mathrm{~V} \mathrm{~T}=10 \mathrm{~s}$ ) …..........................6 66

Figura 62 Resposta do controlador PID ( ITAE ) com sinal de referência senoidal $2 \mathrm{~V} / \mathrm{T}=2,7 \mathrm{~s}$.......... 67

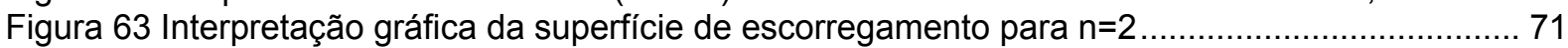

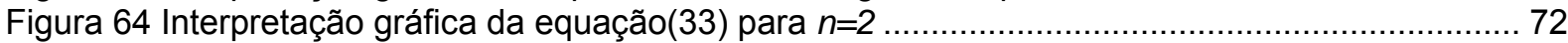

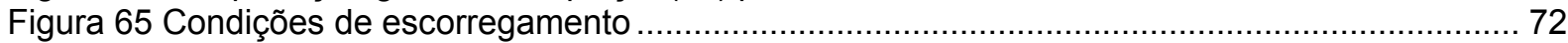

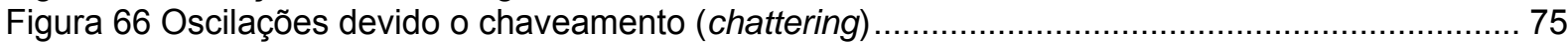

Figura 67 Camada limite para $n=2$ (adaptado de Slotine e Li (1991)) ........................................... 76

Figura 68 Controle introduzido na camada limite (adaptado de Slotine e Li (1991)) .......................... 76

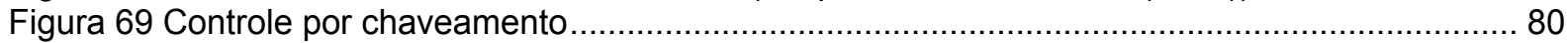

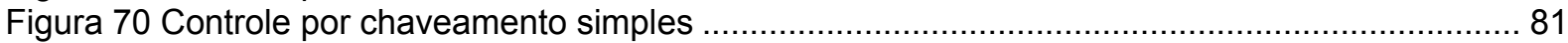

Figura 71 Efeito do chaveamento sobre o sinal de referência........................................................ 81

Figura 72 Efeito do chaveamento sobre o sinal de referência sinal senoidal $2 \mathrm{~V}$ e $\mathrm{T}=20 \mathrm{~s}$.................. 82

Figura 73 Efeito do chaveamento sobre o sinal de referência senoidal $2 \mathrm{~V}$ e $\mathrm{T}=10 \mathrm{~s}$.......................... 82

Figura 74 Efeito do chaveamento sobre o sinal de referência senoidal 2V e $\mathrm{T}=5 \mathrm{~s}$............................ 83

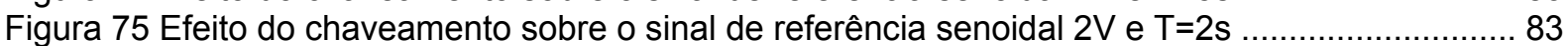

Figura 76 Controle por chaveamento com camada limite .......................................................... 84

Figura 77 Resultado do efeito do chaveamento com camada limite. ............................................ 85

Figura 78 Detalhe da filtragem do controle de chaveamento com camada limite ............................ 85

Figura 79 Filtragem do chaveamento sobre o sinal de referência sinal senoidal $2 \mathrm{~V} \mathrm{e} \mathrm{T=20s} \mathrm{...........} 86$

Figura 80 Filtragem do chaveamento sobre o sinal de referência sinal senoidal $2 \mathrm{~V}$ e $\mathrm{T}=10 \mathrm{~s}$............. 87

Figura 81 Filtragem do chaveamento sobre o sinal de referência sinal senoidal $2 \mathrm{~V}$ e $\mathrm{T}=5 \mathrm{~s}$............... 87

Figura 82 Filtragem do chaveamento sobre o sinal de referência sinal senoidal $2 \mathrm{~V}$ e $\mathrm{T}=2 \mathrm{~s} \ldots \ldots \ldots \ldots . . . . .88$

Figura 83 Controle por modos deslizantes SMC ................................................................ 92

Figura 84 Resposta do atuador SMA degrau suavizado de 2,5cm com : $\lambda=40 ; \phi=0,16$ e $\mathrm{K}_{\mathrm{SM}}=250 \ldots 93$

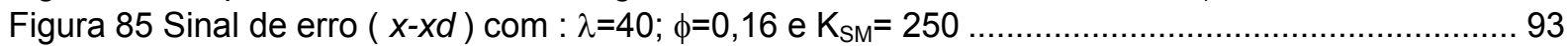

Figura 86 Resposta do atuador SMA degrau suavizado $\left(-2,5 \mathrm{~cm}\right.$ com : $\lambda=40 ; \phi=0,16$ e $\left.\mathrm{K}_{\mathrm{SM}}=250\right) \ldots 94$

Figura 87 Resposta do atuador com $\lambda=40 ; \phi=0,16$ e $\mathrm{K}_{\mathrm{SM}}=250$ (sinais referência senoidais $1 \mathrm{~cm}$ ).... 95

Figura 88 Resposta do sistema com: $\lambda=40 ; \phi=0,16$ e $\mathrm{K}_{\mathrm{SM}}=250$ (sinal senoidal $1 \mathrm{~cm}$ com T=1,56s ).. 95

Figura 89 Resposta do atuador $\operatorname{com} \lambda=40 ; \phi=0,16$ e $\mathrm{K}_{\mathrm{SM}}=250$ (sinais senoidais $2 \mathrm{~cm}$ )................... 96

Figura 90 Resposta do atuador $\operatorname{com} \lambda=40 ; \phi=0,16$ e $\mathrm{K}_{\mathrm{SM}}=250$ (sinais senoidais $0,5 \mathrm{~cm}$ )................ 97

Figura 91 Resposta ao sinal em degrau suavizado $2 \mathrm{~V}$ na subida com controlador SMC ................... 99

Figura 92 Resposta ao sinal em degrau suavizado $2 \mathrm{~V}$ na descida com controlador SMC ................. 99

Figura 93 Resposta ao sinal em degrau suavizado $2 \mathrm{~V}$ na subida com controlador PID ................... 100

Figura 94 Resposta ao sinal em degrau suavizado $2 \mathrm{~V}$ na descida com controlador PID ................. 100

Figura 95 Resposta do controlador SMC com sinal de referência senoidal $1 \mathrm{~V}$ e T=20s ................ 101

Figura 96 Resposta do controlador SMC com sinal de referência senoidal 2V e T=20s .................. 102

Figura 97 Resposta do controlador SMC com sinal de referência senoidal 3V e T=10s ................ 102

Figura 98 Resposta do controlador SMC com sinal de referência senoidal $4 \mathrm{~V}$ e T=10s .................. 103

Figura 99 Resposta do controlador SMC com sinal de referência senoidal $2 \mathrm{~V}$ e $\mathrm{T}=1,55 \mathrm{~s}$............... 104

Figura 100 Resposta do atuador SMA degrau suavizado de 2,5cm com : $\lambda=40 ; \phi=1,6$ e K $\mathrm{SM}_{\mathrm{SM}}=64 \ldots 105$

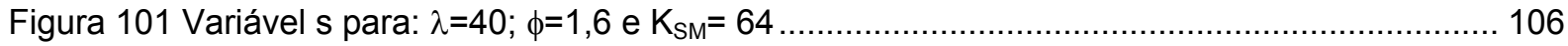

Figura 102 Resposta do atuador SMA degrau suavizado descida com : $\lambda=40 ; \phi=1,6$ e K

Figura 103 Resposta do atuador com $\lambda=40 ; \phi=1,6$ e $K_{S M}=64$ (sinais referência senoidais $1 \mathrm{~cm}$ ).... 108

Figura 104 Resposta do atuador SMA degrau suavizado de 2,5cm com : $\lambda=38 ; \phi=2$ e K $\mathrm{SM}_{\mathrm{SM}}=76 \ldots . .109$

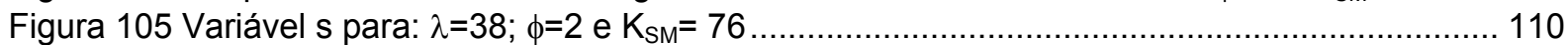

Figura 106 Resposta do atuador SMA degrau suavizado descida com : $\lambda=38 ; \phi=2$ e $\mathrm{K}_{\mathrm{SM}}=76 \ldots \ldots . .111$

Figura 107 Resposta do atuador $\operatorname{com} \lambda=38$; $\phi=2$ e $\mathrm{K}_{\mathrm{SM}}=76$ (sinais referência senoidais $1 \mathrm{~cm}$ )....... 112

Figura 108 Resposta do controlador SMC com sinal de referência senoidal $(1 \mathrm{~cm}$ e T=1,45s) $\ldots \ldots \ldots . .113$

Figura 109 Resposta do atuador $\operatorname{com} \lambda=38 ; \phi=2$ e $\mathrm{K}_{\mathrm{SM}}=76$ (sinais referência senoidais $2 \mathrm{~cm}$ )....... 113

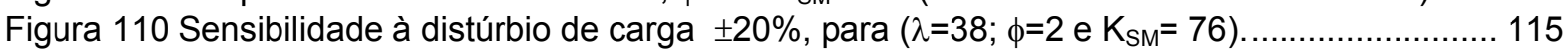

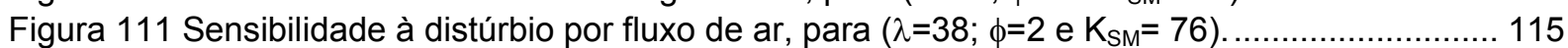


Figura 112 Efeito Seebeck-Peltier (ddp $\alpha \Theta_{1}-\Theta_{2}$ )

Figura 113 Associação de pastilhas termoelétricas 


\section{LISTA DE TABELAS}

Tabela 1 Regras de sintonia de Ziegler e Nichols (adaptado de Ogata (1990)) ................................ 49

Tabela 2 Regras de sintonia de Ziegler e Nichols modificada ....................................................... 50

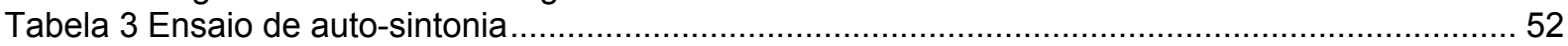

Tabela 4 Método de Ziegler e Nichols para Curva de Reação ....................................................... 56

Tabela 5 Relações utilizadas por Cohen e Coon para a curva de reação. ………............................. 58

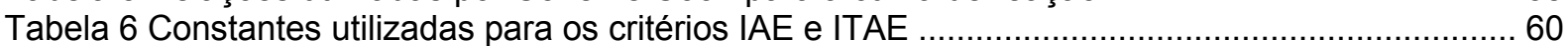

Tabela 7 Parâmetros P, I, D , para os critérios IAE e ITAE ......................................................... 61

Tabela 8 Tabela comparativa dos métodos de sintonia de um controlador PID. ............................... 63

Tabela 9 Erro de acompanhamento do controlador PID com sinais senoidais ................................. 66

Tabela 10 Erro de acompanhamento do controlador SMC com sinais senoidais ................................. 98

Tabela 11 Comparação de desempenho entre controladores modos deslizantes e PID.................. 101

Tabela 12 Erro de acompanhamento do controlador SMC com sinais senoidais (1V; 2V; 3V; 4V)... 103

Tabela 13 Erro de acompanhamento do controlador SMC para $\lambda=40 ; \phi=1,6$ e $\mathrm{K}_{\mathrm{SM}}=64 \ldots \ldots \ldots \ldots \ldots . .108$

Tabela 14 Comparação dos efeitos obtidos com os parâmetros de controle ..................................... 110

Tabela 15 Erro de acompanhamento do controlador SMC (senóides $1 \mathrm{~cm})\left(\lambda=38 ; \phi=2\right.$ e $\left.K_{S M}=76\right) .111$

Tabela 16 Erro de acompanhamento do controlador SMC (senóides $2 \mathrm{~cm})\left(\lambda=38 ; \phi=2\right.$ e $\left.\mathrm{K}_{\mathrm{SM}}=76\right) .114$ 


\section{LISTA DE ABREVIATURAS E SIGLAS}

$\begin{array}{ll}\text { A } & \text { relativo a austenita } \\ \text { C } & \text { relativo a control } \\ \text { D } & \text { relativo a derivativo } \\ \text { E } & \text { relativo a norma } \\ \text { I } & \text { relativo a integral } \\ \text { IAE } & \text { relativo a Integral of absolute error. } \\ \text { ITAE } & \text { relativo a Integral of time-weighted absolute error } \\ \text { M } & \text { relativo a martensita } \\ \text { Ni } & \text { relativo a níquel } \\ \text { P } & \text { relativo a proporcional } \\ \text { PID } & \text { relativo a proporcional, integral e derivativo } \\ \text { PWM } & \text { relativo a pulse width modulation } \\ \text { SM } & \text { relativo a sliding mode } \\ \text { SMA } & \text { relativo a shape memory alloy } \\ \text { SMC } & \text { relativo a sliding mode control } \\ \text { SPQ } & \text { relativo a programação seqüencial quadrática } \\ \text { Ti } & \text { relativo a titânio } \\ \text { TMA } & \text { relativo a teorema do momento angular }\end{array}$




\section{LISTA DE SÍMBOLOS}

A

Ac

Ae

Af

As

$b(x)$

$c$

C

$\mathrm{C}_{P}$

e

$E A$

$E m$

$F$

$f(x)$

$h$

i

I

J

K

$K_{c}$

$K_{p}$

$K_{p u}$

$K_{S M}$

I

L

Io

$m$

$m_{L}$

$M f$

Ms

$n$

$P_{u}$

$R$

$r_{1}$

$r_{2}$

$S$

$T$

$T_{1}$

$T_{2}$

$T_{d}$

$T_{i}$

$T_{p}$

$T_{\text {amb }}$

$u$

$x$

$x_{d}$

área da seção transversal do fio, $\mathrm{m}^{2}$

área de contato entre o fio e a pastilha, $\mathrm{m}^{2} / \mathrm{m}$

área externa do fio de SMA, $\mathrm{m}^{2}$

temperatura final da austenita, ${ }^{\circ} \mathrm{C}$

temperatura inicial da austenita, ${ }^{\circ} \mathrm{C}$

funções do sistema

coeficiente de amortecimento, $\mathrm{Ns} / \mathrm{m}$

coeficiente de condução, $\mathrm{W} /{ }^{\circ} \mathrm{C} / \mathrm{m}$.

calor específico, J/Kg.K

espessura da pasta térmica entre o fio e a pastilha , $\mathrm{m}$

módulo de Young na austenita, $\mathrm{N} / \mathrm{m}^{2}$

módulo de Young na martensita, $\mathrm{N} / \mathrm{m}^{2}$

máximo erro de modelagem

funções do sistema

coeficiente de convecção natural, $\mathrm{W} / \mathrm{m}^{2}{ }^{\circ} \mathrm{C} / \mathrm{m}$

corrente elétrica no fio, $A$

inércia total, $\mathrm{kg}$

momento de inércia da polia, $\mathrm{kg} \cdot \mathrm{m}^{2}$

coeficiente de rigidez equivalente do fio, $\mathrm{N} / \mathrm{m}$

coeficiente de condução da pasta térmica, $\mathrm{W} / \mathrm{m}^{\circ} \mathrm{C}$

ganho proporcional

ganho supremo

ganho do controle por modo deslizante

comprimento do fio de SMA, $m$

dimensão predominante do fio, $\mathrm{ft}$

comprimento inicial do fio de SMA

massa por unidade de comprimento, $\mathrm{Kg} / \mathrm{m}$

massa da carga, $\mathrm{kg}$

temperatura final da martensita, ${ }^{\circ} \mathrm{C}$

temperatura inicial da martensita, ${ }^{\circ} \mathrm{C}$

fator de amplificação do movimento

período supremo (min ou s)

resistência elétrica do fio por unidade de comprimento, $\Omega / \mathrm{m}$

raio interno da polia, $m$

raio externo da polia, $\mathrm{m}$

superfície deslizante

temperatura no fio de SMA, ${ }^{\circ} \mathrm{C}$

tração no fio da carga, $\mathrm{N}$

tração no fio de SMA, N

tempo derivativo, $\min ^{-1}$ ou s ${ }^{-1}$

tempo integral, $\min ^{-1}$ ou s ${ }^{-1}$

temperatura na superfície da pastilha termoelétrica, ${ }^{\circ} \mathrm{C}$

temperatura ambiente, ${ }^{\circ} \mathrm{C}$

entrada de controle

posição da carga, $\mathrm{m}$

referência desejada

erro de acompanhamento 


\section{Símbolos Gregos}

$\Delta$

$\varepsilon$

$\varepsilon_{m y}$

$\phi$

$\eta$

$\lambda$

V

$\theta$

$\sigma$

$\sigma_{A}$

$\sigma_{M}$

$\omega$

$\xi$

$\xi A$

$\xi_{m}$

variação do comprimento no fio, $m$ deformação do fio de SMA

máxima elasticidade de deformação da martensita espessura da camada limite

velocidade de convergência para a superfície deslizante parâmetro do controle por modo deslizante

nova entrada de controle na linearização por realimentação

posição angular da polia, rad

tensão mecânica no fio de SMA, N/m²

tensão mecânica no fio de SMA na fase de austenita, $\mathrm{N} / \mathrm{m}^{2}$

tensão mecânica no fio de SMA na fase de martensita, $\mathrm{N} / \mathrm{m}^{2}$

velocidade angular da polia, $\mathrm{rad} / \mathrm{s}$

fração de martensita (0 to $100 \%$ )

valor inicial da martensita durante o resfriamento

maior fração da martensita durante o resfriamento 


\section{SUMÁRIO}

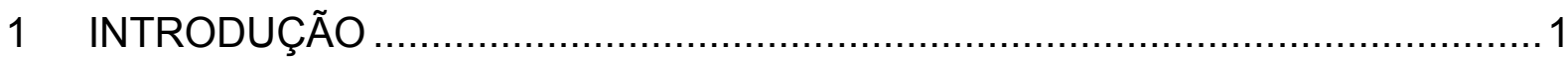

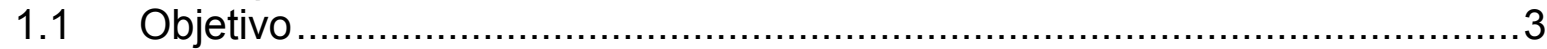

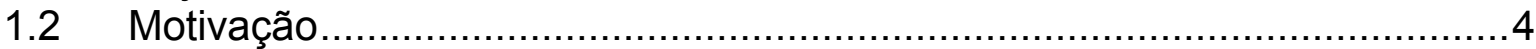

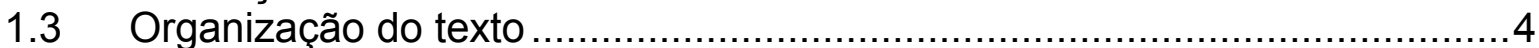

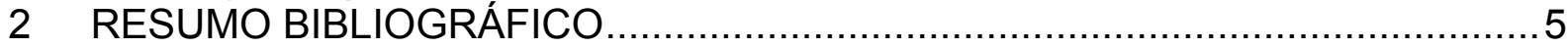

2.1 Atuador SMA com resfriamento forçado por fluxo de ar ..........................5

2.2 Atuador SMA com resfriamento por condução de calor .............................

2.3 Atuador SMA com refrigeração via úmida...........................................11

3 MONTAGEM EXPERIMENTAL DO ATUADOR SMA REFRIGERADO POR

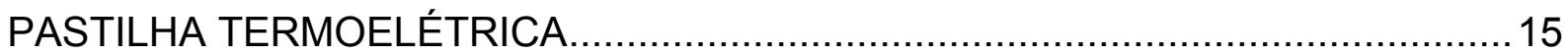

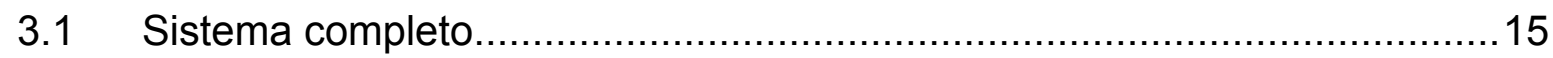

3.2 Montagem do sistema mecânico ………........................................16

3.3 Montagem da pastilha termoelétrica do atuador SMA …......................18

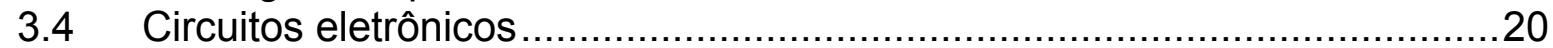

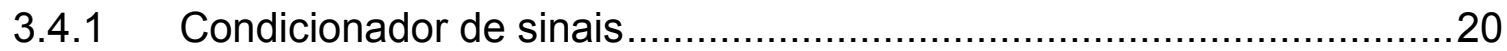

3.4.2 Sistema de interface A/D e D/A ...............................................22

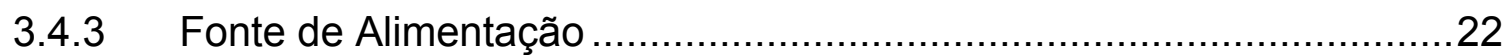

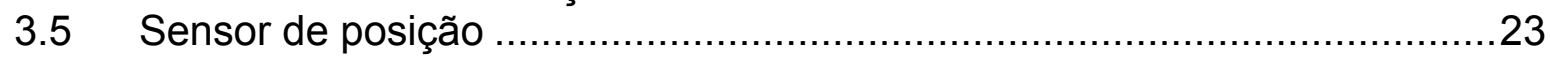

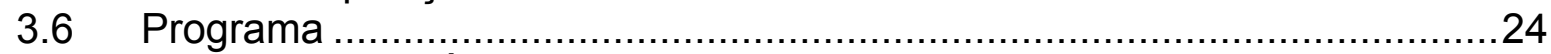

4 MODELO MATEMÁTICO DO ATUADOR SMA REFRIGERADO POR

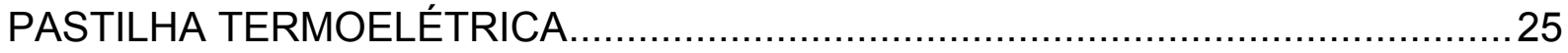

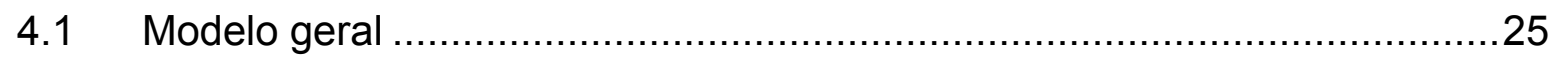

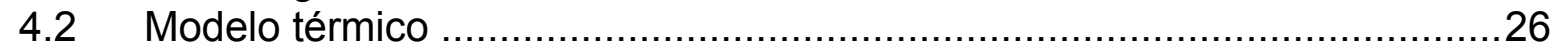

4.2.1 Considerações adotadas para modelo térmico .................................26

4.2.2 Determinação do coeficiente de condução térmica ...........................27

4.2.3 Determinação do coeficiente de convecção $h$.................................29

4.3 Transformação de fase e propriedades mecânicas ....................................30

4.3.1 Modelos da transformação de fase ..................................................30

4.4 Modelo das propriedades mecânicas ....................................................31

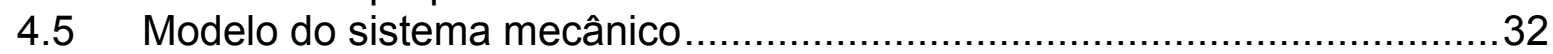

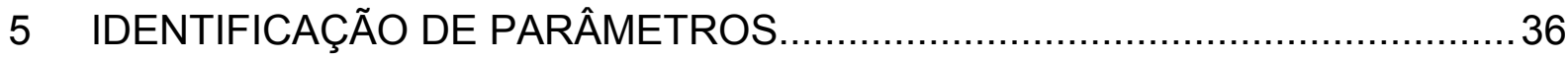

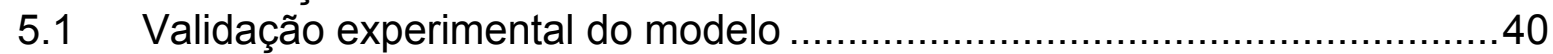

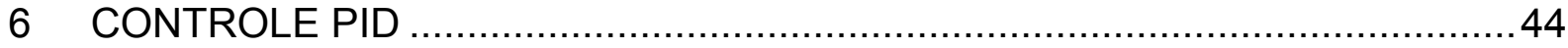

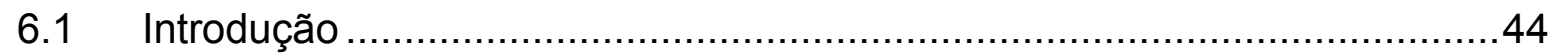

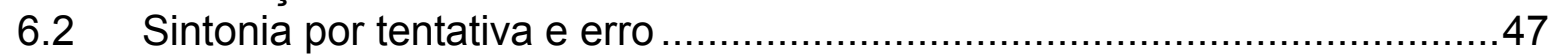

6.3 Método da oscilação mantida com sintonia automática (autotuning) ..........49

6.3.1 Método da curva de reação ..........................................................54

6.3.2 Métodos baseados em minimização da integral do erro.......................59

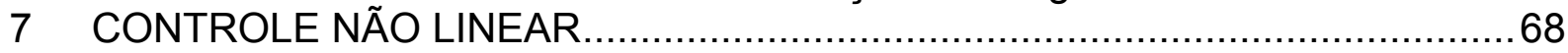

7.1 Abordagem teórica de controle não linear ...............................................69

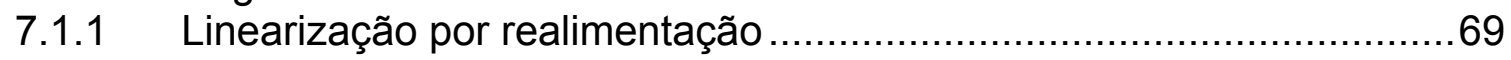

7.1.2 Controle por modos deslizantes.................................................

7.1.3 Controle integral....................................................................

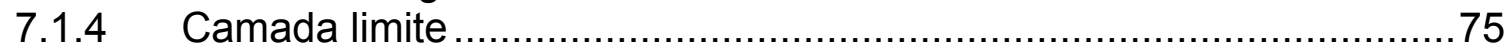

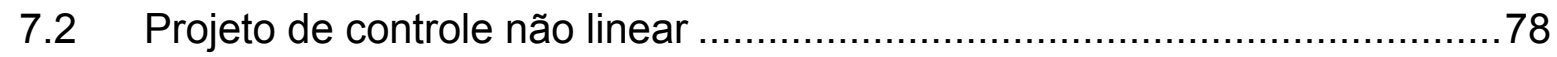

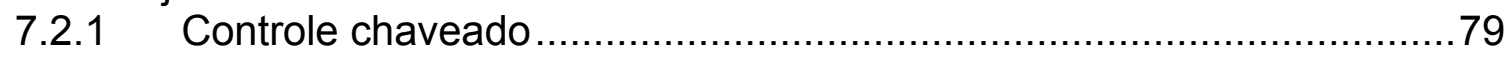

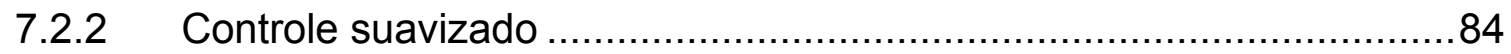


8 PROJETO DE CONTROLE POR MODOS DESLIZANTES E LINEARIZAÇÃO

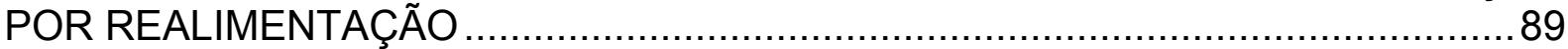

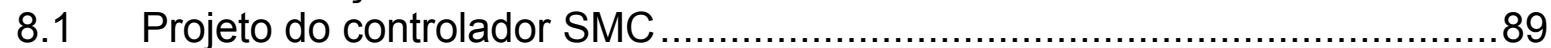

8.2 Resultados experimentais ...................................................................... 91

8.3 Ensaios com sinais de referência senoidal utilizando o controlador SMC ..94

8.4 Comparações de desempenho entre controlador SMC e PID ...................98

8.5 Avaliação da sensibilidade a parâmetros de controle ..............................104

8.5.1 Reajuste de parâmetros........................................................105

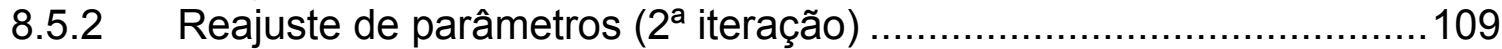

8.6 Verificação da sensibilidade à distúrbios ...........................................114

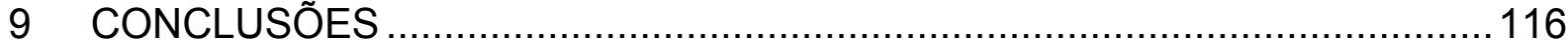

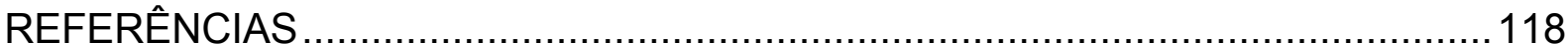

APÊNDICE A- Desenhos mecânicos do atuador SMA ...................................... 121

APÊNDICE B- Detalhes da pastilha termoelétrica ...........................................124

APÊNDICE C- Diagrama do condicionador de sinais ...................................... 127 


\section{INTRODUÇÃO}

As ligas com memória de forma (Shape Memory Alloy - SMA) são ligas metálicas especiais que possuem a propriedade de serem termicamente ativas, retornando ao seu estado original quando aquecidas. Esta característica é conhecida como "efeito memória". Em baixas temperaturas, a estrutura cristalina da liga apresenta a forma cúbica modificada (tetragonal), chamada de martensita. Nesta fase, o limite elástico do material é baixo, apresentando um comportamento semelhante a plástico, com maior facilidade de deformação. Aquecendo-se a SMA até uma determinada temperatura, ocorre uma mudança de fase na estrutura cristalina do material, transformando em uma estrutura de forma cúbica de face centrada. Esta fase, chamada de austenita, possui limite elástico elevado, uma grande porção da tensão aplicada na liga é recuperada, ocorrendo assim uma contração (TEXAS A\&M SMART LAB, 2004).

Como na fase fria ocorre um estiramento devido à carga aplicada e à alta plasticidade e no aquecimento ocorre a contração do material, pode-se utilizar esse fenômeno para construir atuadores leves e silenciosos, como verdadeiros músculos metálicos (Figura 1).
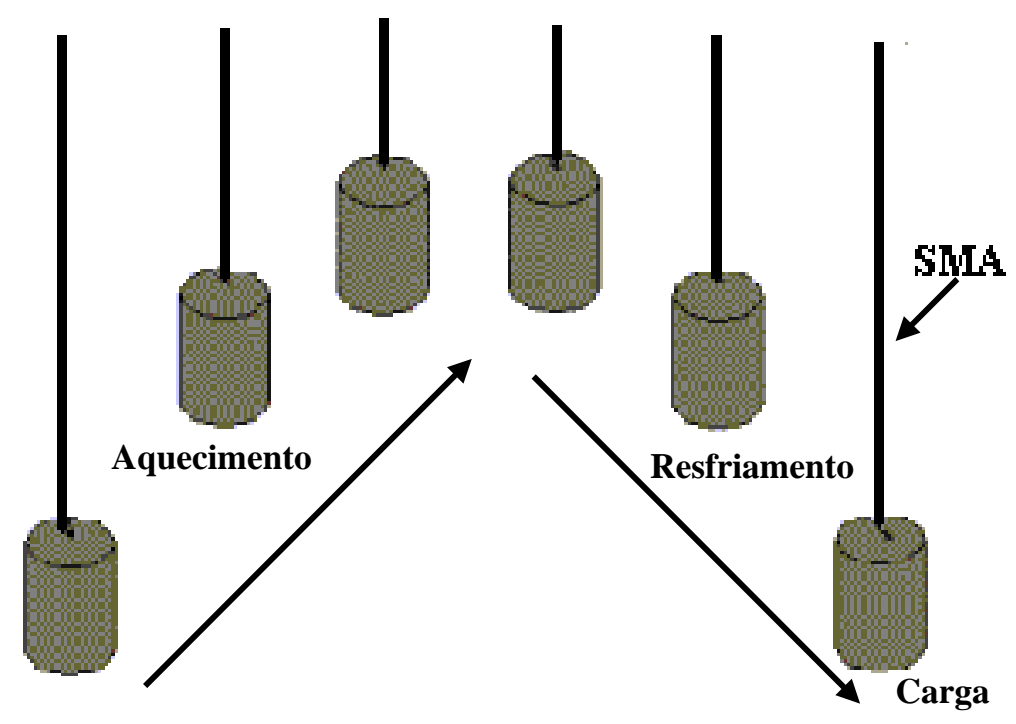

Figura 1 Princípio de funcionamento de um atuador SMA 
O desenvolvimento de atuadores com as SMAs apresenta grandes atrativos para diversos campos da engenharia, principalmente na área de robótica, substituindo os atuadores convencionais de grande peso e ruidosos, como motores e válvula solenóides. Os atuadores baseados em SMA possuem a maior relação de carga útil por peso do atuador em relação aos atuadores convencionais. Entretanto, o desempenho dinâmico dos atuadores com SMA é ruim devido ao elevado tempo de resposta. Para a SMA operar rapidamente, deve-se aquecê-la para haver a contração e resfriá-la na recuperação. O aquecimento é um processo simples e rápido, podendo ser feito com a passagem de corrente elétrica pelo fio de SMA. Entretanto, o resfriamento é lento, sendo esta a fase que limita o comportamento dinâmico dos atuadores SMA. Além disso, este processo não é termodinamicamente reversível, apresentando histerese. Esta característica não linear exige, portanto, um complexo sistema de controle.

Diversas propostas em reduzir o tempo de resfriamento para aumentar a velocidade do atuador foram estudadas. Algumas utilizam métodos estáticos, como o atuador descrito por Tanaka e Yamada (1991). Os fios de SMA são resfriados continuamente, por meio de fluxo de ar constante. De forma semelhante, já se relataram outras propostas como imersão em água ou até mesmo dissipador de calor, com promissores resultados. Essas técnicas aumentam a velocidade, em detrimento a um grande aumento de consumo de potência. $\mathrm{Na}$ fase de aquecimento será liberada muito mais energia para compensar a perda excessiva e desordenada de calor ocorrida na fase do resfriamento. Por exemplo, Furuya e Shimada (1990) descreveram a aplicação de um radiador que, embora tenha diminuído em 10 vezes o tempo de resposta do atuador, elevou o consumo de potência em 20 vezes. Portanto é importante obter a melhor resposta com o menor consumo de energia para que o projeto utilizando as SMAs como atuadores não se torne inviável pelo consumo excessivo de energia. Em muitas aplicações, esse é um fato determinante na aplicação de atuadores (por exemplo, robôs móveis, alimentados por baterias).

O atuador desenvolvido por Golbert e Russel (1995) utiliza a condução de calor em um dissipador metálico móvel para promover o resfriamento do fio. Um sistema mecânico elaborado permite que o dissipador fique em contato apenas com o fio que deve ser resfriado, melhorando o desempenho dinâmico do sistema. $O$ consumo de energia também é minimizado, já que o dissipador utilizado é passivo. A 
complexidade da montagem dinâmica é, sem dúvida, a grande desvantagem deste atuador.

Buscando um melhor desempenho dinâmico, Asada e Mascaro (2003) desenvolveram um atuador cujo resfriamento forçado é feito com circulação de água pelo fio de SMA. Um elaborado sistema de controle garante que a circulação de água só ocorra na fase de resfriamento, diferentemente do sistema de resfriamento a ar previamente mencionado. Adicionalmente, a troca de calor com a água circulante é mais eficiente do que com um dissipador metálico, melhorando a resposta dinâmica do atuador. Neste caso, a complexidade do sistema de controle e circulação de água é uma desvantagem deste atuador.

A fim de melhorar o desempenho dinâmico destes atuadores, mantendo-se a simplicidade construtiva e de controle e um baixo consumo de energia, será proposto um sistema de resfriamento forçado baseado em pastilha termoelétrica (efeito Seebeck-Peltier). Um modelo matemático completo foi desenvolvido para o atuador. Um protótipo experimental foi construído, a fim de se validar o modelo desenvolvido e se identificar todos os parâmetros necessários. O modelo foi implementado em Matlab/Simulink, e diversos experimentos realizados com o protótipo confirmam sua validade.

O modelo será utilizado para se avaliar o desempenho dinâmico e para implementar um sistema de controle eficiente para o atuador. Será analisado inicialmente o clássico algoritmo PID, utilizando diversos métodos de ajuste de ganhos. Em seguida, será implementado um controlador não linear baseado em modos deslizantes, que possui a vantagem de levar em conta as não linearidades do sistema, em detrimento a uma formulação matemática mais complexa. Serão feitas comparações entre os controladores, avaliando-se as vantagens de cada um em termos de desempenho e robustez.

\subsection{Objetivo}

Desenvolver um atuador baseado em liga de memória de forma, melhorar o desempenho dinâmico do atuador com um sistema de refrigeração forçada por pastilha termoelétrica e utilizar um sistema de controle de posição não linear baseado no controle por modos deslizante (sliding mode control). 


\subsection{Motivação}

A principal motivação está no fato de tais ligas poderem ser empregadas em robôs, naves espaciais, satélites, aviões, entre outros e principalmente na medicina como prótese e substituindo músculos danificados. Atualmente, diversas pesquisas têm sido realizadas objetivando melhorar a resposta dinâmica dos atuadores SMA.

\subsection{Organização do texto}

No capítulo 2 será feito um estudo de casos onde serão apresentados e discutidos três trabalhos da literatura sobre atuadores utilizando SMAs e as formas propostas para melhorar o desempenho dinâmico dos mesmos. Para cada caso, será feita uma descrição do funcionamento do atuador e do método de refrigeração adotado, com o intuito de se avaliar o seu desempenho e as vantagens do método de refrigeração empregado.

No capítulo 3 será detalhada a montagem experimental do protótipo do atuador proposto. Em seguida, no capítulo 4, será desenvolvido o modelo matemático do atuador, sendo que os parâmetros relevantes serão identificados e validados no capítulo 5 . No capítulo 6 serão apresentados o projeto do sistema de controle PID (proporcional, integral e derivativo) e a avaliação do desempenho com esse tipo de controlador.

No capítulo 7 será feitas uma abordagem teórica do controle não linear por modos deslizantes e a verificação do funcionamento de um controle não linear simplificado descrito na literatura. No capitulo 8, será feito um projeto completo do controlador por modos deslizantes (sliding mode control) e a avaliação do desempenho com esse tipo de controlador. Finalmente, no capitulo 9 , serão feitas as conclusões finais. 


\section{RESUMO BIBLIOGRÁFICO}

Neste capítulo serão mostrados 3 atuadores SMA descritos na literatura, utilizando diferentes tipos de resfriamento forçado. Será enfatizada a importância do resfriamento na melhoria da resposta em freqüência dos atuadores SMA.

\subsection{Atuador SMA com resfriamento forçado por fluxo de ar}

Tanaka e Yamada (1991) desenvolveram um atuador rotativo baseado em SMAs, com aplicação em robótica. Apresenta-se na Figura 2 o esboço do mecanismo, constituído por uma caixa metálica que envolve o sistema, dois trechos de fio SMA de níquel titânio (NiTi), polias, guias, eixos e eletrodos.

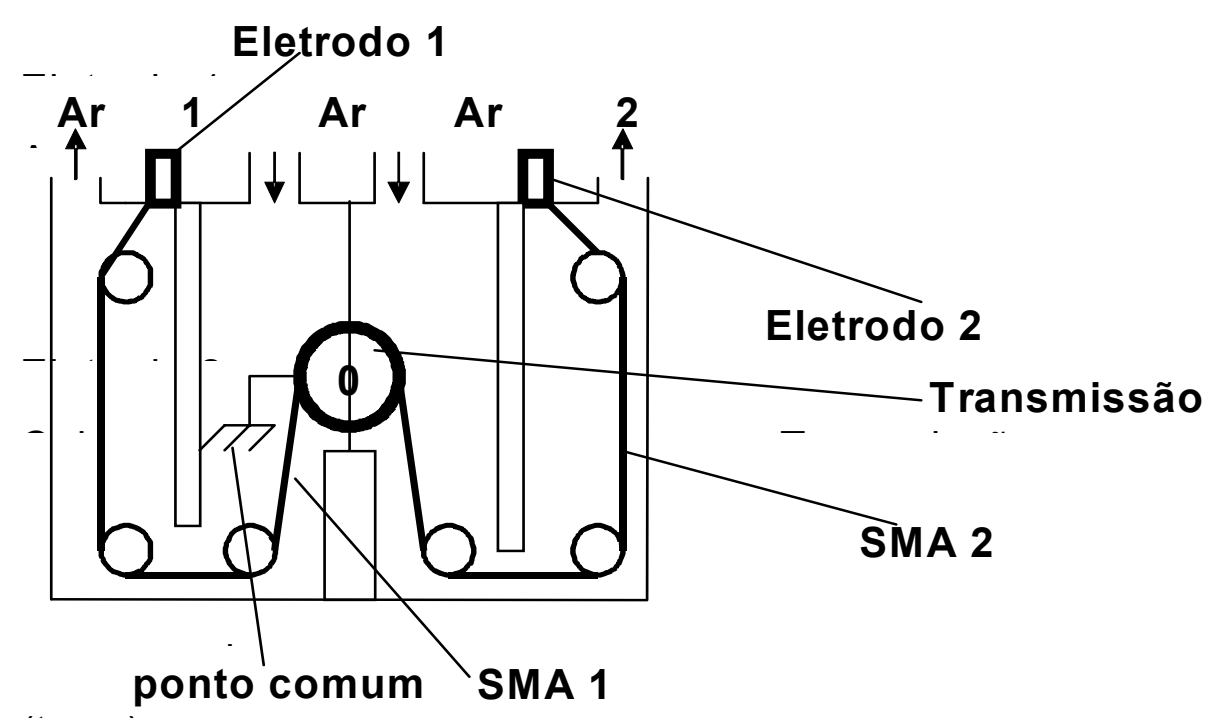

Figura 2 Mecanismo do atuador SMA proposto por Tanaka e Yamada (1991)

Cada fio SMA foi fixado no centro do eixo da transmissão (ponto comum) e, na outra extremidade, nos eletrodos de ligação. Cada eletrodo é alimentado por uma fonte de tensão externa, com o ponto neutro ligado à estrutura metálica da caixa (ponto comum). Ao se energizar o eletrodo 1, uma corrente elétrica circula pelo fio de SMA 1, o que leva a seu aquecimento e conseqüente contração. Este fato provoca uma rotação da polia ligada ao eixo da transmissão no sentido anti-horário. É importante que, neste instante, o fio SMA 2 seja resfriado, para que o mesmo possa se distender rapidamente. Para isso, injeta-se o fluxo de ar continuamente 
dentro da caixa onde os fios estão alojados. $\mathrm{O}$ ar quente é assim liberado para o exterior da caixa metálica. A rotação no sentido horário ocorre pelo processo inverso (corrente pelo SMA 2, resfriamento do SMA 1). Os fios de SMAs agem, portanto, de forma sincronizadas, como verdadeiros músculos metálicos. A lógica de controle deve garantir que quando um fio está sendo aquecido, o outro está sendo resfriando e vice-versa, nunca ocorrendo aquecimento ou resfriamento simultâneos.

Nesse projeto foi utilizado fio de SMA de $0,3 \mathrm{~mm}$ de diâmetro e $236 \mathrm{~mm}$ de comprimento, com deslocamento máximo da ordem de $5 \%$ de seu comprimento total. O atuador é leve e compacto, com dimensões totais de $64 \times 64 \times 26 \mathrm{~mm}$ e peso de $140 \mathrm{~g}$. Utilizou-se um potenciômetro no eixo da transmissão, para a medição do ângulo de atuação, sinal este utilizado pelo controlador descrito a seguir. Adicionalmente, instalaram-se dois termopares ligados aos fios SMA. Os autores não explicam, entretanto, como foram fixados os termopares nos fios das SMAs. Os termopares são utilizados na malha de controle e garantem também que os fios não sejam superaquecidos, o que poderia danificá-los permanentemente.

Esse atuador requer um suprimento de ar com fluxo continuo vindo de um compressor e uma fonte de energia elétrica ou um circuito gerador de tensão.

Nesse sistema, utilizou-se um complexo sistema de controle e acionamento, composto por um controlador PID, duas placas de circuito eletrônico que geram uma tensão tipo PWM (pulse width modulation) que serão os amplificadores de corrente dos fios de SMA e três amplificadores de sinais, sendo dois para os termopares e outro para o potenciômetro. O diagrama de blocos do sistema de controle e acionamento é apresentado na Figura 3. 


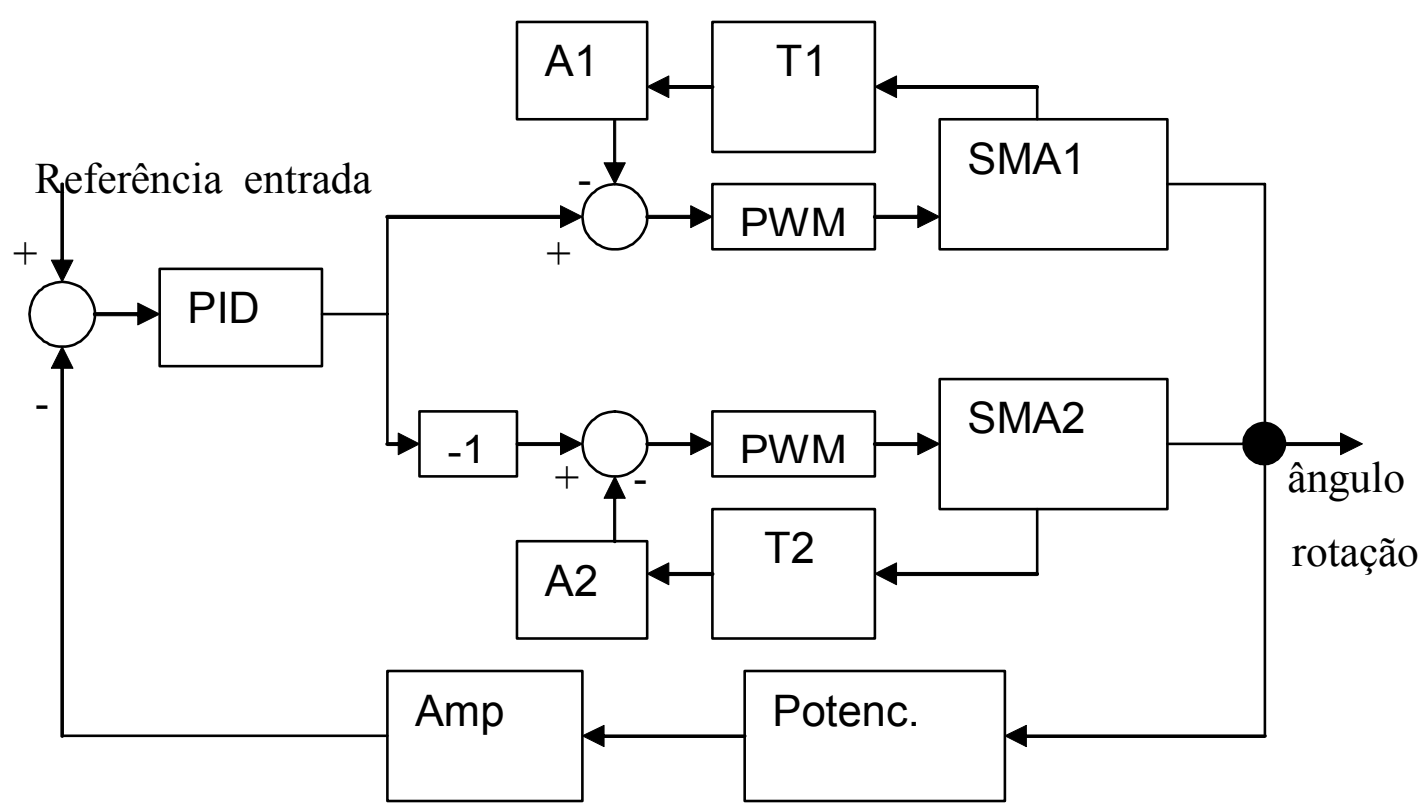

Figura 3 Sistema de controle atuador SMA proposto por Tanaka e Yamada (1991)

no qual:

PID: Controlador Analógico

PWM: Amplificadores de corrente

A1, A2:Amplificadores dos termopares

Amp: Amplificador do potenciômetro

Potenc.: Potenciômetro

T1,T2: Termopares

O controlador analógico PID recebe um sinal de referência de posição que corresponde ao ângulo desejado no eixo do atuador. Este sinal é comparado à realimentação do potenciômetro. Em seguida, o controlador calcula a temperatura requerida para os fios, enviando um sinal analógico de comando ao circuito de PWM, que irá comparar com o sinal amplificado do termopar, equivalente à temperatura do fio SMA. É interessante notar que o controlador PID envia um único sinal para os dois circuitos PWMs, sendo que a entrada da SMA2 é invertida em relação à SMA1. Assim, quando um fio SMA estiver sendo aquecido, o outro receberá o sinal invertido, fazendo com que não se forneça corrente para o mesmo, ou se diminua a corrente na mesma proporção.

O suprimento de ar é feito continuamente por um compressor, garantindo a refrigeração das SMAs quando não estão sendo alimentadas pelos circuitos PWMs e 
a troca de calor necessária com o meio ambiente para que o atuador não aqueça demasiadamente.

Uma desvantagem deste atuador é a falta de controle no sistema de refrigeração, que é mantido atuante o tempo todo, elevando o consumo de energia. Este excesso de refrigeração, mesmo no fio que está em aquecimento, prejudicou o comportamento dinâmico do atuador. Ensaios experimentais relatados pelos autores indicaram que o atuador apresenta resposta lenta, com uma faixa de freqüência de $0,64 \mathrm{~Hz}$.

A grande inovação do atuador está contida em sua concepção mecânica, já que a transmissão do movimento pelos fios garante robustez e silêncio durante a operação, sendo excelente para ser utilizado como atuador robótico.

\subsection{Atuador SMA com resfriamento por condução de calor}

Com o intuito de melhorar a resposta dinâmica dos atuadores SMA até então existentes, com redução no consumo de energia, Golbert e Russel (1995) desenvolveram um sistema inovador, no qual o resfriamento forçado é feito com um dissipador de calor móvel.

A configuração do atuador mostrada na Figura 4 consiste de um fio de SMA de níquel-titânio ( $\mathrm{NiTi}$ ), com $35 \mathrm{~cm}$ de comprimento e $0,3 \mathrm{~mm}$ de diâmetro. O ponto central do fio está fixo à haste com $6 \mathrm{~mm}$ de diâmetro. Esta haste é presa de forma a amplificar a rotação do encoder óptico e movimentar a saída do atuador. O encoder gera 2000 pulsos por volta, com resolução angular de $0,18^{\circ}$ correspondendo a $10 \mu \mathrm{m}$ de variação do comprimento do fio do SMA. O fio possui uma conexão elétrica comum na haste (no seu ponto central) e dois terminais em suas extremidades, por onde ocorre a energização de cada trecho. Esses terminais podem ser ajustados por meio de parafusos de modo a posicionar a haste e o dissipador de calor no centro. $O$ parafuso é regulado para $3 \%$ de pré-deformação nos fios do SMA, colocando o fio de SMA, aproximadamente no meio da fase de martensita (baixa temperatura). 


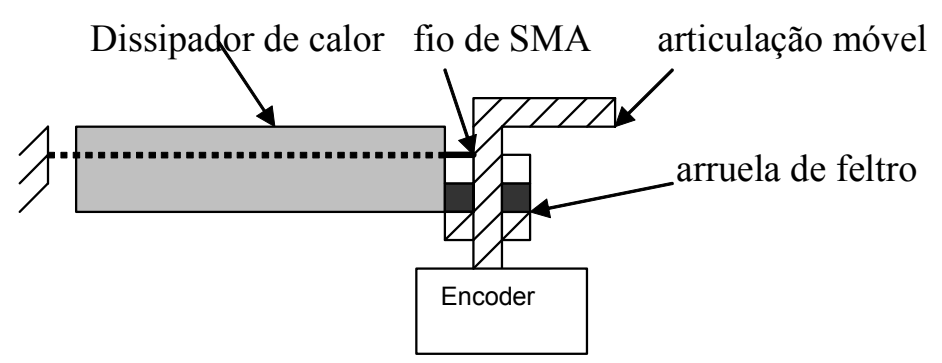

(a) Vista da seção transversal

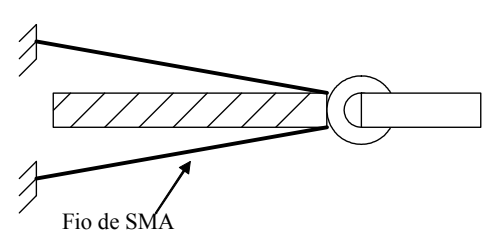

(b) Posição inicial

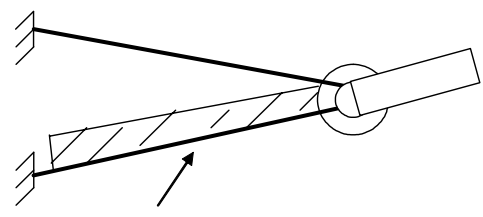

(c) Dissipador de calor em contato com fio SMA

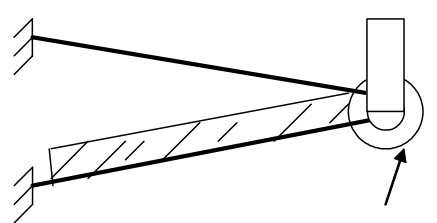

(d) Escorregamento da embreagem

Figura 4 Atuador SMA proposto por Golbert e Russel (1995)

O fio do SMA é preso no centro da roda do atuador e os dois terminais são presos a uma distância que permite tencionar o fio. O dissipador de calor móvel é fixado ao centro de um disco de embreagem.

Inicialmente, os dois trechos do fio estão à temperatura ambiente e possuem o mesmo comprimento (Figura 4b). Quando o trecho superior é aquecido causando uma rotação do atuador no sentido anti-horário, ocorre a fricção do disco da embreagem arrastando o dissipador de calor ao encontro com o trecho inferior do fio, promovendo uma troca de calor. Apesar de o atuador continuar se movimentando a embreagem permite que o dissipador de calor continue em contato com o trecho inferior, sem danificá-lo, devido à ação do sistema de embreagem que permite um escorregamento entre o disco e o feltro. Com a inversão do aquecimento, o atuador gira em sentido contrário até que o dissipador encoste agora no trecho superior, fazendo com que este se resfrie e produza um movimento mais rápido devido à contração do trecho inferior e ao alongamento do trecho superior que está trocando calor com o dissipador de calor. A maior inovação dessa montagem está no mecanismo de embreagem ligado à haste de saída com o dissipador de calor. 
No protótipo do atuador, uma rotação angular de $3,5^{\circ}$ é suficiente para mover o dissipador de calor para colocá-lo em contato com o fio do SMA.

O movimento provoca uma leve diminuição do torque na saída devido ao atrito requerido do sistema de embreagem no momento em que o dissipador pressiona o fio da SMA, mas essa perda de torque não é significativa para diminuir o desempenho desse atuador.

Quando o aquecimento do fio cessa, a força externa do fio diminui tornandose elástico. Isso ocasiona o movimento do dissipador de calor para o outro lado do fio. Mesmo durante movimentos repetidos, o sistema de controle garante que o fio SMA nunca é aquecido enquanto estiver em contato com o dissipador de calor. Como resultado, o consumo de energia será menor do que os dissipadores fixos.

O diagrama de blocos mostrado na Figura 5 ilustra a montagem completa do atuador de posição SMA e o sistema de controle a ele incorporado. Os dados de posição são enviados por um encoder óptico para um computador PC-486/50MHz. O computador compara a posição real com a referência de posição (set-point) e, por meio de um algoritmo de controle, calcula a corrente a ser aplicada no fio SMA. O valor calculado digitalmente é aplicado a um conversor Digital/Analógico e a um amplificador. Dois diodos contrapostos são colocados em série com o amplificador de corrente para direcionar a corrente de forma apropriada nos fios do SMA, evitando o aquecimento e resfriamento simultâneos no mesmo trecho de fio.

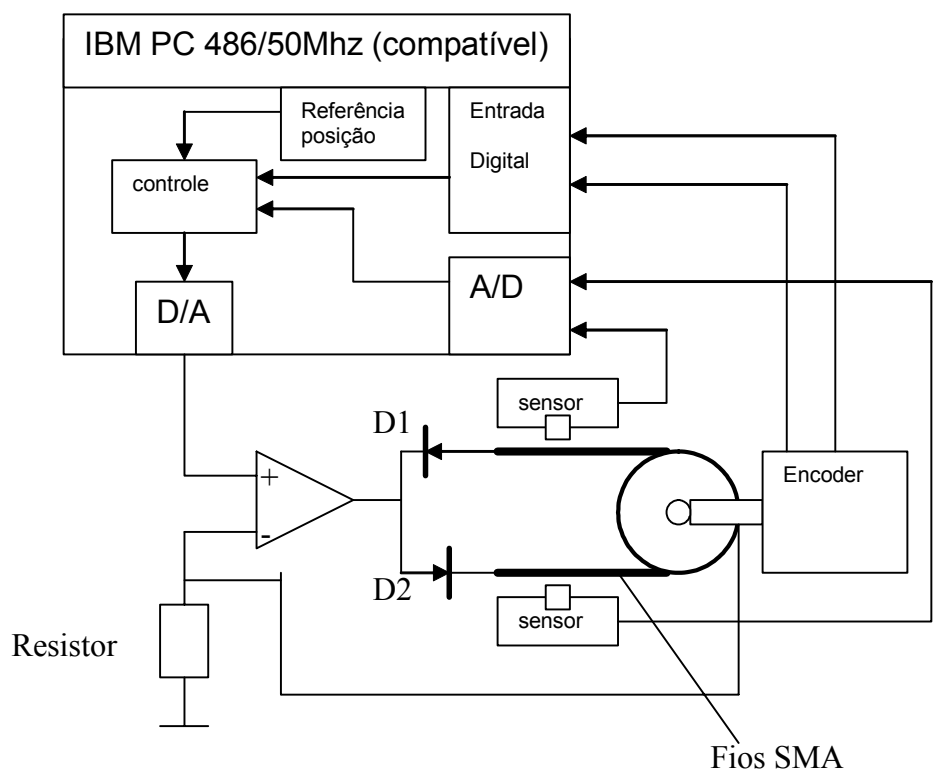

Figura 5 Sistema de atuação e controle do atuador SMA proposto por Golbert e Russel (1995) 
Segundo Gorbet e Russel (1995), testes experimentais revelaram que o atuador possui largura de faixa em freqüência de $0,8 \mathrm{~Hz}$. A Figura 6 mostra, como exemplo, a forma de onda conseguida no atuador em função do tempo, com e sem o dissipador de calor móvel. Verifica-se que, sem o dissipador de calor, o atuador SMA não atinge a posição desejada (set-point). Com o dissipador de calor, o atuador alcança o set-point, ilustrando a importância do sistema de refrigeração.

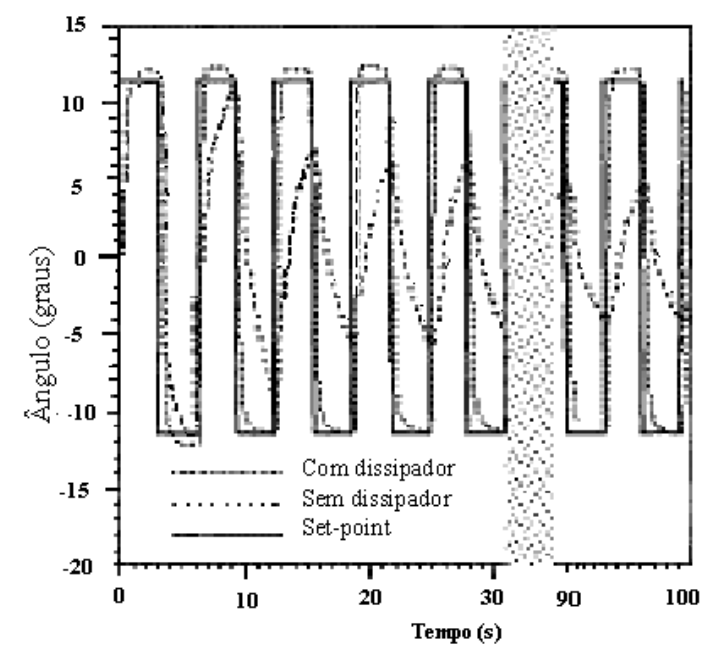

Figura 6 Resposta em malha fechada do atuador SMA com refrigeração por condução (adaptado de Golbert e Russel (1995)

Este atuador apresenta uma melhora significativa em relação ao estudado anteriormente, devido ao fato de que naquele caso, o refrigerador a ar era mantido ligado o tempo todo, prejudicando a retomada do aquecimento, e aumentando o consumo de energia. Como conseqüência, o comportamento dinâmico do presente atuador é superior, com o aumento da largura de faixa de $0,64 \mathrm{~Hz}$ para $0,8 \mathrm{~Hz}$.

\subsection{Atuador SMA com refrigeração via úmida}

Neste capítulo será abordado um novo conceito de atuador SMA, no qual o controle de temperatura do fio é feito por circulação de água. Esse projeto foi desenvolvido por Asada e Mascaro (2003). A Figura 7 apresenta um esquema do atuador. Um fio de SMA é envolvido por um tubo flexível em forma de artéria, que contém um fluido que pode ser água. Uma vez que o tubo é flexível, o mesmo pode facilmente contrair e expandir junto com o fio de SMA e, portanto não interfere no funcionamento do atuador. 
Um conector é mecanicamente fixado no final do fio de SMA, para transmitir a força mecânica e o deslocamento do fio. Esse conector é também eletricamente condutivo, transmitindo a corrente elétrica para o fio de SMA. O conector é vazado permitindo a passagem do fluido através do tubo. Esse processo é necessário para que ocorra a troca de calor, refrigerando o fio de SMA.

O atuador irá contrair pela passagem da corrente elétrica no fio de SMA, ou passando água quente através do tubo. $O$ processo inverso ocorre com a passagem de água fria no tubo e o desligamento da corrente elétrica no fio de SMA, provocando a distensão do fio de SMA e o atuador retorna para a posição original.

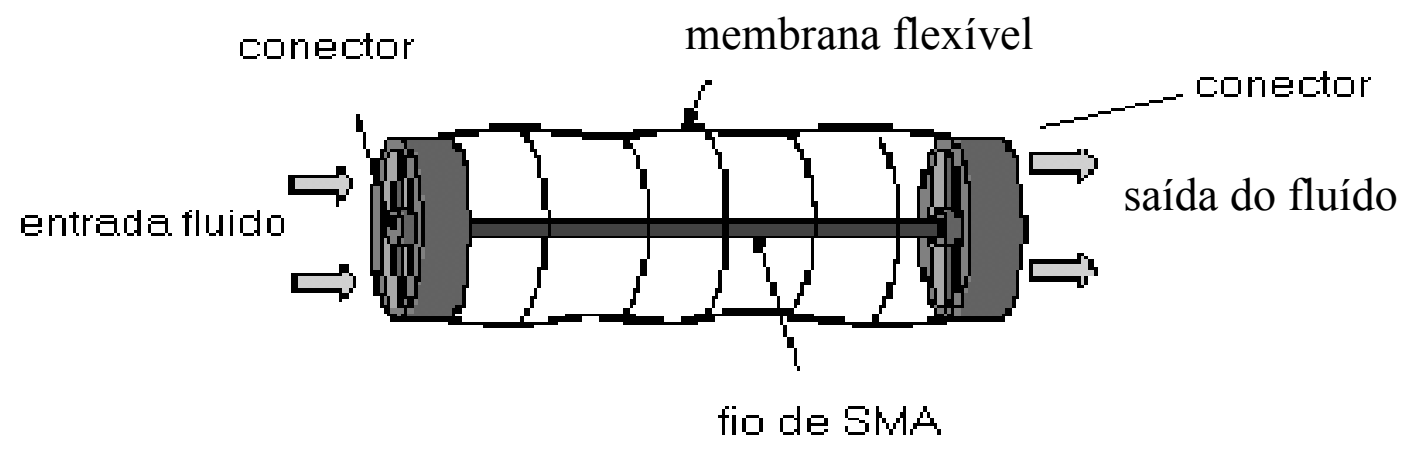

Figura 7 Atuador com refrigeração via úmida (adaptado de Asada e Mascaro (2003)).

O conector pode ser preso proporcionando a fixação mecânica e elétrica do sistema, sendo similar a um músculo artificial, irrigado pelo fluido que atravessa o tubo. Segundo Asada e Mascaro (2003), o atuador possui um valor máximo de deformação da ordem de $4 \%$ de seu comprimento. A força é proporcional à área da seção transversal, sendo da ordem de $20 \mathrm{MN} / \mathrm{m}^{2}$ para ligas de NiTi. Como o comprimento e a seção transversal são relativamente pequenos, uma solução seria fazer conexões em série e paralelo para ampliar o movimento e a força respectivamente dos fios de SMA, que geralmente são finos e flexíveis. Múltiplos atuadores de SMA podem ser envolvidos por uma membrana e resfriados ou aquecidas pelo fluxo do fluido interno, ampliando a força desses atuadores.

O protótipo descrito possui um fio de SMA de $40 \mathrm{~cm}$ de comprimento e $0,15 \mathrm{~mm}$ de diâmetro e um tubo flexível de látex com entrada de $3 \mathrm{~mm}$ de diâmetro. $A$ água flui por meio de uma bomba peristáltica, através de uma válvula solenóide na entrada do conector e um tubo fino de bypass que permite que a água possa ser desviada para um reservatório quando a válvula solenóide é desligada, fechando a passagem de água para o interior do conector. A válvula solenóide tem como função 
fazer o controle da água dentro do tubo onde se encontra o fio da SMA. A temperatura da água é cerca de $20^{\circ} \mathrm{C}$, a uma vazão de $300 \mathrm{ml} / \mathrm{min}$. Na fase de aquecimento, a temperatura no fio atinge $70^{\circ} \mathrm{C}$. Uma das extremidades do conector é fixada na mesa de teste, enquanto a outra é presa no tendão metálico (corda), que passa através de um par de roldanas e então esse puxa a mola de carga provocando o deslocamento do transdutor. (potenciômetro linear). A Figura 8 esquematiza o princípio de atuação do transdutor SMA úmido.

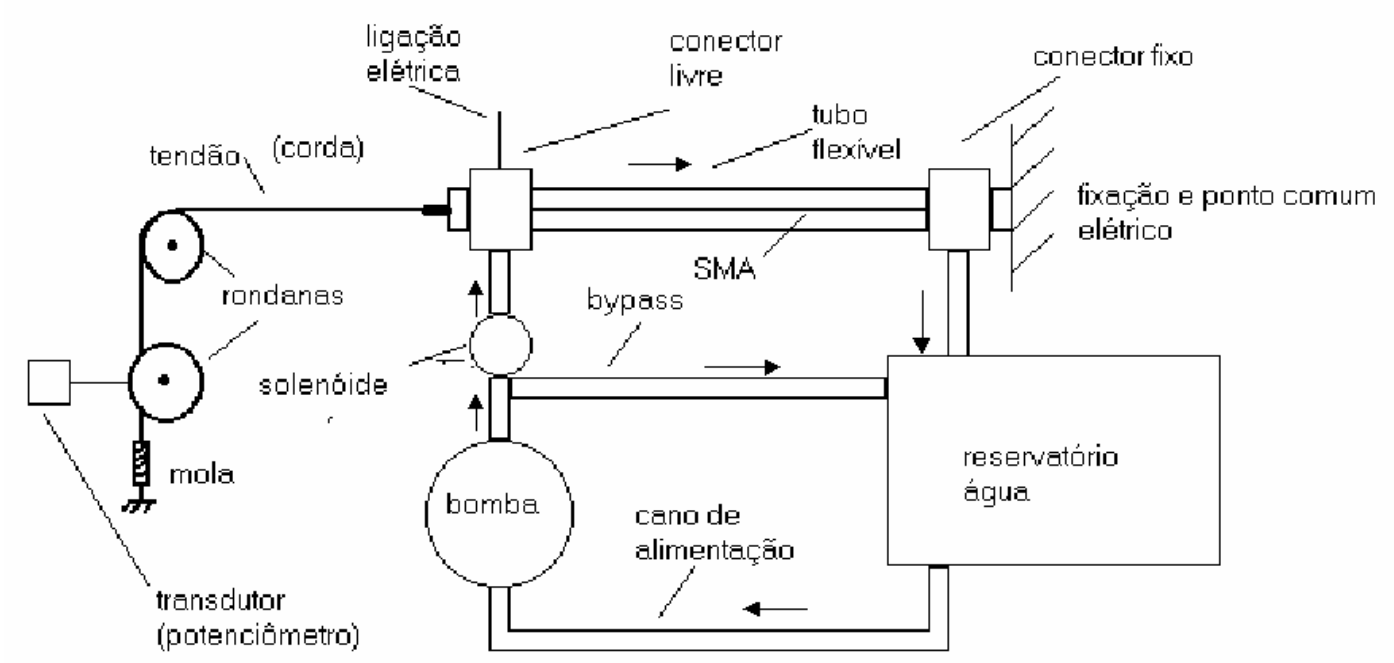

Figura 8 Esquema simplificado do atuador SMA úmido (adaptado de Asada e Mascaro (2002))

Um microcomputador Pentium III foi utilizado para controlar o sistema acionando os transistores de potência que controlam a corrente elétrica no fio de SMA e faz a válvula solenóide abrir ou fechar quando for necessário. No experimento, Asada e Mascaro (2003) obtiveram um deslocamento de $10 \mathrm{~mm}$ (2\% de deformação) com largura de faixa de $2 \mathrm{~Hz}$. Como ilustra a Figura 9, a fase de aquecimento é, para este atuador, mais lenta que o resfriamento, devido a grande troca de calor do fio com a água no ciclo de resfriamento. Assim, os autores constataram que a velocidade de resposta poderia ser ainda melhorada, fazendo-se passar água quente no momento em que o fio de SMA está sendo aquecido (pela corrente elétrica). Logicamente, com isso a complexidade do sistema aumentaria, bem como o consumo de energia. 


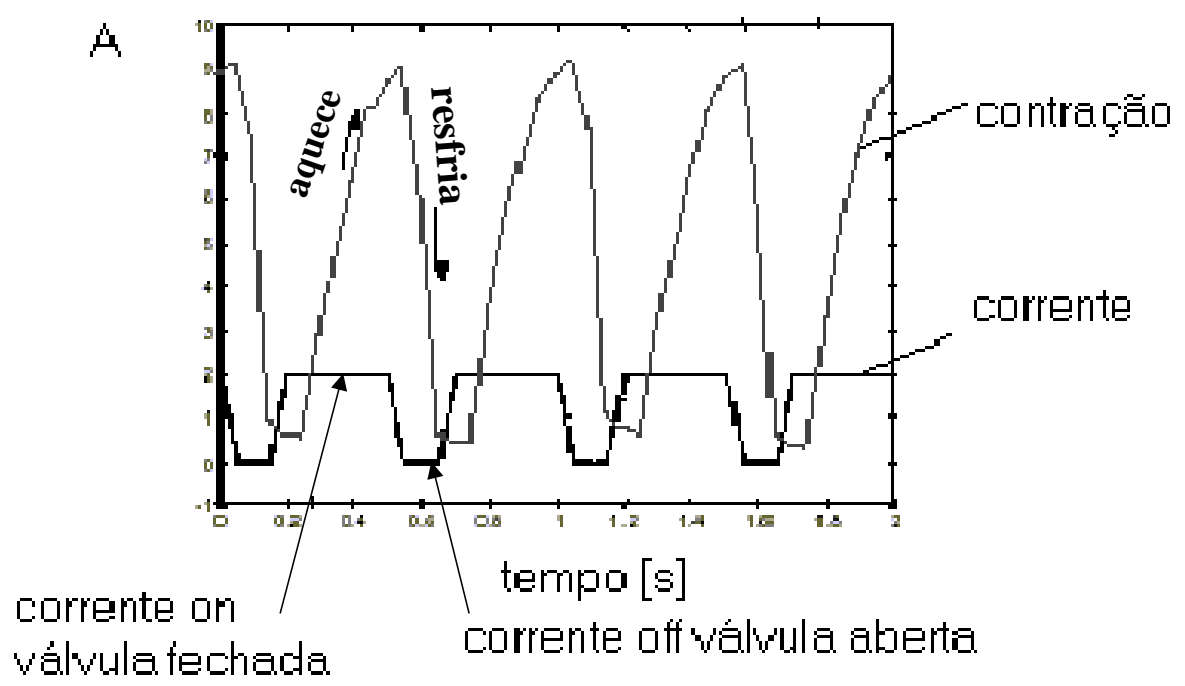

Figura 9 Dados experimentais do SMA úmido (adaptado de Asada e Mascaro (2003))

Conclui-se que o atuador SMA úmido possui uma resposta na largura de faixa superior aos estudados anteriormente $(2 \mathrm{~Hz})$, devido ao controle do fluxo de água no sistema de refrigeração. Essa resposta rápida é devido ao sistema de resfriamento mais eficiente. A complexidade do sistema é, entretanto, uma desvantagem do presente atuador, que requer um sistema de circulação de água para seu funcionamento.

Portanto, torna-se evidente com os casos acima estudados que para se aumentar a resposta em freqüência ou largura de faixa de um atuador SMA é necessário um sistema de refrigeração forçada para compensar a inércia térmica durante o ciclo de resfriamento. 


\section{MONTAGEM EXPERIMENTAL DO ATUADOR SMA REFRIGERADO POR PASTILHA TERMOELÉTRICA}

Um protótipo experimental do atuador SMA refrigerado com pastilha termoelétrica foi construído, com a finalidade de se validar o modelo matemático exposto na seção seguinte, bem como testar as metodologias de controle .

\subsection{Sistema completo}

Na Figura 10 mostra-se um diagrama esquemático, como o atuador está interligado com o computador, permitindo que todos os comandos sejam feitos diretamente através do teclado e facilitando a aquisição, registro e tratamento dos dados provenientes do atuador, bem como a execução das ações de controle.

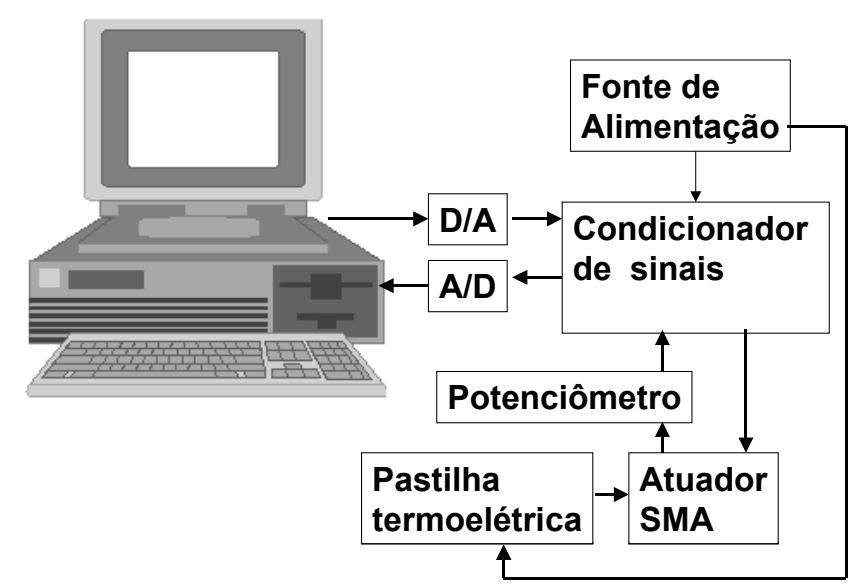

Figura 10 Atuador SMA acoplado ao microcomputador

O conjunto completo, que compreende atuador, pastilha termoelétrica, circuito amplificador de corrente e sinal do potenciômetro, fonte de alimentação e microcomputador com a placa $A / D$ e $D / A$ instalada internamente, está mostrado na Figura 11. 


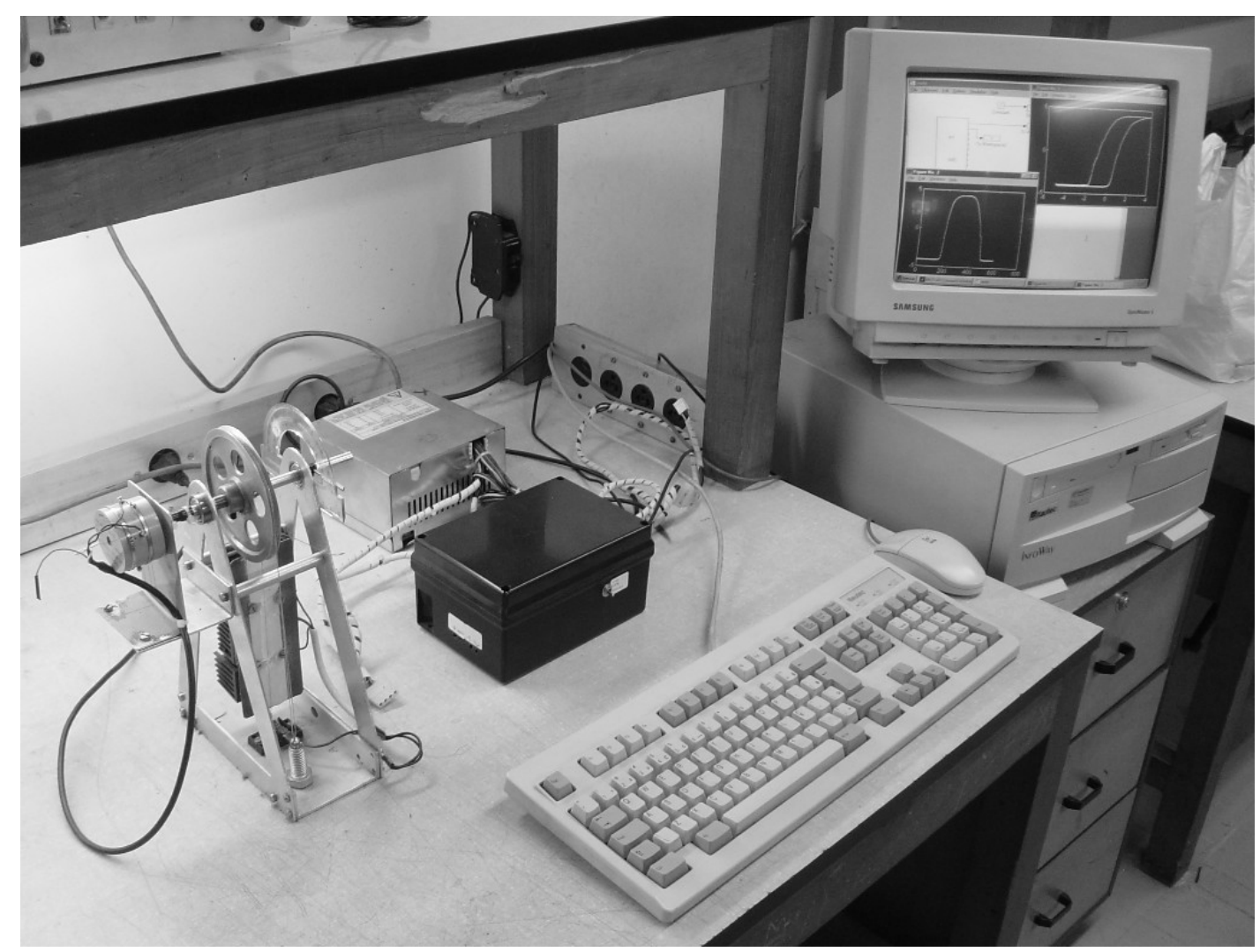

Figura 11 Atuador SMA interligado ao circuito condicionador e microcomputador

\subsection{Montagem do sistema mecânico}

Um esboço da montagem mecânica do atuador pesando aproximadamente $1 \mathrm{Kg}$ está mostrada na Figura 12 (desenhos mecânicos detalhados no apêndice A). Nota-se em evidência o fio de SMA em contato com a pastilha termoelétrica, provendo assim a refrigeração forçada. A pastilha possui um dissipador de calor $\mathrm{e}$ um pequeno ventilador para melhorar a troca de calor entre a pastilha e o meio ambiente, como será detalhado adiante no capítulo 3.3.

O fio de SMA está fixado em uma extremidade no suporte da estrutura, por intermédio de um conector elétrico $\left(\mathrm{C}_{1}\right)$. Sua outra extremidade é fixada diretamente no eixo da polia (raio $r_{1}=0,45 \mathrm{~cm}$ ). Uma massa de $40 \mathrm{~g}$, servindo como carga, está acoplada ao diâmetro externo da polia (raio $r_{2}=4,5 \mathrm{~cm}$ ) por meio de um fio comum. Como a relação $n=r_{2} / r_{1} \cong 10$, o movimento da massa será amplificado por um fator 10 em relação ao deslocamento do fio de SMA, que sofrerá uma contração aproximada de 4 a $4,5 \%$ do seu comprimento útil $(15 \mathrm{~cm})$, quando alimentado com a corrente elétrica. Isto, portanto, resulta num movimento da carga de aproximadamente $6 \mathrm{~cm}$, com uma rotação do eixo de $76^{\circ}$. 
O sistema de medida é feito por um potenciômetro ligado ao eixo da polia. Com a medida de posição angular do eixo, pode-se obter diretamente a posição da carga. A polia está aterrada eletricamente ao potencial neutro da fonte de corrente.

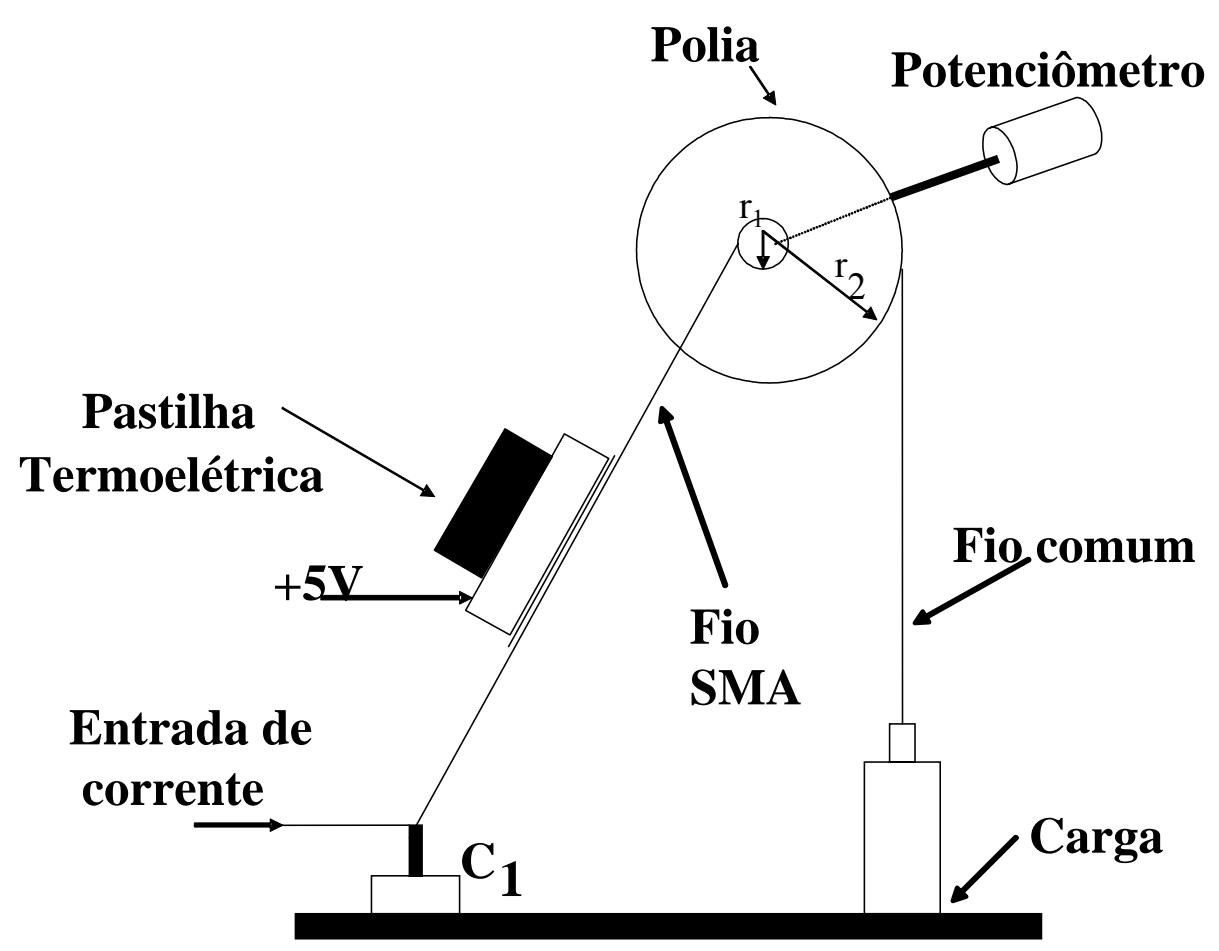

Figura 12 Montagem mecânica do atuador SMA

O atrito é minimizado pela utilização de rolamentos para o apoio do eixo, além da seleção de um potenciômetro com rolamentos internos e baixo atrito. Assim, todo esforço do atuador será feito para elevar a carga de cerca de $40 \mathrm{~g}$, que é refletida na tração do fio de SMA com cerca de $400 \mathrm{~g}$, uma vez que a relação de amplificação é de aproximadamente 10 .

Uma foto do atuador construído é mostrada na Figura 13, onde se pode ver a estrutura de alumínio responsável pela sustentação dos componentes mecânicos (polia, fio de SMA, rolamentos, potenciômetro de medida, transferidor, pastilha termoelétrica, carga de teste, fio de sustentação da carga e conectores elétricos). Nota-se também um transferidor fixado à estrutura e um ponteiro fixado ao eixo móvel, utilizado para medir a posição angular do eixo. Esse dispositivo serve apenas como referência visual. 


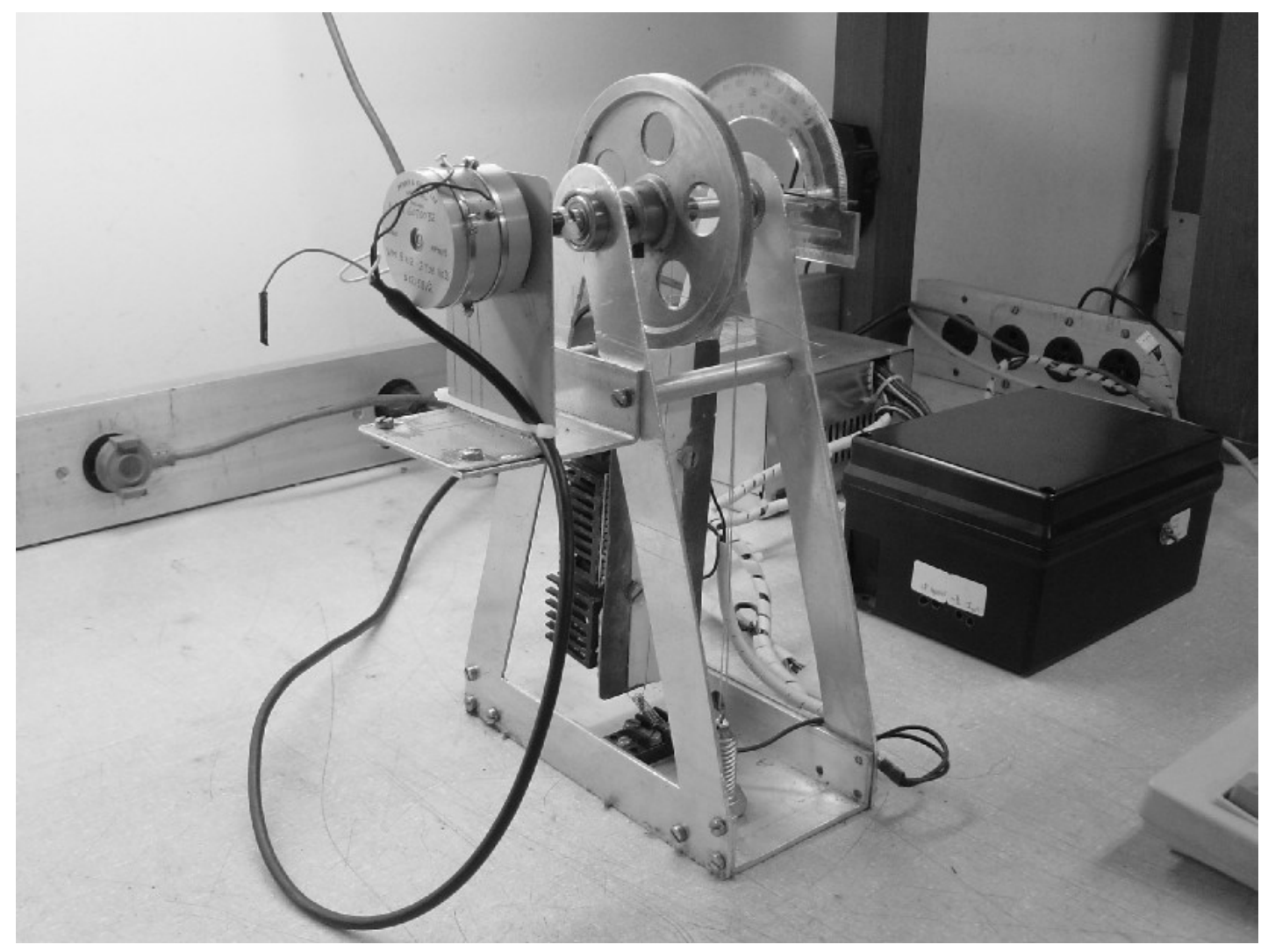

Figura 13 Atuador SMA refrigerado com pastilha termoelétrica

\subsection{Montagem da pastilha termoelétrica do atuador SMA}

A pastilha termoelétrica utilizada no atuador em estudo é mostrada na Figura 14. Esta possui dimensão de $50 \times 50 \mathrm{~mm}$ e sua área de dissipação foi ampliada com uma chapa de cobre de $1 \mathrm{~mm}$ de espessura e de dimensão 50x150 mm. Além disso, o dissipador de calor montado no corpo da pastilha termoelétrica possui aletas de alumínio pintadas de preto e um ventilador montado sobre as mesmas, aumentando sua eficiência e evitando-se que o ar quente se propague por convecção para o fio de SMA e para o lado frio da pastilha termoelétrica. Para manter o ar quente que foi expelido do dissipador de calor fora do alcance das partes frias da pastilha termoelétrica, foi colocada uma placa isolante de isopor de $10 \mathrm{~mm}$ de espessura, entre o dissipador de calor e a placa de cobre.

A pastilha termoelétrica é alimentada continuamente com $5 \mathrm{~V}$ e circula por ela uma corrente aproximada de $2 \mathrm{~A}$. Os teste mostraram que a mesma atinge, em alguns minutos, uma temperatura de aproximadamente $15^{\circ} \mathrm{C}$, dispensando, portanto, o controle de temperatura da pastilha. $O$ ventilador utilizado é alimentado 
independente com $12 \mathrm{~V}$ e uma corrente de aproximada de 0,1 $\mathrm{A}$. Assim o consumo total da pastilha termoelétrica em conjunto com o ventilador é de 11,2W.

Entre a placa de cobre e o fio de SMA foi fixada uma placa cerâmica de alumina com $1 \mathrm{~mm}$ de espessura, que é um bom condutor térmico e um bom isolante elétrico, permitindo que o fio de SMA fique em contato direto sobre a pastilha termoelétrica sem provocar curto circuito.

O fio de SMA fica em contato com a placa de alumina com uma fina camada de pasta térmica de baixa resistência térmica comumente utilizada em componentes eletrônicos que trabalham com dissipador de calor. Utilizando-se essa técnica obtém-se uma melhora considerável na condução de calor entre fio e a pastilha termoelétrica, uma vez que se eliminam as bolhas de ar entre a placa cerâmica de alumina e o fio de SMA.

Para melhorar a condução térmica entre a pastilha termoelétrica, chapa de cobre e cerâmica (alumina), é também aplicada uma fina camada de pasta térmica entre esses elementos.
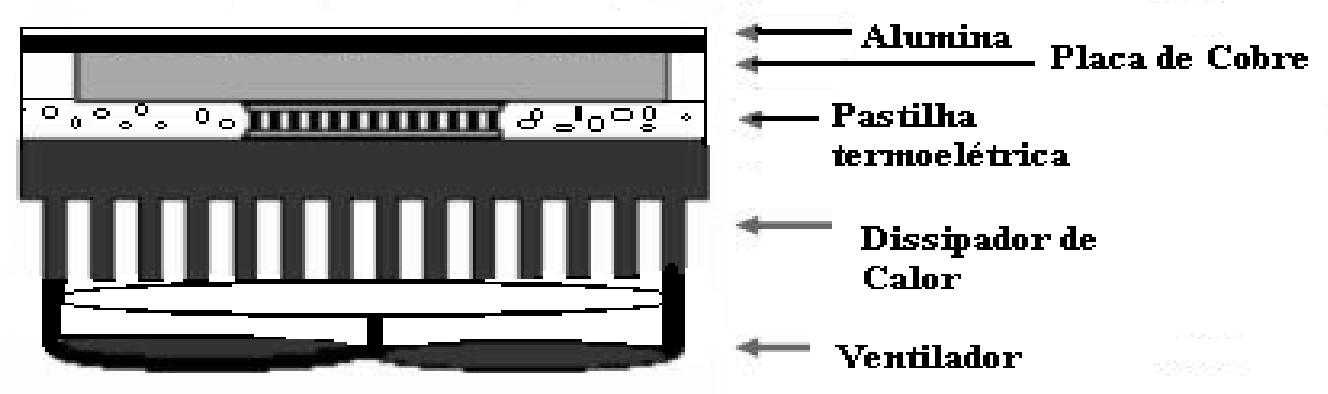

Figura 14 Detalhes de montagem da pastilha termoelétrica

Na Figura 15 mostra-se a montagem da pastilha termoelétrica com a placa de cobre e a cerâmica de alumina em contato com o fio de SMA e a vista traseira com dissipador de calor acoplado ao ventilador. 


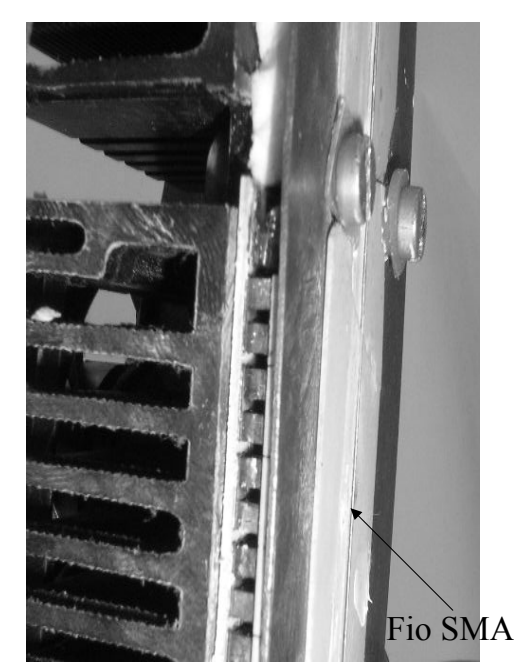

Vista lateral

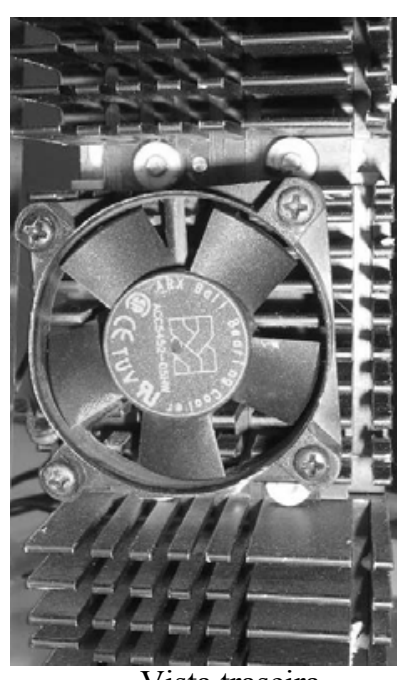

Vista traseira

Figura 15 Pastilha termoelétrica em contato com o fio de SMA e sistema dissipador de calor

Mais detalhes do funcionamento e características das pastilhas termoelétricas podem ser encontrados no apêndice $B$

\subsection{Circuitos eletrônicos}

Neste capítulo serão descrito os circuitos eletrônicos que interligam o atuador SMA em estudo com o microcomputador.

\subsubsection{Condicionador de sinais}

O sistema possui um circuito condicionador de sinais, contendo um amplificador de corrente constante que fornece a potência necessária para o aquecimento do fio de SMA e um circuito amplificador ligado ao potenciômetro de medida. Esses circuitos estão interligados a um microcomputador (Pentium 100MHz) com uma placa conversora com saídas digital/analógico (D/A) e entradas analógica/digital (A/D), fazendo a interface entre o atuador em estudo e o programa interno no microcomputador.

O modulo condicionador de sinais (amplificador de corrente e o amplificador do sinal do potenciômetro) foi projetado utilizando amplificadores operacionais e transistores bipolares. Um amplificador de corrente fornece uma corrente constante independente da variação da resistência do fio de SMA, ou variação dos contatos de conexões entre o gerador de corrente e o fio de SMA. Na Figura 16 mostra-se um diagrama em blocos do circuito condicionador (esquema eletrônico detalhado 
apêndice $\mathrm{C}$ ). Esse circuito tem como característica o baixo consumo e alta linearidade. Possui reguladores de tensões internos impedindo derivas nos sinais por flutuação de tensões ou derivas térmicas, além de possuir uma ótima imunidade a ruídos, uma vez que sua impedância de saída é baixa (50 $\Omega$ ) e impedância de entrada não é muito alta (cerca $10 \mathrm{~K} \Omega$ )

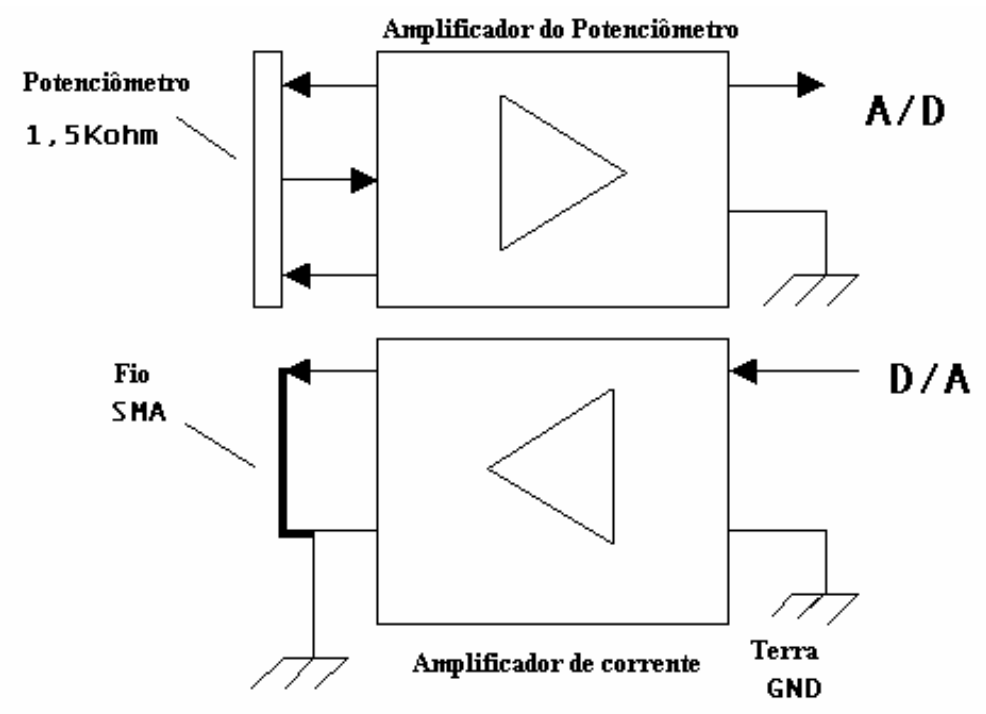

Figura 16 Esquema em blocos do condicionador de sinais.

Optou-se por esse tipo de tecnologia, utilizando amplificadores operacionais lineares, por serem mais simples, baratos e confiáveis que os drivers tipo PWM (pulse width modulation), citados por muitos pesquisadores em seus projetos com SMA.

O circuito do condicionador de sinais foi alojado em uma caixa plástica conforme mostra a Figura 17, proporcionando uma isolação elétrica, térmica e evitando-se resíduos e poeira que poderiam interferir no funcionamento do circuito.

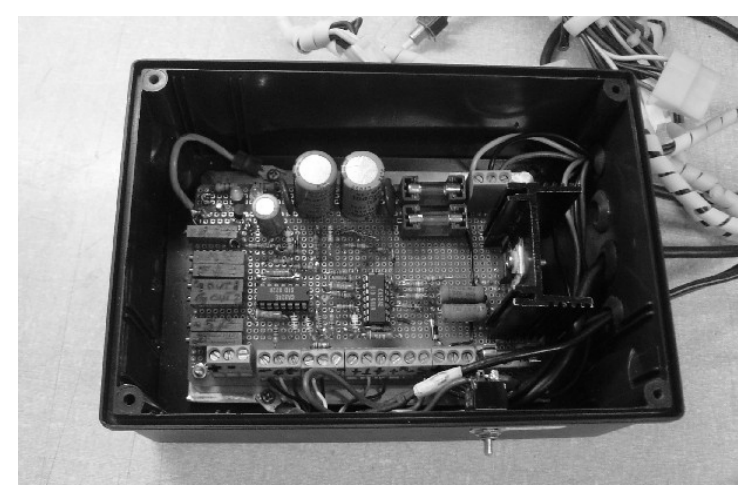

Figura 17 Condicionador de sinais 


\subsubsection{Sistema de interface A/D e D/A}

A placa conversora A/D e D/A foi obtida comercialmente, e modelos similares podem ser facilmente encontrados no mercado nacional. A placa utilizada no sistema em estudo possui uma resolução de 10 bits no conversor $A / D$, com sinal de entrada corresponde de -5 a $+5 \mathrm{~V}$ (sinal amplificado do potenciômetro). Possui 8 bits no conversor D/A com uma variação no sinal de saída de $-5 a+5 \mathrm{~V}$, sendo esse sinal correspondente de 0 a $1 \mathrm{~A}$ no fio de SMA do atuador.

Essa placa possui ótima imunidade a ruídos e, para garantir uma boa blindagem, optou-se em utilizar cabos de interligação blindados aterrando-se apenas uma das pontas ao ponto comum do microcomputador, evitando-se com isso a circulação de corrente de terra, que poderia provocar ruídos indesejáveis. Na Figura 18 mostra a placa instalada dentro do gabinete do microcomputador Pentium 100.

\section{Placa A/D e D/A}

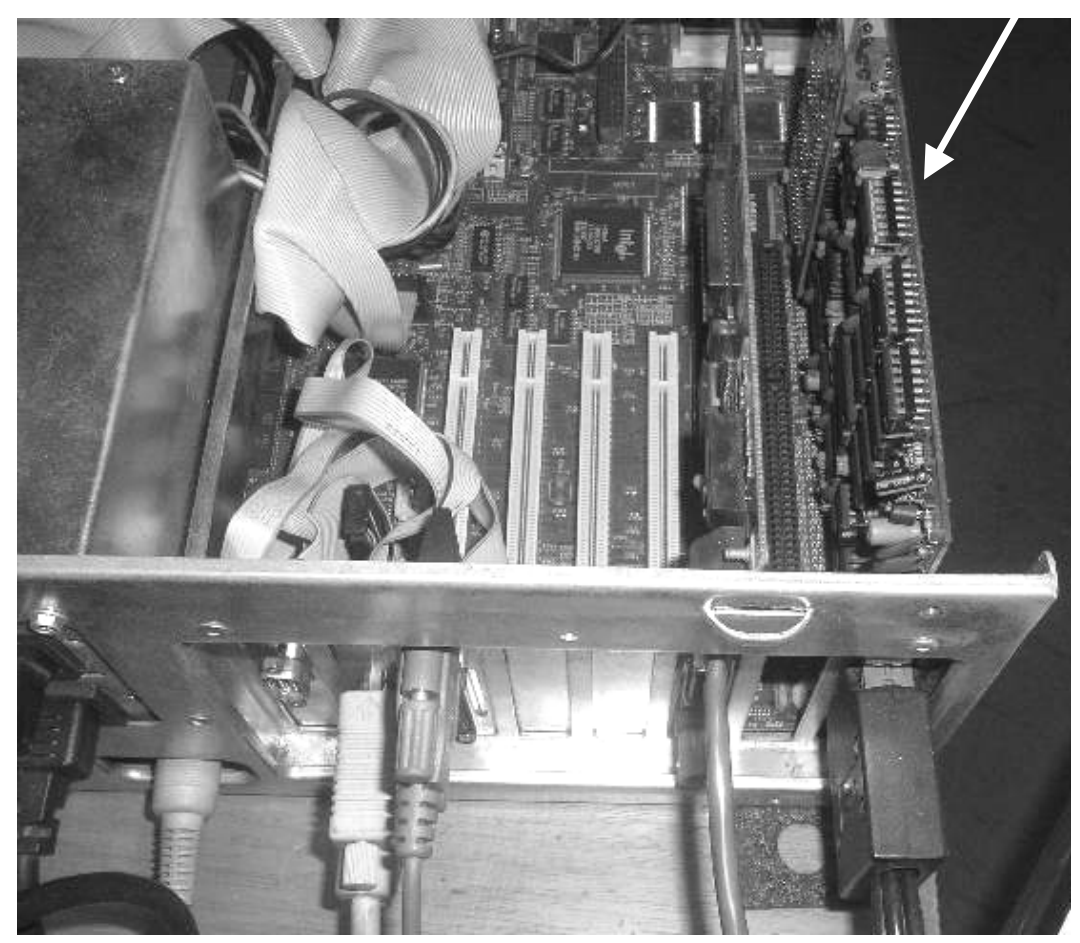

Figura 18- Placa A/D, D/A instalada dentro do gabinete do microcomputador Pentium 100

\subsubsection{Fonte de Alimentação}

A alimentação do sistema de resfriamento (pastilha termoelétrica) e circuito condicionador de sinais é realizado por uma fonte chaveada de $250 \mathrm{~W}$ com saída de $+12 \mathrm{~V},-12 \mathrm{~V},+5 \mathrm{~V},-5 \mathrm{~V}$ padrão $\mathrm{AT}$, comumente utilizada em microcomputadores 
conforme mostra a Figura 19, que oferece a robustez e regulação necessária para essa aplicação, sendo um item comum e barato encontrado facilmente no mercado de equipamentos para informática e portanto de fácil aquisição e substituição.

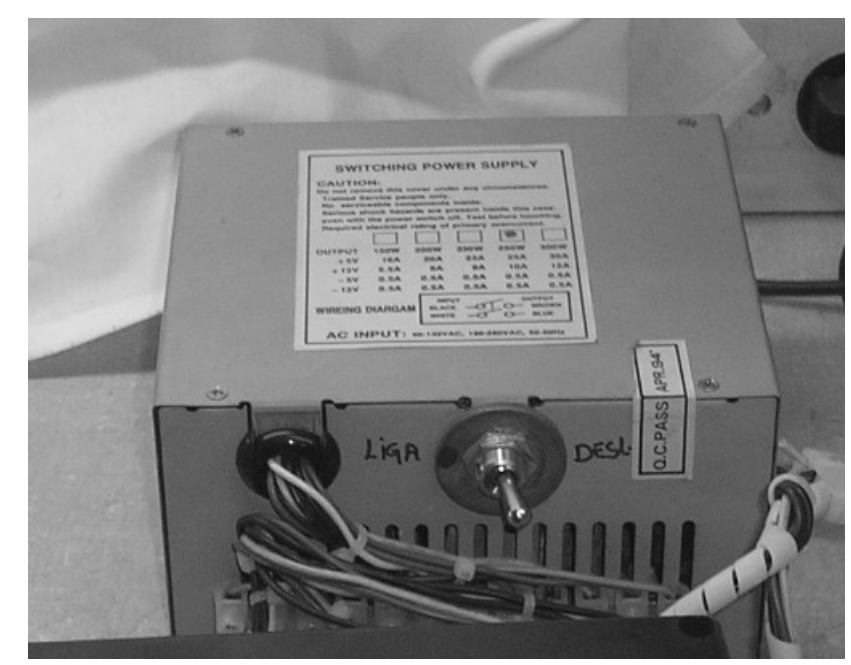

Figura 19 Fonte de Alimentação (+12V; -12V; +5V; -5V)

\subsection{Sensor de posição}

Conforme já mencionado anteriormente o sensor de posição é um potenciômetro linear de $1,5 \mathrm{~K} \Omega$ de precisão $1 \%$ com rolamentos internos a fim de reduzir o atrito mecânico, muito utilizado em registradores gráficos e ploters, de precisão. A Figura 20 mostra o potenciômetro acoplado ao eixo do atuador SMA.

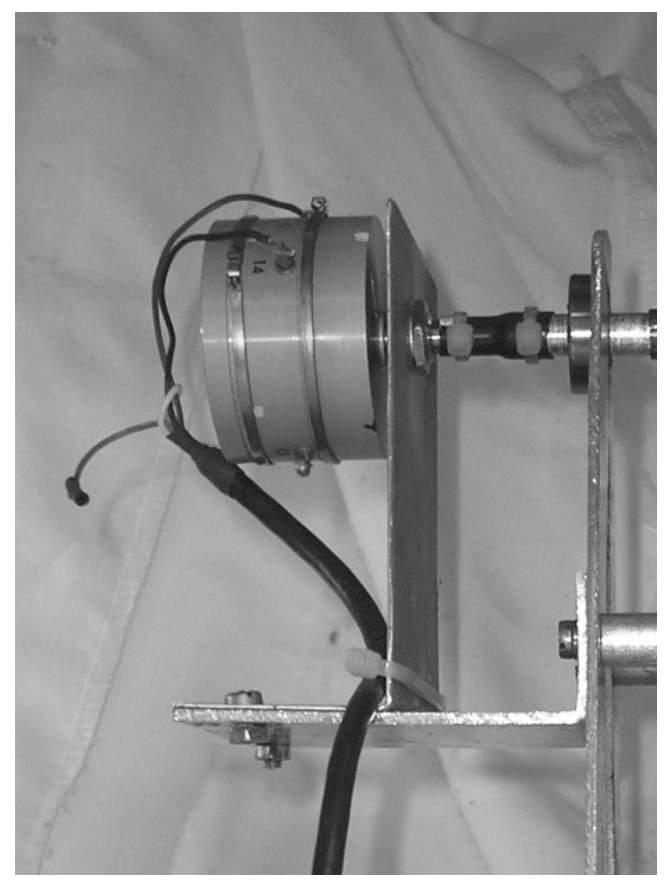

Figura 20-Sensor de posição com potenciômetro interligado ao eixo do atuador 


\subsection{Programa}

O microcomputador possui um aplicativo desenvolvido em ambiente Matlab/Simulink conforme mostra a Figura 21, onde todos os dados e sinais serão processados. Esse software permite ao operador enviar sinais externos e recebê-los do sensor que está ligado ao eixo do atuador, por meio de uma interface com a placa de aquisição. Com esse aplicativo tem-se a possibilidade de se implementar um controlador e acoplá-lo diretamente nos blocos de sinais de entrada e de saída, controlando o sistema diretamente pelo microcomputador.

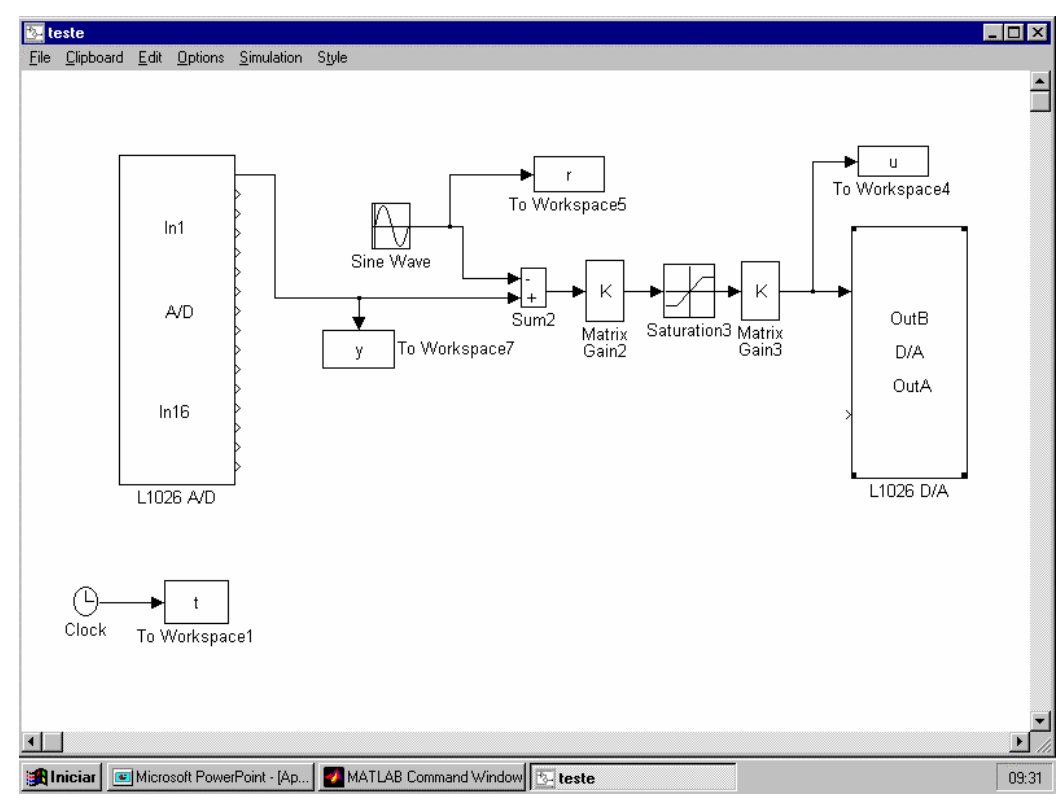

Figura 21 Ambiente Matlab/Simulink

A grande vantagem em se utilizar esse aplicativo, em conjunto com o Matlab/Simulink, está na facilidade da sua implementação. Sua versatilidade permite a realização de mudanças na lógica de controle de maneira bastante simples, além da possibilidade de se fazer simulações no projeto, antes da sua implementação definitiva no sistema. 


\section{MODELO MATEMÁTICO DO ATUADOR SMA REFRIGERADO POR PASTILHA TERMOELÉTRICA}

Neste capítulo será desenvolvido um modelo matemático para posterior utilização no projeto do sistema de controle do atuador SMA em estudo.

\subsection{Modelo geral}

O presente desenvolvimento do modelo matemático foi baseado nos trabalhos de Hirose, Ikuta e Tsukamoto (1991); Grant, Hayward e Lu (1997); Ashrafiuon e Elahinia (2002); Hoder, Solc e Vasina (2003). As equações básicas foram descritas conforme a lógica mostrada na Figura 22.

O fio de SMA é percorrido por uma corrente elétrica sofrendo um aquecimento por efeito Joule e, em seguida, ocorre a transformação de fase com a posterior deformação do fio. No primeiro bloco serão analisadas as equações dos fenômenos térmicos do sistema e posteriormente os fenômenos envolvendo a transformação de fase e finalmente as deformações mecânicas ocorridas no fio de SMA.

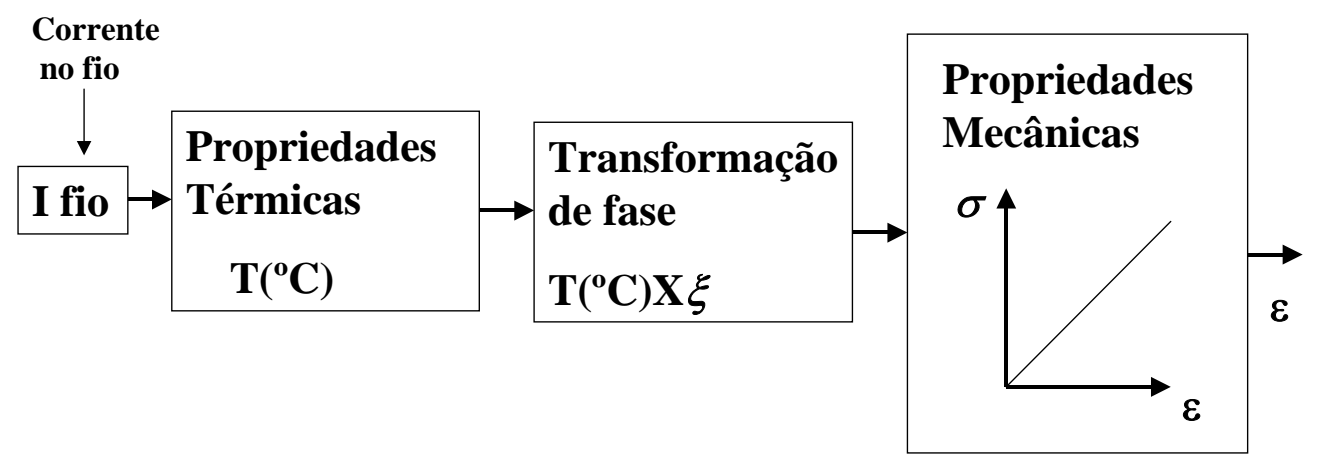

Figura 22 Modelo matemático das propriedades do fio da SMA

As variáveis envolvidos na Figura 22 são:

$I_{\text {fio }}$ - corrente elétrica no fio da SMA (em A)

$\mathbf{T}$ - temperatura no fio da $\operatorname{SMA}\left(\mathrm{em}^{\circ} \mathrm{C}\right)$

$\xi$ - fração de martensita (0 a $100 \%$ ou 0 a 1)

$\sigma$ - tensão mecânica no fio de SMA $\left(\mathrm{em} \mathrm{N} / \mathrm{m}^{2}\right)$

$\varepsilon$ - deformação $(\Delta \mathrm{L} / \mathrm{L})$-variação do comprimento / comprimento do fio 


\subsection{Modelo térmico}

O modelo térmico foi baseado na estrutura de montagem mostrada na Figura 23, onde o fio da SMA está em contato com a pastilha termoelétrica e entre o fio de SMA e a pastilha há uma fina camada de pasta térmica permitindo que a condução de calor entre o fio de SMA e a pastilha cerâmica seja eficiente.

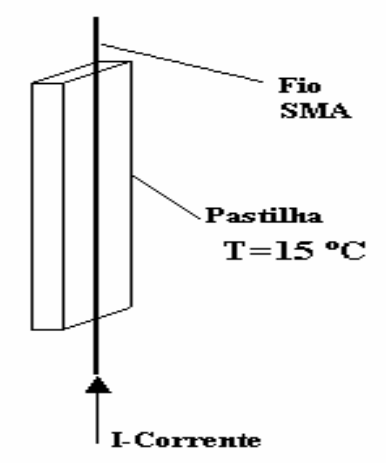

Figura 23 Fio de SMA em contato com a pastilha termoelétrica

\subsubsection{Considerações adotadas para modelo térmico}

Nesse modelo serão feitas as seguintes hipóteses:

1. A resistência térmica do fio é desprezível.

2. A troca de calor do fio de SMA com a pastilha será feita por condução através de uma fina camada de pasta térmica depositada entre o fio e a pastilha cerâmica.

3. A temperatura será uniforme ao longo do comprimento do fio.

4. Para efeito de simplificação, considerou-se que o fio de SMA possui uma resistência média constante, ignorando-se a variação da resistência durante as transformações de fase.

5. A temperatura na pastilha cerâmica acoplada à pastilha termoelétrica é constante ao longo do tempo.

6. A temperatura ambiente é constante ao longo do tempo (temperatura ambiente controlada).

7. As deformações no fio de SMA são uniformes durante as transformações de fase. 
8. O efeito da radiação será considerado desprezível, uma vez que as temperaturas envolvidas são relativamente baixas (menores que $100^{\circ} \mathrm{C}$ ).

9. Serão considerados apenas os efeitos da convecção e condução de calor.

Baseando-se no trabalho de Grand, Hayward e Lu (1997) e os conceitos básicos da termodinâmica, conservação de energia e transmissão de calor (INCROPERA; WITT, 1998) o modelo térmico pode ser expresso conforme mostra a equação (1):

$m \cdot c_{p} \cdot \frac{d T}{d t}=i^{2} \cdot R-h \cdot A .\left(T-T_{a m b}.\right)-C \cdot\left(T-T_{p}\right)$

Segundo catálogo técnico Dynalloy (2005), referente ao fio de SMA utilizado (Flexinol -FLX00870 0.008" $70^{\circ} \mathrm{C}$ ), este possui as seguintes especificações técnicas:

$m$ - massa por metro do fio $\left(2.10^{-4} \mathrm{Kg} / \mathrm{m}\right)$

$c_{p}$ - calor específico do fio SMA (837 J/Kg.K)

$R$-resistência elétrica do fio de SMA por metro ( $32 \Omega / \mathrm{m})$

$A$ - área da seção transversal do fio $\left(6,28 \cdot 10^{-4} \mathrm{~m}^{2}\right)$

$d$-diâmetro fio SMA $\left(2.10^{-4} \mathrm{~m}\right)$

i-corrente elétrica no fio $(\mathrm{A})$

Além disso, considera-se a temperatura da pastilha na face fria $\left(T_{p}\right)$ igual a $15^{\circ} \mathrm{C}$ e a temperatura ambiente $\left(T_{a m b}\right)$ igual a $20^{\circ} \mathrm{C}$.

Resta ainda estimar dois parâmetros da equação (1), a saber: $h$ (coeficiente de convecção natural por unidade de comprimento, em $\mathrm{W} / \mathrm{m}^{2}{ }^{\circ} \mathrm{C} / \mathrm{m}$ ) e $C$ (coeficiente de condução térmica do fio de SMA com a pastilha por unidade de comprimento W/ $\left.{ }^{\circ} \mathrm{C} / \mathrm{m}\right)$.

\subsubsection{Determinação do coeficiente de condução térmica}

O coeficiente de condução da pastilha será calculado conforme a equação (2), segundo Incropera e Witt (1998): 
$C=\frac{K_{c} \cdot A_{c}}{e}$

na qual:

$K_{\mathrm{c}^{-}}$Coeficiente de condução da pasta térmica entre o fio e a pastilha $\left(\mathrm{W} / \mathrm{m}^{\circ} \mathrm{C}^{\circ}\right)$ $A_{c}$-Área de contato entre o fio e a pastilha por unidade de comprimento $\left(\mathrm{m}^{2} / \mathrm{m}\right)$ e-espessura da pasta térmica entre o fio e a pastilha $(\mathrm{m})$

O coeficiente de condutividade térmica da pasta $\left(K_{\mathrm{c}}\right)$ é dado em catálogo segundo Implastec (2006) com o valor de $2 \mathrm{~W} / \mathrm{m}^{\circ} \mathrm{C}$. Estima-se ainda que a área de contato entre a pasta térmica e o fio de SMA seja de aproximadamente $5 \%$ da área total do fio, considerando-se as imperfeições de contato e as possíveis bolhas de ar entre o fio e a pastilha. A espessura $e$ da camada de pasta térmica foi medida com micrometro de precisão e obteve-se uma valor aproximado de $0,15.10^{-3} \mathrm{~m}$.

A Figura 24 mostra o sistema térmico (pastilha, pasta térmica e fio de SMA):

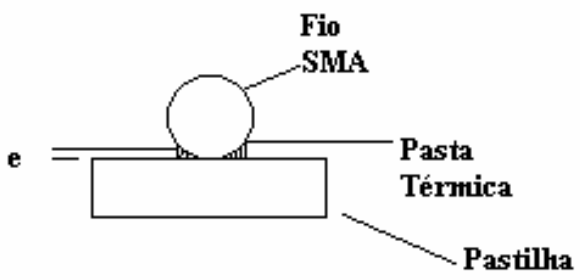

Figura 24 Sistema térmico de condução de calor

A área de contato da pasta térmica pode ser determinada conforme mostra a equação (3).

$A_{c}=0,05 \cdot A_{e}$

$A_{e}=\pi \cdot d . l$

onde:

$A_{c}$ - área de contato fio pasta térmica pastilha $\left(\mathrm{m}^{2}\right)$

$A_{e}$ - área externa do fio de SMA $\left(\mathrm{m}^{2}\right)$

l - comprimento do fio de SMA (m) 
Substituindo os valores encontrados da equação (3) em (2) obtém-se o valor $C=0,4 \mathrm{~W} /{ }^{\circ} \mathrm{C} / \mathrm{m}$, uma vez que todos os parâmetros estão expressos por unidade de comprimento. $O$ valor calculado de $C$, será utilizado como ponto de partida na identificação dos parâmetros do modelo físico real do sistema, não sendo portanto considerado como definitivo.

\subsubsection{Determinação do coeficiente de convecção $h$}

A determinação do coeficiente de convecção $h$ é de extrema complexidade, pois é influenciado por diversos fatores físicos, como as dimensões do elemento, a viscosidade, coeficiente de expansão volumétrica, densidade, condutividade e velocidade do ar, a gravidade local e pela diferença de temperatura entre o ar ambiente e o elemento aquecido (HOLMAN, 1977).

Assim, optou-se por fazer o cálculo com uma fórmula empírica para convecção natural mostrada na equação (4), dada em Holman (1977). Esta considera um cilindro de diâmetro qualquer na posição vertical. Essa equação tem uma incerteza de aproximadamente $6 \%$, o que não é crítico para esse coeficiente que será ajustado durante a identificação do sistema.

$h=0,29 \cdot\left(\frac{\Delta T}{L}\right)^{1 / 4}$

com:

$h$ - coeficiente de convecção natural do ar (Btu/h.ft ${ }^{2}{ }^{\circ} \mathrm{F}$ )

$\Delta T$ - diferença de temperatura entre o meio e o fio de SMA ( $\left.{ }^{\circ} \mathrm{F}\right)$

$L$ - dimensão predominante (comprimento do fio (ft))

Considerando uma temperatura de trabalho no fio de $90^{\circ} \mathrm{C}$, realizando-se todas as conversões de unidade necessárias, obtém-se $h=1,155 \mathrm{Btu} / \mathrm{h} \cdot \mathrm{ft}^{2} .{ }^{\circ} \mathrm{F}$, ou equivalentemente $h=6,55 \mathrm{~W} / \mathrm{m}^{2 \circ} \mathrm{C}$. Este valor está de acordo com a tabela dada em Incropera e Witt (1998), que indica que o coeficiente de convecção natural é da ordem de 2 a $25 \mathrm{~W} / \mathrm{m}^{2}{ }^{\circ} \mathrm{C}$, servindo, portanto como valor inicial na identificação dos parâmetros do modelo,adotando-se portanto na equação (1) $h=6,55 \mathrm{~W} / \mathrm{m}^{20} \mathrm{C} / \mathrm{m}$ 


\subsection{Transformação de fase e propriedades mecânicas}

\subsubsection{Modelos da transformação de fase}

No aquecimento ocorre a transformação no fio da fase de Martensita (M) para Austenita (A). No resfriamento, ocorre a transformação no fio da fase de Austenita (A) para Martensita (M). As equações básicas que modelam esta transformação, em função da temperatura, são dadas em (5), obtidas do trabalho de Hirose, Ikuta e Tsukamoto (1991).

$$
\begin{aligned}
& \xi=\frac{\xi_{m}}{1+\exp \left[\frac{6,2}{A f-A s}\left(T-\frac{A s+A f}{2}\right)\right]} \text { (aquecimento) } \\
& \xi=\frac{1-\xi_{A}}{1+\exp \left[\frac{6,2}{M f-M s}\left(T-\frac{M s+M f}{2}\right)\right]}+\xi_{A} \text { (resfriamento) }
\end{aligned}
$$

onde:

As- temperatura inicial da transformação para austenita $\left({ }^{\circ} \mathrm{C}\right)$

Af - temperatura final da transformação para austenita $\left({ }^{\circ} \mathrm{C}\right)$

Ms- temperatura inicial da transformação para martensita $\left({ }^{\circ} \mathrm{C}\right)$

Mf- temperatura final da transformação para martensita $\left({ }^{\circ} \mathrm{C}\right)$

$\xi$ - fração de martensita (0 a 1 ou de 0 a 100\%)

$\xi_{m}$ - maior fração de martensita durante o resfriamento (ou valor inicial durante o aquecimento)

$\xi_{A}$ - valor inicial da fração de austenita durante o resfriamento

Os valores característicos para as fases de transformação são $A s=68^{\circ} \mathrm{C}, \mathrm{Af}=$ $78^{\circ} \mathrm{C}, \mathrm{Ms}=52^{\circ} \mathrm{C}$ e $\mathrm{Mf}=42^{\circ} \mathrm{C}$ (DYNALLOY, 2005). Entretanto, admitem-se variações de até $15^{\circ} \mathrm{C}$ nestes valores, o que impões a necessidade de um procedimento de identificação, exposto na próxima seção.

Segundo Hoder; Solc e Vasina (2003) o aspecto do gráfico das fases de transformação é mostrado na Figura 25, onde verifica-se a histerese do fio de SMA. 


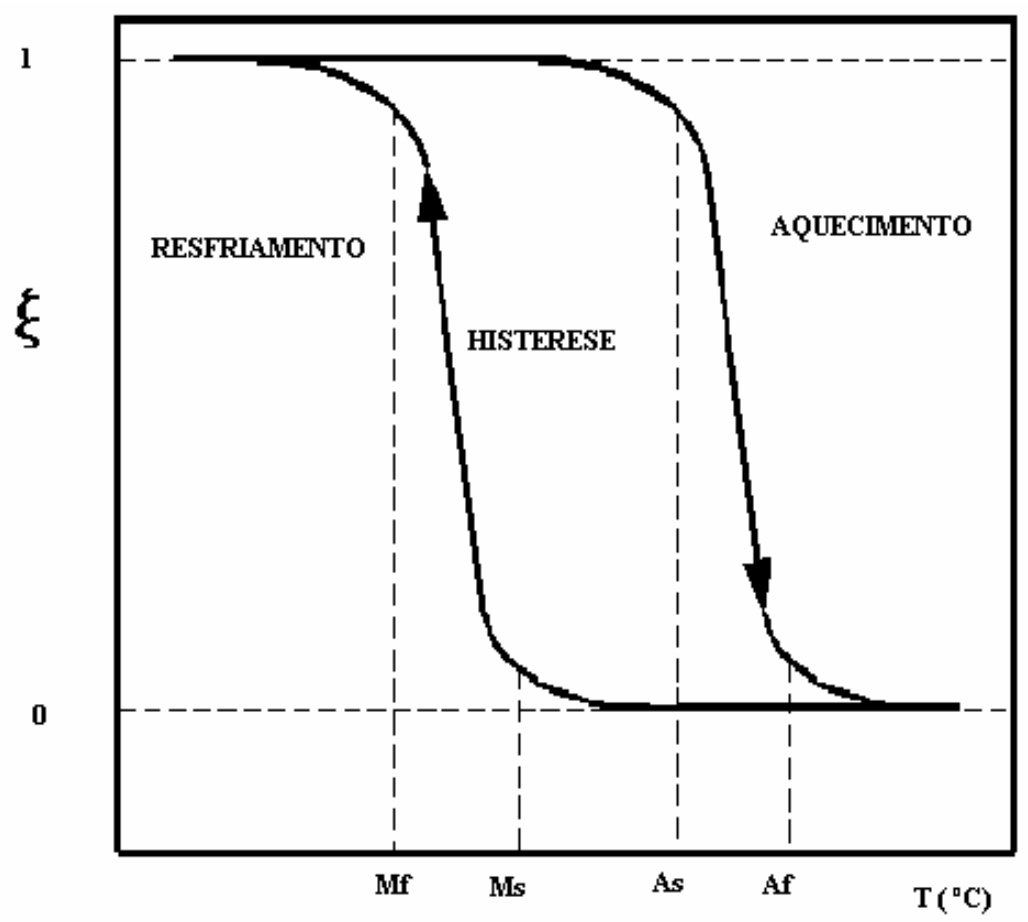

Figura 25 Curva de histerese do fio SMA $\xi$ versus temperatura (adaptado de Mavroidis; Pfeiffer e Mosley (1999))

\subsection{Modelo das propriedades mecânicas}

Na literatura científica, as propriedades mecânicas das ligas com memória de forma são obtidas com um modelo de camadas. Na fase de austenita (alta temperatura), o fio de SMA torna-se elástico e, portanto, para $\xi=0$, a relação entre tensão e deformação é dada na equação (6):

$\sigma_{A}=E_{A} \cdot \varepsilon$

$\sigma_{A}$ - Tensão na fase de austenita

$E_{A}$ - Módulo de elasticidade (módulo de Young para austenita).

$\varepsilon$ - Deformação do fio de SMA.

O outro caso extremo, quando $\xi=1$, equivale à fase da martensita (fria). Nesta, o comportamento mecânico é semelhante ao de um material plástico, modelada segundo equação (7), cujo o gráfico característico é mostrado na Figura 26. 
$\begin{array}{lll}\sigma_{M}=E_{m} \cdot \varepsilon & \text { se } & |\varepsilon| \leq\left|\varepsilon_{m y}\right| \\ \sigma_{M}=E_{m} \cdot \varepsilon_{m y} & \text { se } & |\varepsilon|>\left|\varepsilon_{m y}\right|\end{array}$

onde:

$E_{m}$ - módulo de elasticidade da martensita.

$\varepsilon_{m y}$ - limite elástico na fase da martensita.

$\sigma_{M^{-}}$tensão máxima do fio na fase de martensita.

$\varepsilon$ - deformação do fio.

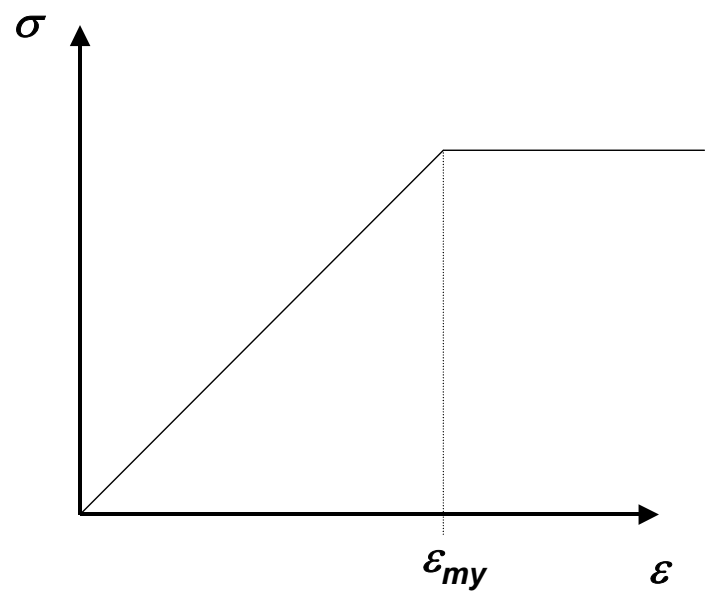

Figura 26 Gráfico característico da tensão por deformação na martensita

Baseando-se nas equações anteriores obtém-se, para o caso intermediário $(0<\xi<1)$, a relação entre a tensão e a deformação dada por:

$\sigma=\xi . \sigma_{M}+(1-\xi) \cdot \sigma_{A} \Rightarrow\left\{\begin{array}{c}\varepsilon=\frac{\sigma}{\xi \cdot E_{M}+(1-\xi) \cdot E_{A} \cdot} \quad \text { para } \quad|\varepsilon| \leq\left|\varepsilon_{m y}\right| \\ \varepsilon=\frac{\sigma-\xi \cdot E_{M} \cdot \varepsilon_{m y}}{(1-\xi) \cdot E_{A}} \quad \text { para }|\varepsilon|>\left|\varepsilon_{m y}\right|\end{array}\right.$

\subsection{Modelo do sistema mecânico}

O atuador proposto é composto por uma polia, na qual acoplam-se a carga deslocada e o fio de SMA, responsável pelo movimento. Um esquema simplificado é apresentado Figura 27. A posição da carga é dada pela coordenada $x$, orientada positivamente para cima. 


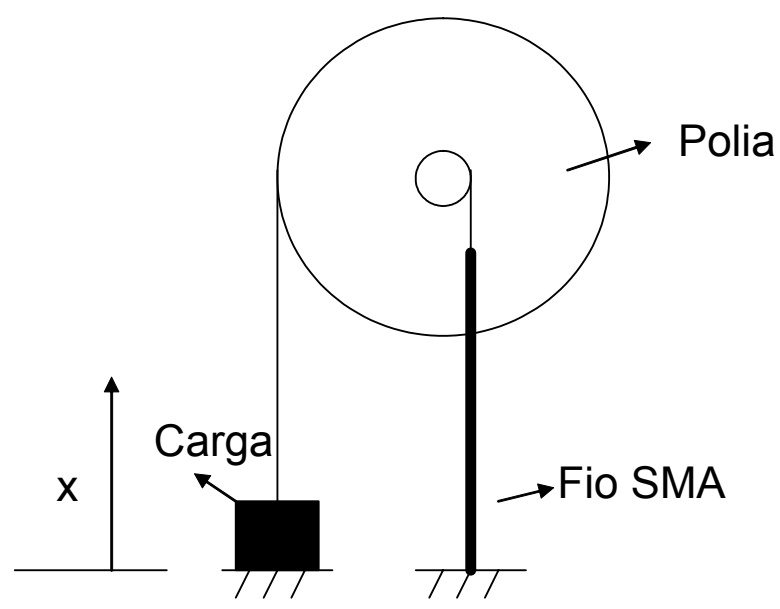

Figura 27 Esquema simplificado da montagem mecânica do experimento

O diagrama de corpos livres da polia, da carga e do fio de SMA, apresentado na Figura 28, é utilizado para a dedução das equações do movimento. Neste, $T_{1}$ é a tração no fio que suporta a carga, $T_{2}$ é a tração no fio de SMA, $\omega$ é a velocidade de rotação da polia e $r_{2}$ é o raio externo.

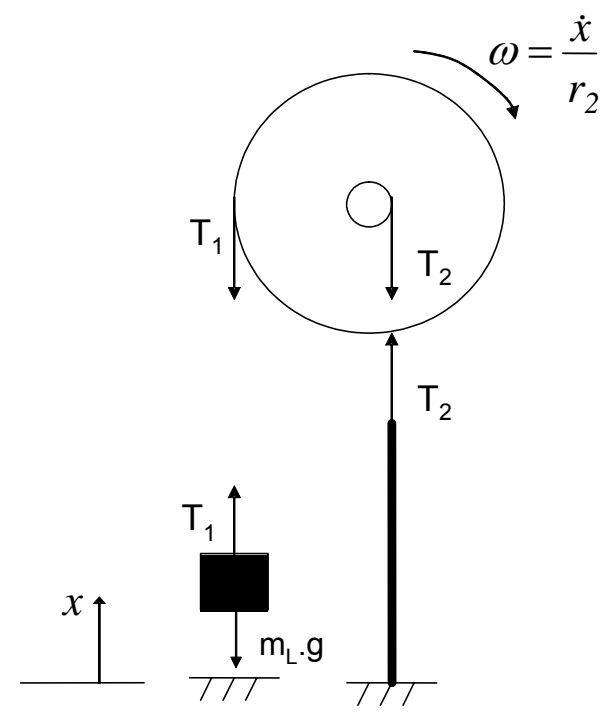

Figura 28 Diagrama de corpos livres

Assim, aplicando-se o Teorema do Momento Angular (TMA) para a polia obtém-se:

$-T_{1} \cdot r_{2}+T_{2} r_{1}=J \cdot \frac{\ddot{x}}{r_{2}}$ 
onde $\mathrm{J}$ o momento de inércia da polia. Sendo $\mathrm{m}_{\mathrm{L}}$ a massa da carga, a $2^{\mathrm{a}}$ Lei de Newton aplicada para esta fornece:

$-m_{L} g+T_{1}=m_{L} \ddot{x}$

Para estimar a tração no fio $\mathrm{T}_{2}$, considera-se a Figura 29 que apresenta o fio de SMA em seus três estados possíveis. Será feita uma analogia com uma mola linear a fim de se obter um modelo simplificado para a tração $T_{2}$. Na fase de austenita pura, considera-se o comprimento inicial da "mola" $l_{0}$. Na fase de martensita pura, o fio atinge seu comprimento máximo $l_{\text {fio }}$, que também corresponde à situação na qual a carga encontra-se na posição $x=0$. A diferença entre os comprimentos $l_{0}$ e $l_{\text {fio }}$ é aproximadamente $4 \%$ do comprimento $l_{\text {fio }}$, conforme visto anteriormente. Numa situação intermediária, a deformação $\Delta l$ da "mola" em relação ao seu comprimento inicial $l_{0}$ é dada por $4 \% . l_{\text {fio }}-x / n$, onde n é a relação entre os raios da polia $\left(n=r_{2} / r_{1}\right)$.

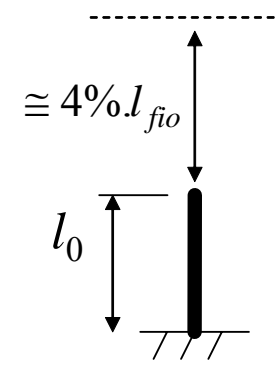

Austenita Pura

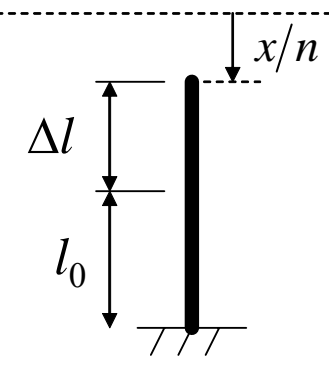

Intermediária

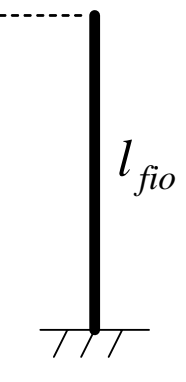

Martensita Pura $(x=0)$

Figura 29 Situações do Fio SMA

Assim, a tração $T_{2}$ será dada por:

$T_{2}=K \cdot \Delta l=K \cdot\left(0,04 . l_{\text {fio }}-x / n\right)$

na qual K é a rigidez equivalente do fio de SMA, que será estimada posteriormente.

De posse das equações (9), (10) e (11), incluindo-se um termo extra de amortecimento, obtém-se o seguinte modelo mecânico: 
$\left(J / r_{2}^{2}+m_{L}\right) \ddot{x}+c \cdot \dot{x}+K / n^{2} \cdot x=-m_{L} g+\left(K .0,04 . l_{f i o}\right) / n$

sendo c o coeficiente de amortecimento equivalente, a ser ajustado posteriormente. $\mathrm{A}$ rigidez $\mathrm{K}$ pode ser obtida de forma aproximada, utilizando-se a formulação dada em (8). Assumindo-se deformações elásticas nas parcelas de martensita e austenita, pode-se escrever:

$\sigma=\left[\xi \cdot E_{M}+(1-\xi) \cdot E_{A}\right] \cdot \varepsilon$

Sendo $A_{\text {fio }}$ a área seccional do fio de SMA, pode-se reescrever a equação anterior:

$\frac{T_{2}}{A_{f i o}}=\left[\xi \cdot E_{M}+(1-\xi) \cdot E_{A}\right] \frac{\Delta l}{l_{0}}$

Assim, comparando-se as equações (11) e (14) obtém-se:

$K=\left[\xi \cdot E_{M}+(1-\xi) \cdot E_{A}\right] \frac{A_{f i o}}{l_{0}}$

Entretanto, no presente experimento a tensão na martensita supera o seu limite elástico $\left(\varepsilon_{m y}\right)$, e a mesma opera na fase plástica, onde a rigidez equivalente é muito inferior. Assim, faz-se uma simplificação na equação (15), retirando-se a parcela de rigidez proveniente da fase elástica da martensita. Logo:

$K=\left[(1-\xi) \cdot E_{A}\right] \frac{A_{f i o}}{l_{0}}$ 


\section{IDENTIFICAÇÃO DE PARÂMETROS}

Nesta seção será exposto o procedimento experimental utilizado para se identificar os parâmetros do modelo desenvolvido.

Conforme já exposto na equação térmica (1), os parâmetros a serem determinados são:

a) C - coeficiente de condução térmica do fio de SMA com a pastilha;

b) $h$-Coeficiente de convecção natural do ar.

Apesar desses parâmetros já terem sido estimados teoricamente, esses serão ajustados para a planta real.

No modelo termo-mecânico os parâmetros a serem identificados são as temperaturas Ms, Mf, As e Af. Como já mencionado, os valores de catálogo podem sofrer variações de até $\pm 15^{\circ} \mathrm{C}$, o que requer, portanto, uma identificação para cada fio utilizado.

O processo de identificação de parâmetros foi realizado em malha aberta e o utilizando um ensaio em rampa. O programa de controle gera um sinal de comando sobre o fio em forma de rampa, conforme mostra a Figura 30

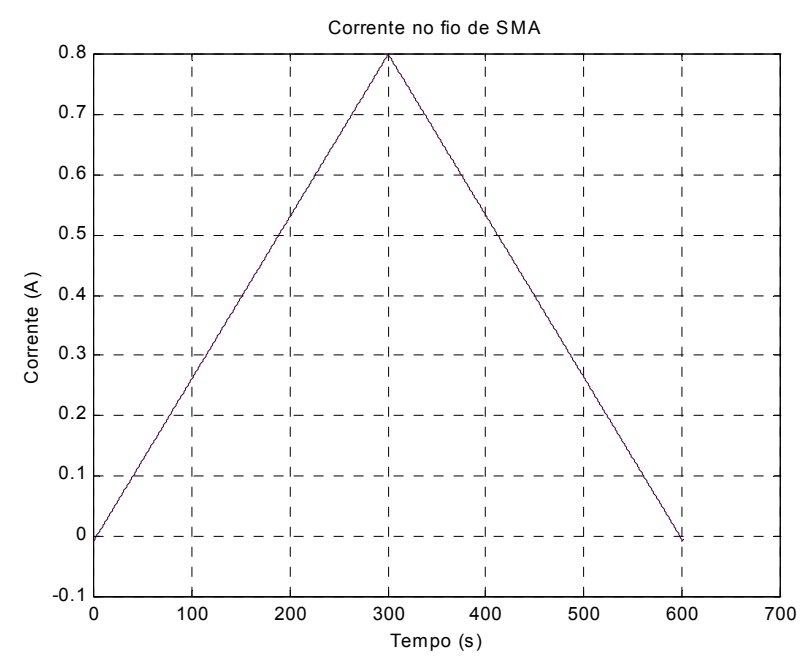

Figura 30 Corrente no fio SMA

O sinal obtido referente ao deslocamento real é mostrado na Figura 31. 


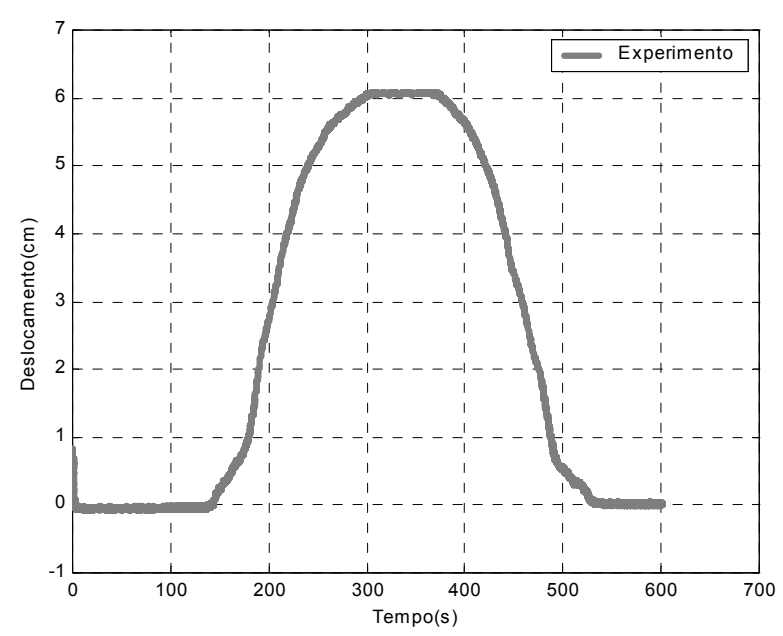

Figura 31 Deslocamento real

Com os parâmetros originais calculados e fornecidos pelo fabricante do fio, foram traçados os gráficos da planta real juntamente ao resultado da simulação do modelo (Figura 32). Pode-se concluir que o modelo térmico está mal ajustado, pois a temperatura não está atingindo as fases de transformação. Isto pode ser confirmado pela Figura 33, que mostra que a temperatura do fio obtida pelo modelo matemático atinge o valor máximo de $65^{\circ} \mathrm{C}$. O principal parâmetro que causa esta elevada dissipação é o coeficiente de condução $C$.

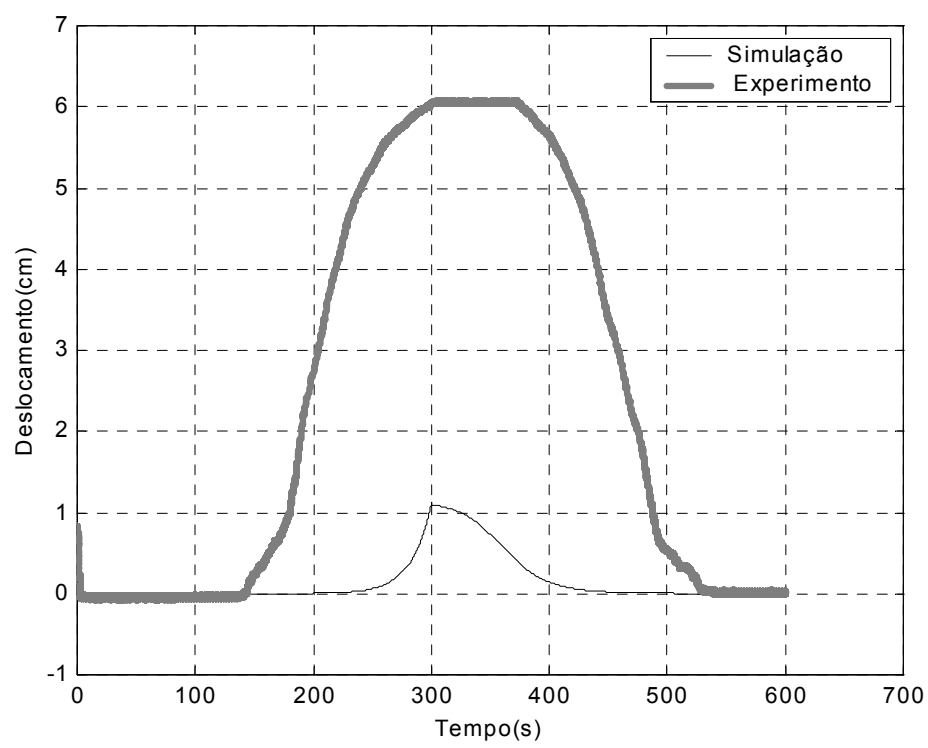

Figura 32 Deslocamento real e do modelo com parâmetros originais $\left(C=0,4 \mathrm{~W} /{ }^{\circ} \mathrm{C} / \mathrm{m} ; h=6,55\right.$ $\left.\mathrm{W} / \mathrm{m}^{20} \mathrm{C} / \mathrm{m}\right)$ 


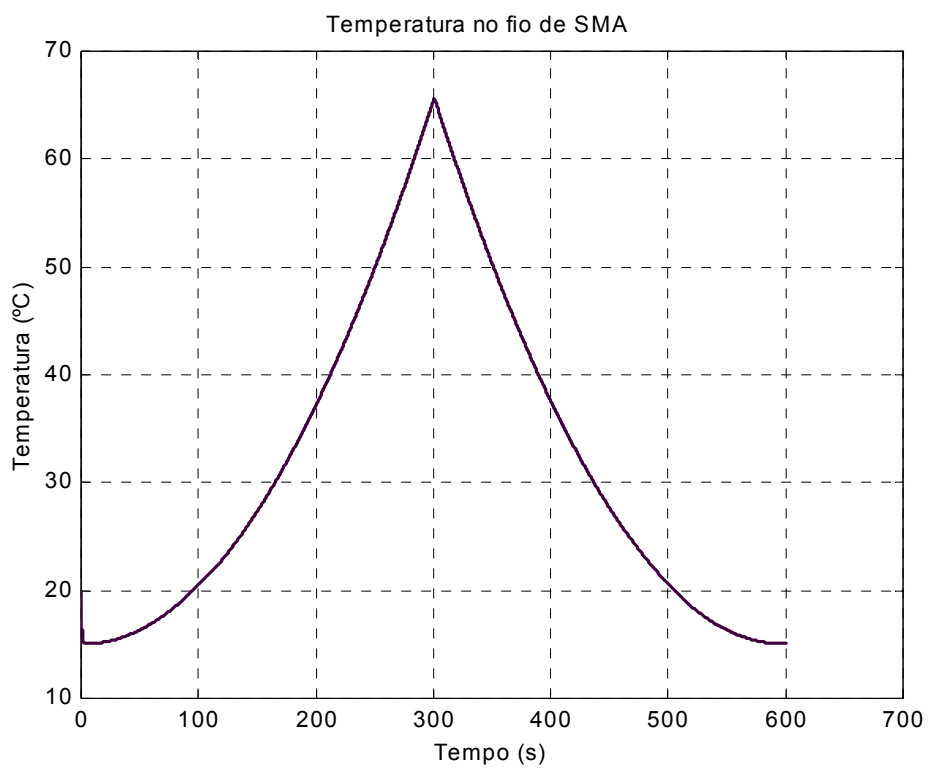

Figura 33 Temperatura no fio de SMA, obtida pelo modelo matemático originais ( $C=0,4$ $\left.\mathrm{W} /{ }^{\circ} \mathrm{C} / \mathrm{m} ; h=6,55 \mathrm{~W} / \mathrm{m}^{2}{ }^{\circ} \mathrm{C} / \mathrm{m}\right)$

Desenvolveu-se então um programa de otimização dos parâmetros baseado no algoritmo de Programação Quadrática Seqüencial (SQP), que minimiza a norma E dada por:

$E(\vec{p})=\int_{0}^{T}\left(y_{\text {medido }}-y_{\text {simulado }}\right)^{2} d t$

onde $\vec{p}=\left(\begin{array}{llllll}h & C & M_{s} & M_{f} & A_{s} & A_{f}\end{array}\right)$ é o vetor de parâmetros a serem estimados,

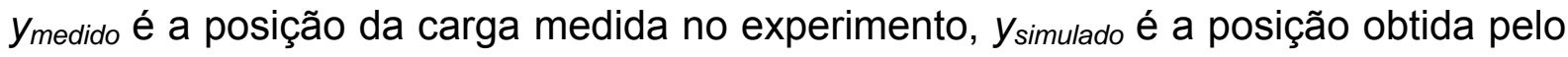
modelo matemático e $T$ é o tempo do ensaio (600s).

A variação dos parâmetros foi limitada. Para as temperaturas, admitiu-se uma variação máxima de $\pm 15^{\circ} \mathrm{C}$, valor dado no catálogo do fio. Para o coeficiente de condução térmica $C$, permitiu-se uma variação de $\pm 0,2 \mathrm{~W} /{ }^{\circ} \mathrm{C} / \mathrm{m}$ em relação ao valor previamente estimado, e para o coeficiente de convecção $h$ permitiu-se uma variação de $\pm 3 \mathrm{~W} / \mathrm{m}^{2}{ }^{\circ} \mathrm{C} / \mathrm{m}$.

Obtiveram-se, assim, os seguintes valores para os parâmetros: $C=0,2547$ $\mathrm{W} /{ }^{\circ} \mathrm{C} / \mathrm{m}, h=7 \mathrm{~W} / \mathrm{m}^{2 \circ} \mathrm{C} / \mathrm{m}, \mathrm{Ms}=66^{\circ} \mathrm{C}, \mathrm{Mf}=34^{\circ} \mathrm{C}$ As $=53^{\circ} \mathrm{C}, \mathrm{Af}=93^{\circ} \mathrm{C}$ e com um coeficiente de amortecimento $c=100 \mathrm{~N} . \mathrm{s} / \mathrm{m}$ (obtido experimentalmente). Obteve-se, portanto, o gráfico da Figura 34. 


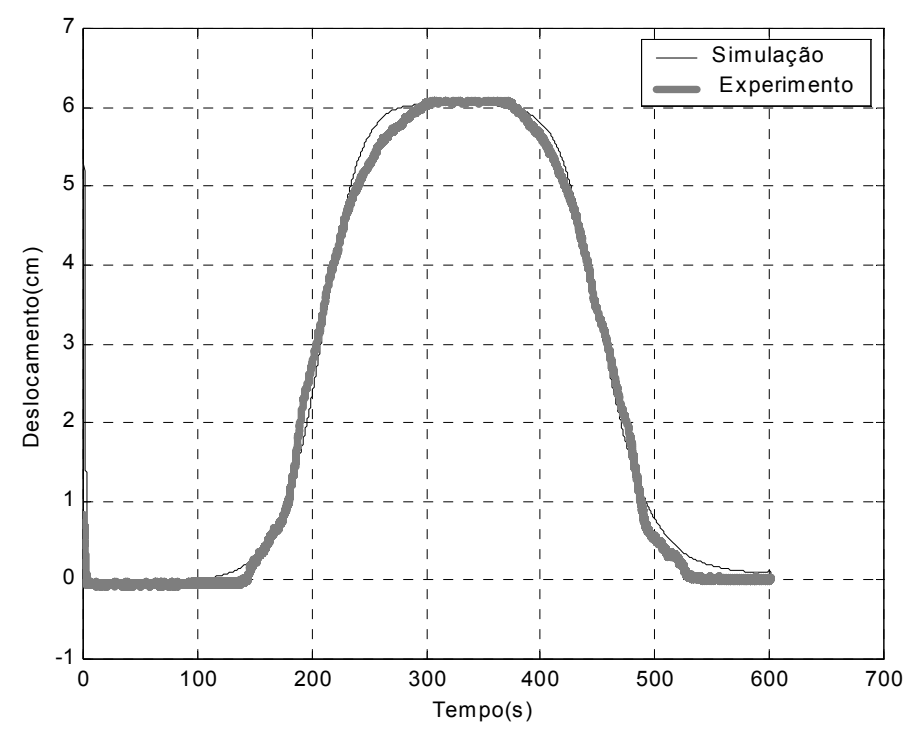

Figura 34 Gráfico do deslocamento após a correção dos parâmetros

Pode-se verificar que esses parâmetros estão bem mais adequados e os formatos das curvas estão bastante próximos, mostrando que o modelo obtido é semelhante ao caso real.

A verificação da temperatura no fio de SMA é mostrada na Figura 35. Nota-se que a temperatura máxima alcança aproximadamente $94^{\circ} \mathrm{C}$, que é um valor aceitável pelas características físicas do fio de SMA.

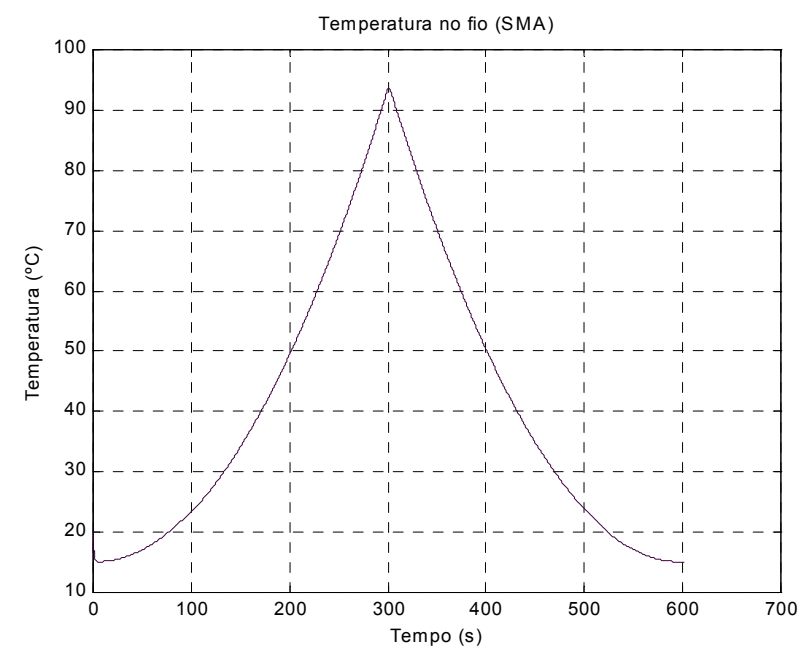

Figura 35 Temperatura no fio SMA após ajuste dos parâmetros 


\subsection{Validação experimental do modelo}

Após a identificação dos parâmetros, realizaram-se ensaios em degrau para validar o modelo matemático. No primeiro caso, aplicou-se uma entrada de corrente cíclica em degrau no fio de SMA com amplitude máxima de $0,8 \mathrm{~A}$, conforme mostra a Figura 36.

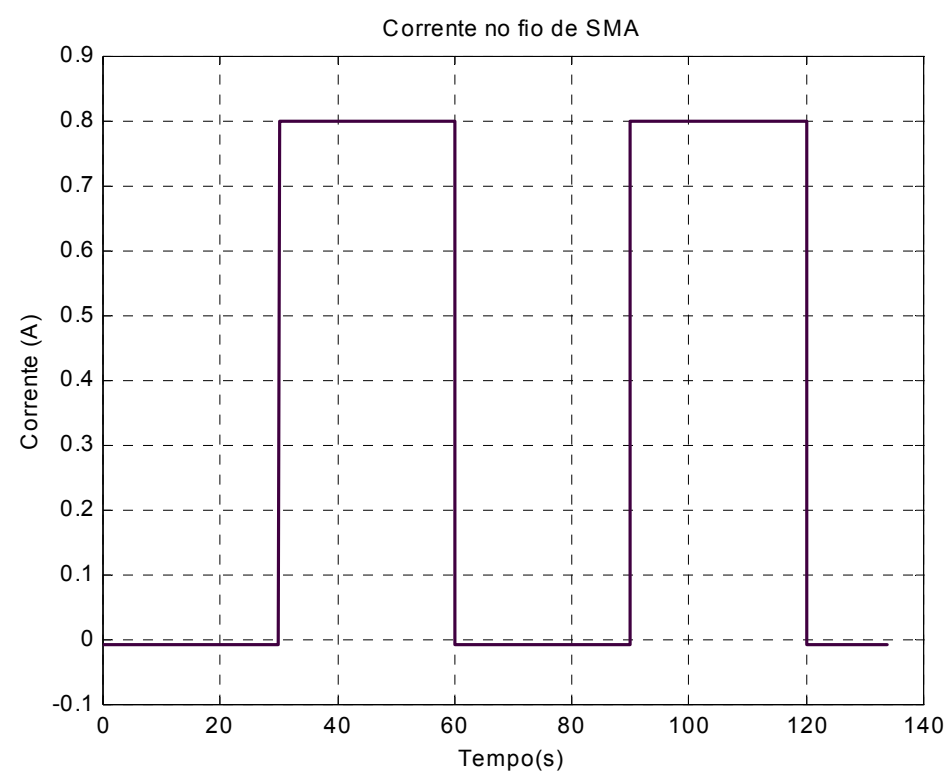

Figura 36 Corrente cíclica em degrau no fio de SMA

A posição da carga é mostrada na Figura 37, onde confronta-se o resultado medido com o obtido pela simulação.

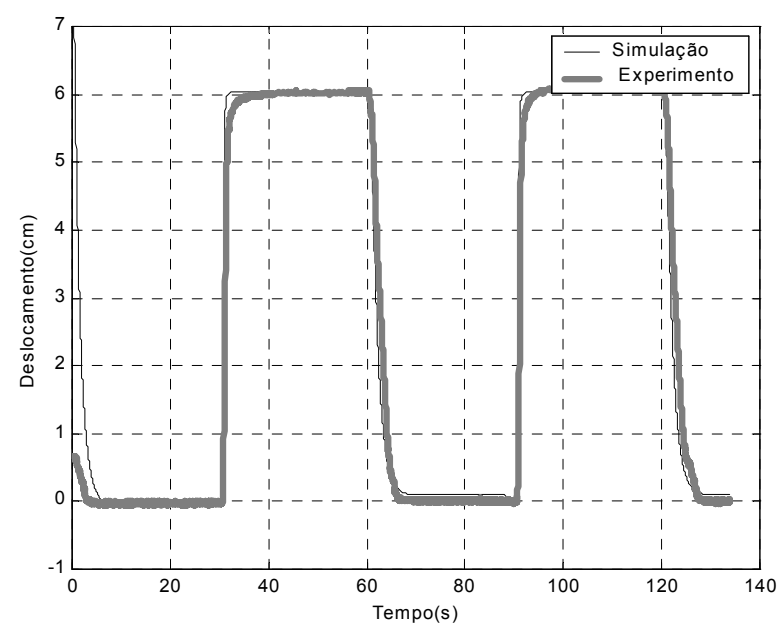

Figura 37 -Resposta ao degrau de corrente cíclica 0,8 A 
Detalhes da resposta na subida e na descida são mostradas na Figura 38 (a) e (b) respectivamente. Verifica-se que a resposta experimental é muito bem reproduzida pelo modelo de simulação durante a subida. O tempo de estabilização $5 \%$ é da ordem de 1,2 s na simulação, e 2,15s na medida experimental. Na descida, entretanto, verifica-se uma maior discrepância entre as curvas experimentais e teóricas. Isto pode ser explicado pelo fato de que no resfriamento, o fenômeno térmico mais importante é a condução do calor do fio para a placa cerâmica, fenômeno este muito complexo e que fora modelado segundo diversas hipóteses simplificadoras. Já no aquecimento, o fenômeno térmico mais importante é a geração de calor por efeito Joule (passagem de corrente), cuja modelagem é mais precisa.

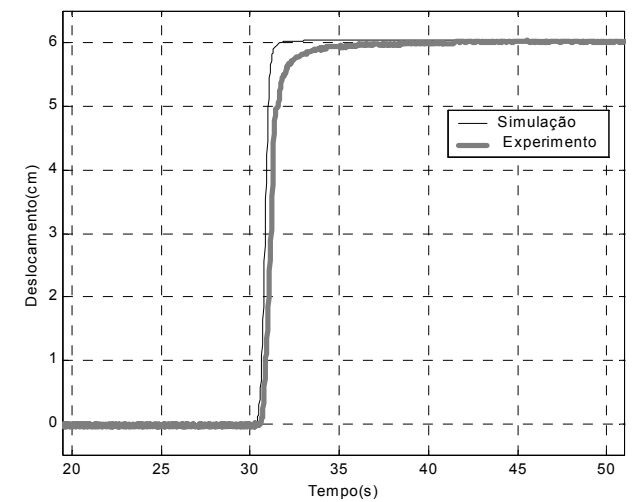

(a)

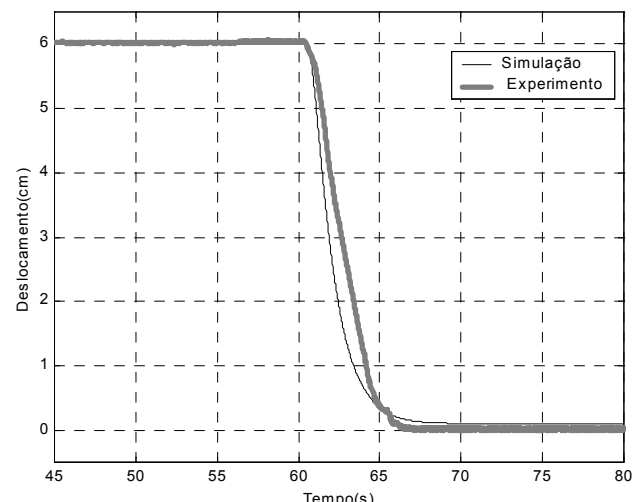

(b)

Figura 38 Resposta ao degrau de subida 0,8 A. (a) subida; (b) descida

A temperatura estimada na simulação está mostrada na Figura 39. Pode-se verificar que a temperatura máxima nessas condições é de aproximadamente $94^{\circ} \mathrm{C} \mathrm{e}$ acompanha o sinal de corrente injetado no fio de SMA. 


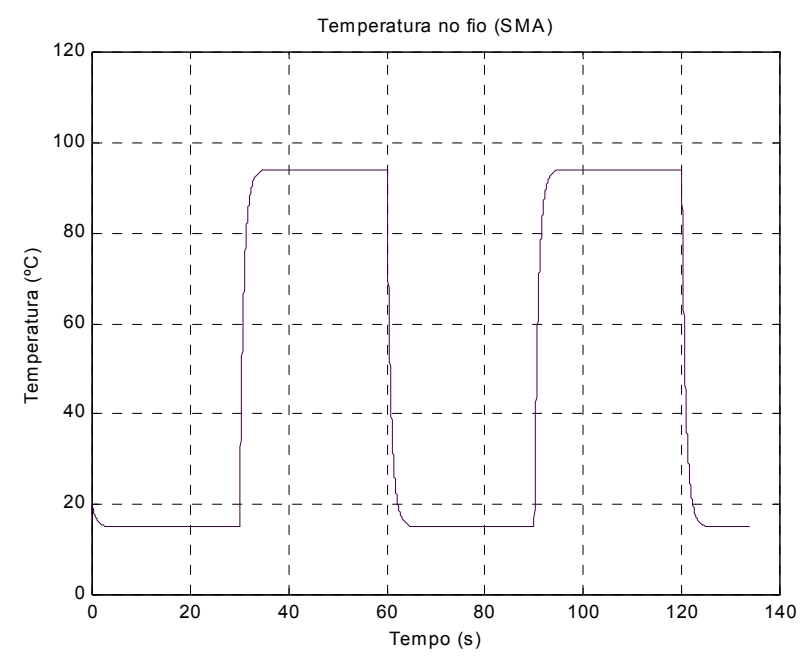

Figura 39 Temperatura cíclica no fio de SMA

Os gráficos mostrados na Figura 40 mostram o comportamento da resposta do sistema para os vários níveis de corrente.

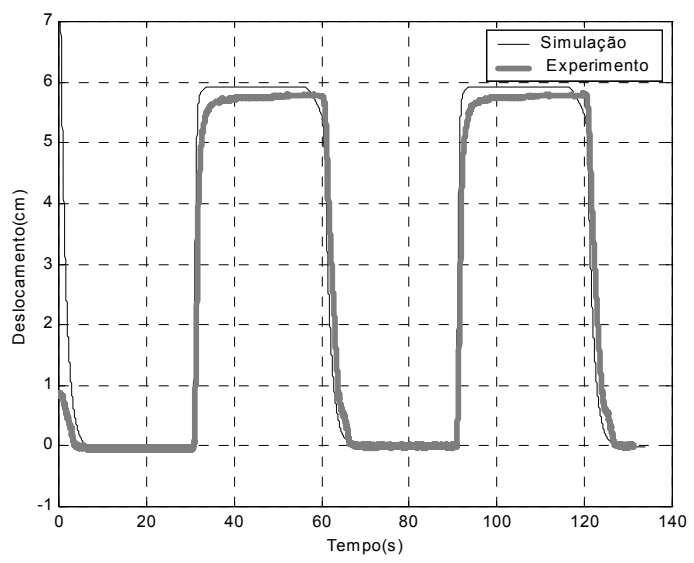

$0,7 \mathrm{~A}$

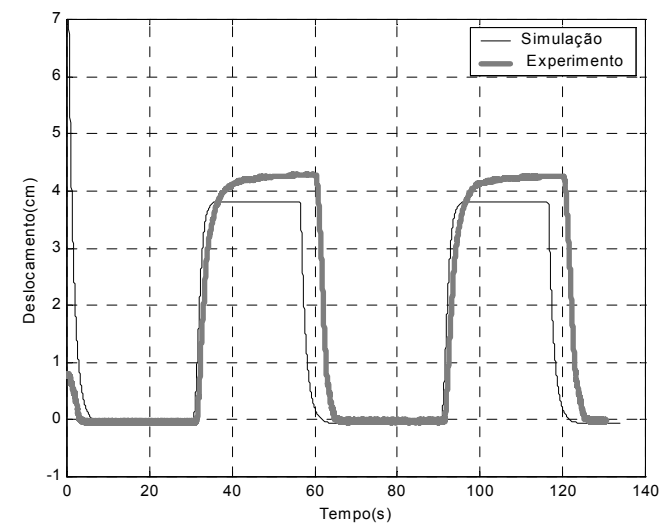

$0,57 \mathrm{~A}$

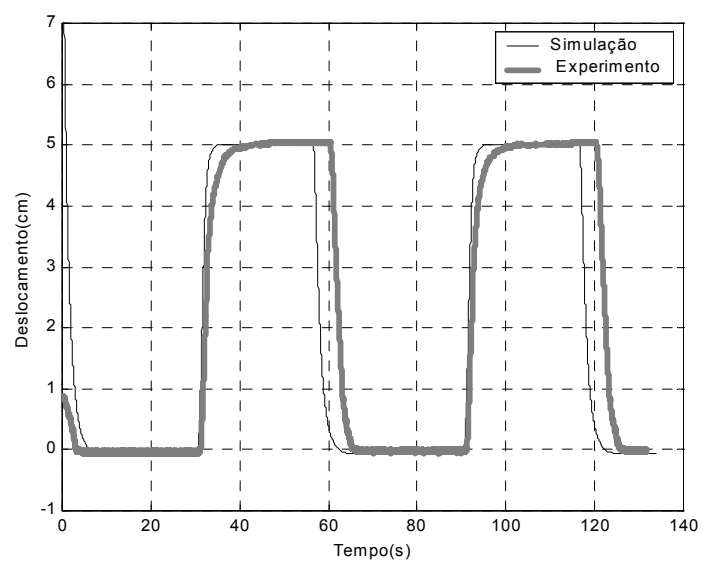

$0,6 \mathrm{~A}$

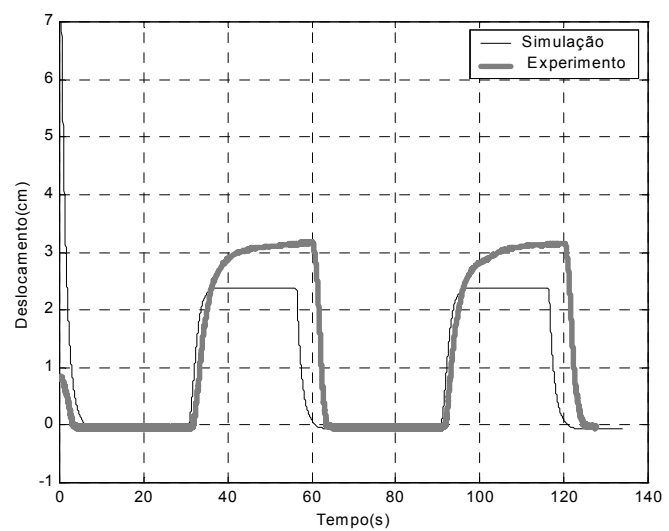

$0,53 \mathrm{~A}$

Figura 40 Resposta para corrente cíclica com várias amplitudes de degrau 
Nota-se que há uma maior discrepância entre a simulação e os valores experimentais conforme a corrente imposta ao fio é reduzida. Esse efeito é novamente explicado pelo fato de que para correntes inferiores, o fenômeno de condução passa a ser mais importante em relação à geração de calor por efeito Joule.

O sistema de controle em malha fechada deverá corrigir as imperfeições obtidas em malha aberta, que será o objetivo final desse trabalho. 


\section{CONTROLE PID}

Neste capitulo serão estudadas as diversas técnicas descritas na literatura para a sintonia de um controlador PID (proporcional, integral e derivativo), e utilizálas para otimizar o desempenho do atuador SMA em estudo.

Serão comparados os resultados obtidos entre as várias técnicas e o desempenho de cada projeto.

\subsection{Introdução}

O algoritmo PID é o mais conhecido e utilizado industrialmente em sistemas de controle. Pode ser utilizado em sistemas simples ou com modelo matemático conhecido, porém também é muito comum em sistemas onde o modelo é desconhecido, principalmente na indústria onde as plantas ou sistemas são complexos e de difícil modelagem.

Existem diversas formas de se definir o controlador PID, sendo a mais conhecida dada por:

$$
G_{c}(s)=K_{p} \cdot\left(1+\frac{1}{T_{i} \cdot s}+T_{d} . s\right)
$$

Na expressão acima, o parâmetro $K_{p}$ é o ganho proporcional; $T_{i}$ é o tempo integral, dado em min $^{-1}$ ou s ${ }^{-1}$ e $T_{d}$ é o tempo derivativo, dado em min ou s.

Como se trata de um controlador bastante versátil, é interessante verificar seu desempenho no controle do atuador SMA em estudo, apesar desse ser não linear e apresentar uma grande histerese.

Desenvolveu-se um sistema no simulador Matlab/Simulink interligado fisicamente com as placas A/D e D/A ao sistema físico do atuador SMA em estudo conforme mostra o diagrama esquemático da Figura 41. 


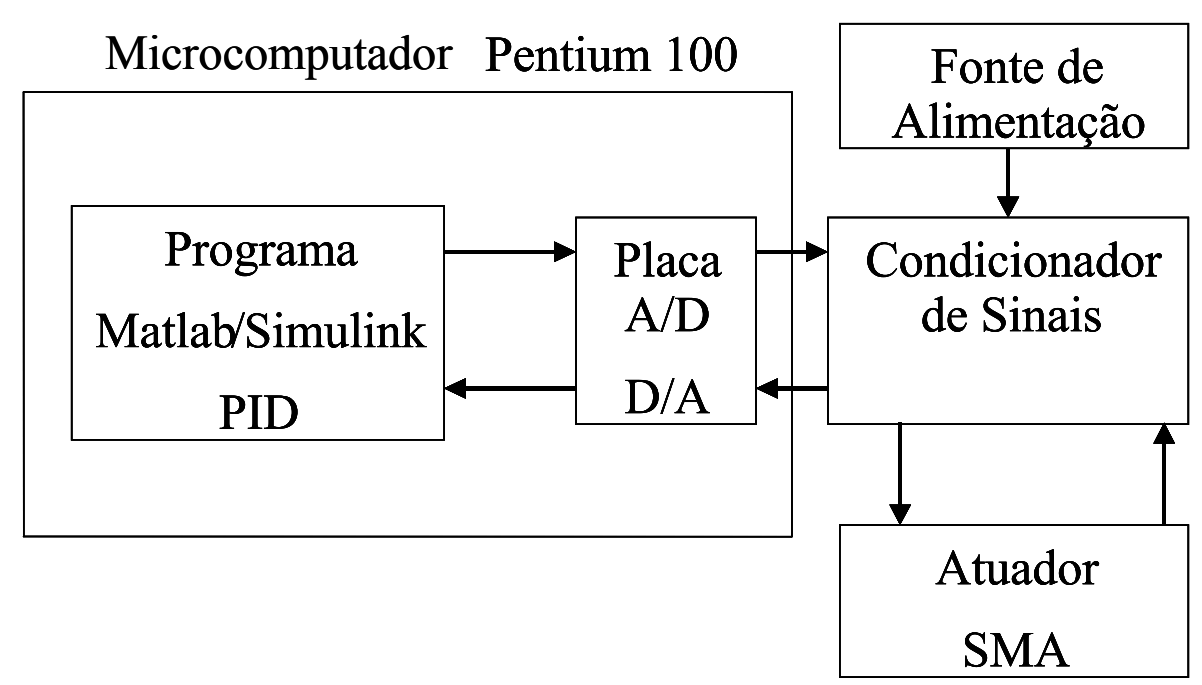

Figura 41 Sistema de controle em malha fechada acoplado ao atuador SMA

O programa feito no Matlab/Simulink pode ser visualizado na Figura 42 e permite variar os parâmetros do PID diretamente no bloco do controlador.

Os sinais de referência podem ser escolhidos na barra de fontes do Simulink (sources) onde se geram diversas formas de onda, com vários níveis de amplitudes e períodos.

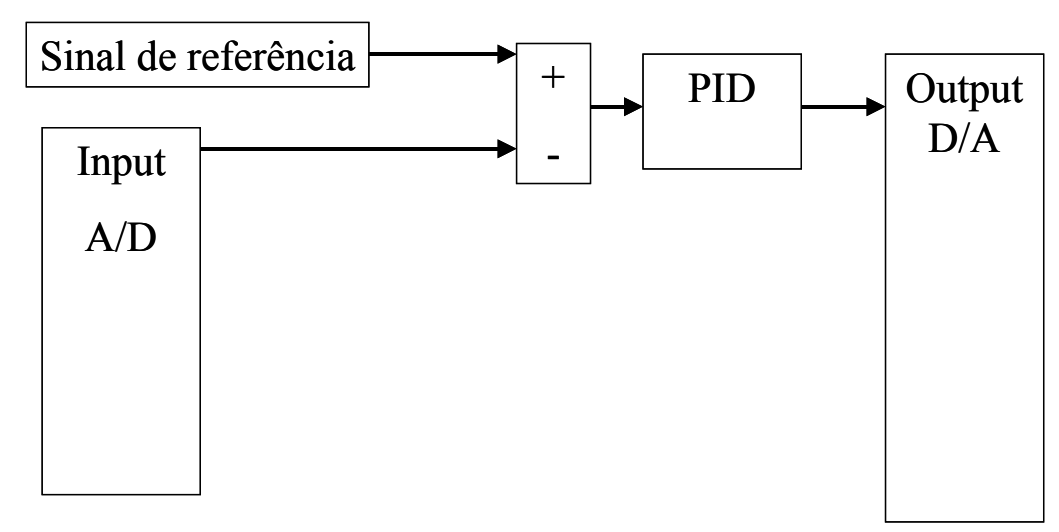

Figura 42 Programa Matlab/Simulink PID

Um sinal de referência é injetado no bloco somador (sum) e subtraído do sinal proveniente da entrada (Input $A / D$ ) que está interligada ao sistema de medida (placa condicionadora de sinais e potenciômetro de medida de posição). O sinal de erro (sinal de referência subtraído do sinal de medida) é ligado ao bloco do controlador PID. Na saída do controlador tem-se o sinal de controle, e é enviado à saída (Output $D / A)$ ligada fisicamente ao condicionador de sinais, que possui o amplificador de corrente ligado ao fio de SMA do atuador. 
Com esse sistema implementado pode-se facilmente verificar o desempenho do sistema fazendo a aquisição dos dados diretamente e com auxílio do programa Matlab. Os gráficos dos sinais de referência e de saída podem ser traçados. Assim é possível fazer uma avaliação do desempenho do sistema em conjunto com o controlador.

O controlador PID utilizado no simulador Matlab/Simulink possui uma forma diferente da expressa em (18). Sua função de transferência é dada por:

$$
G_{c}(s)=P+\frac{I}{s}+D . s
$$

A relação entre o conjunto de parâmetros $\left(K_{p}, T_{i}, T_{d}\right)$ e os parâmetros $(P, I, D)$ é dada por:

$$
P=K_{p} ; I=\frac{K_{p}}{T_{i}} ; D=K_{p} . T_{d}
$$

Existem várias técnicas de sintonia ou ajuste descritas na literatura para se determinar os parâmetros $\mathrm{K}_{\mathrm{p}}, \mathrm{T}_{\mathrm{i}}$ e $\mathrm{T}_{\mathrm{d}}$ de um controlador PID, com o objetivo de otimizar o funcionamento de um sistema e obter o melhor desempenho e estabilidade possível.

Neste capítulo serão utilizada basicamente as técnicas descritas em Ogata (1990), Seborg; Edgar e Mellichamp (1989) e Smith e Corripio (1997) e Ziegler e Nichols (1942) para fazer a sintonia de um controlador PID em um sistema ou planta.

Fazer a sintonia de um controlador em um sistema físico com modelo matemático não conhecido é, muitas vezes, um trabalho árduo e demorado que exige vários ensaios práticos e de difícil execução. O ajuste de parâmetros determinará o desempenho do sistema em malha fechada para que o mesmo possua boas características, como baixo tempo de acomodação, baixo sobre-sinal na mudança do valor do sinal de referência (set point) e rejeição a distúrbios ou variação de carga.

Serão utilizadas as seguintes técnicas de sintonia:

1-Sintonia por tentativa e erro

2-Método da oscilação mantida com sintonia automática (autotuning)

3- Método da curva de reação. 
4-Método baseado em minimização da integral do erro.

\subsection{Sintonia por tentativa e erro}

A sintonia de um controlador PID em campo pode ser realizada pelo método da tentativa e erro. Esse método é geralmente sugerido pelos próprios fabricantes do controlador e depende da habilidade e conhecimento que o operador possui da planta ou sistema que se deseja controlar. Constitui-se, portanto, de um método empírico de difícil execução.

Segundo Ogata (1990), Seborg; Edgar e Mellichamp (1989) e Ziegler e Nichols (1942), o método pode ser sistematizado pelos sete passos seguintes:

1. Desativar os termos integral e derivativo escolhendo $T_{i}$ (tempo integral) com seu valor máximo $\left(T_{i} \rightarrow \infty\right)$ e $T_{d}$ (tempo derivativo) com seu valor mínimo $\left(T_{d} \rightarrow 0\right)$.

2. Impor o menor valor possível ao parâmetro $K_{p}$ (ganho proporcional).

3. Aumentar o ganho $K_{p}$ até que o sistema apresente uma oscilação com amplitude constante. $\mathrm{O}$ valor de $\mathrm{K}_{\mathrm{p}}$ para o qual ocorre tal oscilação é chamado na literatura de ganho supremo, denominado como $\mathrm{K}_{\mathrm{pu}}$ (SEBORG; EDGAR; MELLICHAMP, 1989).

4. Quando o sistema começar a oscilar com amplitude constante deve-se reduzir o valor de $\mathrm{K}_{\mathrm{pu}}$ pela metade; com isso sistema pára de oscilar e esse será o novo valor de $\mathrm{K}_{\mathrm{p}}$.

5. Reduzir o valor de $T_{i}$ até que se observe uma nova oscilação, então $T_{i}$ é fixado em três vezes esse valor, e esse será o novo valor para $\mathrm{T}_{\mathrm{i}}$.

6. Aumentar o valor de $T_{d}$ gradativamente até que o sistema comece a oscilar novamente, fixando $T_{d}$ em 1/3 desse valor. Esse será o novo valor para $T_{d}$.

7. Com isso o sistema teoricamente estará preliminarmente otimizado devendo o operador fazer pequenos ajustes finos para encontrar o ponto ótimo de operação do sistema.

Deve-se observar que é muito importante verificar se a saída do controlador não está saturada, para que esse procedimento tenha validade.

Esse procedimento possui a vantagem de poder ser realizado em malha fechada e não ter a necessidade de se "abrir" a malha de controle, o que poderia causar instabilidade na planta ou sistema. Entretanto, esse procedimento não é 
possível de ser executado em alguns casos, pois determinadas plantas ou sistemas não podem sofrer sobre-sinais com valores muito elevados. Adicionalmente, se o processo for muito lento, tal procedimento irá depender muito da sensibilidade do operador. Constitui-se, portanto, de um método pouco recomendado em plantas ou sistemas com alta sensibilidade ou processos demasiadamente lentos.

Aplicando-se essa metodologia e fazendo os ajustes finos os parâmetros encontrados foram: $P=8 ; \mathrm{I}=2 ; \mathrm{D}=2$.

Realizou-se um teste com um sinal de referência onda quadrada de $2 \mathrm{~V}$ de amplitude com período de 20s. Considerou-se nos ensaios que o tempo de acomodação será aquele em que o sinal medido se estabiliza em $\pm 5 \%$ do valor do sinal de referência, sendo denominado critério dos 5 \% (OGATA, 1990). Considerouse ainda que o sobre-sinais nos ciclos de subida e descida foram calculados como $\%$ sS $=(|V s S| /|\Delta v|) .100 \%$, onde:

- \%ss-porcentagem de sobre-sinal.

- Vss- amplitude acima do valor do sinal referência no ciclo de subida ou amplitude abaixo do sinal de referência no ciclo de descida (V)

- $\Delta v$ - Diferença entre os valores máximos e mínimos do sinal de referência (V). Obteve-se como resposta do sistema o gráfico mostrado na Figura 43.

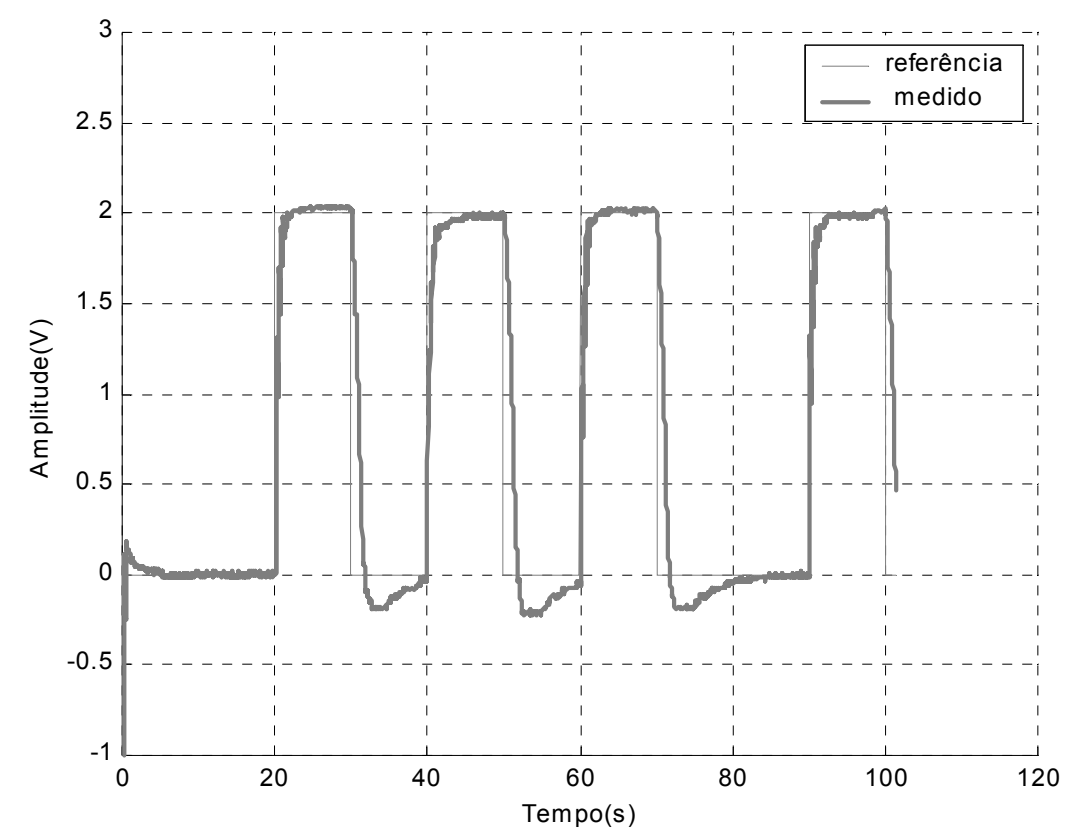

Figura 43 Resposta do atuador com : $P=8 ; I=2 ; D=2$ 
Pode-se observar na Figura 43 que houve sobre-sinal aceitável no ciclo de subida, ultrapassando em apenas $0,03 \mathrm{~V}$ correspondendo a $1,5 \%$ e o tempo de acomodação foi de $1,5 \mathrm{~s}$. No ciclo descida o sinal ficou abaixo do nível de referência zero em $0,25 \mathrm{~V}$ correspondendo a $12,5 \%$ de sobre-sinal e houve uma excessiva demora no tempo de acomodação que foi de $7 \mathrm{~s}$. 0 controle com esses parâmetros ficou insatisfatório, necessitando, portanto, de um método mais adequado para se fazer a sintonia do controlador PID.

\subsection{Método da oscilação mantida com sintonia automática (autotuning)}

O método da oscilação mantida, desenvolvido por Ziegler e Nichols (1942), baseia-se em se determinar experimentalmente o ganho supremo $K_{p u}$ e o período supremo $P_{u}$.

Seguindo a mesma metodologia de tentativa e erro, o ganho do controlador PID é calculado a partir de $K_{p u}$ e $P_{u}$. Usando as relações empíricas obtidas por Ziegler e Nichols (1942) pode-se facilmente calcular os ganhos $K_{p}, T_{i}, T_{d}$, conforme mostra a Tabela 1, extraída de Ogata (1990).

Tabela 1 Regras de sintonia de Ziegler e Nichols (adaptado de Ogata (1990)).

\begin{tabular}{|l|l|l|l|}
\hline \multicolumn{1}{|c|}{ Controlador } & $K_{P}$ & $T_{I}$ & $T_{D}$ \\
\hline $\mathbf{P}$ & $0.50 K_{P U}$ & $\infty$ & 0 \\
\hline PI & $0.45 K_{P U}$ & $P_{U} / 1.2$ & 0 \\
\hline PID & $0.60 K_{P U}$ & $P_{U} / 2.0$ & $0,125 . P_{U}$ \\
\hline
\end{tabular}

Conforme Ziegler e Nichols (1942) e Smith e Corripio (1997), essas regras têm o objetivo de garantir que valor do sobre-sinal em relação ao sinal de referência (set point) decaia a uma taxa de $1 / 4$ do valor do sobre-sinal.

Entretanto, alguns cuidados devem ser tomados na determinação de $K_{p}$. Em um sistema em malha fechada, $K_{p}<K_{p u}$ implicará que a resposta do sinal de saída do sistema $\mathrm{c}(\mathrm{t})$ se torne super amortecida ou levemente oscilatória conforme mostra a Figura 44 (a). Por outro lado, caso $K_{p}>K_{p u}$, o sistema torna-se instável. Devido à saturação da saída do controlador, a amplitude na saída $\mathrm{c}(\mathrm{t})$ não cresce indefinidamente, produzindo então oscilações mantidas conforme mostra a Figura 
44(b). Assim, o operador deve tomar cuidado para verificar se a oscilação mantida observada é decorrente de saturação na saída de controle (quando $K_{p}>K_{p u}$ ) ou se, de fato, o ganho $K_{p}$ está próximo de $K_{\mathrm{pu}}\left(K_{p}=K_{p u}\right)$.

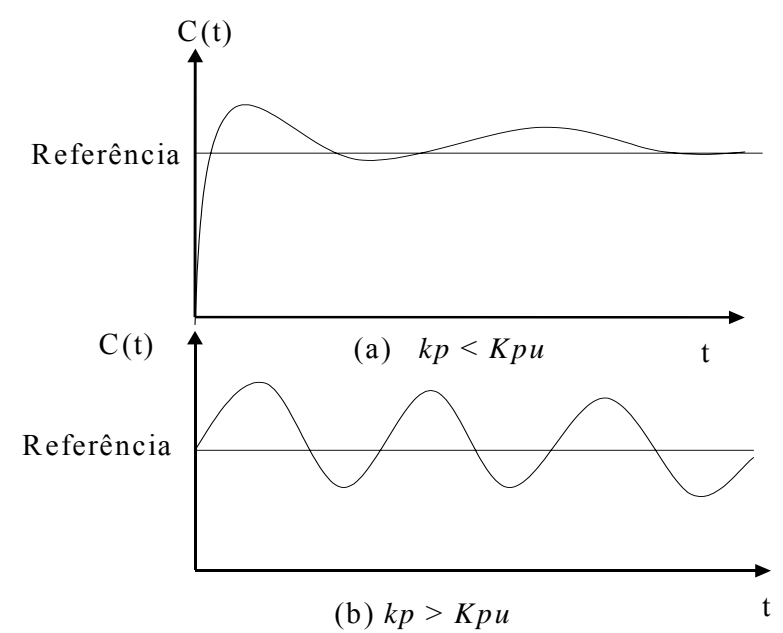

Figura 44 Respostas do sistema quando: (a) Kp<Kpu ; (b) Kp>Kpu

Ziegler e Nichols (1942), propuseram também o método de sintonia modificado, mostrado na Tabela 2, extraída de Seborg; Edgar e Mellichamp (1989). Este possibilita escolher uma saída com ou sem sobre-sinal e, embora muito utilizado, dependendo do tipo de sistema a ser controlado os resultados podem ser insatisfatórios.

Tabela 2 Regras de sintonia de Ziegler e Nichols modificada

\begin{tabular}{|l|l|l|l|}
\hline & $K p$ & $T i$ & $T d$ \\
\hline $\begin{array}{l}\text { Ziegler-Nichols } \\
\text { original }\end{array}$ & $0.6 . K p u$ & $P_{U} / 2$ & $P_{U} / 8$ \\
\hline Com sobre-sinal & $0.33 K_{P U}$ & $P_{U} / 2$ & $P_{U} / 3$ \\
\hline Sem sobre-sinal & $0.20 K_{P U}$ & $P_{U} / 2$ & $P_{U} / 3$ \\
\hline
\end{tabular}

Deve-se mencionar que os ganhos indicados nas tabelas anteriores são valores preliminares, que podem servir como ponto de partida para um ajuste mais fino, que dependerá da experiência e conhecimento do operador do sistema que está sendo controlado.

Devido a grande dificuldade de observar as oscilações do atuador SMA em estudo, optou-se em executar o procedimento denominado de sintonia automática (autotuning) em conjunto com o método de Ziegler e Nichols modificado. 
O método de sintonia automática (autotuning), obedece a seguinte seqüência, descrita em Seborg; Edgar e Mellichamp (1989):

1. Substituir o controlador PID que está em malha fechada, por um controlador liga-desliga (on-off), ou seja um relé sem histerese, conforme mostra a Figura 45. O relé força oscilações com pequena amplitude sem que ocorra saturação no sinal de saída do sistema

2. Mede-se a amplitude do sinal de saída a e a amplitude do sinal de entrada $d$ conforme mostra a Figura 46.

3. Aplicando-se a equação $K_{P U}=\frac{4 d}{\pi a}$ obtém-se o ganho supremo $K_{p u}$

4. O período supremo $P_{u}$ é obtido diretamente medindo-se o período de oscilação do sistema em malha fechada.

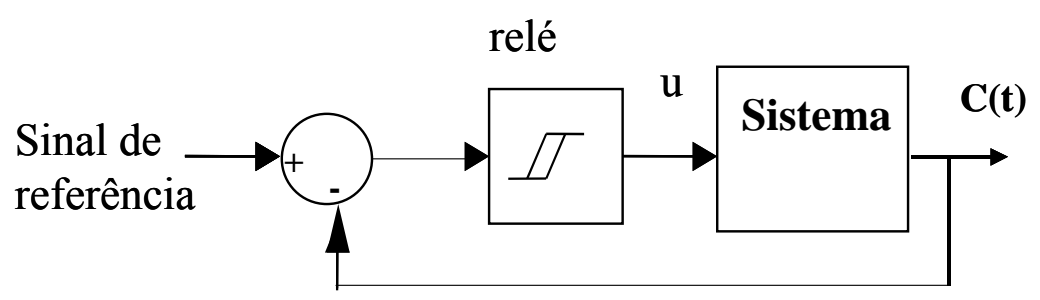

Figura 45 Diagrama em blocos utilizado na auto-sintonia

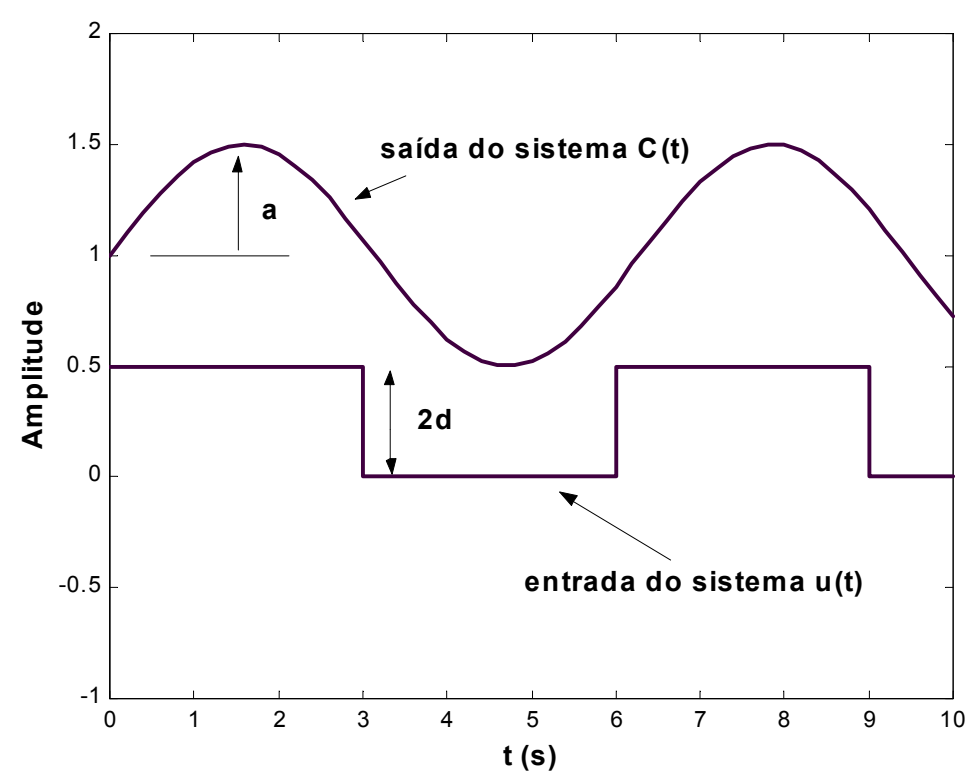

Figura 46 Gráficos de sinal de saída do sistema c(t) e sinal de entrada do sistema $u(t)$.

Com este procedimento pode-se determinar de uma forma mais precisa e direta o ganho supremo $K_{p u}$ e o período supremo $P_{u}$. Como as oscilações são 
forçadas pelo relé de uma forma controlada, não ocorre saturação na saída do sistema, podendo-se medir as amplitudes e os períodos de oscilação uma única vez e calcular rapidamente $K_{p}, T_{i}, T_{d}$ utilizando a Tabela 1 ou Tabela 2.

Aplicando esse método ao sistema do atuador SMA em estudo obtiveram-se os resultados conforme mostra a Tabela 3 :

Tabela 3 Ensaio de auto-sintonia
\begin{tabular}{|l|l|}
\hline Ensaio 1 & Ensaio 2 \\
\hline$a=0,075$ & $a=0,1$ \\
\hline$d=2,5$ & $d=3,5$ \\
\hline$K_{p u}=42,4$ & $K_{p u}=44,5$ \\
\hline$P_{u}=1,6 s$ & $P_{u}=1,8 s$ \\
\hline
\end{tabular}

A fim de se aumentar a acurácia, utilizaram-se valores médios, obtendo-se, portanto $K_{p u}=43,45$ e $P_{u}=1,7 \mathrm{~s}$. Utilizando a Tabela 3 na condição sem sobre-sinal obteve-se $K_{p}=0,2 . K_{p u}=8,7 ; T_{i}=P_{u} / 2=0,85$ e $T_{d}=P_{u} / 3=0,56$.

Aplicando-se a equação (20) obtêm-se, portanto $P=K_{p}=8,7 ; \quad I=K_{p} / T_{i}=10,2$ e $D=K_{p} \cdot T_{d}=4$,8. Inserindo esses parâmetros no controlador, com o mesmo sinal de referência anterior (onda quadrada $2 \mathrm{~V}$ de amplitude com período de $20 \mathrm{~s}$ ) os resultados obtidos são mostrado na Figura 47.

Pode-se observar que o sobre-sinal ficou maior que no caso anterior; na parte superior obteve-se um sobre-sinal de $29 \%$, com tempo de acomodação de $3,5 \mathrm{~s}$. Na parte inferior do gráfico, ocorreu um sobre-sinal de 34\% (abaixo da referência zero) e um tempo de acomodação de $8 \mathrm{~s}$, mostrando que esse método apesar de ser indicado para não ocorrer sobre-sinais, não funcionou adequadamente neste caso e os tempos de acomodação aumentaram em relação ao caso anterior. 


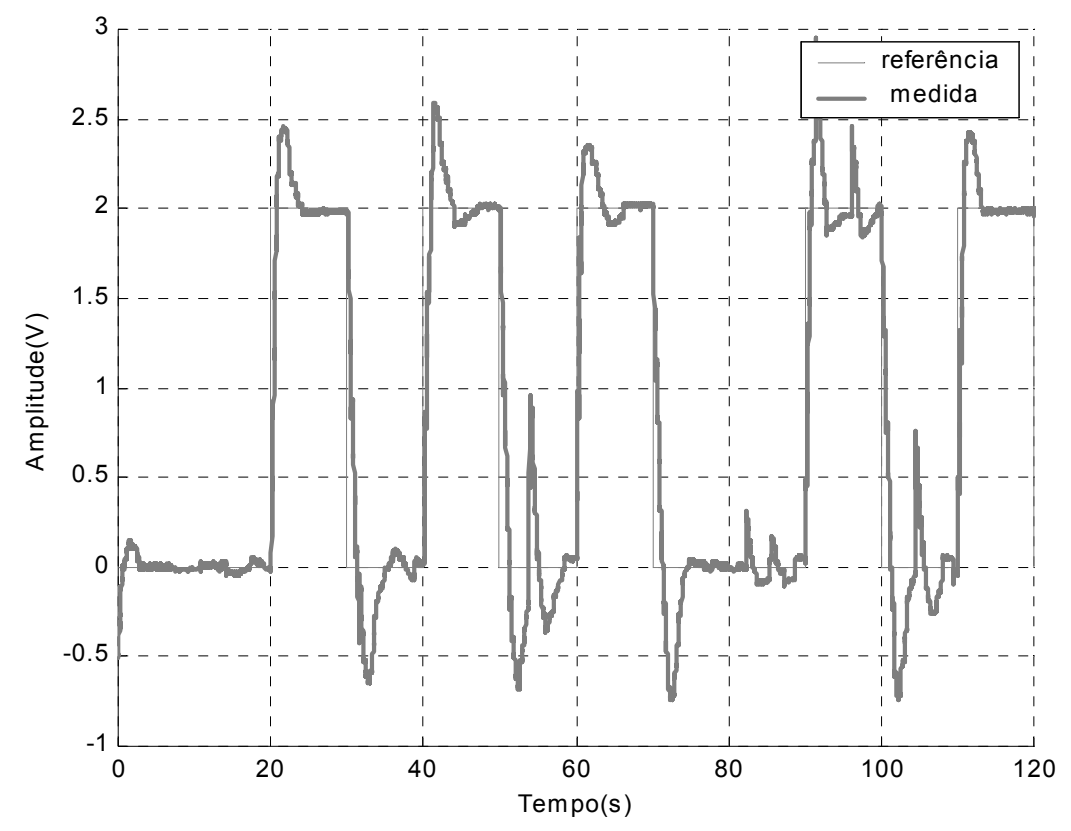

Figura 47 Resposta do atuador com : $P=8,7 ; I=10,2 ; D=4,8$

Aplicando-se o método original de Ziegler e Nichols (Tabela 1), obtêm-se $K_{p}=0,6 \cdot K_{p u}=26 ; \quad T_{i}=P_{u} / 2=0,85$ e $T_{d}=0,125 \cdot P_{u}=0,21$. e equivalentemente, $P=26$; $I=30,58 ; D=5,46$. O resultado obtido do ensaio está mostrado na Figura 48.

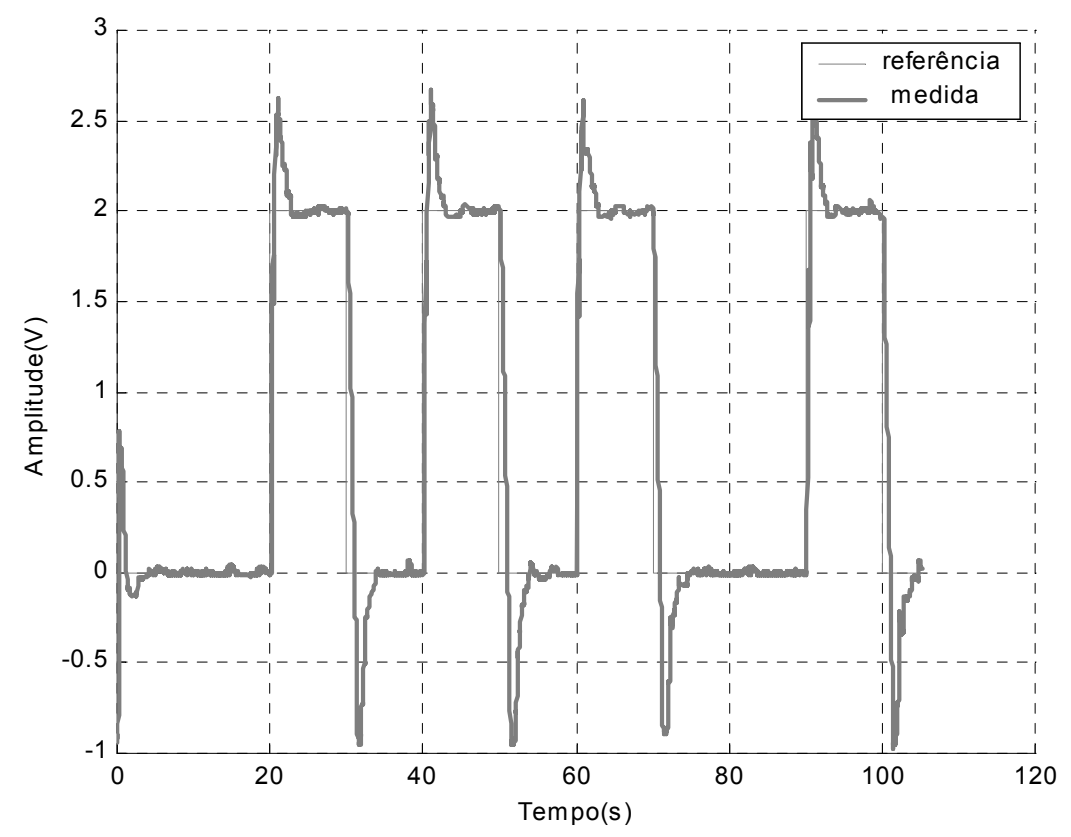

Figura 48 Resposta do atuador com : $P=26$; $I=30,58 ; D=5,46$

Conforme mostra a Figura 48, o método tradicional de Ziegler e Nichols, obteve-se um sobre-sinal de $47,5 \%$ na subida e tempo de acomodação de $2,5 \mathrm{~s}$. Na 
descida, o sobre-sinal da parte inferior do gráfico foi de $30 \%$, com um tempo de acomodação de 3,5s. O tempo de acomodação foi reduzido, mas os sobre-sinais aumentaram, em relação ao método de Ziegler e Nichols modificado, pois esse método não elimina os sobre-sinais.

\subsubsection{Método da curva de reação}

A proposta desse método também foi abordada por Ziegler e Nichols e consiste basicamente em se aplicar um degrau de amplitude A na entrada da planta e verificar o resultado na saída conforme mostra a Figura 49. Caso o resultado seja uma curva com aspecto de "S" como mostra a Figura 50, conclui-se que a planta não possui integradores nem pólos complexos conjugados dominantes, podendo ser aproximada a um sistema de primeira ordem com atraso. Esse fato foi constatado no atuador SMA em estudo na ocasião da identificação do modelo, em malha aberta conforme mostra a Figura 38.

O método da curva de reação é bastante empregado na prática, porém possui a desvantagem de ser realizado em malha aberta, sendo portanto impossível de ser aplicado para sistemas instáveis.

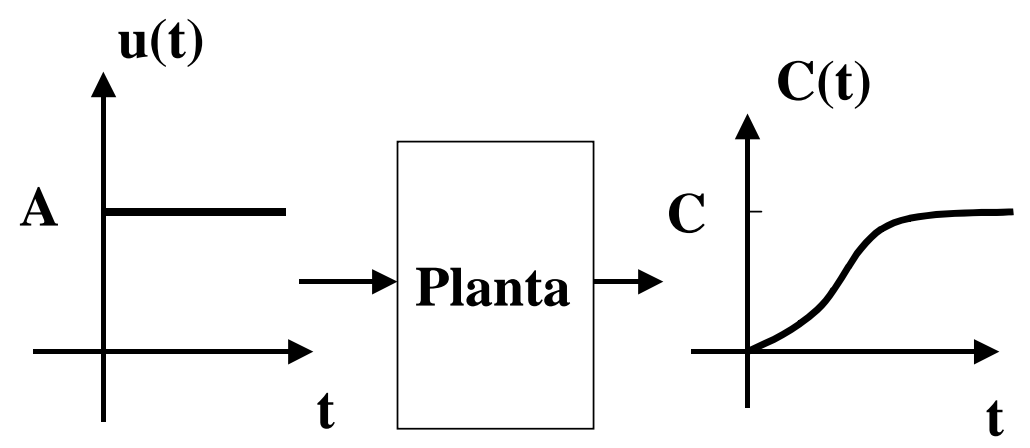

Figura 49 Método da curva de reação

Na curva de reação mostrada na Figura 50, L é denominado tempo de retardo e T é a constante de tempo. A amplitude em regime $\mathrm{c}(\infty)=\mathrm{K}$.A permite obter-se $\mathrm{O}$ ganho do sistema $\mathrm{K}=\mathrm{C}(\infty) / \mathrm{A}$, onde $\mathrm{A}$ é a amplitude do sinal de entrada e $\mathrm{K}$ é o ganho do sistema e $\mathrm{c}(\mathrm{t})$ saída do sistema.

Segundo Ogata (1990), a função obtida pode ser aproximada a um sistema de primeira ordem conforme mostra a equação (21). 


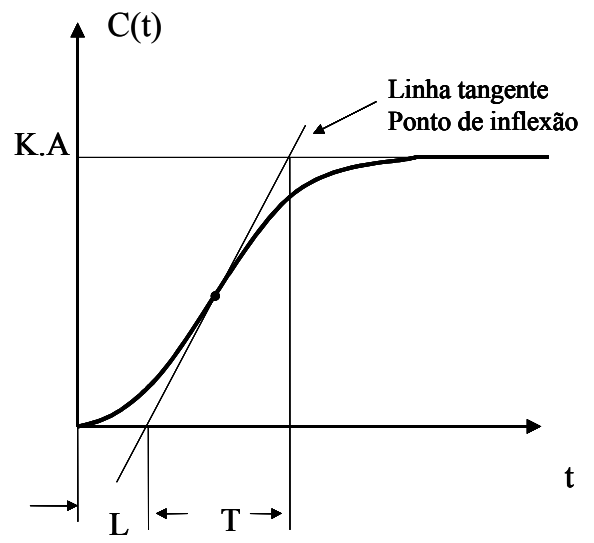

Figura 50 Curva de reação

$\frac{C(s)}{U(s)}=\frac{K \cdot e^{-L s}}{T s+1}$

Como é muito difícil encontrar o ponto exato de inflexão da curva de reação e como o sistema se aproxima a um sistema de primeira ordem, pode-se utilizar o método de identificação de um sistema de primeira ordem com atraso proposto por Smith e Corripio (1997).

Esse método define dois tempos $t_{a} e t_{b}$. O tempo $t_{a}$ será obtido quando $a$ amplitude da curva atingir $28,3 \%$ de K.A e $t_{b}$ quando esse nível atingir $63,2 \%$ da amplitude de K.A.

Segundo Smith e Corripio (1997), os parâmetros da curva de reação podem ser obtidos conforme mostra a equação (22) .

$$
\begin{aligned}
& T=\frac{3}{2} \cdot\left(t_{b}-t_{a}\right) \\
& L=t_{b}-T
\end{aligned}
$$




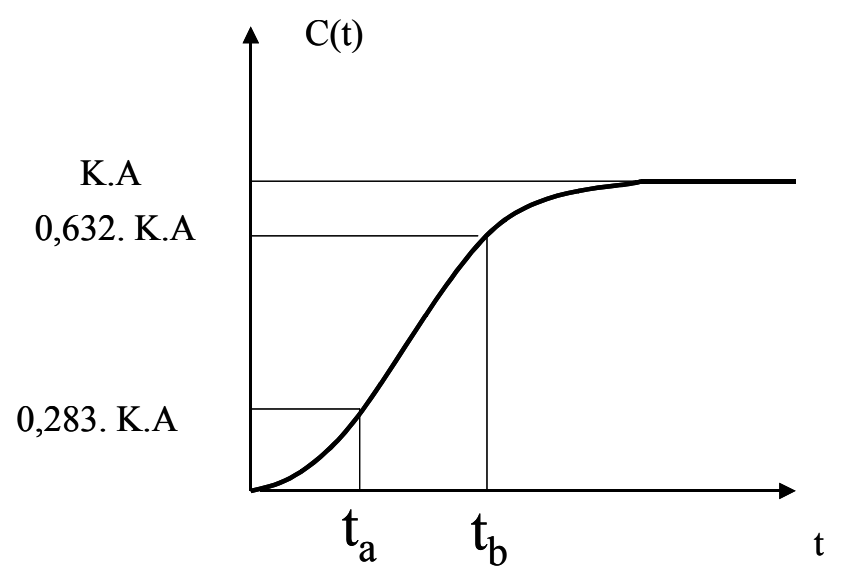

Figura 51 Determinação de $t_{a}$ e $t_{b}$ em função das amplitudes da curva de reação.

$\mathrm{Na}$ Tabela 4 estão indicadas as novas relações fornecidas por Ziegler e Nichols, nas quais determinam-se os parâmetros $K_{p}, T_{i}, T_{d}$. Esta tabela foi adaptada a partir de Ogata (1990), Seborg; Edgar e Mellichamp (1989) e Smith e Corripio (1997).

Tabela 4 Método de Ziegler e Nichols para Curva de Reação

\begin{tabular}{|l|l|l|l|}
\hline Controlador & $\mathrm{K}_{\mathrm{P}}$ & $\mathrm{T}_{\mathrm{I}}$ & $\mathrm{T}_{\mathrm{D}}$ \\
\hline $\mathbf{P}$ & $\frac{1}{K} \frac{T}{L}$ & $\infty$ & 0 \\
\hline PI & $0,9 \frac{1}{K} \frac{T}{L}$ & $\frac{L}{0,3}$ & 0 \\
\hline PID & $1,2 \frac{1}{K} \frac{T}{L}$ & $2 L$ & $0,5 L$ \\
\hline
\end{tabular}

Baseando-se nessa nova metodologia foram feitos ensaios em malha aberta e obteve-se $K=0,5$ próximo ao ponto médio de operação do atuador SMA. Deve-se enfatizar que o atuador SMA possui ganho variável em diferentes pontos de operação, pois o sistema não é linear, além do que possui uma grande histerese.

Em seguida, aplicou-se um sinal em degrau na entrada do sistema em malha aberta com amplitude de $A=1 \mathrm{~V}$. Obteve-se um sinal cujo valor correspondente a $28,3 \%$ de K.A correspondeu ao tempo $t_{\mathrm{a}}=1,6 \mathrm{~s}$ e o valor relativo a $63,2 \%$ de K.A 
correspondeu ao tempo $t_{b}=3,4 \mathrm{~s}$. Substituindo os valores obtidos com $t_{a}$ e $t_{b}$ na equação (22) obtêm-se $T=2,7 \mathrm{~s}$ e $L=0,7$. Substituindo valores obtidos para $T$ e $L$ na Tabela 4 para o caso do projeto do controlador PID obtiveram-se $K_{p}=9,25 ; T_{i}=1,4 \mathrm{e}$ $T_{d}=0,35$, que equivalem a $P=9,25 ; I=6,61 ; D=3,24$. O resultado obtido do sistema em malha fechada é mostrado na Figura 52.

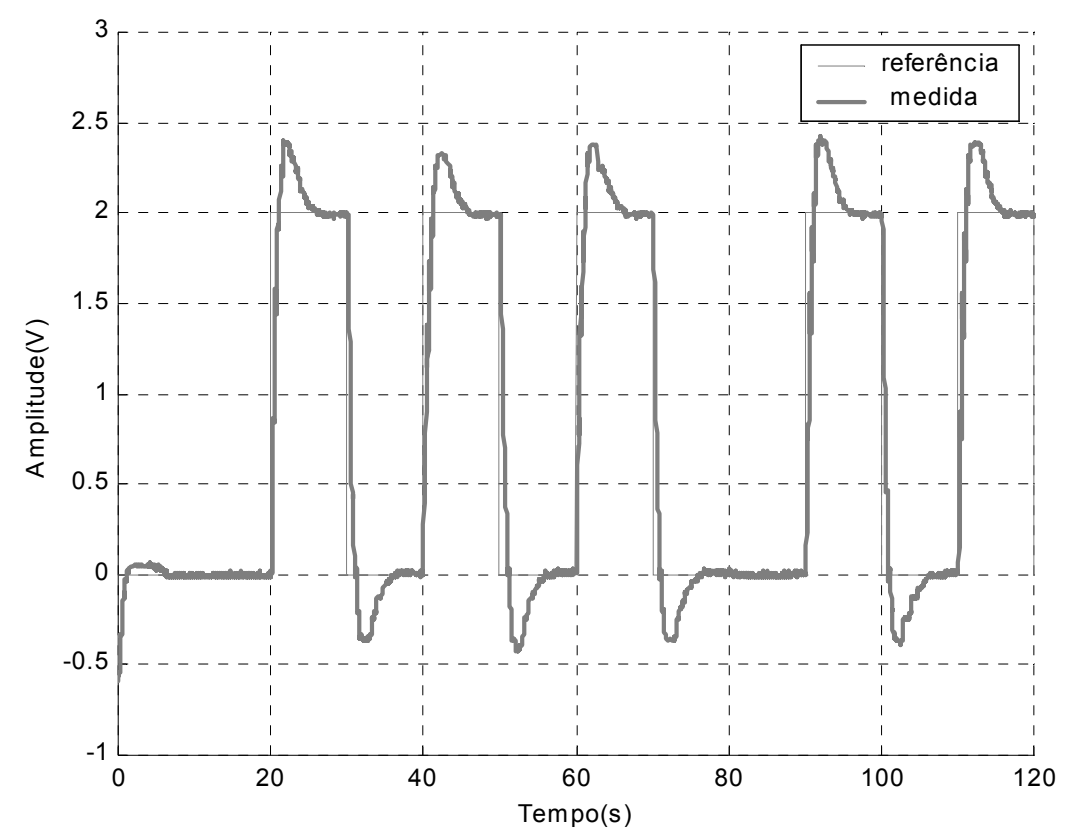

Figura 52 Resposta do atuador com: $P=9,25 ; I=6,61 ; D=3,24$

Verifica-se que houve uma ligeira melhora no sobre-sinal no ciclo de subida, resultando 17,5\% acima da referência, mas o tempo de acomodação aumentou para 4,3s. Na descida o sinal ultrapassou a referência do nível zero em 0,4V que corresponde a um sobre-sinal de $20 \%$, e o tempo de acomodação aumentou para 4,5s, valor ainda muito elevado.

Projetando um controlador PI conforme mostra a Tabela 4 obtiveram-se os parâmetros: $P=6,94$ e $I=2,98$ e o resultado obtido na simulação está mostrado na Figura 53. Verifica-se que o sobre-sinal na subida diminuiu para $15 \%$, e o tempo de acomodação para $2 \mathrm{~s}$. Na descida o sobre-sinal diminuiu para $9,5 \%$ e o tempo de acomodação também diminuiu para $4 \mathrm{~s}$. Entretanto, considera-se que este ainda não é um bom projeto. 


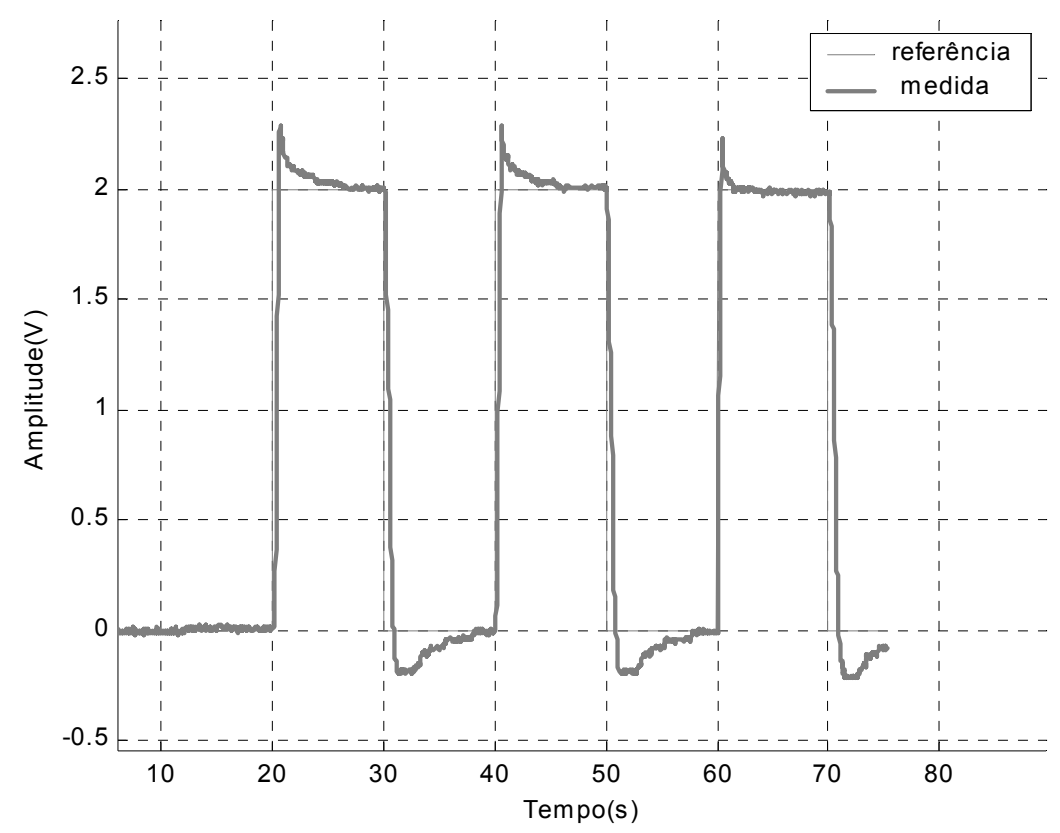

Figura 53 Resposta do atuador com : $P=6,94 ; l=2,98$

Existem outros métodos de cálculo utilizando a curva de reação. Um método empírico proposto por Cohen e Coon é citado em Seborg; Edgar e Mellichamp, (1989). Possui o mesmo objetivo dos métodos anteriores, ou seja, garantir uma taxa de descaimento de $1 / 4$ no sobre-sinal. Os ganhos estão mostrados na Tabela 5.

Tabela 5 Relações utilizadas por Cohen e Coon para a curva de reação.

\begin{tabular}{|l|l|l|l|}
\hline Controle & $\mathrm{K}_{\mathrm{P}}$ & $\mathrm{T}_{\mathrm{I}}$ & $\mathrm{T}_{\mathrm{D}}$ \\
\hline $\mathbf{P}$ & $\frac{1}{K} \frac{T}{L}[1+L / 3 T]$ & $\infty$ & 0 \\
\hline $\mathbf{P I}$ & $\frac{1}{K} \frac{T}{L}[0,9+L / 12 T]$ & $\frac{L[30+3(L / T)]}{9+20(L / T)}$ & 0 \\
\hline PID & $\frac{1}{K} \frac{T}{L}\left[\frac{16 T+3 L}{12 T}\right]$ & $\frac{L[32+6(L / T)]}{13+8(L / T)}$ & $\frac{4 L}{11+2(L / T)}$ \\
\hline
\end{tabular}

Utilizando as relações empíricas determinadas por Cohen e Coon mostradas na Tabela 5 e mantendo-se as mesmas condições anteriores, o novo projeto do controlador PID resulta $K_{p}=10,28 ; T_{i}=1,55$ e $T_{d}=0,24$, que equivalem a $P=10,28$; $I=6,63 ; D=2,46$. Observa-se que esses valores ficaram muito próximos ao método de Ziegler e Nichols calculado anteriormente. 
Na Figura 54 mostra o resultado da simulação com as mesmas condições aplicadas nos casos anteriores.

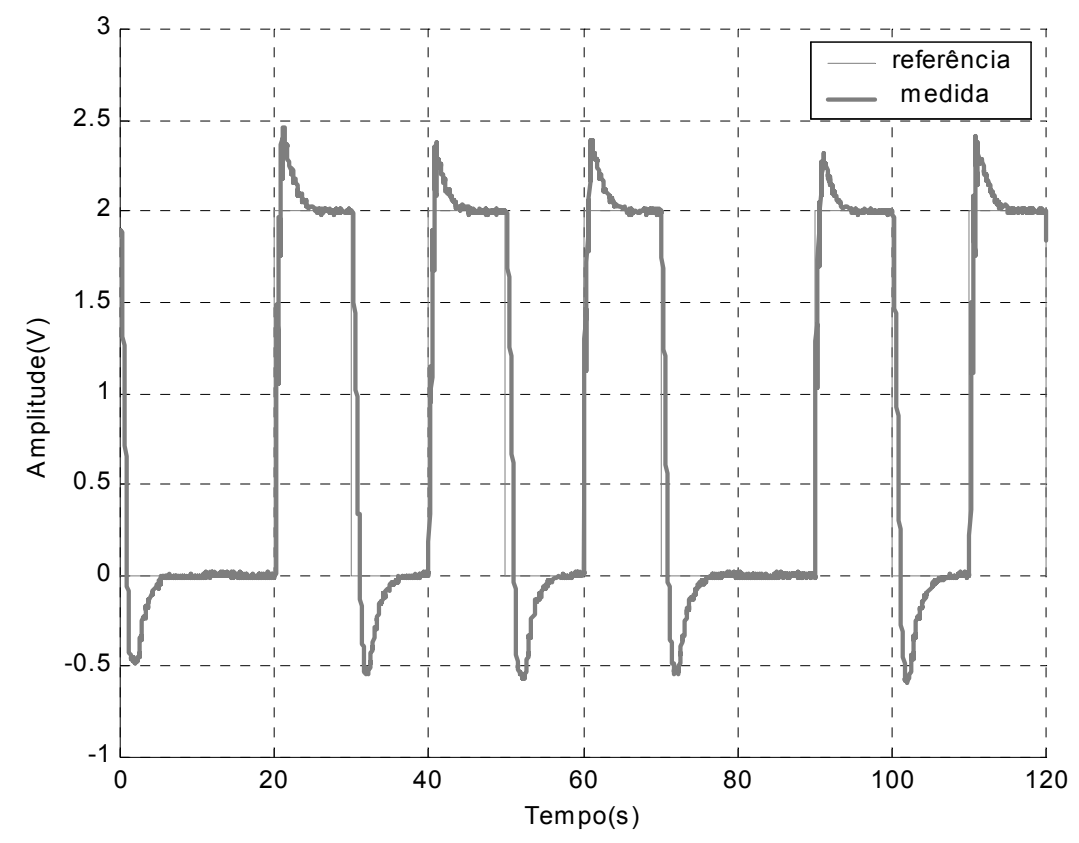

Figura 54 Resposta do atuador com : $P=10,28 ; I=6,62 ; D=2,46$

Pode-se observar que o sobre-sinal na subida do sinal foi de $22,5 \%$ e o tempo de acomodação foi de 3s. Na descida o sobre-sinal foi de $25 \%$ e o tempo de acomodação foi de $4 \mathrm{~s}$, ou seja, o desempenho é pior em relação ao método de Ziegler e Nichols para curva de reação.

\subsubsection{Métodos baseados em minimização da integral do erro.}

O objetivo desses métodos é fazer com que o controlador PID minimize determinada norma do erro de controle (SEBORG; EDGAR; MELLICHAMP, 1989).

Uma das normas adotadas é a integral do valor absoluto do erro (Integral of absolute error) IAE, dada na equação (23). Alternativamente, utiliza-se a integral ponderada pelo tempo do valor absoluto (Integral of time-weighted absolute error) ITAE, apresentada na equação (24). Ambas as normas são descritas em Seborg; Edgar e Mellichamp (1989) e Smith e Corripio (1997).

$I A E=\int_{0}^{\infty}|e(t)| d t$ 
$\operatorname{ITAE}=\int_{0}^{\infty} t|e(t)| d t$

O cálculo dos ganhos de controle baseia-se nos parâmetros da curva de reação $L, T$ e K. As constantes A e B utilizadas em cada método são dadas na, Tabela 6 adaptada de Seborg; Edgar e Mellichamp (1989).

Tabela 6 Constantes utilizadas para os critérios IAE e ITAE

\begin{tabular}{|l|l|l|l|l|l|}
\hline \multirow{2}{*}{ Minimização } & \multirow{2}{*}{$\begin{array}{l}\text { Controlador } \\
\text { PID }\end{array}$} & \multicolumn{2}{|l|}{ Constantes IAE } & \multicolumn{2}{l|}{ Constantes ITAE } \\
\cline { 2 - 6 } & $\mathrm{A}$ & $B$ & $A$ & $B$ \\
\hline \multirow{2}{*}{ Distúrbio } & $\mathrm{Kp}$ & 1,435 & $-0,921$ & 1,357 & $-0,947$ \\
\cline { 2 - 6 } & $\mathrm{Ti}$ & 0,878 & 0,749 & 0,842 & 0,738 \\
\cline { 2 - 6 } & $\mathrm{Td}$ & 0,482 & 1,137 & 0,381 & 0,995 \\
\hline \multirow{2}{*}{$\begin{array}{l}\text { Mudança no } \\
\text { sinal de } \\
\text { referência }\end{array}$} & $\mathrm{Kp}$ & 1,086 & $-0,869$ & 0,965 & $-0,855$ \\
\cline { 2 - 6 } & $\mathrm{Ti}$ & 0,740 & $-0,130$ & 0,796 & $-0,147$ \\
\cline { 2 - 6 } & $\mathrm{Td}$ & 0,348 & 0,914 & 0,308 & 0,929 \\
\hline
\end{tabular}

Aplicando as constantes $A$ e $B$ nas equações (25), (26), (27), (28) obtém-se os ganhos de controle. A equação (26) é referente ao cálculo de $T_{i}$ para o caso de minimizar o erro devido a distúrbios e a equação (27) refere-se ao cálculo de $T_{i}$ para o caso de minimizar o erro devido à mudança do sinal de referência.

$$
\begin{aligned}
& K p=\frac{A}{K}\left(\frac{L}{T}\right)^{B} \\
& T_{i}=\frac{T}{A}\left(\frac{L}{T}\right)^{B} \\
& T_{i}=\frac{T}{A+B(L / T)} \\
& T_{D}=A T\left(\frac{L}{T}\right)^{B}
\end{aligned}
$$


Sendo $L=0,7 \mathrm{~s}$ e $T=2,7 \mathrm{~s}$ e $K=0,5$, obtidos anteriormente, aplicaram-se os critérios IAE e ITAE com o objetivo de minimizar a integral do erro devido à mudança do sinal de referência. A Tabela 7 mostra os valores obtidos dos parâmetros do controlador PID.

Tabela 7 Parâmetros P, I, D, para os critérios IAE e ITAE

\begin{tabular}{|l|l|l|l|}
\hline IAE & $\mathrm{P}=7,02$ & $\mathrm{I}=1,83$ & $\mathrm{D}=1,92$ \\
\hline ITAE & $\mathrm{P}=6,12$ & $\mathrm{I}=1,72$ & $\mathrm{D}=1,45$ \\
\hline
\end{tabular}

O resultado obtido para o critério de IAE é mostrado na Figura 55. Verifica-se que houve um sobre-sinal na subida de $5 \%$ e um tempo de acomodação de $0,7 \mathrm{~s}$. $\mathrm{Na}$ descida, houve um sobre-sinal de 7,5\% e apresenta um tempo de acomodação $7 \mathrm{~s}$.

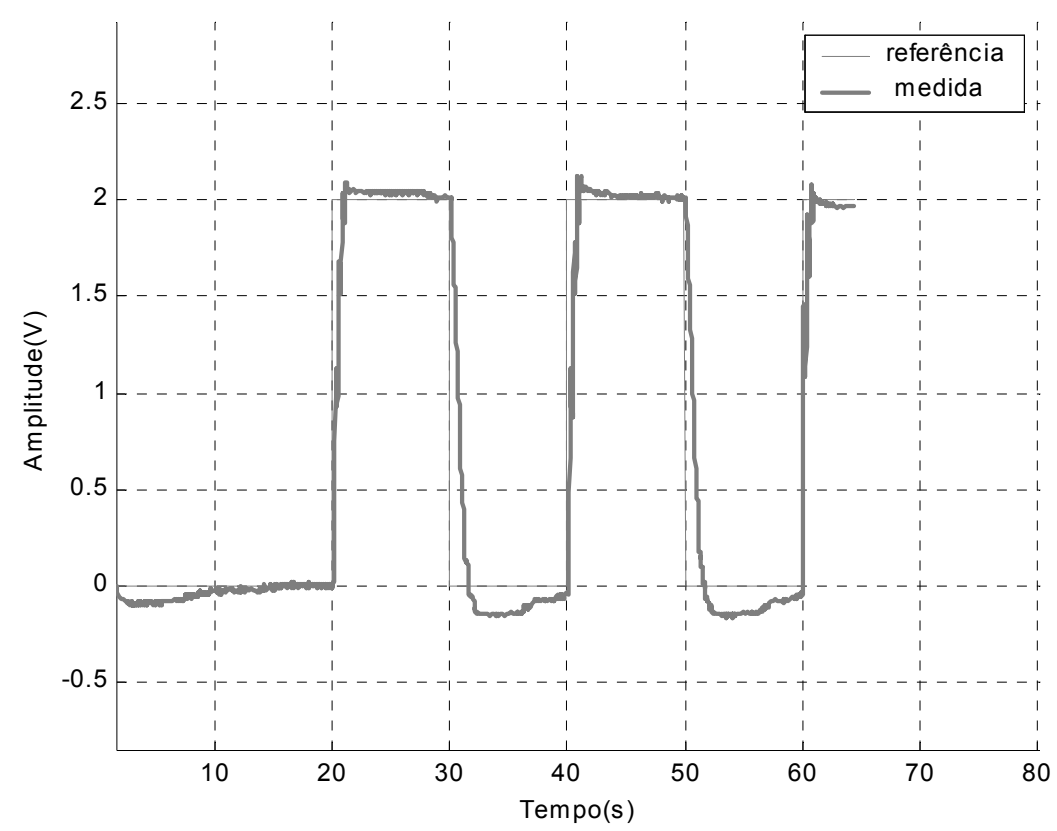

Figura 55 Critério de IAE: $P=7,02 ; I=1,83 ; D=1,92$

Os resultado para o critério ITAE está mostrado na Figura 56. Verifica-se que no ciclo de subida houve sobre-sinal de $0,5 \%$ e o tempo de acomodação foi de 1,4s. $\mathrm{Na}$ descida, houve sobre-sinal de apenas 3,5\%, com um tempo de acomodação de 1,3s. O critério de ITAE resultou melhor desempenho que o de IAE, apesar do tempo de acomodação no ciclo de subida ser o dobro do valor do obtido no ensaio com os parâmetros calculados pelo critério de IAE. 


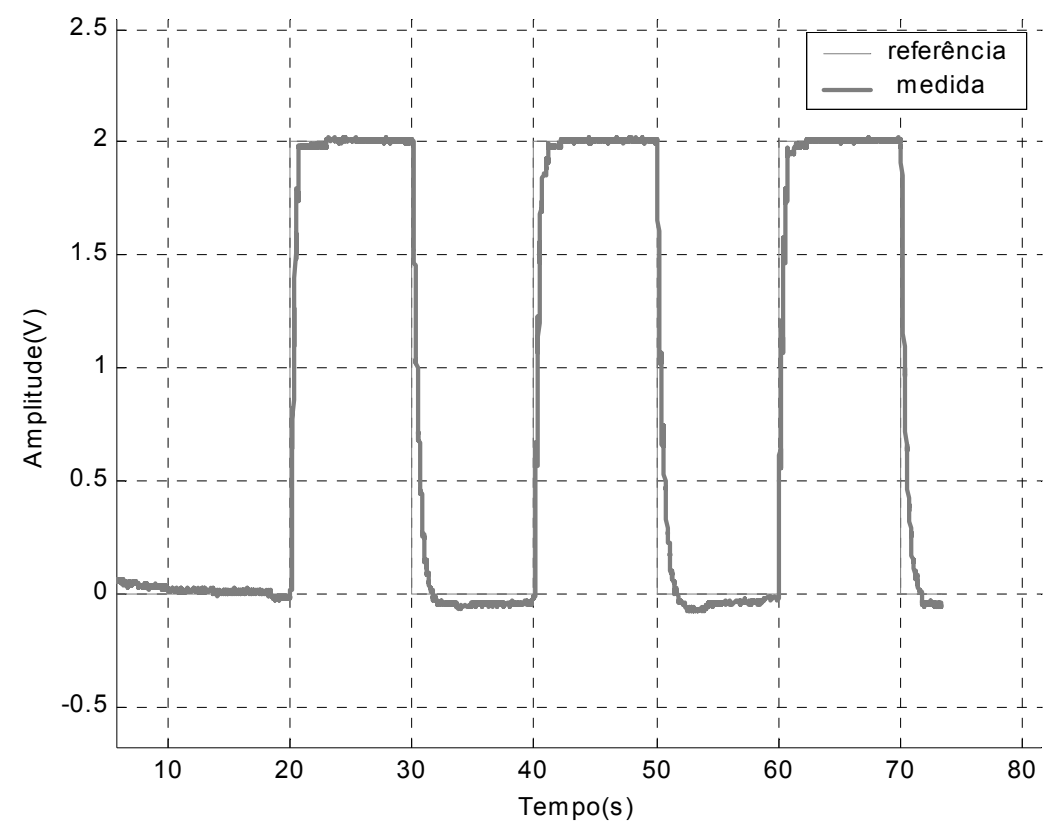

Figura 56 Critério de ITAE: $P=6,12 ; l=1,72 ; D=1,45$

$\mathrm{Na}$ Tabela 8 tem-se um quadro comparativo entre os métodos descritos acima. O erro de acompanhamento no tempo após o sistema entrar em regime permanente foi definido como: $e(\%)=\frac{\max (|y-r|)}{\max (|r|)} \cdot 100 \%$.

Onde:

- $e(\%)$-porcentagem do erro de acompanhamento

- $y$-Amplitude sinal medido $(\mathrm{V})$

- $r$-sinal de referência $(\mathrm{V})$.

Esses resultados foram incluídos na Tabela 8, a fim de se verificar qual dos métodos introduz menor erro de acompanhamento do sinal de referência, uma vez que essa é uma especificação importante no projeto do controlador.

Pelos dados da Tabela 8, verifica-se que o método que apresentou melhores resultados foi o método de ITAE.

Como os parâmetros $\mathrm{P}, \mathrm{I}, \mathrm{D}$ encontrados pelo método de ITAE são os mais adequados, optou-se por explorar mais o seu funcionamento variando a amplitude do sinal de referência e verificar o comportamento dinâmico do sistema.

Mantendo-se os parâmetros encontrados no critério de ITAE mudou-se o valor do nível de referência para uma onda quadra da de $1 \mathrm{~V}$ com período de $20 \mathrm{~s}$ de amplitude, sendo o resultado do ensaio mostrado na Figura 57. 
Tabela 8 Tabela comparativa dos métodos de sintonia de um controlador PID.

\begin{tabular}{|l|l|l|l|l|l|}
\hline Método & $\begin{array}{l}\text { Erro de } \\
\text { acompanhamento } \\
(\%)\end{array}$ & $\begin{array}{l}\text { Tempo } \\
\text { acomodação } \\
\text { Subida } \\
(\mathrm{s})\end{array}$ & $\begin{array}{l}\text { Tempo } \\
\text { acomodação } \\
\text { descida } \\
(\mathbf{s})\end{array}$ & $\begin{array}{l}\text { Sobre-sinal } \\
\text { Subida (\%) }\end{array}$ & $\begin{array}{l}\text { Sobre-sinal } \\
\text { descida(\%) }\end{array}$ \\
\hline Empírico & 12,5 & 1,5 & 7 & 1,5 & 12 \\
\hline $\begin{array}{l}\text { Osc. mantida } \\
\text { Z-N Modificado }\end{array}$ & 80 & 3,5 & 8 & 29 & 34 \\
\hline $\begin{array}{l}\text { Z-N } \\
\text { Original }\end{array}$ & 75 & 2,5 & 3,5 & 30 & 47,5 \\
\hline $\begin{array}{l}\text { Z-N } \\
\text { Curva de reação }\end{array}$ & 37,5 & 4,3 & 4,5 & 20 & 17,5 \\
\hline $\begin{array}{l}\text { Controlador PI Curva } \\
\text { de reação }\end{array}$ & 25 & 2 & 4 & 15 & 9,5 \\
\hline Cohen-Coon & 45 & 3 & 4 & 22,5 & 25 \\
\hline IAE & 10 & 0,7 & 7 & 5 & 3,5 \\
\hline ITAE & 2,5 & 1,4 & 0,5 & \\
\hline
\end{tabular}

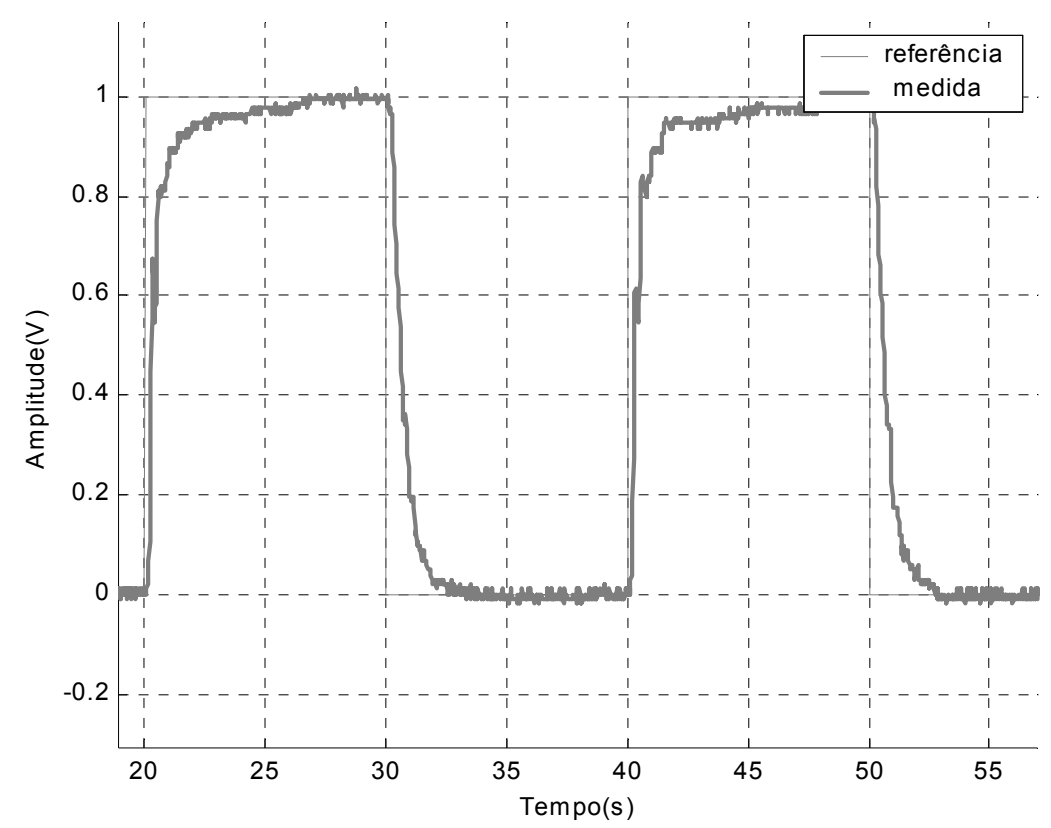

Figura 57 Mudança do valor do sinal de referência para $1 \mathrm{~V}$ com $P=6,12, I=1,72, D=1,45$ (ITAE) 
Verifica-se que a simples mudança do valor do sinal de referência fez com que o sistema ficasse ligeiramente melhor no ciclo de subida não ocorrendo sobresinal e o tempo de acomodação foi diminuído para 1s. Na descida, não ocorreu sobre-sinal e o tempo de acomodação se manteve em 1,3s. O erro de acompanhamento calculado foi de $10 \%$, o que ficou pior em relação ao ensaio anterior. Esta mudança de comportamento com a alteração do valor do sinal de referência evidencia a não linearidade do sistema que está sendo controlado.

Mantendo-se esses parâmetros, utilizando agora um sinal de referência senoidal de amplitude $1 \mathrm{~V}$ e período 20 s, obteve-se o resultado mostrado na Figura 58.

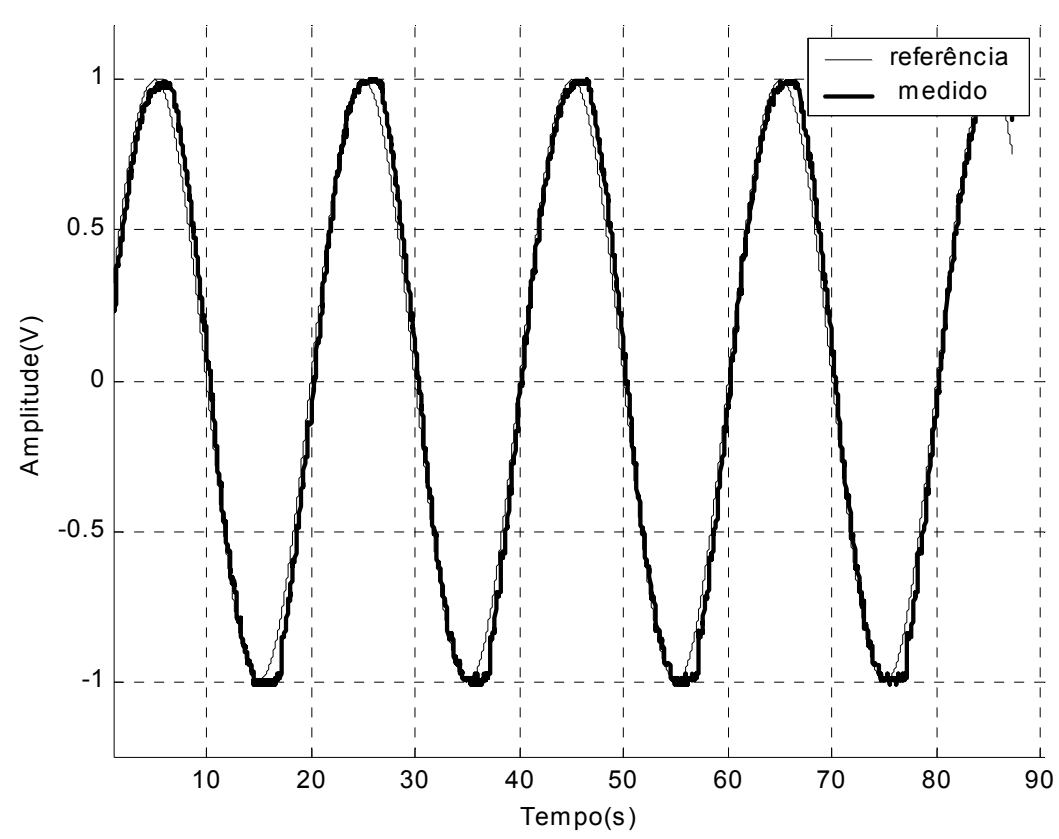

Figura 58 Critério de ITAE: $P=6,12 ; \mathrm{I}=1,72 ; \mathrm{D}=1,45$ (sinal senoidal 1V T=20s)

Verifica-se que a mudança da forma de onda para senoidal, o erro de acompanhamento foi reduzido em $13 \%$ e não houve um sobre-sinal significativo.

Mudando-se agora a amplitude para 2V com período 20s, obteve-se o resultado mostrado na Figura 59. Não houve sobre-sinal de valor elevado e o erro de acompanhamento obtido foi de $10 \%$. 


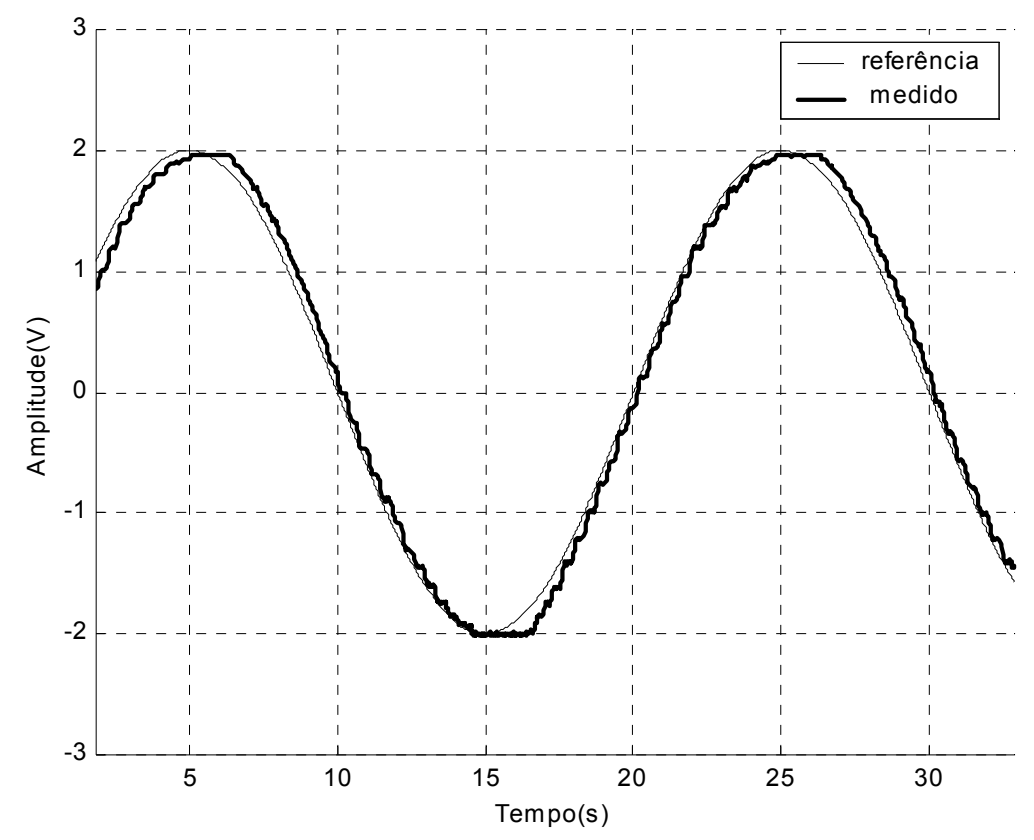

Figura 59 Critério de ITAE : $P=6,12 ; I=1,72 ; D=1,45$ (sinal senoidal 2V T=20s)

Aumentando-se a amplitude do sinal da referência (sinal senoidal de $3 \mathrm{~V}$ ) e diminuindo-se o período para 10s, o resultado obtido está mostrado na Figura 60.

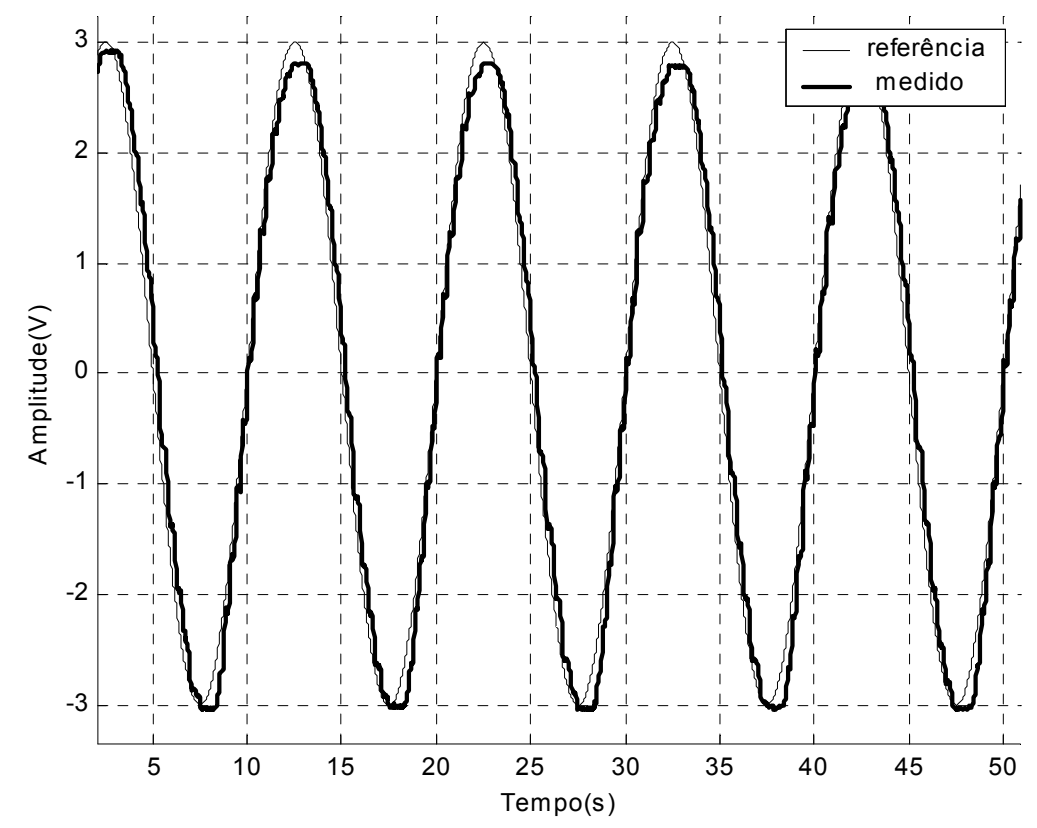

Figura 60 Critério de ITAE : $P=6,12 ; l=1,72 ; D=1,45$ (sinal senoidal $3 \mathrm{~V} T=10 \mathrm{~s}$ )

Pode-se notar que há uma ligeira piora no acompanhamento da referência $(16,6 \%)$. Esta piora é verificada no próximo caso, ao manter-se o período de 10 s e 
aumentando-se a amplitude do sinal de referência para 4V (Figura 61). Neste caso, o erro de acompanhamento calculado foi de $17,5 \%$.

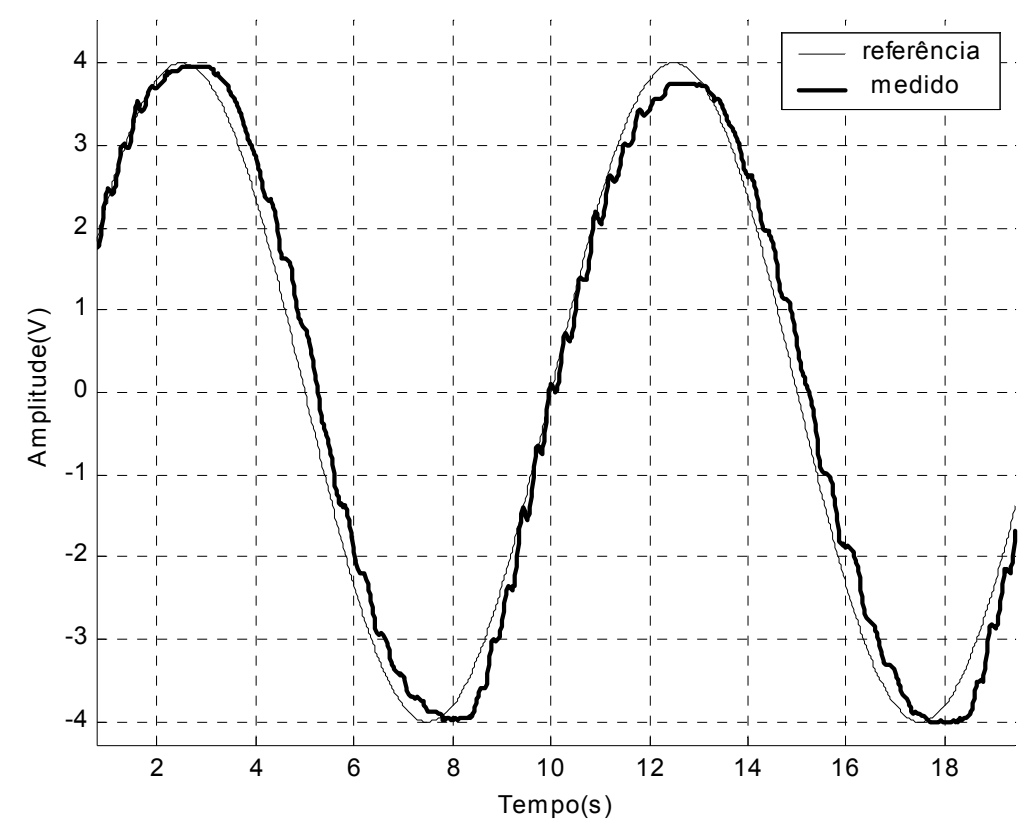

Figura 61 Critério de ITAE: $P=6,12 ; I=1,72 ; D=1,45$ (sinal senoidal 4 V T=10s)

Observa-se que o controlador PID conseguiu seguir as referências relativamente bem nos casos da Figura 58 e Figura 59, mas no momento em que se aumentaram a freqüência e a amplitude, o sistema não mais consegue acompanhar essas referências com precisão, conforme mostra a Figura 60 e Figura 61. Um quadro comparativo é mostrado na Tabela 9.

Tabela 9 Erro de acompanhamento do controlador PID com sinais senoidais

\begin{tabular}{|l|l|l|}
\hline $\begin{array}{l}\text { Onda senoidal } \\
\text { Amplitude/Período }\end{array}$ & $\begin{array}{l}\text { Erro } \\
\text { acompanhamento } \\
\Delta \mathrm{V}\end{array}$ & $\begin{array}{l}\text { Erro } \\
\text { acompanhamento } \\
\mathrm{e}(\%)\end{array}$ \\
\hline $1 \mathrm{~V} / \mathrm{T}=20 \mathrm{~s}$ & $0,13 \mathrm{~V}$ & $13 \%$ \\
\hline $2 \mathrm{~V} / \mathrm{T}=20 \mathrm{~s}$ & $0,2 \mathrm{~V}$ & $10 \%$ \\
\hline $3 \mathrm{~V} / \mathrm{T}=10 \mathrm{~s}$ & $0,5 \mathrm{~V}$ & $16,6 \%$ \\
\hline $4 \mathrm{~V} / \mathrm{T}=10 \mathrm{~s}$ & 0,7 & $17,5 \%$ \\
\hline
\end{tabular}


Verifica-se, portanto, que mudança da forma de onda, níveis e períodos dos sinais de referência, podem mudar o desempenho do controlador PID.

A máxima largura de faixa obtida com o controlador utilizado pelo critério de ITAE ficou em torno de $0,37 \mathrm{~Hz}$, conforme mostra a Figura 62

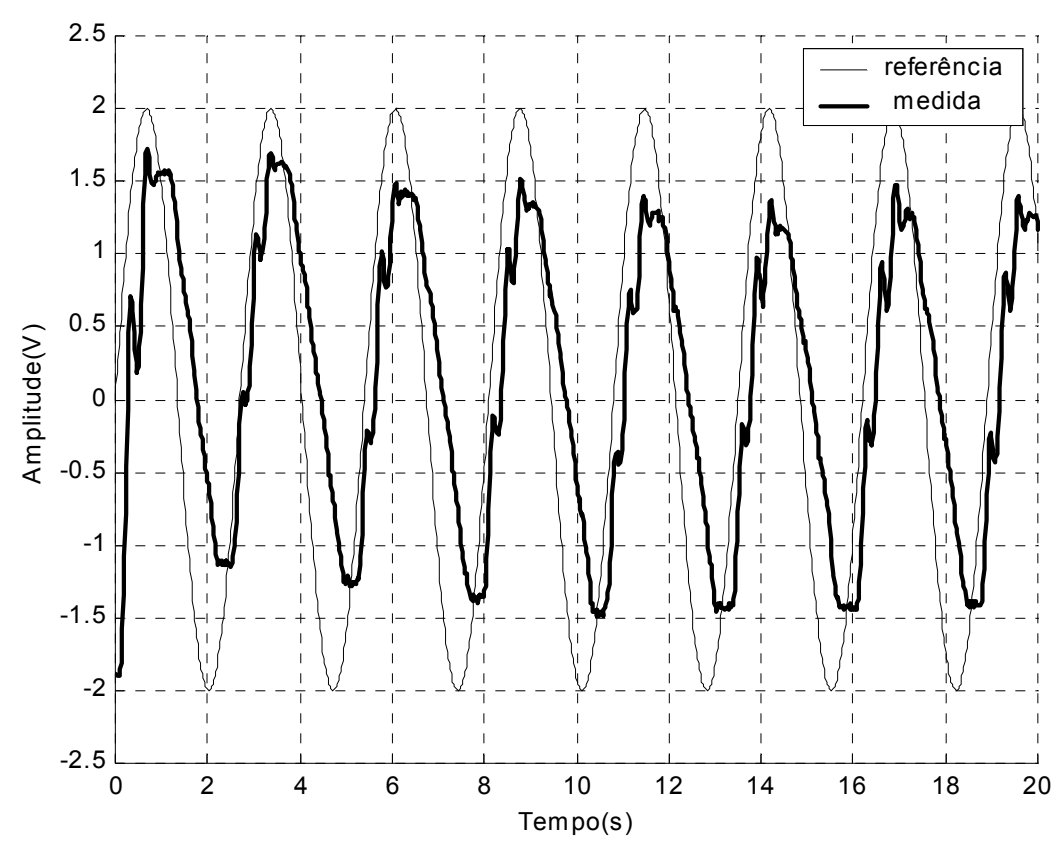

Figura 62 Resposta do controlador PID ( ITAE ) com sinal de referência senoidal $2 \mathrm{~V} / \mathrm{T}=2,7 \mathrm{~s}$

Conclui-se que somente em casos especiais como baixas freqüências, baixos níveis de sinais de referência e sinais suaves o PID poderá ser utilizado de forma satisfatória.

Todos os métodos até aqui empregados na tentativa de fazer uma otimização do atuador SMA em estudo com o controlador PID não obtiveram um resultado muito satisfatório, pois essas metodologias foram desenvolvidas para serem empregadas em sistemas lineares. No próximo capítulo será estudada uma metodologia de controle não linear. 


\section{CONTROLE NÃO LINEAR}

Segundo Elahinia (2004), devido à não linearidade de um atuador SMA, relacionadas ao complexo comportamento termo-mecânico e à grande histerese, um controlador PID linear não é capaz de realizar o controle com desempenho satisfatório, exigindo-se, portanto, um sistema de controle não linear. Assim, no capítulo anterior, o projeto e sintonia do controlador PID por vários métodos reforçou a necessidade de se projetar um controlador mais sofisticado que consiga melhorar o desempenho dinâmico do atuador.

$\mathrm{Na}$ literatura são citadas algumas formas de se fazer esse tipo de controle. Elahinia (2004), por exemplo, utiliza a técnica do controle por modos deslizantes (sliding mode control), amplamente abordada em problemas envolvendo ligas de memória de forma. No presente trabalho, a técnica do controle por modos deslizantes será também aplicada.

Segundo Edwards e Spurgeon (1998), a técnica do controle por modos deslizantes foi desenvolvida na Rússia por Emel'yanov e Barbashin no início de 1960, mas somente foi publicada fora da Rússia por Utkin (1977). Essa técnica foi desenvolvida para ser empregada em sistemas não lineares, com incertezas no modelo.

Apesar de existirem várias técnicas de controle não lineares, optou-se em utilizar a técnica do controle por modos deslizantes devido à facilidade de sua implementação e ao fato de lidar com incertezas nos parâmetros do modelo matemático e também em sistemas que possuem incertezas na estrutura do próprio modelo, como é o caso do modelo do atuador em estudo. Esse tipo de controle garante os objetivos desejados como robustez, acompanhamento do sinal de referência, estabilidade, baixo sobre-sinal e tempo de acomodação e rejeição de distúrbios externos (temperatura ambiente e variações na carga).

A abordagem matemática de projeto a ser seguida neste trabalho baseia-se na versão exposta em Slotine e Li (1991). 


\subsection{Abordagem teórica de controle não linear}

Para uma melhor compreensão da teoria do controle não linear, dividiu-se a teoria em duas partes: linearização por realimentação e controle por modos deslizantes.

\subsubsection{Linearização por realimentação}

Antes de se introduzirem os termos de controle por modos deslizantes, o sistema dinâmico não linear deve ser linearizado em malha fechada, por meio da técnica de linearização por realimentação (feedback linearization).

Essa técnica consiste basicamente em se impor uma entrada de controle de tal forma que o sistema em malha fechada se comporte como um sistema linear, eliminando-se as não linearidades.

Considerando-se um sistema de ordem $n$ do tipo mostrado na equação (29)

$x^{(n)}=f(x, t)+b(x, t) \cdot u$

onde $\boldsymbol{x}=\left[x, \dot{x}, x^{(n-1)}\right]^{T}$ é o vetor de estados, $x$ é a saída do sistema (por exemplo, a posição de um sistema mecânico) e o escalar $u$ é a entrada de controle (por exemplo, o torque de um motor ou uma corrente ou tensão elétrica). $f(x, t)$ e $b(x, t)$ são funções do sistema, geralmente não lineares.

Visando manter a saída próxima à referência desejada $x_{d}(t)$, uma lei de controle para o sistema de malha fechada pode ser dada por:

$u=\frac{1}{b}(v-f)$

sendo $\quad b \neq 0, \quad v=x d^{(n)}-k_{0} \widetilde{x}-k_{1} \dot{\widetilde{x}}-\ldots-k_{n-1} \widetilde{x}^{(n-1)}, \quad \widetilde{x}(t)=x(t)-x_{d}(t) \quad 0 \quad$ erro $\quad$ de acompanhamento e os parâmetros $k_{i}$ convenientemente escolhidos de tal forma que o polinômio $p^{n}+k_{n-1} p^{n-1}+\ldots+k_{0}$ possua todas as raízes estritamente no semi-plano esquerdo do plano complexo. Pode-se verificar que o erro de acompanhamento $e(t)$ converge exponencialmente para um valor nulo $(\widetilde{x}(t) \rightarrow 0)$. 
Esta técnica só é válida se o modelo matemático do sistema (ou seja, as funções $f(x, t)$ e $b(x, t))$ forem bem conhecidas, portanto livre de incertezas. No caso de sistemas com incertezas no modelo, essa técnica não é aplicável diretamente e, portanto, deve-se recorrer à técnica do controle por modos deslizantes (sliding mode control).

\subsubsection{Controle por modos deslizantes}

Considera-se o modelo de um sistema não-linear com incertezas nos parâmetros e/ou em sua própria estrutura matemática. Estas podem ser devidas a simplificações, tais como não considerar efeitos de flexibilidade em sistemas mecânicos ou efeitos indutivos e capacitivos em sistemas elétricos. Estes efeitos geralmente não apresentam influência em baixas freqüências, porém podem ser significativos para as freqüências altas, que podem eventualmente ser alcançadas para o sistema em malha fechada.

Quanto maior for a incerteza do modelo, maior será o esforço de controle na tentativa de manter o sistema controlado. Este é, portanto, o preço a ser pago na tentativa de controlar o sistema com grandes erros de modelagem.

Considera-se um sistema com uma única entrada e única saída descrito pela equação (29), sendo as funções $f(x, t)$ e $b(x, t)$ não exatamente conhecidas, com condições iniciais $x_{d}(0)=x(0)$. Visando facilitar a notação, será suprimida a variável $t$ das equações. $O$ vetor de erro de acompanhamento será definido como $\widetilde{\mathbf{x}}=\left[\widetilde{x} \dot{\widetilde{x}} \ldots . . \widetilde{x}^{(n-1)}\right]^{T}$. O projeto de controle fica resumido em fazer com que o erro de acompanhamento se aproxime de zero mesmo na presença das incertezas de modelo de $f(x)$ e $b(x)$, ainda com a presença de distúrbios.

Define-se uma superfície de escorregamento $S(t)$ no espaço $R^{n}$ por uma equação escalar $s(x, t)=0$, sendo a variável $s$ definida conforme a equação:

$$
s(x, t)=\left(\frac{d}{d t}+\lambda\right)^{(n-1)} \widetilde{x}
$$

na qual $\lambda$ é uma constante estritamente positiva e $n$ é a ordem do sistema. Por exemplo, para um sistema de segunda ordem $(n=2)$ tem-se $s=\dot{\tilde{x}}+\lambda \widetilde{x}$. Sendo $\widetilde{x}$ o erro de malha fechada, conclui-se que, $\widetilde{x}$ é a saída de um filtro passa baixa aplicado 
sobre a variável $\mathrm{s}$, sendo $\lambda$ a freqüência de corte do filtro. Neste caso, a superfície pode ser representada conforme mostra a Figura 63.

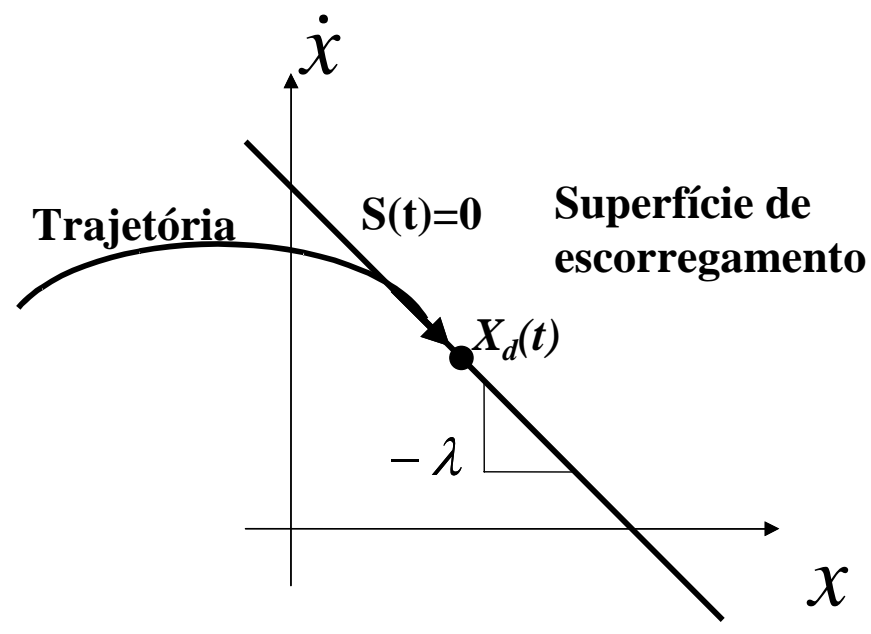

Figura 63 Interpretação gráfica da superfície de escorregamento para n=2

Assim, o problema de acompanhamento (tracking) pode se reduzir a manter a trajetória do sistema sobre a superfície $S(t)$, com $s=0$. De fato, se $s=0$ o erro $\tilde{x}$ tende assintoticamente para zero.

Segundo Slotine e Li (1991), o módulo da variável s possui uma relação com o erro de acompanhamento dado por:

$$
|s(t)|<\phi \Rightarrow\left|\widetilde{x}^{i}(t)\right|<\frac{2^{i}}{\lambda^{n-i-1}} . \phi, \text { para } \forall \phi>0 \quad e \quad i=0,1,2 \ldots . . n
$$

Por exemplo, o erro de acompanhamento $\tilde{x}$ pode ser obtido fazendo $i=0$ e portanto obtém-se: $|s(t)|<\phi \Rightarrow|\widetilde{x}(t)|<\frac{1}{\lambda^{n-1}}$.

Para que todas as trajetórias que se encontram fora da superfície $S(t)$ sejam levadas para dentro dessa superfície, uma lei de controle deve satisfazer as condições da equação (33), também chamada de condições de escorregamento.

$\frac{1}{2} \frac{d}{d t} s^{2}<-\eta|s|$ 
onde $\eta$ é uma constante positiva responsável pela velocidade da convergência para dentro da superfície $S(t)$, conforme mostra a Figura 64.

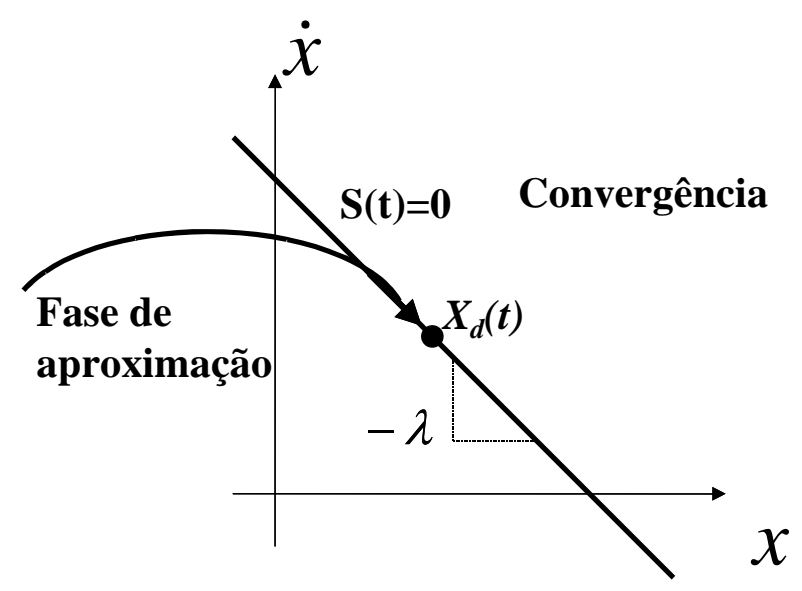

Figura 64 Interpretação gráfica da equação(33) para $n=2$

Essencialmente o significado da equação (33) é que o quadrado da distância à superfície $S(t)$ é diminuído ao longo de todas as trajetórias, com a velocidade de convergência $\eta$.

O tempo para que a trajetória superfície $S(t)$ com condições iniciais $x(0) \neq x_{d}(0)$ ou seja $s(0) \neq 0$ é dada por:

$t_{\text {alcance }} \leq\left|\frac{S_{(0)}}{\eta}\right|$

A condição de escorregamento para a superfície deslizante pode ser representada graficamente conforme mostra a Figura 65.

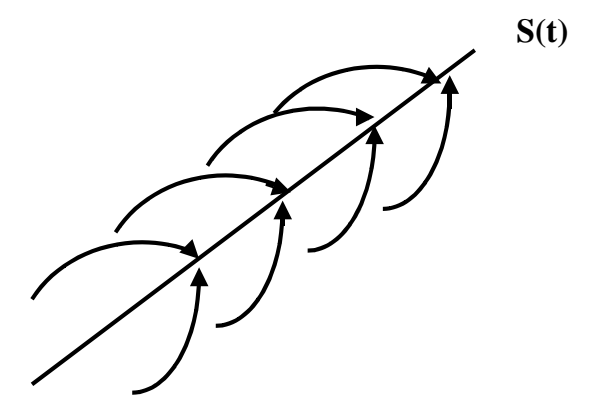

Figura 65 Condições de escorregamento 
Assim que a superfície é atingida, o erro de acompanhamento tende exponencialmente para zero com uma constante de tempo $1 / \lambda$, e a partir desse ponto o sistema segue a dinâmica dada pela equação (31).

Para o caso de um sistema de segunda ordem, conforme mostra a equação (35), será derivada uma lei de controle $u$ que satisfaz as condições da equação (33).

$\ddot{x}=f+u$

onde $f$ é uma função não linear não conhecida exatamente. Define-se $\hat{f} \circ$ valor estimado de $f$ e $F$ o máximo erro de modelagem, ou seja:

$|\hat{f}-f|<F$

De forma geral, para que a entrada de controle $u$ force o sistema a manter-se na trajetória desejada $\left(x \equiv x_{d}\right)$, deriva-se a equação (31) uma vez e obtém-se o termo $x^{(n)}$. Substituindo-se na equação (29), aparece o termo $u$. Para um sistema de segunda ordem por exemplo:

$\dot{s}=\ddot{\widetilde{x}}+\lambda \dot{\widetilde{x}}=0 \quad$ assim $: \ddot{x}=\ddot{x}_{d}-\lambda \dot{\widetilde{x}} \Rightarrow \dot{s}=f(x, \dot{x}, t)+b \cdot(x, \dot{x}, t) \cdot u+\lambda \dot{\widetilde{x}}-\ddot{x}_{d}$

Para o caso específico do modelo (35), obtém-se:

$\dot{s}=\ddot{x}-\ddot{x}_{d}+\lambda \dot{\widetilde{x}}=f+u-\ddot{x}_{d}+\lambda \dot{\widetilde{x}}$

A melhor estimativa de $\hat{u}$ (sem erro de modelagem) para uma lei de controle continuo é atingida quando $s=\dot{s}=0$. Assim, na ausência de erros de modelagem a lei de controle ficaria dada por:

$\hat{u}=-\hat{f}+\ddot{x}_{d}-\lambda \dot{\widetilde{x}}$

Considerando-se as incertezas do modelo, deve-se acrescentar um termo descontínuo na superfície $S(t)$, modificando-se a lei de controle para: 
$u=\hat{u}-k \cdot \operatorname{sinal}(s)$

onde $k$ é o ganho do termo chaveado da função sinal(s) e $\hat{u}$ é o termo da linearização por realimentação descrito na equação (39).

O ganho $k$ é calculado respeitando as condições de escorregamento (33). Assim, resolvendo a equação $\frac{1}{2} \frac{d}{d t} s^{2}=\dot{s} . s$ e fazendo as devidas substituições em (38), (39) e (40), obtém-se:

$\dot{s} . s=[f-\hat{f}-\operatorname{ksinal}(s)] . s=(f-\hat{f}) s-k|s|$

Para satisfazer a condição da equação (33) para todos os valores de $f$, o valor de $k$ deve satisfazer:

$k \geq F+\eta$

Esta equação mostra que $k$ é responsável pela parcela das incertezas do modelo, ou seja, quanto maiores forem as incertezas do modelo, maior será o valor de $k$.

\subsubsection{Controle integral}

Pode-se incluir ação integral no controlador projetado anteriormente. Para tanto, define-se a nova variável de interesse como $\int_{0}^{t} \widetilde{x}(r) d r$. Assim, o sistema de segunda ordem descrito anteriormente por (35), torna-se, na nova variável de interesse, um sistema de terceira ordem. Redefinindo-se a variável s tem-se:

$s=\left(\frac{d}{d t}+\lambda\right)^{2} \cdot \int_{0}^{t} \widetilde{x} d r=\dot{\widetilde{x}}+2 \lambda \widetilde{x}+\lambda^{2} \int_{0}^{t} \widetilde{x} d r$ 
Fazendo $\dot{s}=0$ o novo valor de $\hat{u}$ (linearização por realimentação) obtido, fica conforme mostra a equação (44).

$\hat{u}=-\hat{f}+\ddot{x}_{d}-2 \lambda \dot{\widetilde{x}}-\lambda^{2} \widetilde{x}$

\subsubsection{Camada limite}

A equação (40) possui um termo descontínuo na superfície $S(t)$, fazendo com que o controle apresente sucessivos chaveamentos. Este comportamento será tanto mais pronunciado quanto maior forem as incertezas no modelo ou perturbações no sistema. Estas elevadas freqüências de chaveamento ocorrem próximo à superfície $S(t)$, podendo excitar modos de altas freqüências não modelados causando efeitos indesejáveis. Além disso, esse tipo de controle pode causar um desgaste prematuro nos atuadores. Esse efeito de chaveamento é conhecido como chattering conforme mostra a Figura 66.

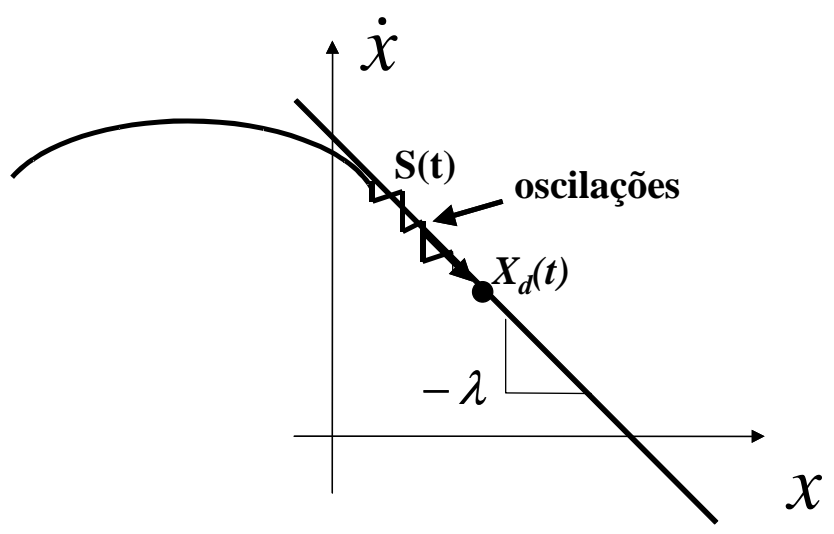

Figura 66 Oscilações devido o chaveamento (chattering)

Para eliminar o efeito de chaveamento, suaviza-se a descontinuidade da função sinal(s). Para tal será definida uma camada limite nas vizinhanças da superfície chaveada, conforme mostra a Equação (45), descrita em Slotine e Li (1991).

$B(t)=\{x,|s(x, t)| \leq \phi\} \quad \phi>0$ 
onde $\phi$ é a largura da camada limite em torno da superfície $S(t)$ e $\varepsilon=\frac{\phi}{\lambda^{n-1}}$ é a largura da camada na direção de $x$.

Na Figura 67 está representada graficamente a camada limite, para caso quando $n=2$.

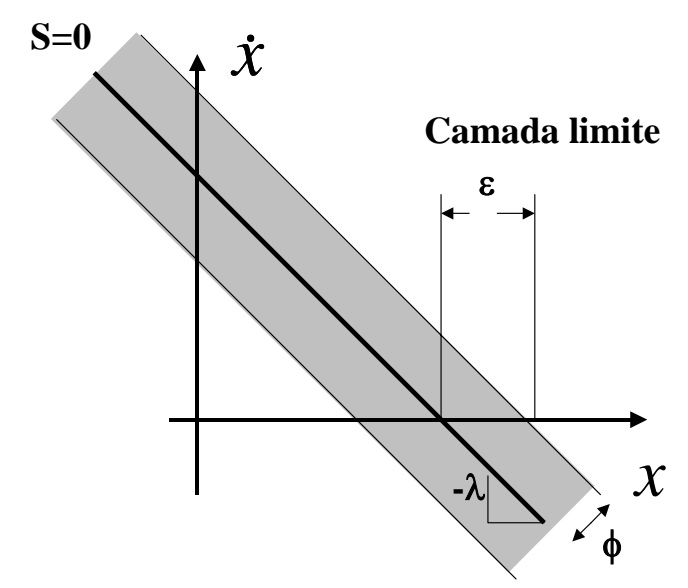

Figura 67 Camada limite para $n=2$ (adaptado de Slotine e Li (1991)).

Assim, a lei de controle suavizada será dada por:

$u=\hat{u}-k \cdot \operatorname{sat}(s / \phi)$

onde: $\operatorname{sat}(s / \phi)=s / \phi$ se $|s / \phi| \leq 1$

e $\operatorname{sat}(s / \phi)=\operatorname{sinal}(s / \phi)$ se $|s / \phi|>1$

O controle fica portanto introduzido dentro da camada limite, onde ocorre a transição do sinal, conforme mostra a Figura 68.

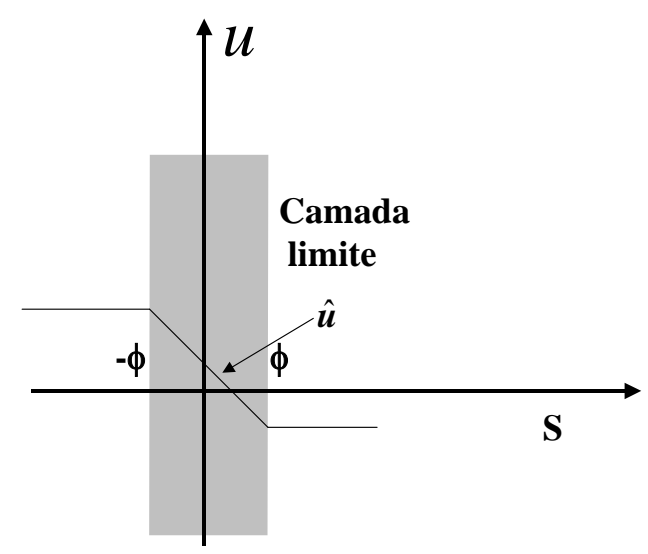

Figura 68 Controle introduzido na camada limite (adaptado de Slotine e Li (1991)). 
Fora da camada limite, o controle $u$ deve satisfazer a equação (33), já que as trajetórias convergem para dentro da camada limite. O erro de acompanhamento $\tilde{x}$ fica limitado pela largura da camada limite conforme:

$$
|\widetilde{x}(t)|<\frac{\phi}{\lambda}=\varepsilon \quad \text { para } \quad n=2
$$

Segundo Slotine e Li (1991), suavizar o controle descontinuo dentro de $B(t)$ equivale a introduzir um filtro passa baixa na dinâmica da variável $s$, eliminando-se com isso as oscilações (chattering). Considerando-se então esse comportamento, é possível fazer o ajustes dos parâmetros $\lambda$ e $\phi$ da lei de controle a fim de otimizar 0 funcionamento do controlador. Demonstra-se que o cálculo da camada limite $\phi$ pode ser obtido conforme mostra a equação (48).

$$
\phi=\frac{\max \left[k\left(x_{d}, \dot{x}_{d}, t\right)\right]}{\lambda}
$$

onde $\max \left[k\left(x_{d}, \dot{x}_{d}, t\right)\right]$ é o maior valor de ganho ao longo da trajetória s.

Obtém-se dessa forma uma camada limite $\phi$, com valor constante ao longo do tempo, uma vez que $\lambda$ é constante e representa a freqüência de corte do filtro aplicado sobre a variável $s$.

Outra relação que pode ser obtida para o maior valor de $k$ é fazer a substituição da equação (48) na equação (47) obtém-se a equação (49).

$\varepsilon \lambda^{2}=\max (k)$

onde $\varepsilon$ foi definido como largura da camada limite na direção de $x$.

Conforme mencionado anteriormente, quanto maior for o erro de modelagem, maior será o ganho $k$ e portanto maior será o erro de acompanhamento. Para que isso não ocorra deve-se aumentar o valor de $\lambda$, que corresponde ao valor da banda passante. Porém isso fisicamente não é possível de ser feito, e portanto o valor de $\lambda$ não pode ser aumentado indefinidamente a fim de diminuir o erro de acompanhamento. 
Em Slotine e Li (1991), sugerem-se alguns critérios para ajustar esses parâmetros:

1. $\lambda$ deve ser menor que a primeira freqüência ressonante não modelada $\left(v_{r}\right)$ do sistema obedecendo a relação: $\lambda<\frac{2 \pi}{3} v_{r}$.

2. $\lambda$ deve ser menor que o maior tempo de atraso de transporte $\left(T_{A}\right)$ do sistema conforme a relação: $\lambda<\frac{1}{3 T_{A}}$.

3. $\lambda$ deve ser menor que a taxa de amostragem $\left(v_{s}\right)$ do sistema conforme a relação: $\lambda<\frac{1}{5}\left(v_{s}\right)$.

4. $\lambda$ escolhido será o menor dos valores calculados pelos critérios acima.

Em Slotine e Li (1991), é proposto a determinação da camada limite variável no tempo $(\dot{\phi})$, fazendo com que nos instantes de menores incertezas no modelo, diminua-se o valor de $k$, e portanto a espessura $\phi$ pode ser reduzida, levando a uma diminuição do erro de acompanhamento $\widetilde{x}$ conforme pode ser visto em (47). Porém trata-se de um método bastante trabalhoso e não será aqui tratado, pois o método da camada limite constante é suficiente para fazer o controle do atuador SMA em estudo.

Em Slotine e Li (1991), é feita uma generalização da teoria de controle por modos deslizantes para sistemas com múltiplas entradas e múltiplas saídas. Essa generalização não será abordada no presente trabalho, pois o sistema em estudo possui uma entrada e uma saída.

\subsection{Projeto de controle não linear}

Após a abordagem teórica do controle por modos deslizantes (sliding mode control) foram realizados vários testes no sistema real, visando verificar o desempenho de algumas técnicas citadas na literatura aplicadas ao atuador SMA em estudo.

Inicialmente foi testado o desempenho do atuador SMA baseando-se em trabalhos similares como Ashrafiuon e Elahinia (2002); Elahinia (2004). Nesses 
trabalhos foram empregadas as técnicas de controle por modos deslizantes (sliding mode control), desde o seu aspecto mais básico que é um simples controle por chaveamento (switching control), até um sistema de controle mais elaborado, com o conhecimento do modelo da planta ou sistema á qual deseja-se controlar. Nestes trabalhos não são incluídos os termos de linearização por realimentação.

O primeiro teste prático teve como objetivo verificar o desempenho do atuador SMA com um simples controlador por chaveamento, depois o controle foi realizado com um sistema suavizado visando eliminar as oscilações devido ao chaveamento (chattering), sendo que até esse ponto não foi necessário o conhecimento do modelo do sistema.

No próximo capítulo, será empregada a técnica completa do controle por modos deslizante considerando-se portanto o modelo do sistema com suas incertezas, incluindo-se os termos de linearização por realimentação.

\subsubsection{Controle chaveado}

Baseando-se na teoria do controle por modos deslizantes (sliding mode control), dado um sistema: $\dot{x}=f(x)+b(x) u$, onde $x$ é o vetor dos estados e $u$ é o controle de entrada do sistema, a estrutura de controle da função chaveamento (switching function) é definida por: (ELAHINIA, 2004).

$$
u(x, t)=\left\{\begin{array}{lll}
V^{+}(x, t) & \text { se } & s(x)<0 \\
V^{-}(x, t) & \text { se } & s(x)>0
\end{array}\right.
$$

onde:

- $s(X)$ é a superfície da função chaveamento (switch surface).

- $V^{+}(x, t)$-máximo valor admissível na entrada do sistema.

- $V^{-}(x, t)$-mínimo valor admissível na entrada do sistema.

Segundo Elahinia (2004), com a equação (50), a condição $s(x)=0$ pode ser alcançada em um tempo finito.

Assim o sistema de controle fica extremamente simplificado conforme mostra a Figura 69, onde a função sinal(s) fará o chaveamento conforme mostra a equação (50). 


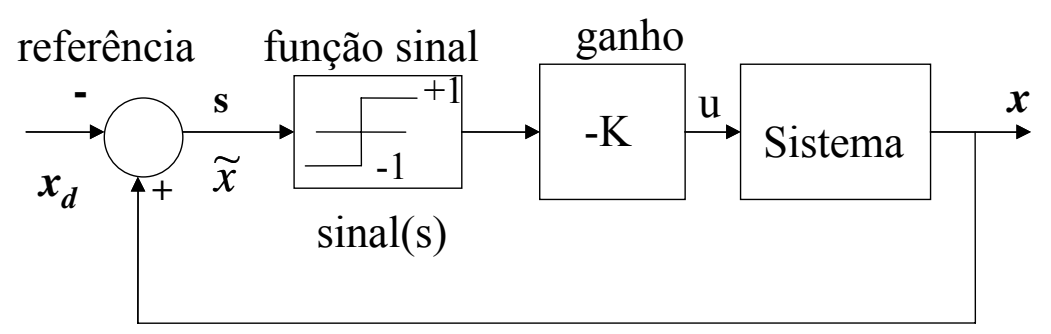

Figura 69 Controle por chaveamento

Neste caso definiu-se $s=\widetilde{x}=x-x_{d}$, onde $\widetilde{x}$ é o erro entre o sinal de referência $x_{d}$ e a medida $x$, também denominado erro de acompanhamento.

Fazendo a implementação desse sistema de controle no sistema físico do atuador SMA em estudo com $k=5$, o resultado obtido no ensaio prático com um sinal de referência com uma onda quadrada com $2 \mathrm{~V}$ de amplitude e com período de $\mathrm{T}=20 \mathrm{~s}$, está mostrado na Figura 70 .

Verifica-se que apesar do sistema seguir a referência, ocorre o efeito indesejável das oscilações pelo chaveamento (chattering), ocorrendo uma oscilação com período de chaveamento constante sobre o do sinal de referência, conforme pode ser visualizado na Figura 71. Esse efeito ocasiona uma oscilação constante no atuador.

O chattering é indesejável pois, além de não se obter uma boa precisão no sistema controle, ocasiona-se um desgaste prematuro do atuador e portanto não é recomendado para ser aplicado em sistemas mecânicos. 


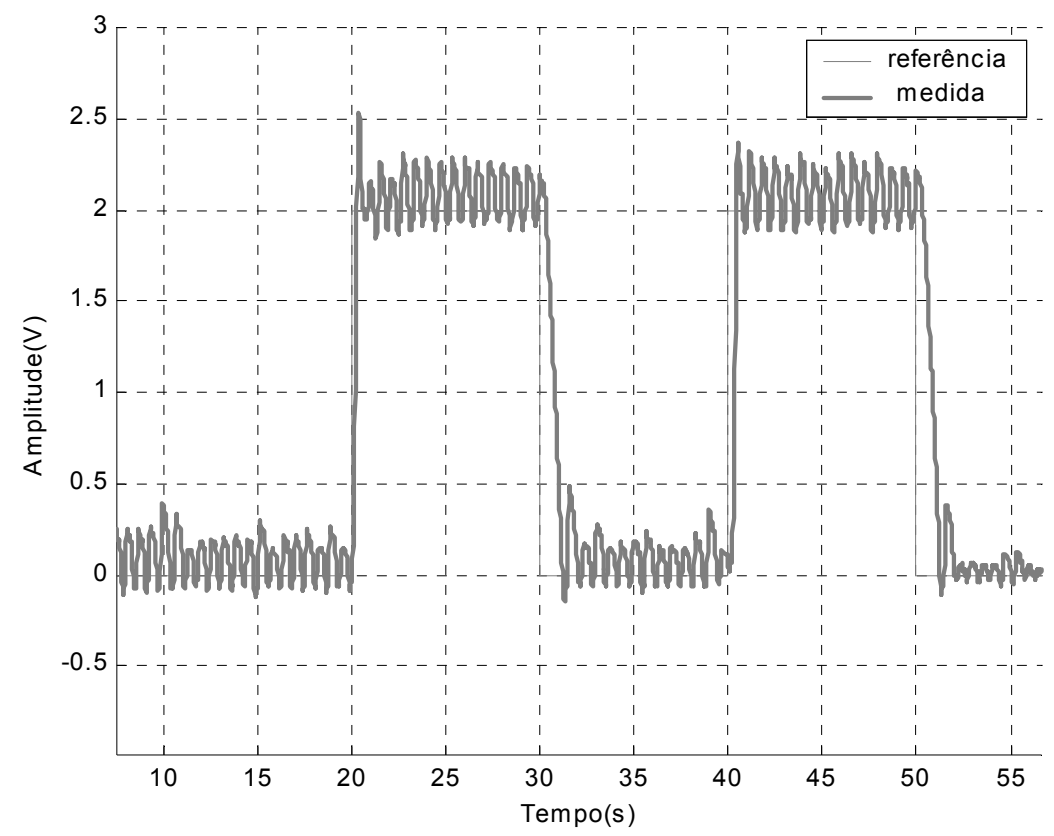

Figura 70 Controle por chaveamento simples

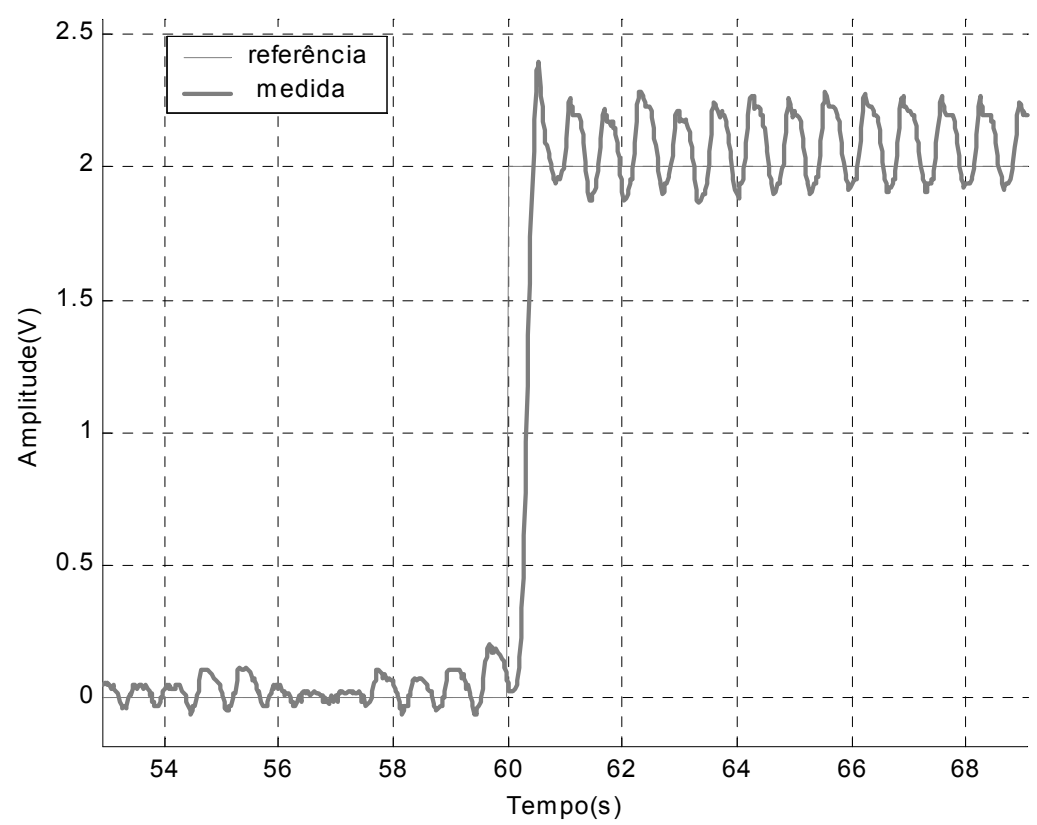

Figura 71 Efeito do chaveamento sobre o sinal de referência

Ainda com relação a este tipo de controle foram realizados alguns testes utilizando-se sinais de referência senoidal de amplitude $2 \mathrm{~V}$ e período variável conforme mostram os gráficos a seguir (Figura 72, Figura 73, Figura 74 e Figura 75). 


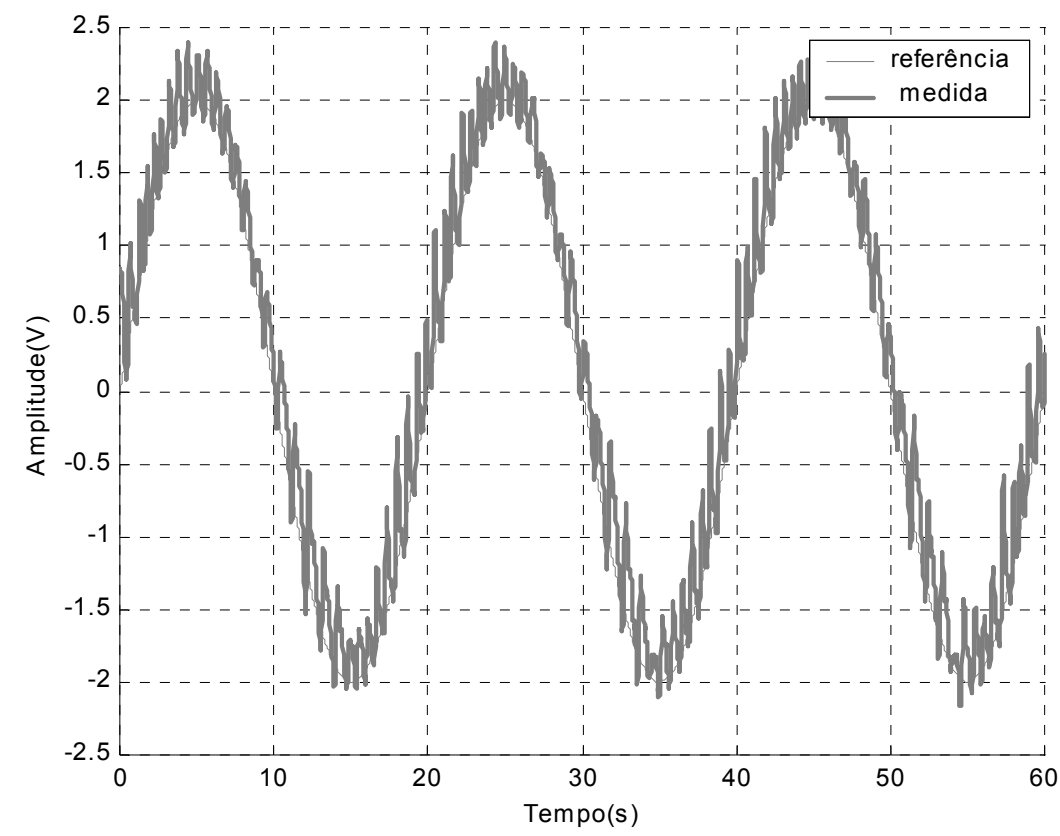

Figura 72 Efeito do chaveamento sobre o sinal de referência sinal senoidal $2 \mathrm{~V}$ e $\mathrm{T}=20 \mathrm{~s}$

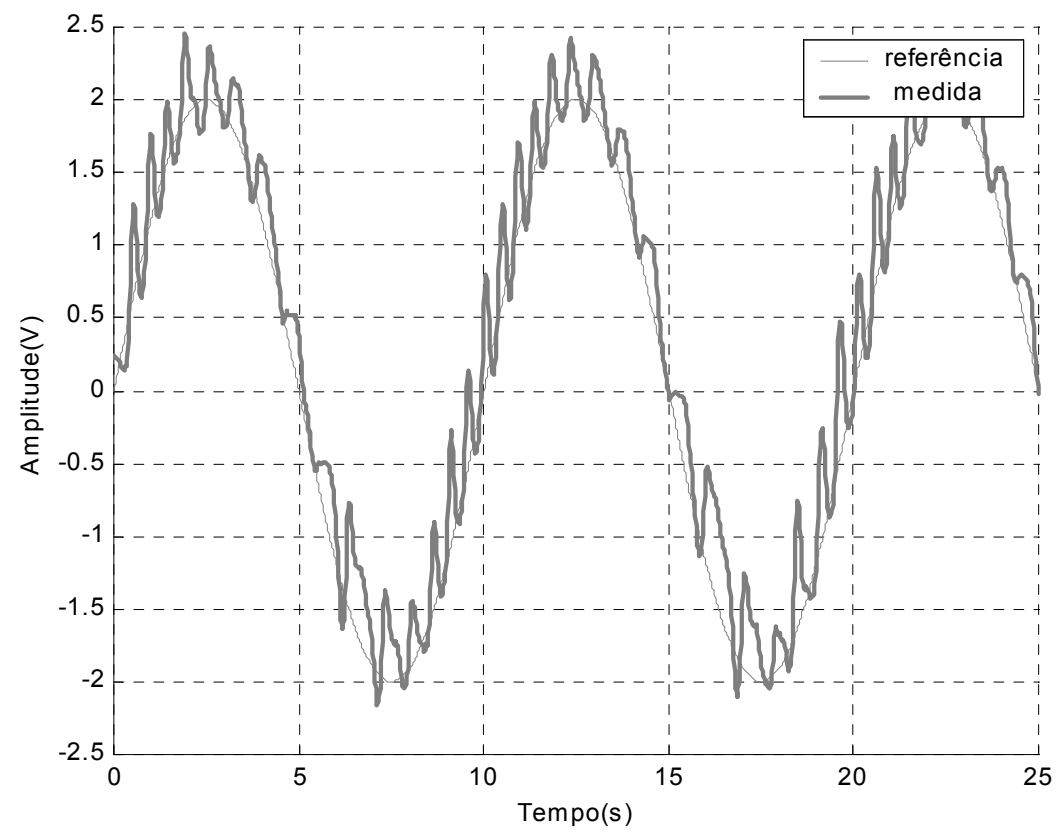

Figura 73 Efeito do chaveamento sobre o sinal de referência senoidal $2 \mathrm{~V}$ e $\mathrm{T}=10 \mathrm{~s}$ 


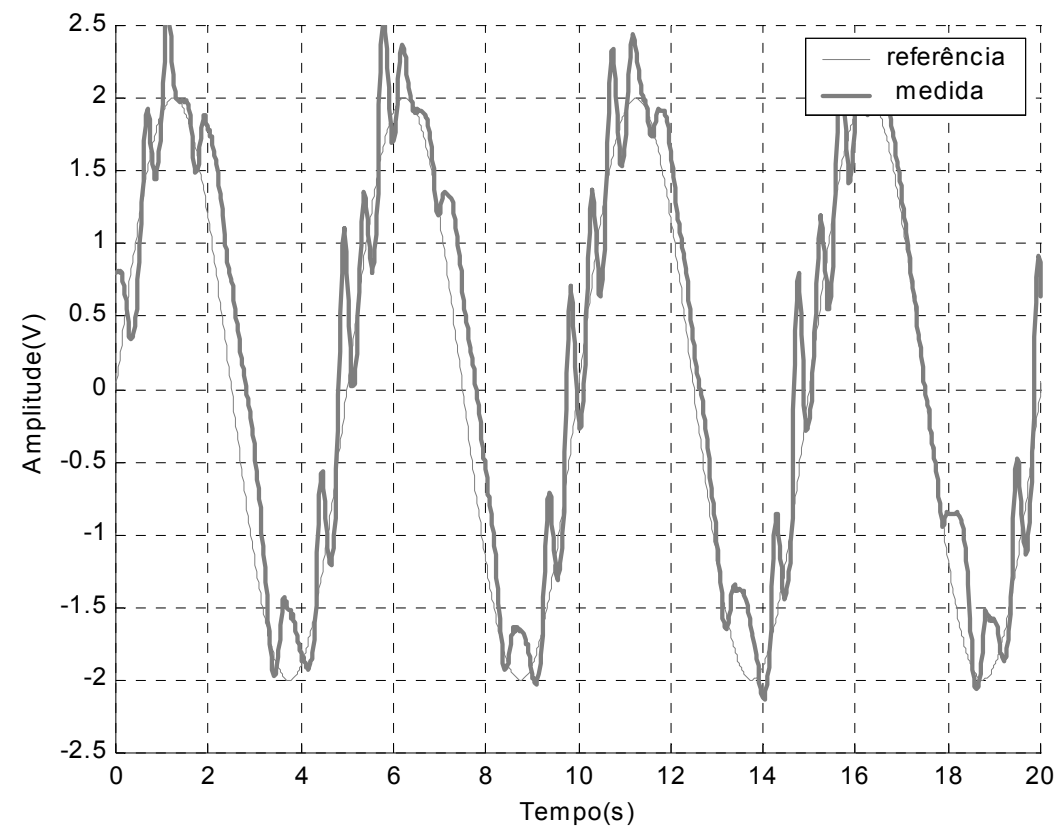

Figura 74 Efeito do chaveamento sobre o sinal de referência senoidal $2 \mathrm{~V}$ e $\mathrm{T}=5 \mathrm{~s}$

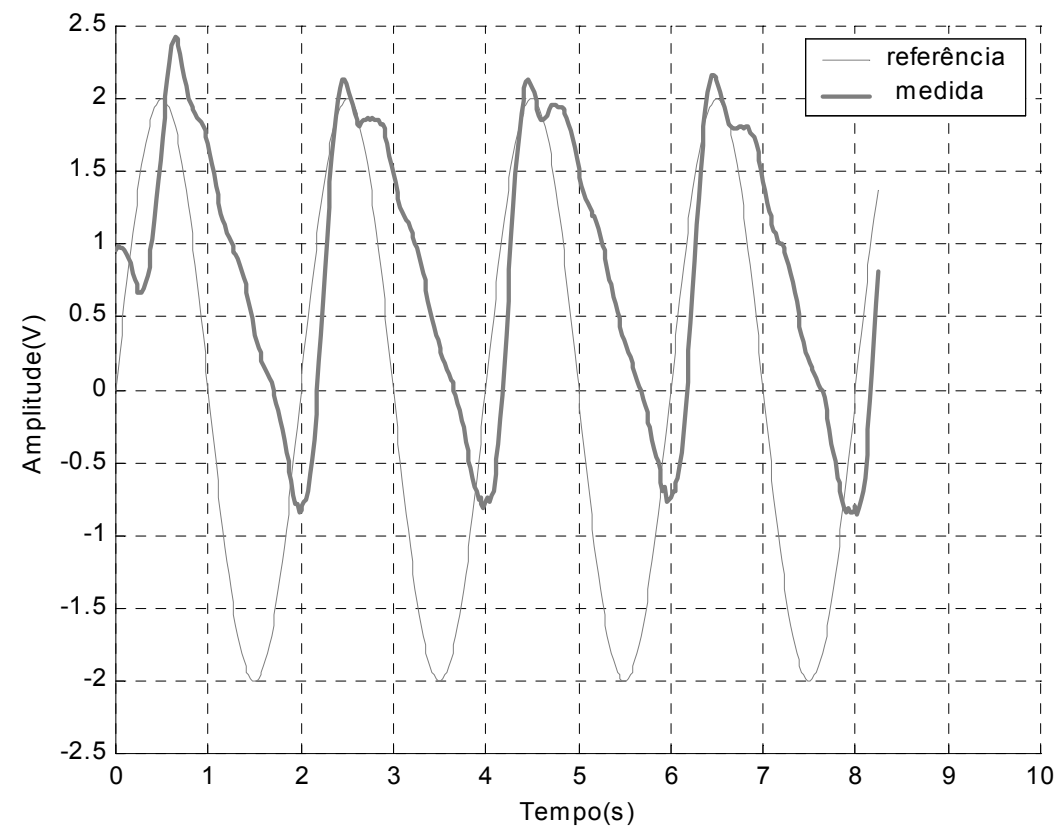

Figura 75 Efeito do chaveamento sobre o sinal de referência senoidal $2 \mathrm{~V}$ e $\mathrm{T}=2 \mathrm{~s}$

Verifica-se que com aumento da freqüência o sistema torna-se mais ruidoso e começa a perder desempenho. O controlador passa a não mais acompanhar o sinal de referência e há uma atenuação do sinal na saída do atuador. 


\subsubsection{Controle suavizado}

Conforme visto na teoria de controle por modos deslizantes, introduz-se uma camada limite para que o sinal chaveado seja filtrado.

Sendo a superfície $s=\widetilde{x}$ equivalente ao erro de acompanhamento, a nova lei de controle para o controle suavizado passa a ser dada por (ELAHINIA, 2004):

$$
u(x, t)=\left\{\begin{array}{ccc}
V^{+}(x, t) & \text { se } & \frac{s}{\phi}<-1 \\
V^{-}(x, t) & \text { se } & \frac{s}{\phi}>+1 \\
k s \quad \text { se } & -1<\frac{s}{\phi}<1
\end{array}\right.
$$

onde $\phi$ é o valor da camada limite e $k$ ganho necessário para excitar a entrada $u$ do sistema em estudo.

A equação (51) substitui a função sinal utilizada na equação (50) pela função sat, ficando portanto o sistema implementado conforme mostra a Figura 76.

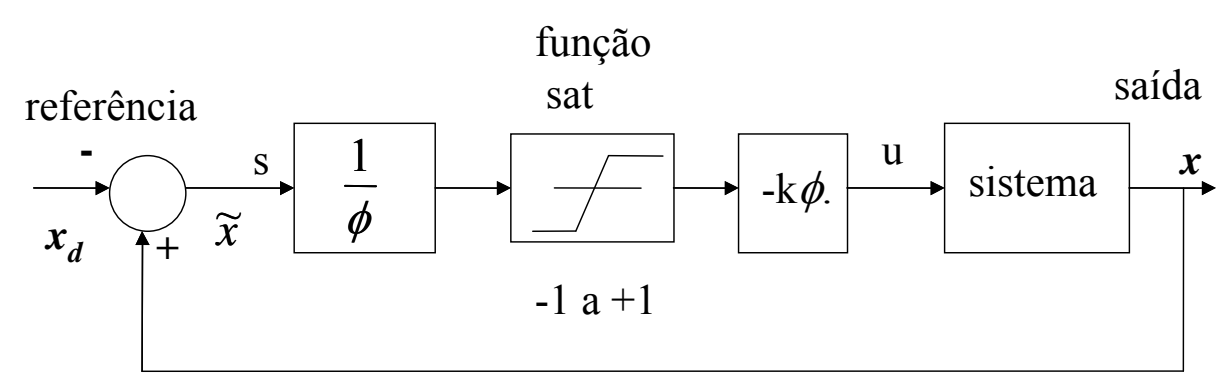

Figura 76 Controle por chaveamento com camada limite

Utilizaram-se $\phi=0,2$ e $k=25$ determinados experimentalmente. Realizaram-se ensaios com um sinal de referência do tipo onda quadrada, com $2 \mathrm{~V}$ de amplitude e período de 20s. Obteve-se o resultado mostrado na Figura 77 . 


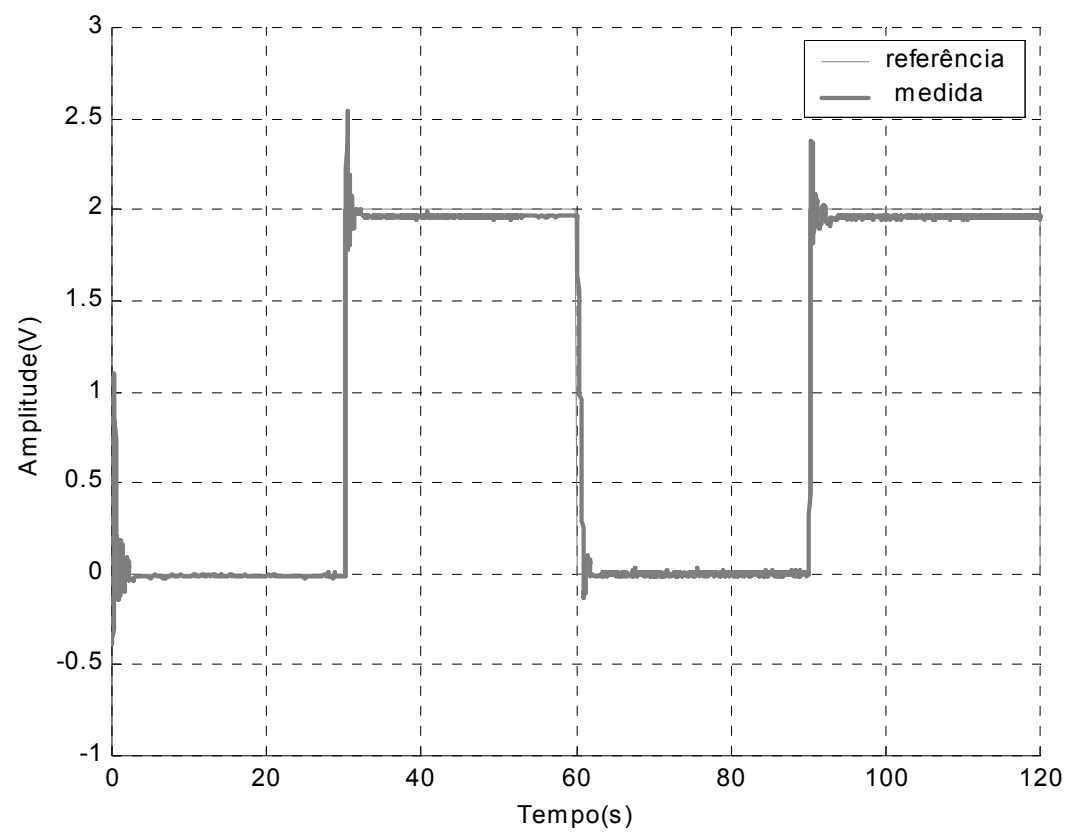

Figura 77 Resultado do efeito do chaveamento com camada limite.

Verifica-se que houve uma boa filtragem no sinal, ocorrendo entretanto um elevado sobre-sinal de aproximadamente $20 \%$ na subida, e um erro de regime permanente de $0,04 \mathrm{~V}$. O tempo de subida é de cerca de 0,5 s e o de descida é de $1,2 \mathrm{~s}$, conforme pode ser visualizado em detalhes na Figura 78.

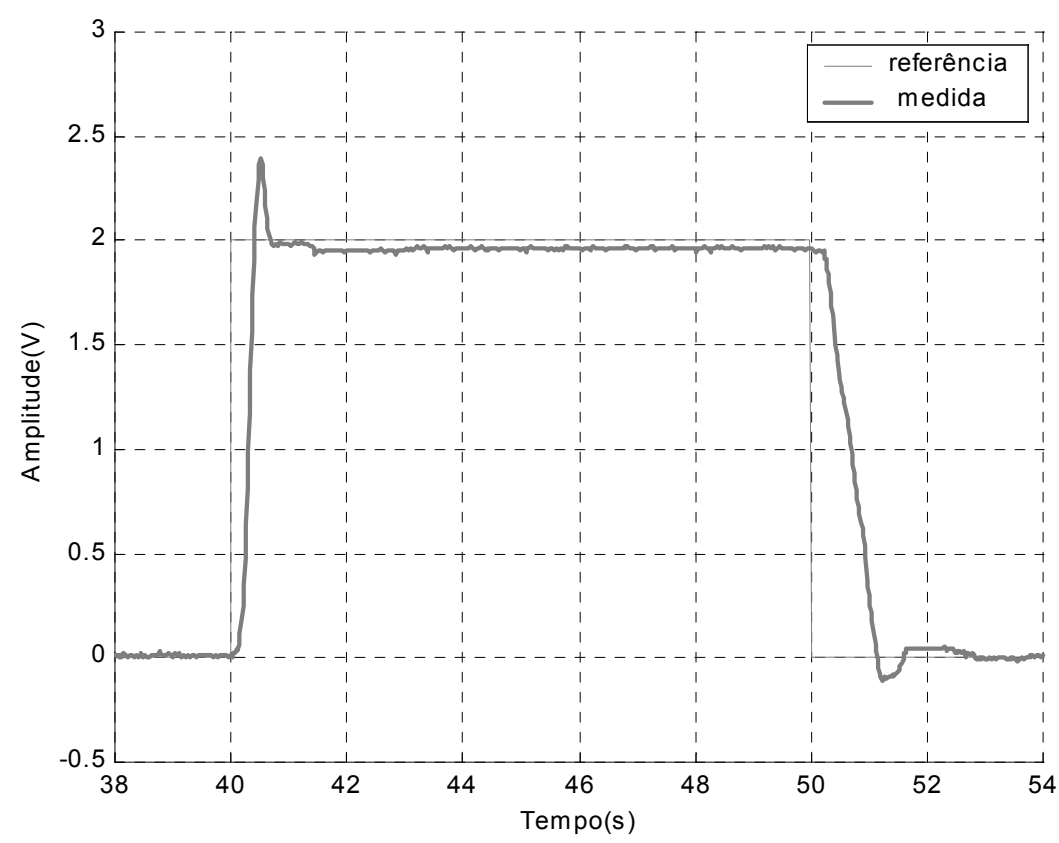

Figura 78 Detalhe da filtragem do controle de chaveamento com camada limite 
Conforme visto anteriormente, o erro de regime permanente ou acompanhamento aumenta com o aumento da filtragem.

Como no caso anterior foram realizados ensaios com um sinal senoidal amplitude $2 \mathrm{~V}$ e período variável conforme mostram os gráficos a seguir (Figura 79, Figura 80, Figura 81 e Figura 82).

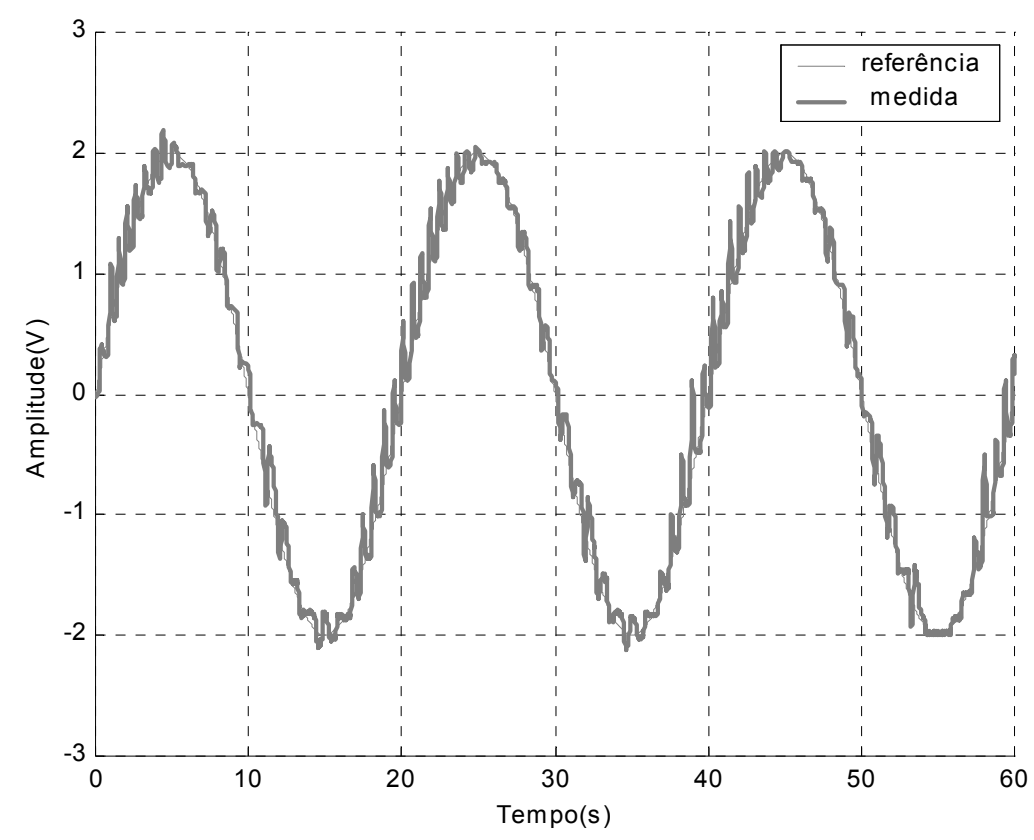

Figura 79 Filtragem do chaveamento sobre o sinal de referência sinal senoidal $2 \mathrm{~V}$ e $\mathrm{T}=20 \mathrm{~s}$ 


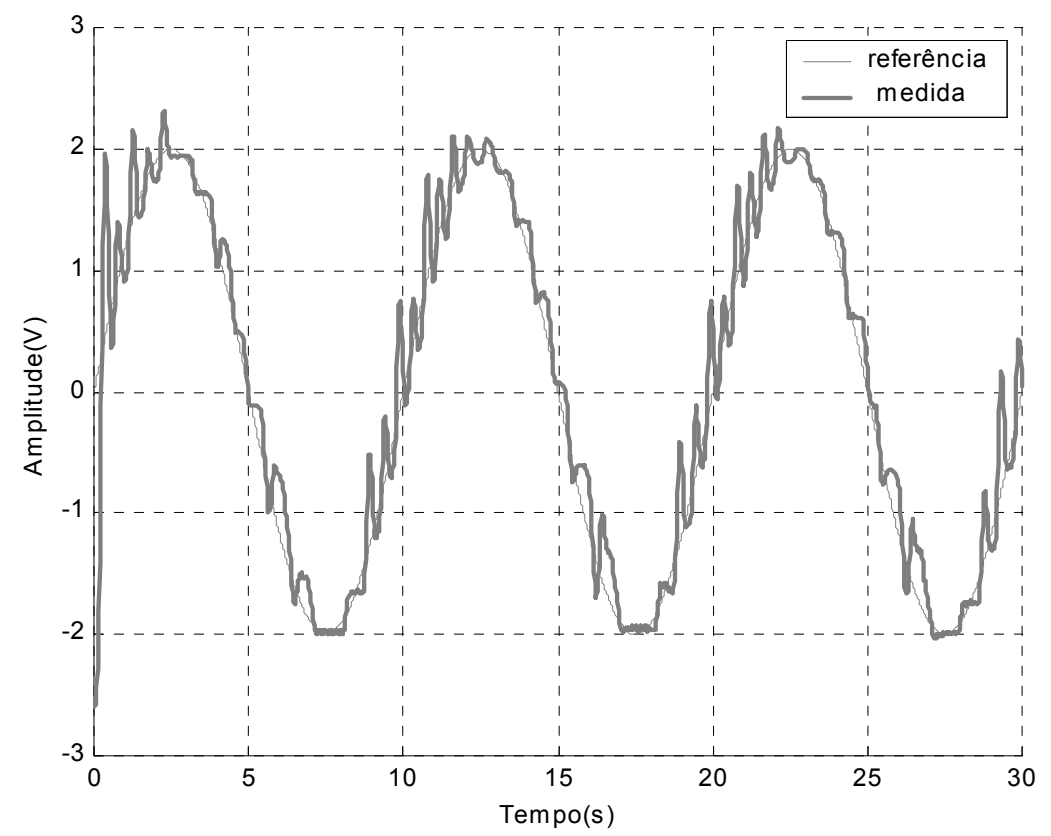

Figura 80 Filtragem do chaveamento sobre o sinal de referência sinal senoidal $2 \mathrm{~V}$ e $T=10 \mathrm{~s}$

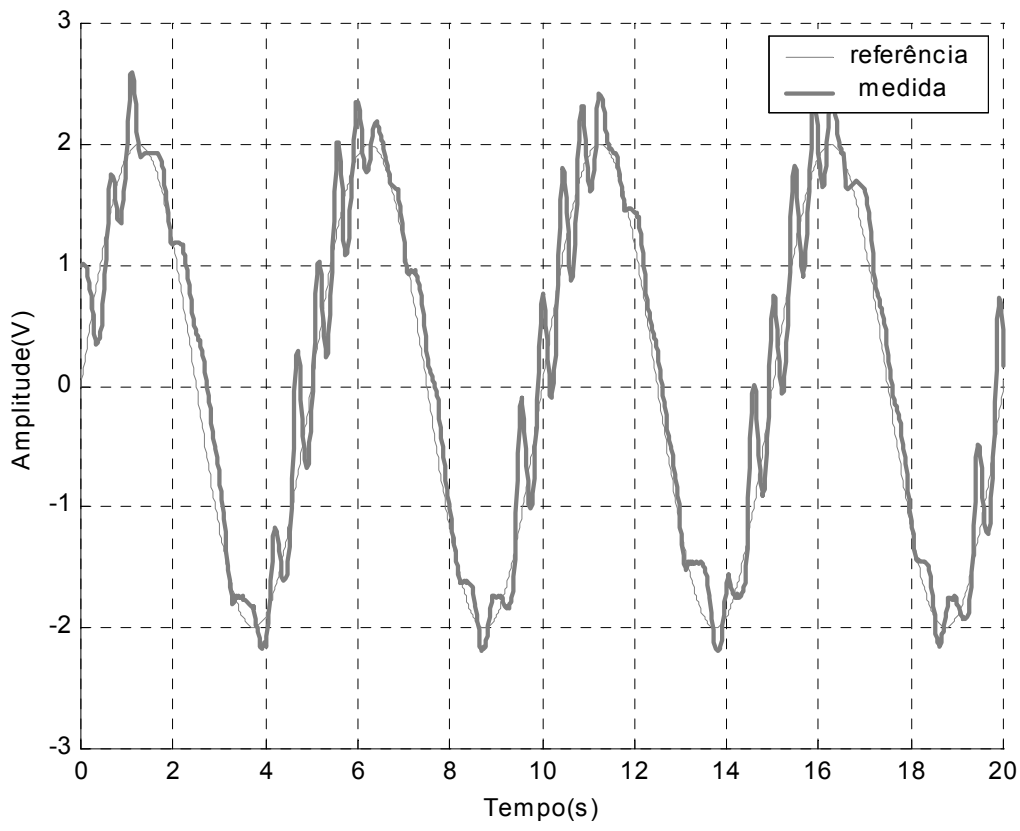

Figura 81 Filtragem do chaveamento sobre o sinal de referência sinal senoidal $2 \mathrm{~V}$ e $\mathrm{T}=5 \mathrm{~s}$ 


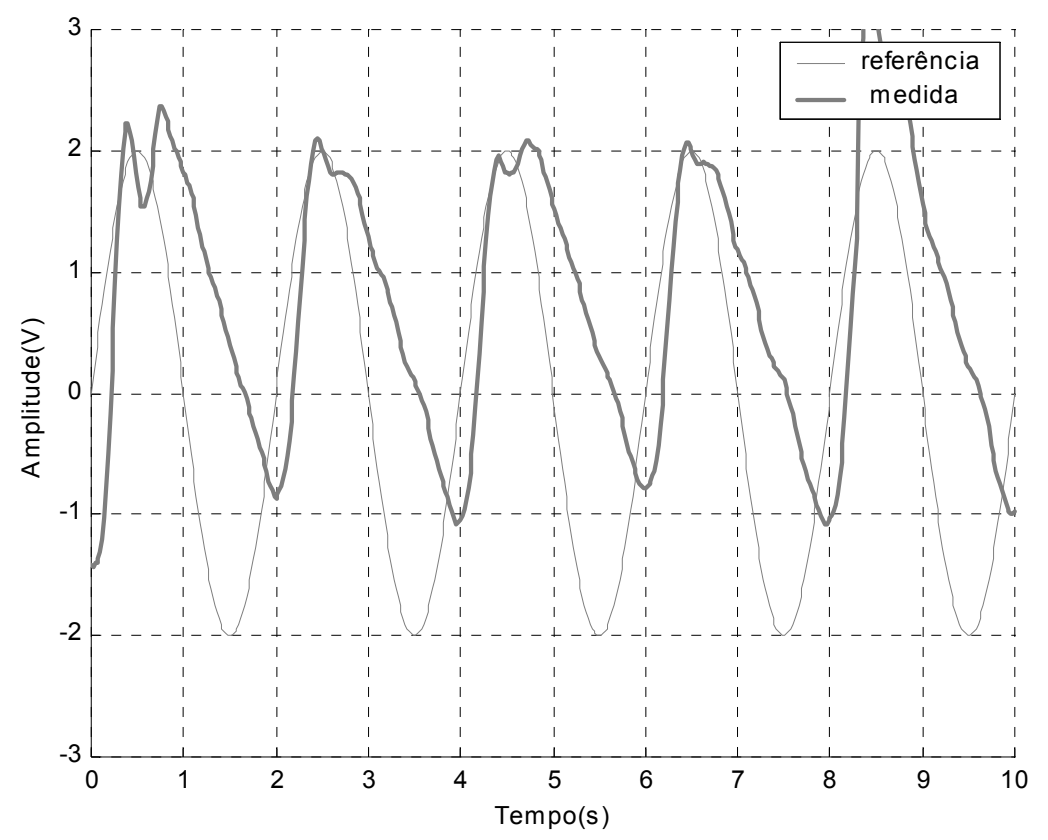

Figura 82 Filtragem do chaveamento sobre o sinal de referência sinal senoidal $2 \mathrm{~V}$ e $T=2 \mathrm{~s}$

Verifica-se que, como no caso do chaveamento simples, com o aumento da freqüência o sistema, aumentam as oscilações espúrias e há uma degradação do desempenho.

Como no caso anterior, o controlador passa a não mais acompanhar o sinal de referência com o aumento da amplitude e freqüência, e há uma atenuação do sinal de saída do atuador. É portanto necessário um sistema de controle dotado de maior "inteligência" para compensar esses efeitos, que será objeto de estudo no próximo capítulo com a implementação do controle por modos deslizantes (sliding mode control) acoplado à linearização por realimentação. 


\section{PROJETO DE CONTROLE POR MODOS DESLIZANTES E LINEARIZAÇÃO POR REALIMENTAÇÃO}

Neste capítulo será realizado um projeto completo de controle por modos deslizantes levando-se em conta o modelo matemático do atuador SMA em estudo. Em seguida serão realizados ensaios práticos para sintonizar parâmetros do controlador SMC (sliding mode control), visando otimizar o desempenho do atuador. Serão comparados os resultados obtidos com o controlador PID. Finalmente será feita uma avaliação do desempenho do sistema de controle com a mudança dos parâmetros do controlador SMC.

\subsection{Projeto do controlador SMC}

A fim de aplicar a teoria de controle por modos deslizantes (sliding mode control) acoplado à linearização por realimentação (feedback linearization) no atuador SMA, o modelo que foi anteriormente obtido no capítulo 4 deve ser adaptado, seguindo a formulação dada em Slotine e Li (1991).

Após algumas manipulações algébricas usando as equações (1) e (5), a dinâmica da transformação de fase pode ser escrita como:

$\dot{\xi}=f(\xi)+b(\xi) \cdot u$

com:

$f(\xi)=\frac{-a}{\xi_{0} m c_{P}}\left(\xi_{0}(\xi-k)-(\xi-k)^{2}\right)\left(h A T_{a m b}+c T_{P}-(h A+c)\left(\frac{1}{a} \ln \left(\frac{\xi_{0}}{\xi-k}-1\right)+b\right)\right)$

$b(\xi)=\frac{-a}{\xi_{0} m c_{P}}\left(\xi_{0}(\xi-k)-(\xi-k)^{2}\right) R$ 
$u=i^{2}$

Modificando-se a equação (5) temos:

$\xi=\frac{\xi_{0}}{1+\exp [a(T-b)]}+k$ (aquecimento/resfriamento)

onde:

$a=\frac{6.2}{A_{f}-A_{s}} ; b=\frac{A_{s}+A_{f}}{2} ; \xi_{0}=\xi_{M} ; k=0$ se $\dot{T}>0$
$a=\frac{6.2}{M_{s}-M_{f}} ; b=\frac{M_{s}+M_{f}}{2} ; \xi_{0}=1-\xi_{A} ; k=\xi_{A}$ se $\dot{T}<0$

Usando (1) e (16), substituindo na equação (12), a dinâmica do movimento pode ser escrita como:

$$
I \ddot{x}+c \dot{x}+\frac{K_{0}(1-\xi)}{n^{2}} x=-m_{L} g+\frac{K_{0}(1-\xi)}{n} \Delta
$$

Sendo: $I=\left(J / r_{2}^{2}+m_{L}\right) ; K_{0}=E_{A} A_{\text {fio }} / l_{0}$ e $\Delta=0.04 l_{\text {fio }}$. Na equação (52) e (58), a variável $x$ é medida, mas a variável $\xi$ deve ser estimada. Isso pode ser feito considerando uma aproximação quase estática para (58), fazendo $\dot{x}=\ddot{x}=0$, que resulta :

$$
\hat{\xi}=1-\frac{m_{L} g}{K_{0}\left(\frac{\Delta}{n}-\frac{x}{n^{2}}\right)}
$$

Diferenciando (58) e usando (52) obtém-se o modelo do atuador SMA adequado para aplicar o controle por modos deslizantes, conforme proposto por Slotine e Li (1991):

$$
\dddot{x}=f(\mathbf{x})+b(\mathbf{x}) \cdot u
$$


com :

$\mathbf{x}=\left(\begin{array}{llll}\xi & x & \dot{x} & \ddot{x}\end{array}\right)^{T}$

$f(\mathbf{x})=\frac{-c}{I} \ddot{x}-\frac{K_{0}(1-\xi)}{I n^{2}} \dot{x}+\left(\frac{K_{0} x}{I n^{2}}-\frac{K_{0} \Delta}{I n}\right) f(\xi) \mathrm{e}$

$b(\mathbf{x})=\left(\frac{K_{0} x}{I^{2}}-\frac{K_{0} \Delta}{I n}\right) b(\xi)$

Assim, a variável de controle $u=i^{2}$ é dada por:

$u=\frac{1}{\hat{b}(\mathbf{x})}\left(-\hat{f}(\mathbf{x})+\dddot{x}_{d}-2 \lambda \ddot{\widetilde{x}}-\lambda^{2} \dot{\widetilde{x}}\right)-K_{S M} \operatorname{sat}(s / \phi)$

Como o sistema obtido é de terceira ordem, aplicando-se a equação (31), a superfície deslizante $s(x, t)$ fica: $s=\ddot{\widetilde{x}}+2 \lambda \dot{\widetilde{x}}+\lambda^{2} \widetilde{x}$. As funções $\hat{f}(\mathbf{x})$ e $\hat{b}(\mathbf{x})$ são as melhores estimativas das funções do modelo (60), considerando os valores validados dos parâmetros e a estimativa da variável $\xi$ dada em (59) $x_{d}$ é a posição desejada da carga do atuador (set-point), $\widetilde{x}=x-x_{d}$ (erro de acompanhamento), $\lambda$ é uma constante positiva refere-se à freqüência de corte do sistema, $\phi$ é a espessura da camada limite para evitar oscilações de chaveamento e $K_{S M}$ é o ganho de controle relativo ao erro de modelagem.

\subsection{Resultados experimentais}

A lei de controle anteriormente desenvolvida foi aplicada no protótipo experimental a fim de se avaliar o desempenho do sistema em malha fechada.

Calculou-se o parâmetro $\lambda$, considerando-se os critérios adotados no capítulo 7 sugeridos em Slotine e Li (1991). Utilizou-se uma freqüência de amostragem de $200 \mathrm{~Hz}$, fazendo $\lambda<1 / 5$ da freqüência de amostragem, obtendo-se $\lambda=40$. Os outros critérios como freqüência ressonante não modelada e maior tempo de atraso de transporte não foram considerados, uma vez que o sistema não possui freqüências de ressonância e tempo de atraso de transporte não foi determinado com precisão. Adotou-se, portanto $\lambda=40$ como uma primeira tentativa de sintonia do sistema. 
A espessura da camada limite $\phi$ pode ser estimada a partir do erro desejado, pela relação $|\widetilde{x}(t)|<\frac{\phi}{\lambda^{n-1}}=\varepsilon$. Impondo-se um erro de $10^{-4}$ e, como o sistema é de terceira ordem $(n=3)$, obtém-se $\phi=0,16$.

O ganho $K_{S M}=250$ foi obtido experimentalmente, uma vez que este depende das incertezas do modelo conforme mostra a equação (42) e deve satisfazer a equação (33), que garante a estabilidade do sistema (SLOTINE; LI, 1991).

Implementou-se no Matlab/Simulink o controlador SMC com os parâmetros acima calculados. A malha de controle é mostrada na Figura 83.

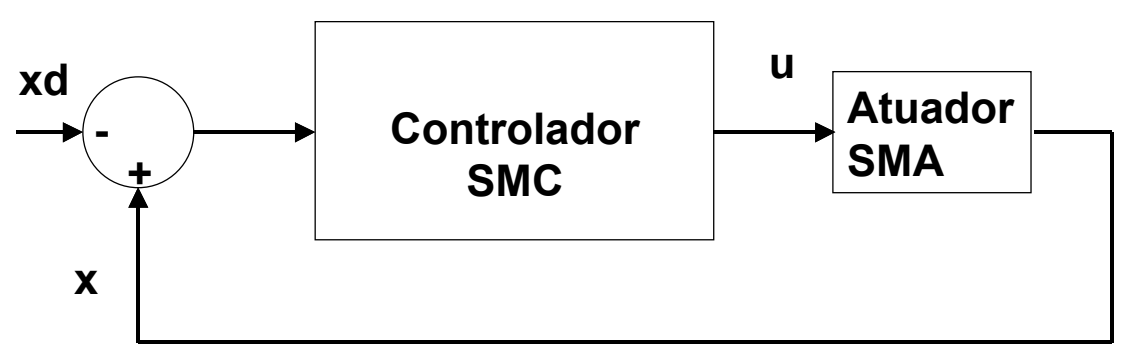

Figura 83 Controle por modos deslizantes SMC

onde xd é o sinal de referência, x é o sinal de medida e u é sinal de controle.

O sinal de referência aplicado no sistema foi um degrau suavizado, $x d=x i+\frac{\Delta x d}{2}[\tanh (10 t-105)+1]$, sendo $x i$ a posição inicial, $\Delta x d$ deslocamento da carga $(\mathrm{m})$ e $t$ o vetor de tempo (s).

Aplicando-se o sinal de referência (degrau suavizado) com amplitude $\Delta x d=2,5 \mathrm{~cm}$, posição inicial $x i=2 \mathrm{~cm}$, e parâmetros de controle $(\lambda=40, \phi=0,16$; $\left.K_{S M}=250\right)$, obtém-se: 


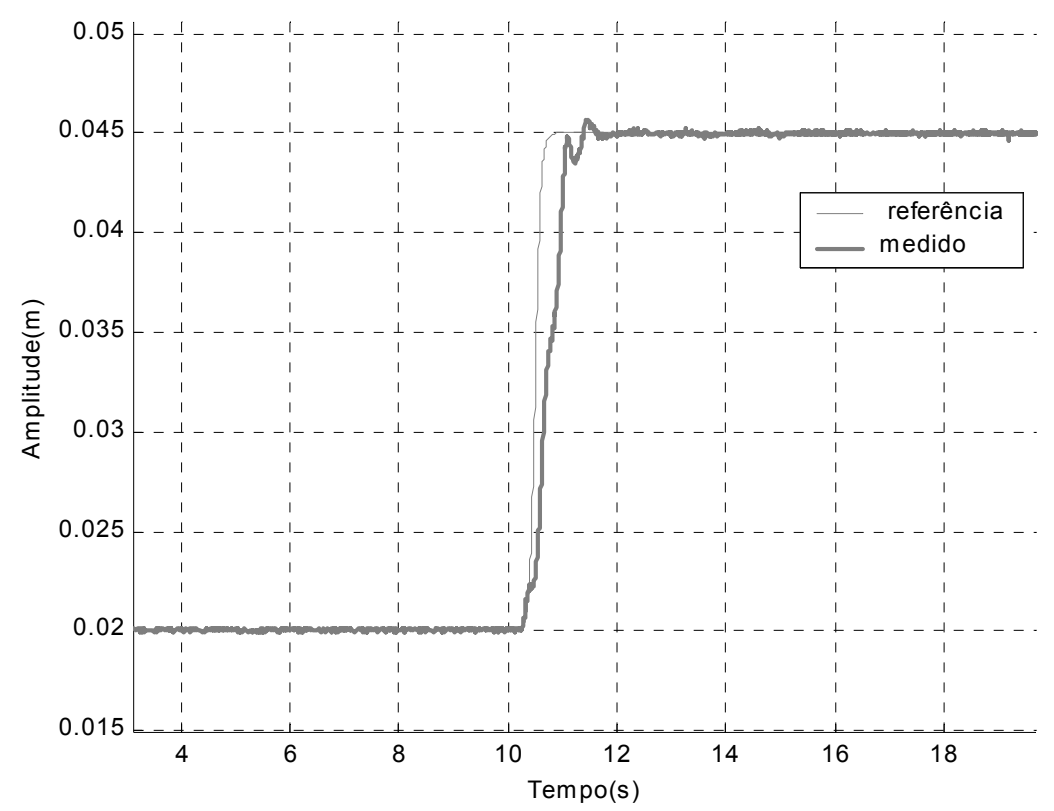

Figura 84 Resposta do atuador SMA degrau suavizado de $2,5 \mathrm{~cm}$ com : $\lambda=40 ; \phi=0,16$ e $\mathrm{K}_{\mathrm{SM}}=250$

Obteve-se, como resultado, tempo de acomodação de 0,4s com sobre-sinal máximo de 1,33\% conforme mostra a Figura 84 . Verifica-se que houve uma resposta rápida e um sobre-sinal bastante satisfatório. Adotou-se como tempo de acomodação o tempo que o sinal leva para atingir 5\% do sinal de referência (critério dos $5 \%$ ).

Conforme mostra a Figura 85, o erro $(x-x d)$ obtido após o sistema alcançar o

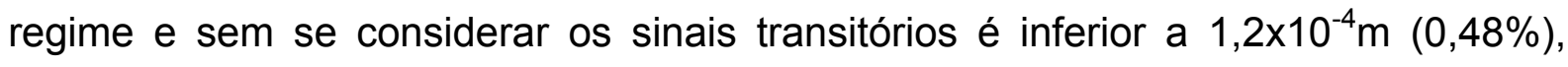
sendo este valor bem satisfatório pela imposição do projeto.

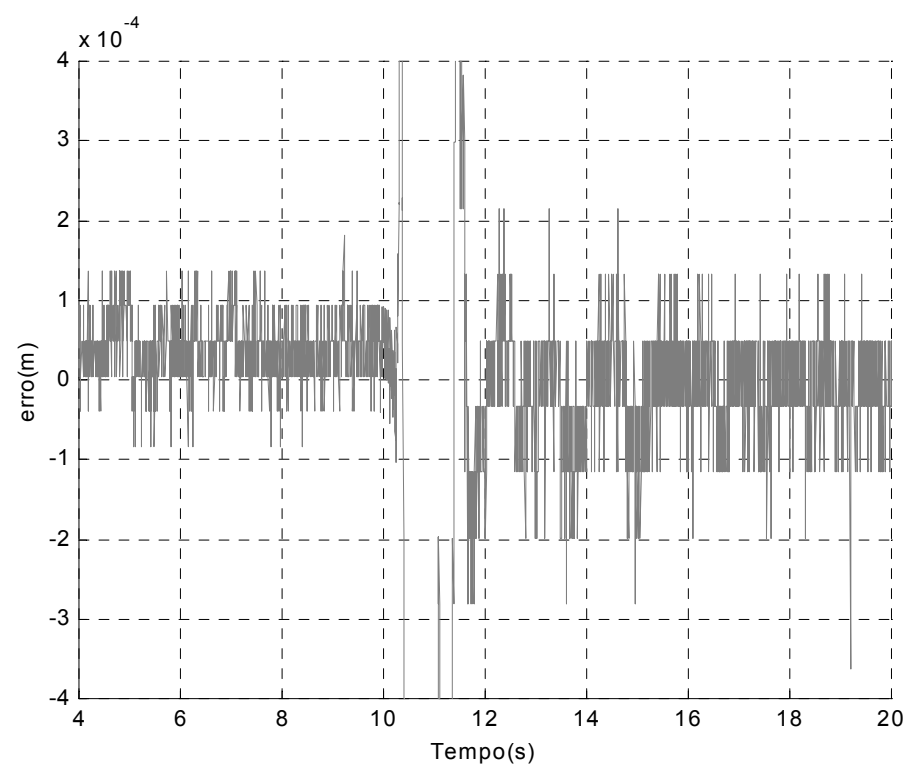

Figura 85 Sinal de erro ( $x-x d$ ) com : $\lambda=40 ; \phi=0,16$ e $K_{\mathrm{SM}}=250$ 
Aplicou-se agora o sinal de referência (degrau suavizado) de descida com amplitude $\Delta x d=-2,5 \mathrm{~cm}$, e posição inicial $x i=4,5 \mathrm{~cm}$.

Obteve-se tempo de acomodação de $0,75 \mathrm{~s}$ sem sobre-sinal, conforme mostra a Figura 86. Verifica-se que houve uma resposta mais lenta que na subida e um sobre-sinal bastante satisfatório. O erro de acompanhamento após o sistema ter entrado em regime permanente é $0,5 \times 10^{-4} \mathrm{~m}$, dentro do valor estipulado no projeto.

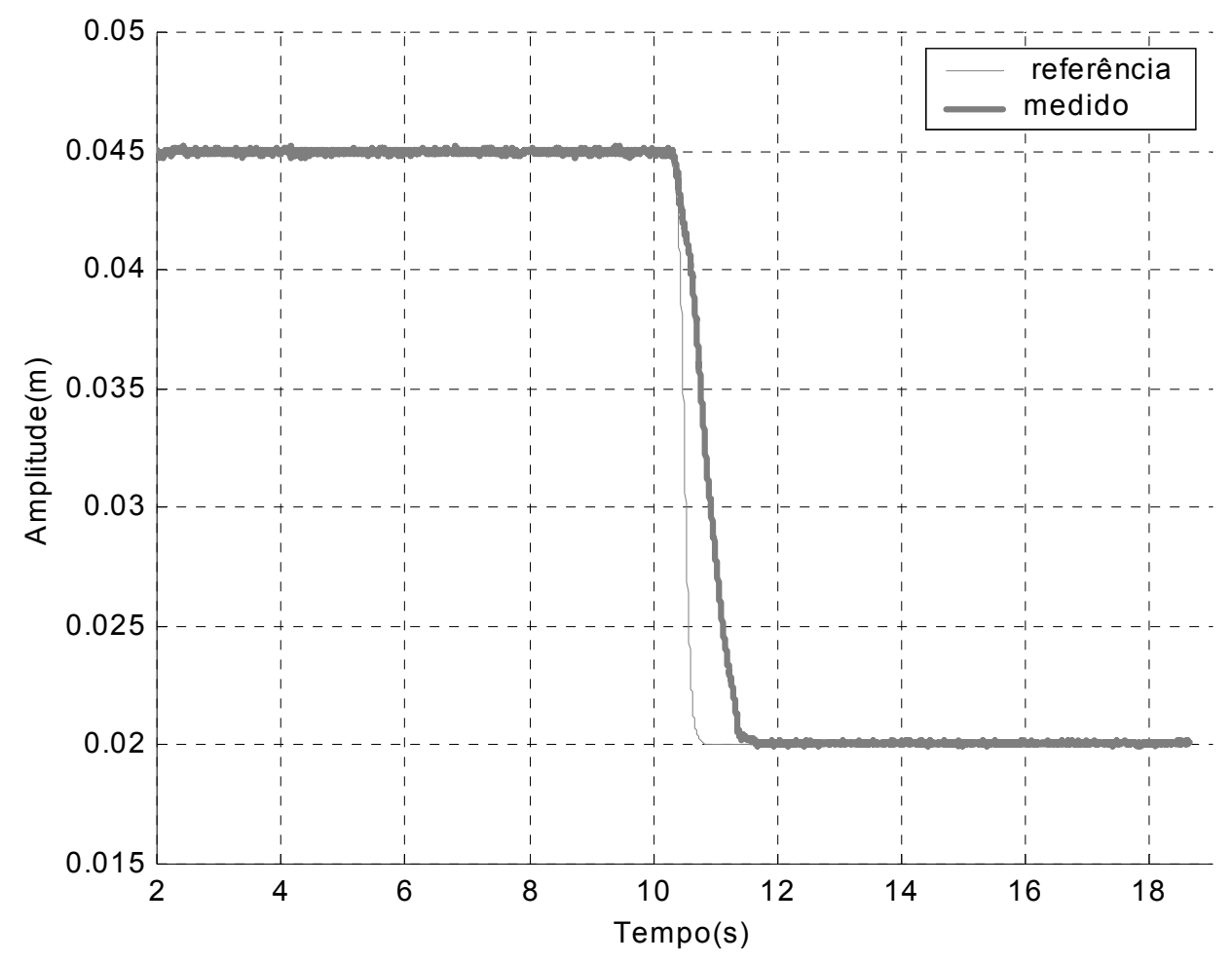

Figura 86 Resposta do atuador SMA degrau suavizado $\left(-2,5 \mathrm{~cm}\right.$ com : $\lambda=40 ; \phi=0,16$ e $\mathrm{K}_{\mathrm{SM}}=250$ )

\subsection{Ensaios com sinais de referência senoidal utilizando o controlador SMC}

Visando verificar o desempenho do sistema de controle SMC foram realizados ensaios com sinais de referência senoidais, com amplitudes e períodos variáveis.

Mantendo-se os mesmos parâmetros utilizados para o ensaio em degrau suavizado, os resultados obtidos para os sinais senoidais, com amplitude de $1 \mathrm{~cm}$ (centralizado em $2 \mathrm{~cm}$ ) podem ser visualizados na Figura 87.

Verificou-se que houve um bom acompanhamento do sinal de referência, sendo que para o pior caso $(\mathrm{T}=3 \mathrm{~s})$ o sobre-sinal nos picos foram de $6 \%$, quando o sistema começa a perder desempenho. Obteve-se uma largura de faixa de 
aproximadamente de $0,64 \mathrm{~Hz}(\mathrm{~T}=1,56 \mathrm{~s})$, conforme pode ser visualizado na Figura 88, na qual os sobre-sinais nos picos foram de 5,6\%. Acima desta freqüência o atuador não consegue mais acompanhar o sinal de referência, ocorrendo um grande erro de acompanhamento $(78 \%)$.

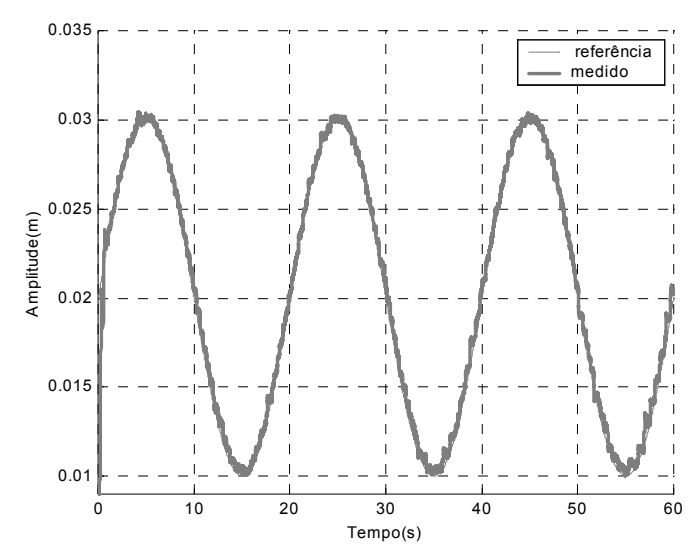

$\mathrm{T}=20 \mathrm{~s}$

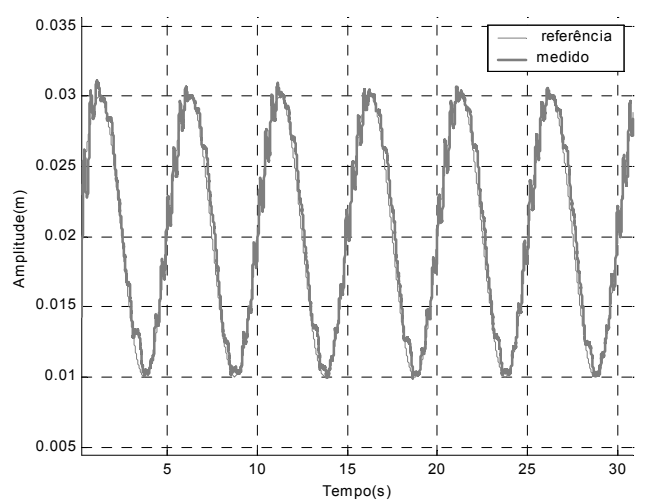

$\mathrm{T}=5 \mathrm{~s}$

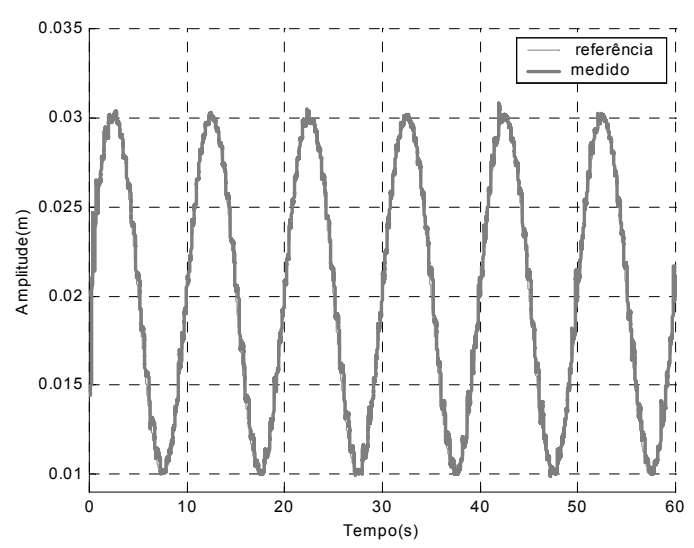

$\mathrm{T}=10 \mathrm{~s}$

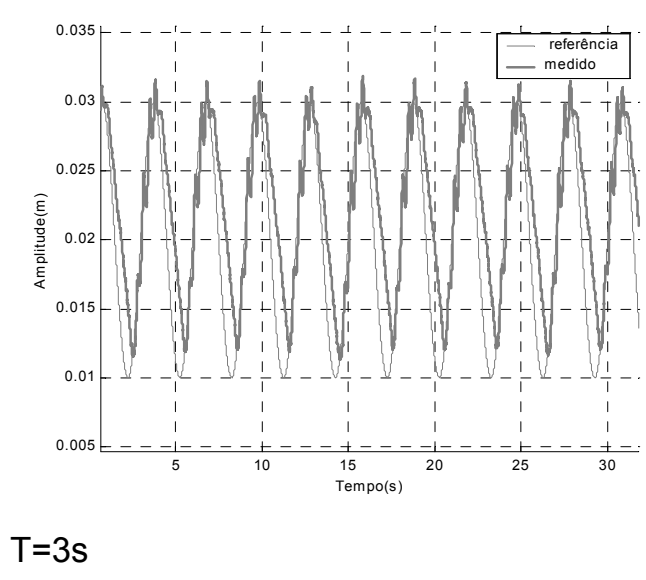

Figura 87 Resposta do atuador $\operatorname{com} \lambda=40 ; \phi=0,16$ e $K_{S M}=250$ (sinais referência senoidais $1 \mathrm{~cm}$ )

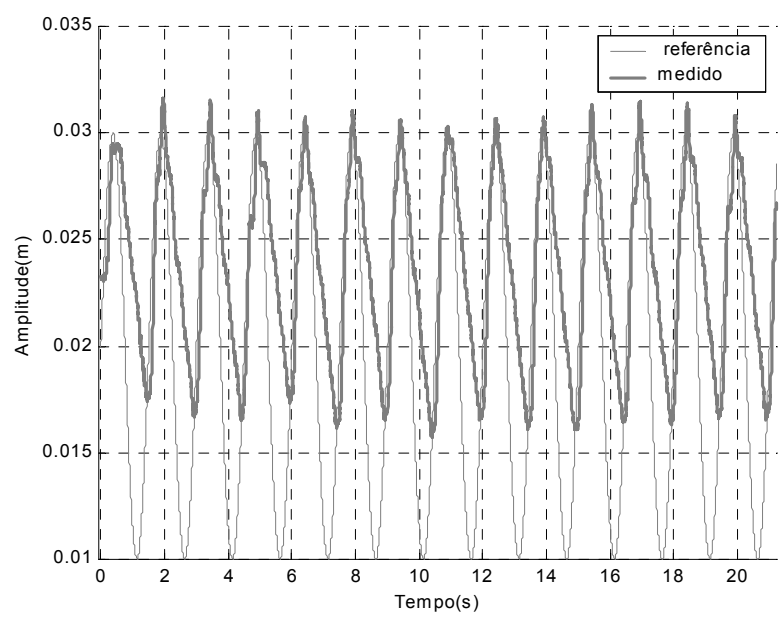

Figura 88 Resposta do sistema com: $\lambda=40 ; \phi=0,16$ e $K_{S M}=250$ (sinal senoidal $1 \mathrm{~cm}$ com $T=1,56 \mathrm{~s}$ ) 
A fim de se avaliar o desempenho desse projeto em relação à mudança dos níveis dos sinais de referência, foram refeitos os ensaios com sinais senoidais com amplitude de $2 \mathrm{~cm}$ (centralizado em $2 \mathrm{~cm}$ ). Mantendo-se os mesmos parâmetros anteriores os resultados obtidos estão mostrados na Figura 89.

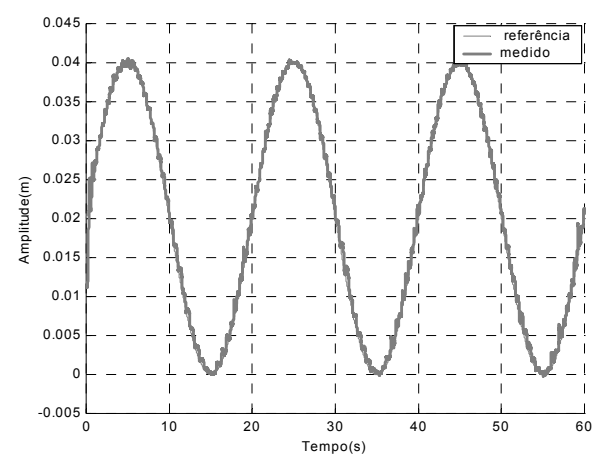

$\mathrm{T}=20 \mathrm{~s}$

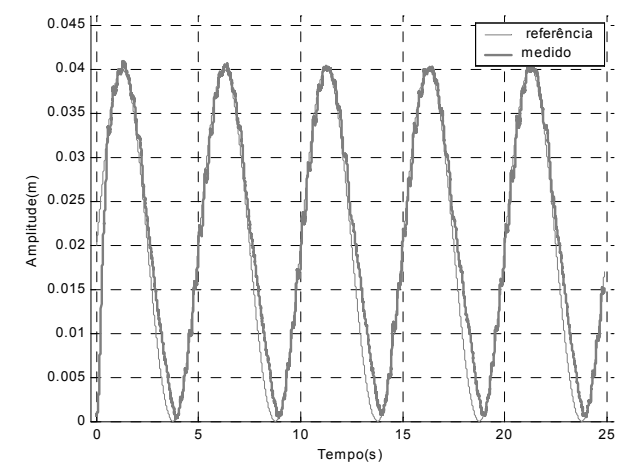

$\mathrm{T}=5 \mathrm{~s}$

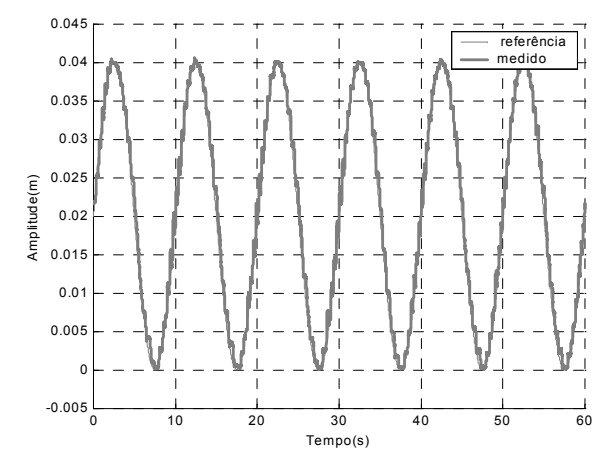

$\mathrm{T}=10 \mathrm{~s}$

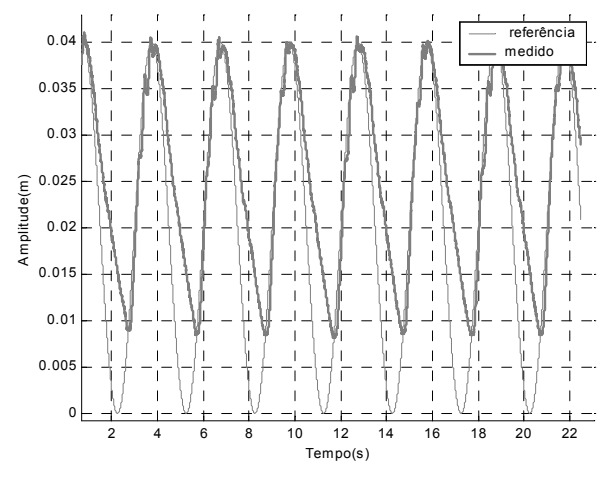

$\mathrm{T}=3 \mathrm{~s}$

Figura 89 Resposta do atuador $\operatorname{com} \lambda=40 ; \phi=0,16$ e $\mathrm{K}_{\mathrm{SM}}=250$ (sinais senoidais $2 \mathrm{~cm}$ )

Pela análise dos gráficos da Figura 89, verifica-se que aumentando-se a freqüência do sinal de referência o desempenho do sistema começa a piorar, a partir do período de $\mathrm{T}=5 \mathrm{~s}$, como ocorre para amplitudes de $1 \mathrm{~cm}$.

Comparando-se os resultados com amplitude de $2 \mathrm{~cm}$ e $1 \mathrm{~cm}$, verifica-se que 0 sistema até $\mathrm{T}=5 \mathrm{~s}$ apresenta comportamento semelhante. Este fato comprova a vantagem da aplicação do controle não linear, já que mantém-se o desempenho do sistema (que é fortemente não linear) para as diversas faixas de operação. Para $\mathrm{T}<5 \mathrm{~s}$, o desempenho para amplitude $2 \mathrm{~cm}$ é degradado, provavelmente devido à influência da saturação do controle.

Alterando-se para sinal de referência com amplitude de $0,5 \mathrm{~cm}$ (centralizado em $2 \mathrm{~cm}$ ), os resultados obtidos são mostrados na Figura 90. 
De forma análoga, para amplitude de $0,5 \mathrm{~cm}$ o desempenho do sistema de controle é mantido aproximadamente igual aos casos anteriores.

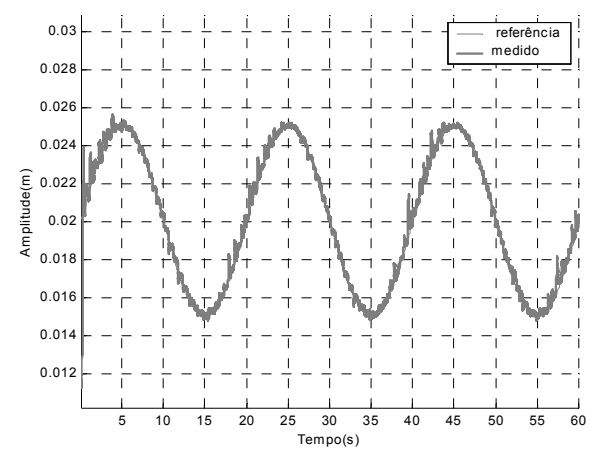

$\mathrm{T}=20 \mathrm{~s}$

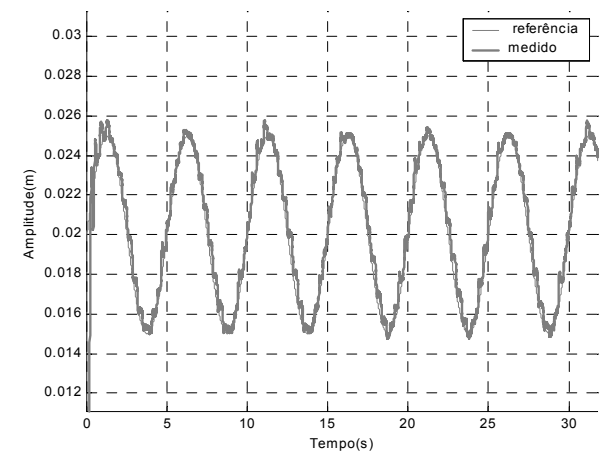

$\mathrm{T}=5 \mathrm{~s}$

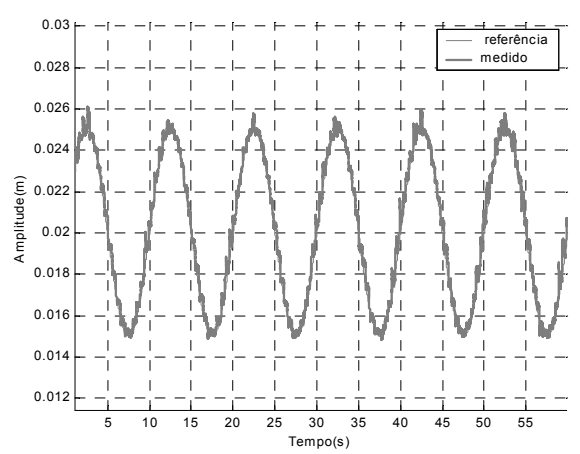

$\mathrm{T}=10 \mathrm{~s}$

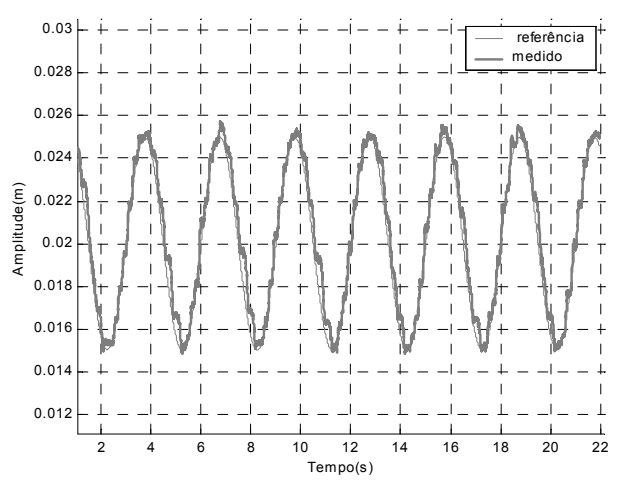

$T=3 \mathrm{~s}$

Figura 90 Resposta do atuador $\operatorname{com} \lambda=40 ; \phi=0,16$ e $K_{S M}=250$ (sinais senoidais $0,5 \mathrm{~cm}$ )

O critério para calcular o erro de acompanhamento, foi o mesmo adotado quando se avaliou o desempenho do controlador PID descrito no capítulo 6 ou seja: $e(\%)=\frac{\max (|y-r|)}{\max (|r|)} .100 \%$, após o sistema entrar em regime permanente, sendo:

- e(\%)-porcentagem do erro de acompanhamento

- $y$-Amplitude sinal medido (m)

- $r$-sinal de referência $(m)$.

O erro de acompanhamento para os vários sinais senoidais mostrados nas figuras anteriores (Figura 87, Figura 89 e Figura 90) são apresentados na Tabela 10.

Baseando-se na Tabela 10 verifica-se que o erro de acompanhamento aumenta com o aumento da freqüência, porém o erro praticamente se mantém com a variação da amplitude do sinal, com exceção da amplitude $2 \mathrm{~cm} / \mathrm{T}=3 \mathrm{~s}$ (degradado, provavelmente devido à influência da saturação do controle). 
Tabela 10 Erro de acompanhamento do controlador SMC com sinais senoidais

\begin{tabular}{|l|l|l|}
\hline $\begin{array}{l}\text { Onda senoidal } \\
\text { Amplitude/Período }\end{array}$ & $\begin{array}{l}\text { Erro } \\
\text { acompanhamento } \\
\Delta \mathrm{cm}\end{array}$ & $\begin{array}{l}\text { Erro } \\
\text { acompanhamento } \\
\mathrm{e}(\%)\end{array}$ \\
\hline $1 \mathrm{~cm} / \mathrm{T}=20 \mathrm{~s}$ & $0,10 \mathrm{~cm}$ & $10 \%$ \\
\hline $1 \mathrm{~cm} / \mathrm{T}=10 \mathrm{~s}$ & $0,16 \mathrm{~cm}$ & $16 \%$ \\
\hline $1 \mathrm{~cm} / \mathrm{T}=5 \mathrm{~s}$ & $0,2 \mathrm{~cm}$ & $20 \%$ \\
\hline $1 \mathrm{~cm} / \mathrm{T}=3 \mathrm{~s}$ & $0,36 \mathrm{~cm}$ & $36 \%$ \\
\hline $2 \mathrm{~cm} / \mathrm{T}=20 \mathrm{~s}$ & $0,2 \mathrm{~cm}$ & $10 \%$ \\
\hline $2 \mathrm{~cm} / \mathrm{T}=10 \mathrm{~s}$ & $0,3 \mathrm{~cm}$ & $15 \%$ \\
\hline $2 \mathrm{~cm} / \mathrm{T}=5 \mathrm{~s}$ & $0,4 \mathrm{~cm}$ & $20 \%$ \\
\hline $2 \mathrm{~cm} / \mathrm{T}=3 \mathrm{~s}$ & $1,6 \mathrm{~cm}$ & $80 \%$ \\
\hline $0,5 \mathrm{~cm} / \mathrm{T}=20 \mathrm{~s}$ & $0,05 \mathrm{~cm}$ & $10 \%$ \\
\hline $0,5 \mathrm{~cm} / \mathrm{T}=10 \mathrm{~s}$ & $0,075 \mathrm{~cm}$ & $15 \%$ \\
\hline $0,5 \mathrm{~cm} / \mathrm{T}=5 \mathrm{~s}$ & $0,10 \mathrm{~cm}$ & $20 \%$ \\
\hline $0,5 \mathrm{~cm} / \mathrm{T}=3 \mathrm{~s}$ & $0.15 \mathrm{~cm}$ & $30 \%$ \\
\hline
\end{tabular}

\subsection{Comparações de desempenho entre controlador SMC e PID}

A fim de se fazer uma comparação de desempenho do controlador SMC com o controlador PID estudado no capítulo 6, converteram-se as unidades do deslocamento da carga de metros $(m)$ para volts $(V)$, uma vez que todas as medições realizadas no controlador PID foram em volts $(\mathrm{V})$.

Os resultados obtidos foram comparados com o controlador PID (método de ITAE), que gerou os melhores resultados com os parâmetros $P=6,12 ; \quad I=1,72$; $D=1,45$.

Nos ensaios foram utilizados sinais tipo degrau suavizado com $2 \mathrm{~V}$ de amplitude. Na subida a expressão é $x d=1+\tanh (10 t-105)$ e na descida a expressão é $x d=1-\tanh (10 t-105)$, onde $t$ é o tempo (s). As figura seguintes ( Figura $91 \mathrm{e}$ Figura 92), mostram as formas de onda obtidas com o controle SMC, com sinal de referência com degrau suavizado na subida e na descida respectivamente. 


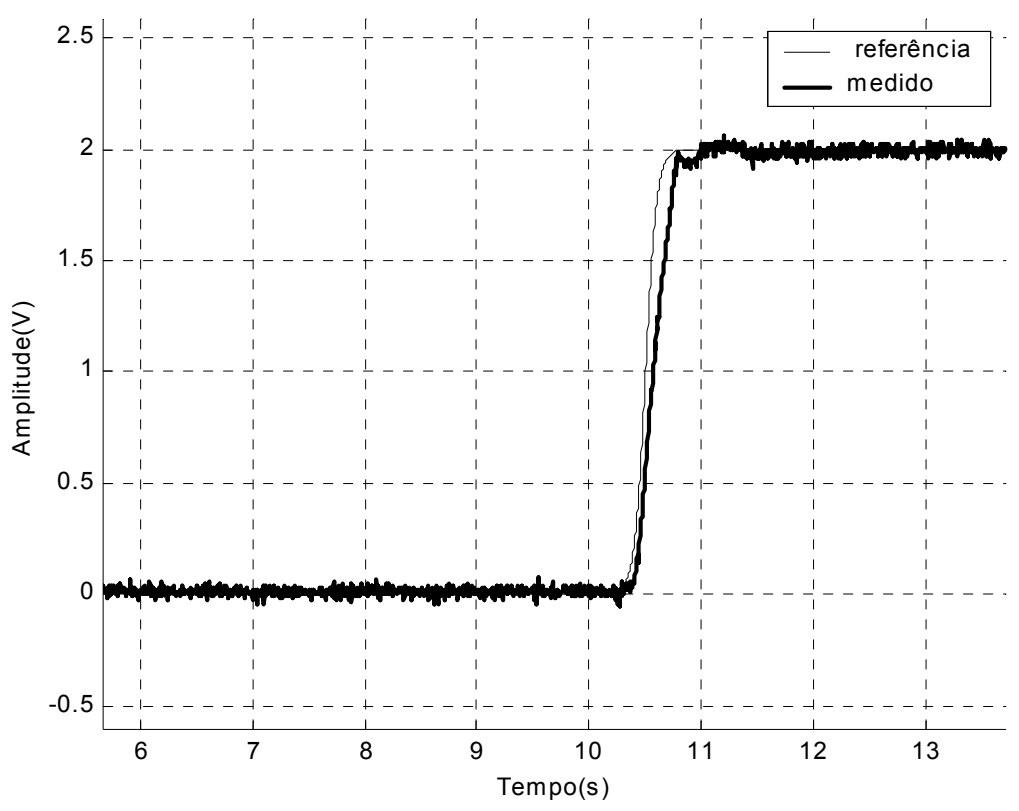

Figura 91 Resposta ao sinal em degrau suavizado $2 \mathrm{~V}$ na subida com controlador SMC

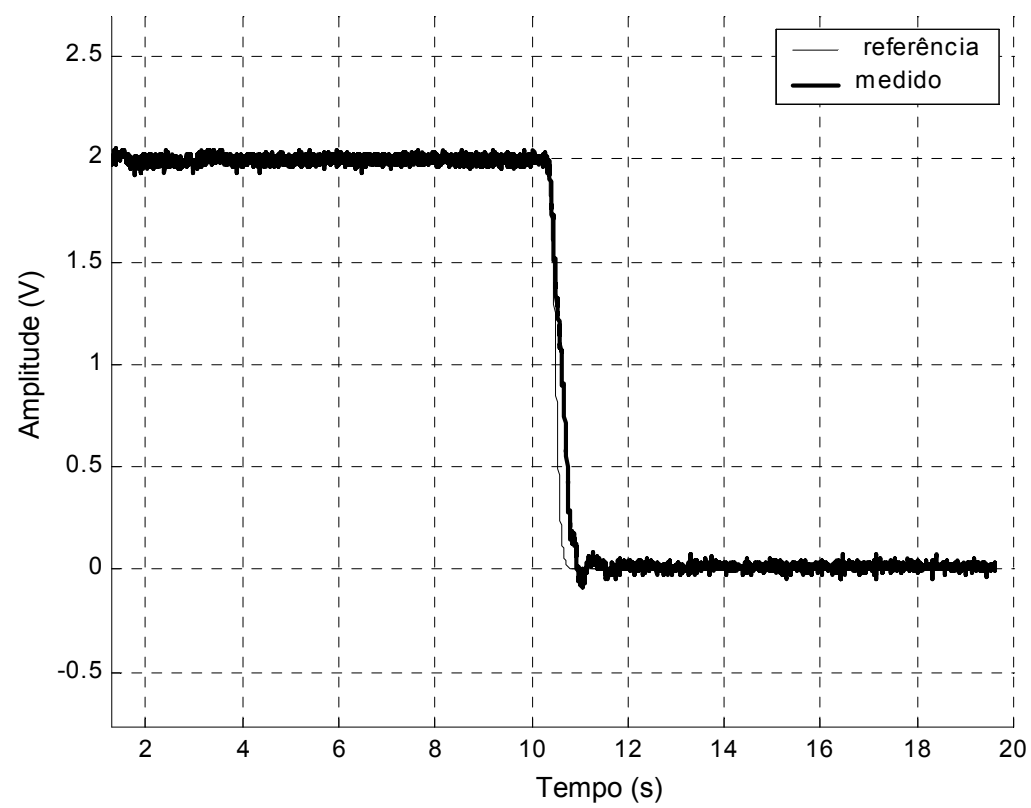

Figura 92 Resposta ao sinal em degrau suavizado $2 \mathrm{~V}$ na descida com controlador SMC 
As figuras seguintes ( Figura 93 e Figura 94), mostram as formas de onda obtidas com o controle PID, com sinal de referência com degrau suavizado na subida e na descida respectivamente.

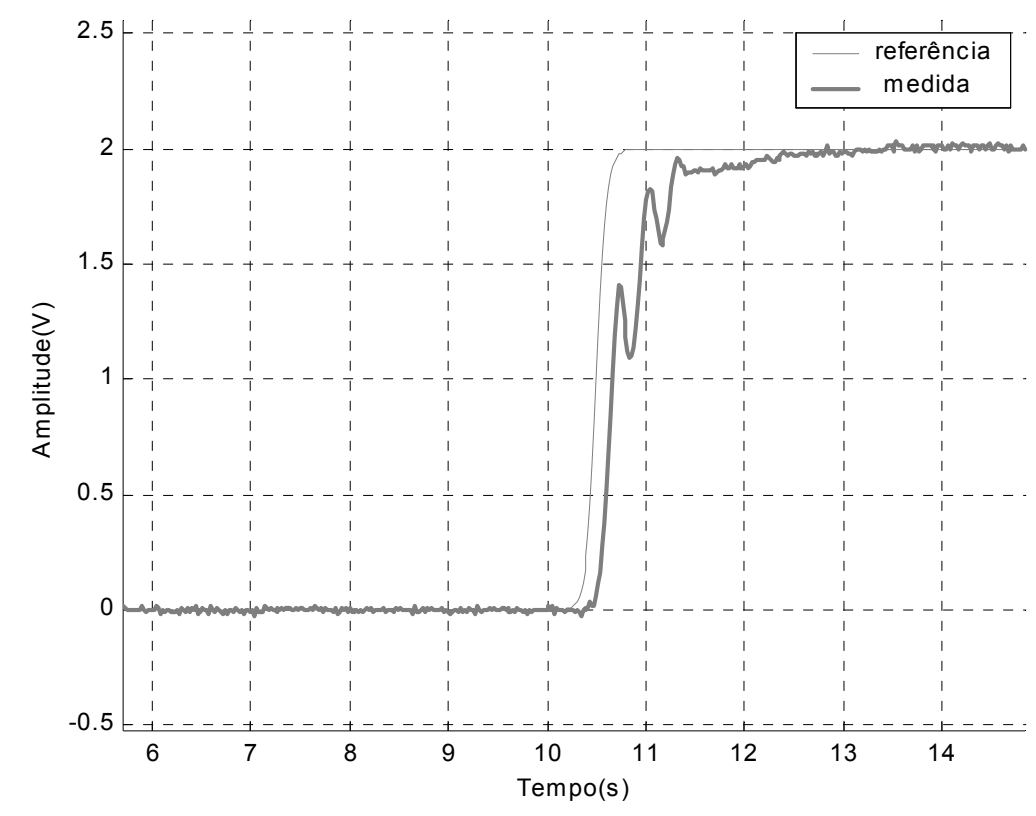

Figura 93 Resposta ao sinal em degrau suavizado $2 \mathrm{~V}$ na subida com controlador PID

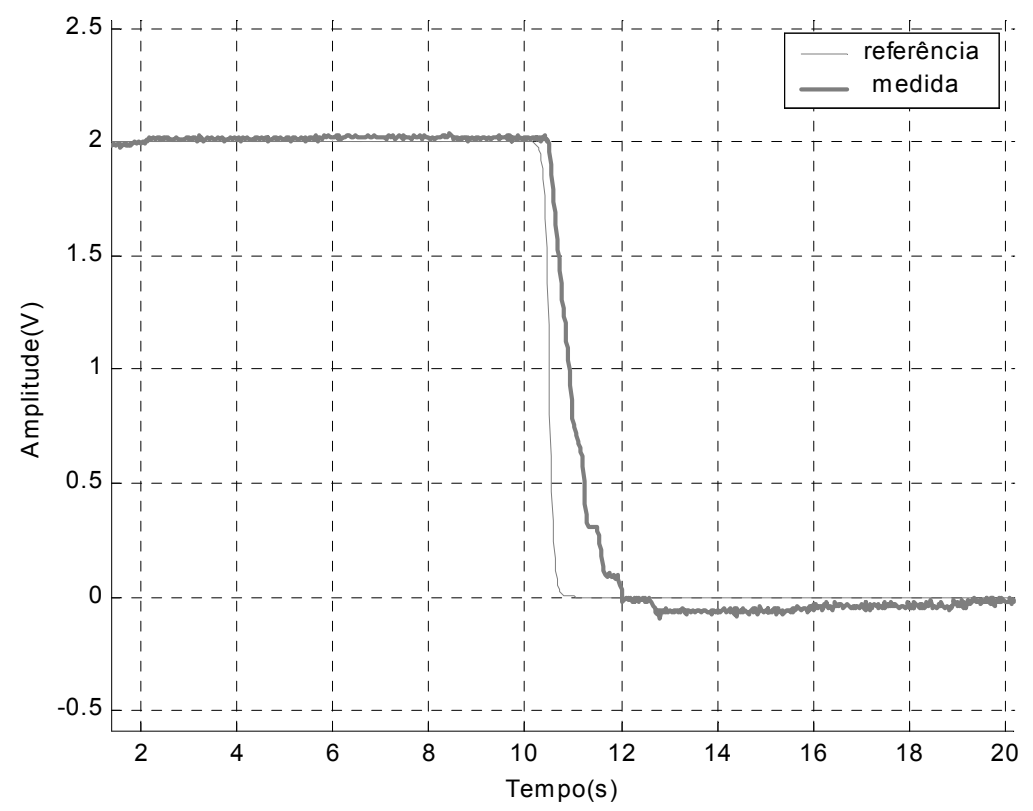

Figura 94 Resposta ao sinal em degrau suavizado $2 \mathrm{~V}$ na descida com controlador PID

A Tabela 11 mostra os resultados obtidos entre os dois sistemas de controle com sinais de referência $2 \mathrm{~V}$ com degrau suavizado. 
Tabela 11 Comparação de desempenho entre controladores modos deslizantes e PID.

\begin{tabular}{|l|l|l|l|l|l|}
\hline Controlador & $\begin{array}{l}\text { Maior erro de } \\
\text { acompanhamento } \\
\text { em regime (\%) }\end{array}$ & $\begin{array}{l}\text { Tempo } \\
\text { acomodação } \\
\text { subida (s) }\end{array}$ & $\begin{array}{l}\text { Tempo } \\
\text { acomodação } \\
\text { descida (s) }\end{array}$ & $\begin{array}{l}\text { Sobre-sinal } \\
\text { Subida (\%) }\end{array}$ & $\begin{array}{l}\text { Sobre-sinal } \\
\text { descida(\%) }\end{array}$ \\
\hline SMC & 1,9 & 0,11 & 0,27 & 2,3 & 4,3 \\
\hline PID & 3,3 & 1,08 & 1,1 & 1,5 & 4,9 \\
\hline
\end{tabular}

Assim, adotando-se os mesmos critérios do capítulo 6, na ocasião em que foi estudado o desempenho do sistema com o controlador PID, os resultados aqui obtidos, mostram que o controlador SMC apresenta desempenho superior ao PID.

Aplicaram-se ao controlador SMC sinais senoidais com os mesmos níveis de amplitude e freqüência que foram testados com o controlador PID no capítulo 6.

Os ensaios realizados com sinais de referência senoidais aplicados no controlador SMC são mostrados nas figuras seguintes (Figura 95, Figura 96, Figura 97 e Figura 98).

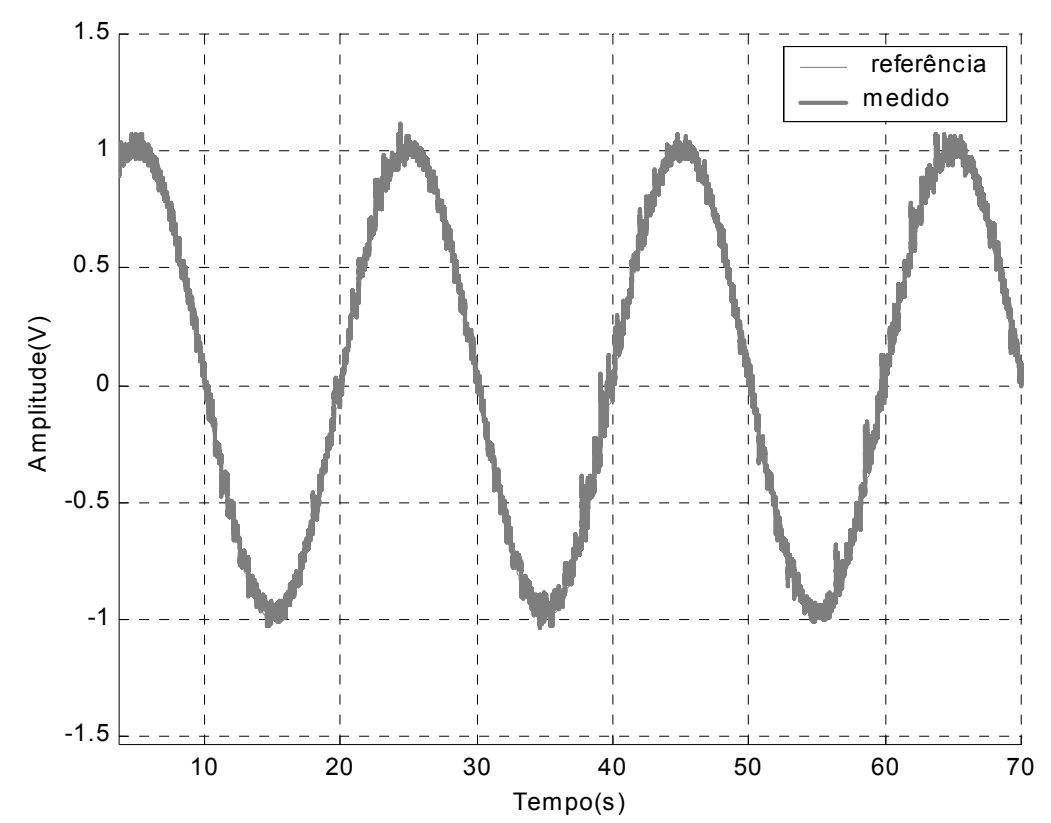

Figura 95 Resposta do controlador SMC com sinal de referência senoidal $1 \mathrm{~V} \mathrm{e} \mathrm{T=20s} \mathrm{.}$ 
102

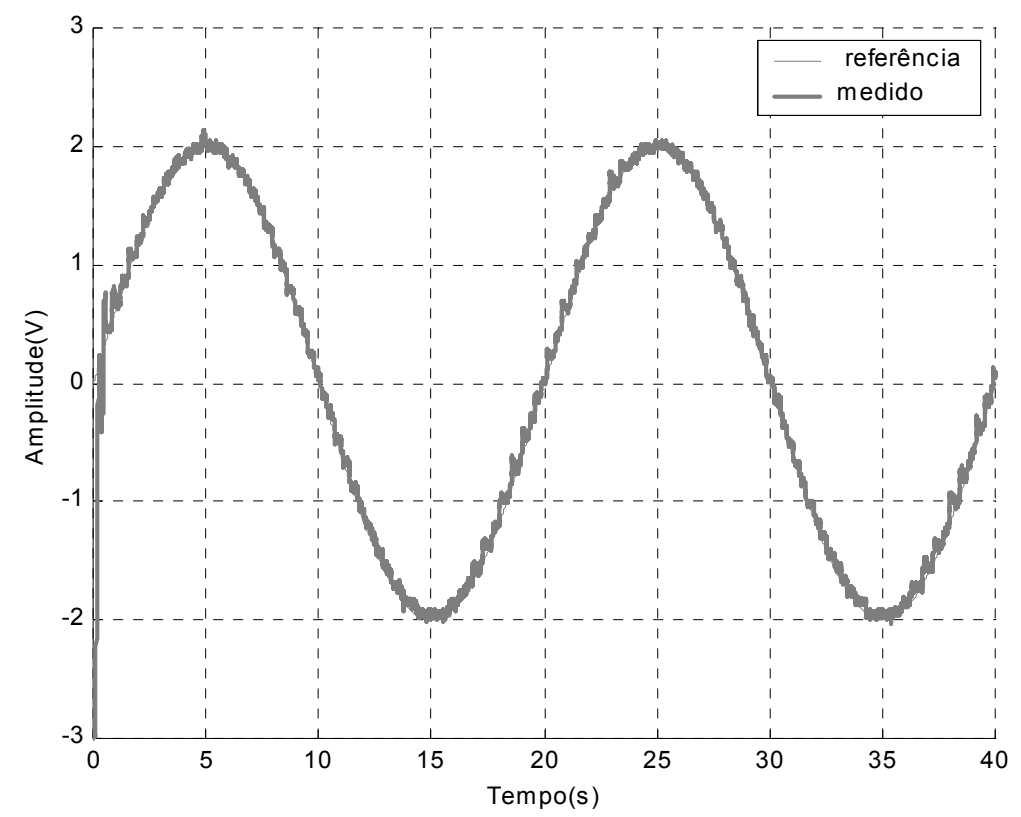

Figura 96 Resposta do controlador SMC com sinal de referência senoidal $2 \mathrm{~V}$ e T=20s

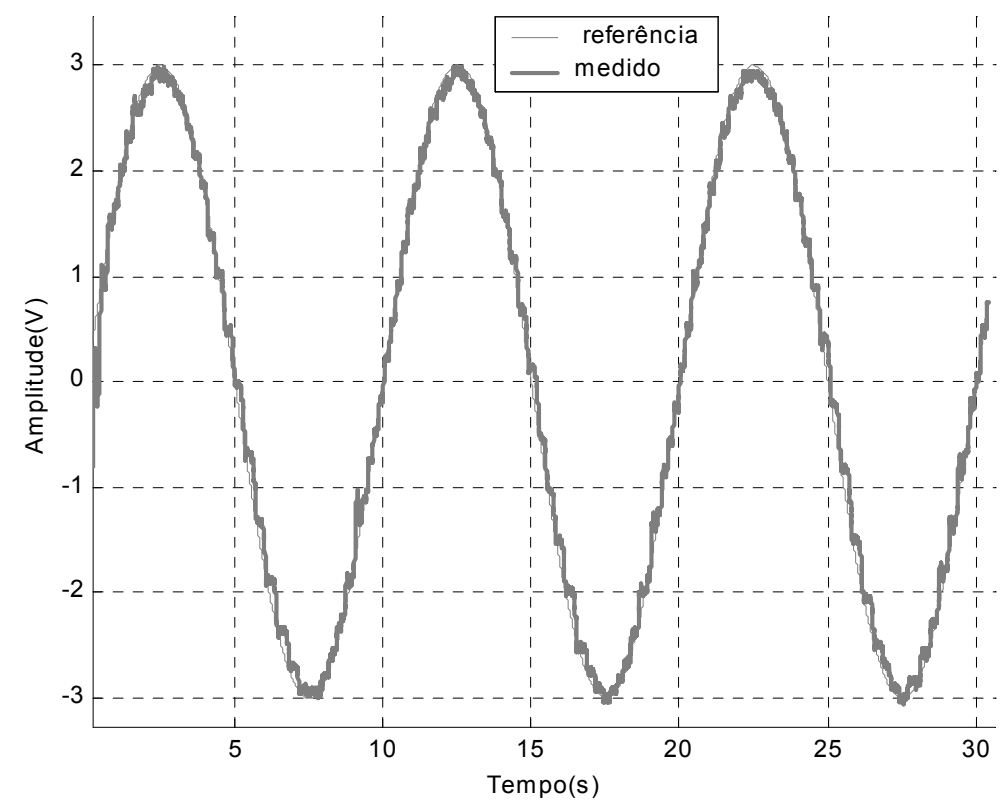

Figura 97 Resposta do controlador SMC com sinal de referência senoidal $3 \mathrm{~V}$ e T=10s . 


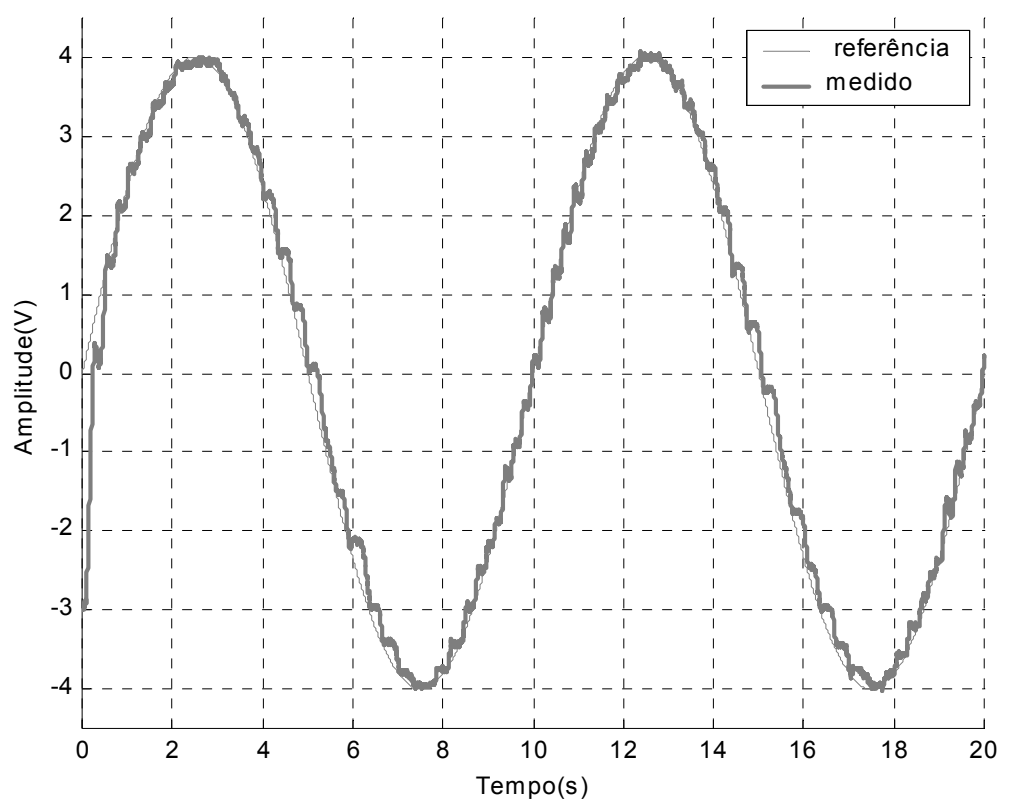

Figura 98 Resposta do controlador SMC com sinal de referência senoidal $4 \mathrm{~V}$ e $\mathrm{T}=10 \mathrm{~s}$

A Tabela 12 mostra o desempenho do controlador SMC com sinais de referência senoidais com níveis de amplitudes e freqüências idênticos aos ensaiados no controlador PID no capítulo 6 .

Tabela 12 Erro de acompanhamento do controlador SMC com sinais senoidais (1V; 2V; 3V; 4V)

\begin{tabular}{|l|l|l|}
\hline $\begin{array}{l}\text { Onda senoidal } \\
\text { Amplitude/Período }\end{array}$ & $\begin{array}{l}\text { Erro } \\
\text { acompanhamento } \\
\Delta \mathrm{V}\end{array}$ & $\begin{array}{l}\text { Erro } \\
\text { acompanhamento } \\
\mathrm{e}(\%)\end{array}$ \\
\hline $1 \mathrm{~V} / \mathrm{T}=20 \mathrm{~s}$ & $0,10 \mathrm{~V}$ & $10 \%$ \\
\hline $2 \mathrm{~V} / \mathrm{T}=20 \mathrm{~s}$ & $0,10 \mathrm{~V}$ & $5 \%$ \\
\hline $3 \mathrm{~V} / \mathrm{T}=10 \mathrm{~s}$ & $0,31 \mathrm{~V}$ & $10,3 \%$ \\
\hline $4 \mathrm{~V} / \mathrm{T}=10 \mathrm{~s}$ & 0,57 & $14,2 \%$ \\
\hline
\end{tabular}

Comparando os resultados obtidos com o controlador SMC (Tabela 12), com os resultados obtidos com o controlador PID (Tabela 9), verifica-se que o controlador SMC obteve um desempenho melhor que o controlador PID.

Por fim comparou-se da máxima largura de faixa do atuador SMA com controlador SMC, em relação ao controle PID. A Figura 99 mostra o comportamento do sistema com um sinal de referência senoidal de amplitude $2 \mathrm{~V}$ e período $\mathrm{T}=1,55 \mathrm{~s}$, freqüência na qual o sinal de medida fica com $70,7 \%$ do valor da amplitude do sinal 
de referência. Este sinal corresponde, portanto à largura de faixa, equivalente à $0,64 \mathrm{~Hz}$. Esta largura de faixa obtida foi superior a obtida com o controlador PID $(0,37 \mathrm{~Hz})$.

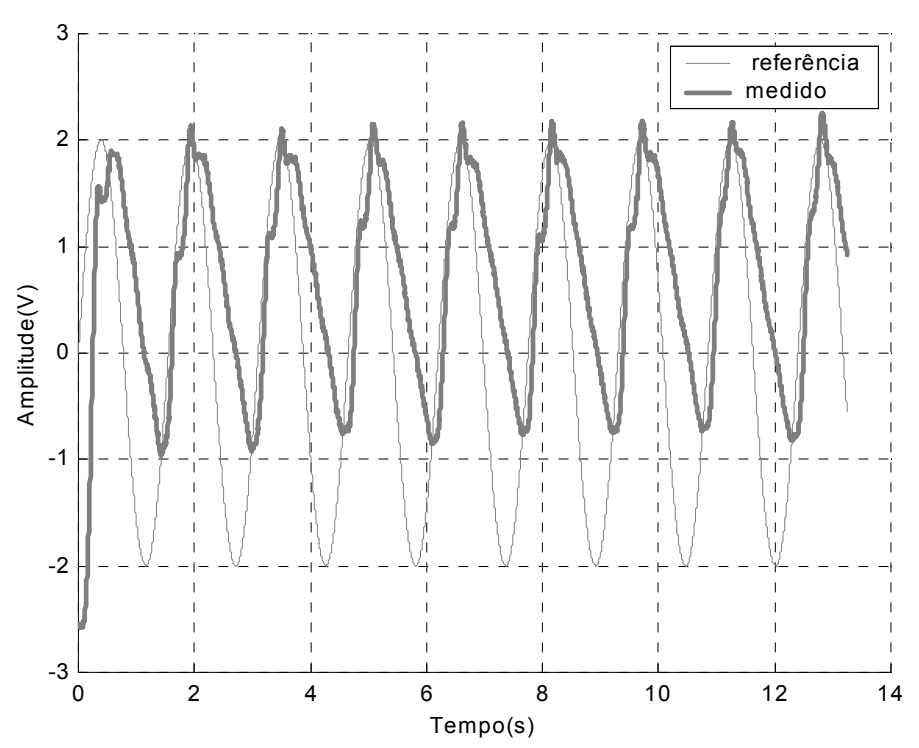

Figura 99 Resposta do controlador SMC com sinal de referência senoidal $2 \mathrm{~V}$ e $\mathrm{T}=1,55 \mathrm{~s}$

Conclui-se que o controle por modos deslizantes acoplados à linearização por realimentação é mais preciso e adequado para se fazer o controle do atuador SMA do que o controlador PID. Será avaliado agora a possibilidade de se melhorar ainda mais a sintonia do controlador SMC .

\subsection{Avaliação da sensibilidade a parâmetros de controle}

A influência dos parâmetros $\lambda, \phi$ e $\mathrm{K}_{S M}$, do controlador SMC serão avaliados, baseando-se na teoria dada em Slotine e Li (1991) e nas recomendações de Ryu e Park (2001).

Utilizando-se a metodologia de Ryu e Park(2001), inicialmente estima-se um valor apropriado para $\lambda$ e $\phi$ e em seguida calcula-se $K_{S M}$ seguindo a relação:

$$
\mathrm{K}_{\mathrm{sm}}=\lambda \cdot \phi
$$

Pode-se, alternadamente, estimarem-se $\mathrm{K}_{\mathrm{sm}}$ e $\lambda$ e se calcula $\phi$. 


\subsubsection{Reajuste de parâmetros}

Adotou-se para o primeiro ensaio uma camada limite $\phi=1,6$ o que corresponde a um erro de acompanhamento de $1 \times 10^{-3}(1 \mathrm{~mm})$ segundo a relação $|\widetilde{x}(t)|<\frac{\phi}{\lambda^{n-1}}=\varepsilon \quad$.

Adotando-se $\lambda=40$ obtém-se $K_{S M}=64$, aplicando-se $o$ sinal de referência (degrau suavizado) com amplitude $\Delta x d=2,5 \mathrm{~cm}$, com a posição inicial $x i=2 \mathrm{~cm}$, no controlador SMC parametrizado com $\left(\lambda=40 ; \phi=1,6 ; K_{S M}=64\right)$, obteve-se como resultado tempo de acomodação de $0,23 \mathrm{~s}$ com sobre-sinal máximo de $0,6 \%$ conforme mostra a Figura 100. Verifica-se que houve uma resposta rápida e um sobre-sinal bastante satisfatório, com erro de acompanhamento de 0,8\%.

A resposta da variável s pode ser visualizada conforme mostra Figura 101. Nota-se que a variável s é mantida dentro da camada limite $\phi$ após os transitórios.

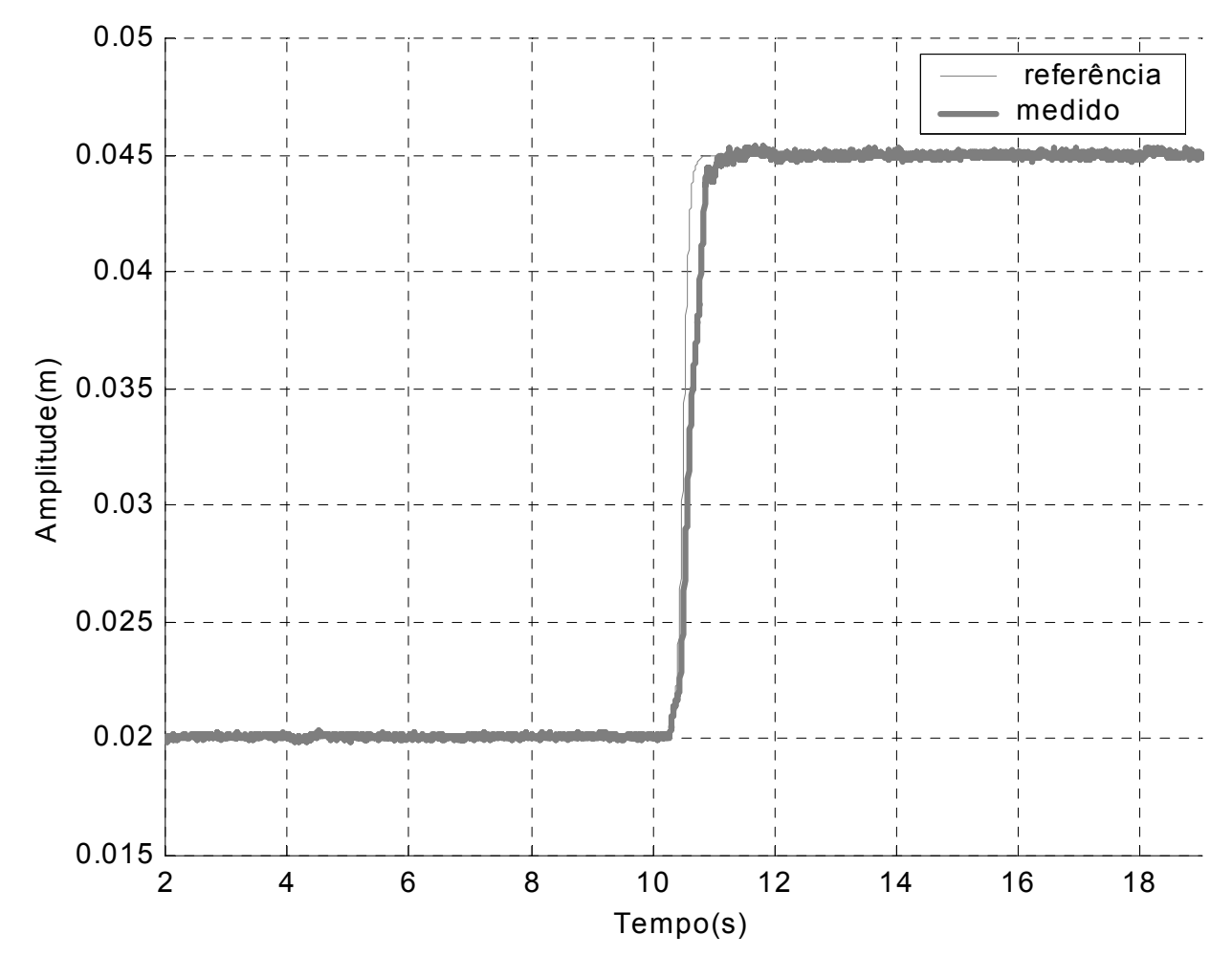

Figura 100 Resposta do atuador SMA degrau suavizado de 2,5cm com : $\lambda=40 ; \phi=1,6$ e $K_{S M}=64$ 


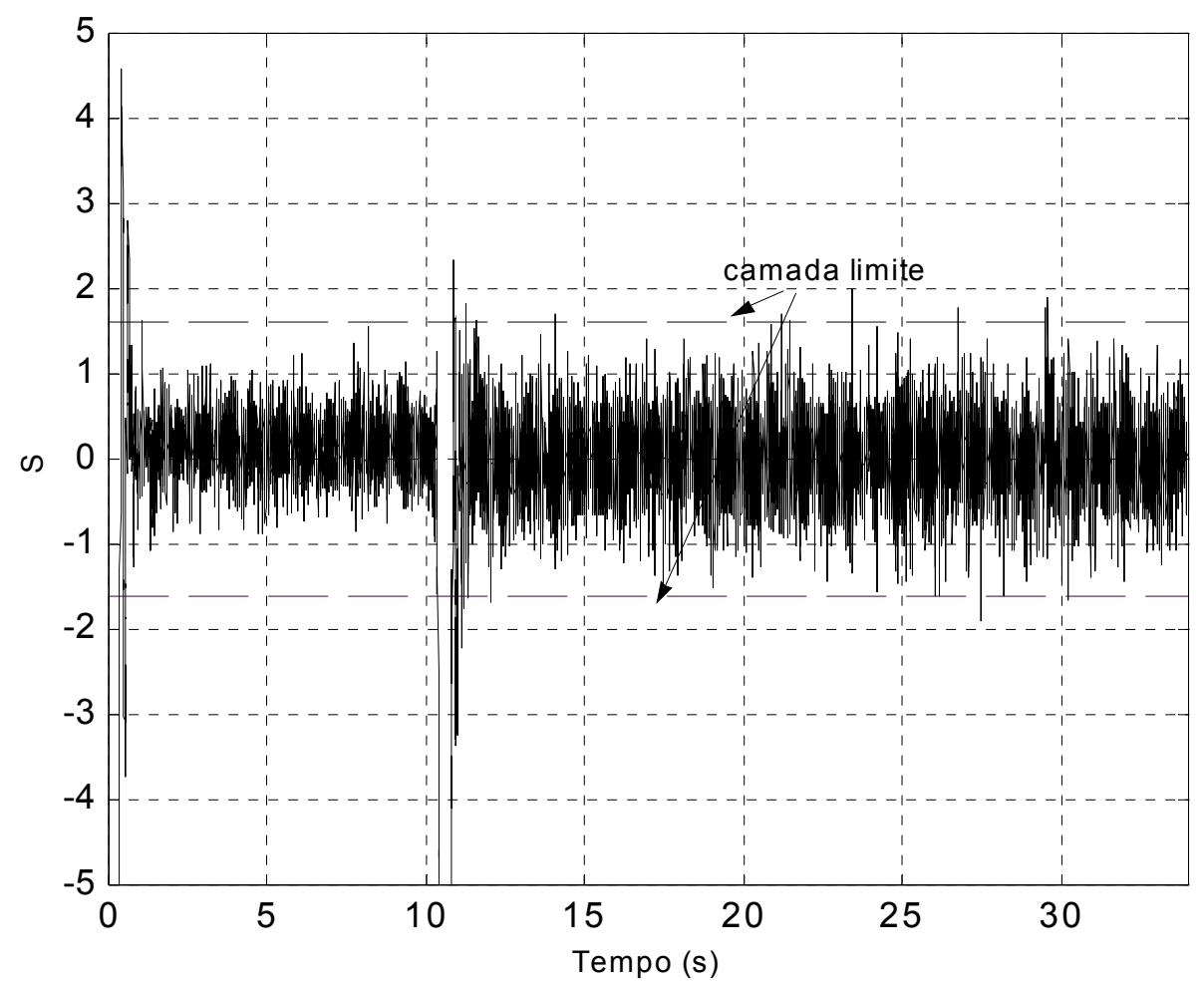

Figura 101 Variável s para: $\lambda=40 ; \phi=1,6$ e $\mathrm{K}_{\mathrm{SM}}=64$

Aplicando-se o sinal de referência (degrau suavizado) de descida com amplitude $\Delta x d=-2,5 \mathrm{~cm}$, com a posição inicial $x i=4,5 \mathrm{~cm}$, no controlador $\mathrm{SMC}$ parametrizado com $\left(\lambda=40, \phi=1,6 ; K_{S M}=64\right)$, obteve-se como resultado tempo de resposta de 0,92s com sobre-sinal máximo de 0,5\% conforme mostra a Figura 102. Verifica-se que houve uma resposta mais lenta que na subida, um sobre-sinal bastante satisfatório e o erro de acompanhamento após o sistema ter entrado em regime permanente inferior a $1 \times 10^{-4}(0,4 \%)$, ou seja, dentro do valor previamente estipulado no projeto. 


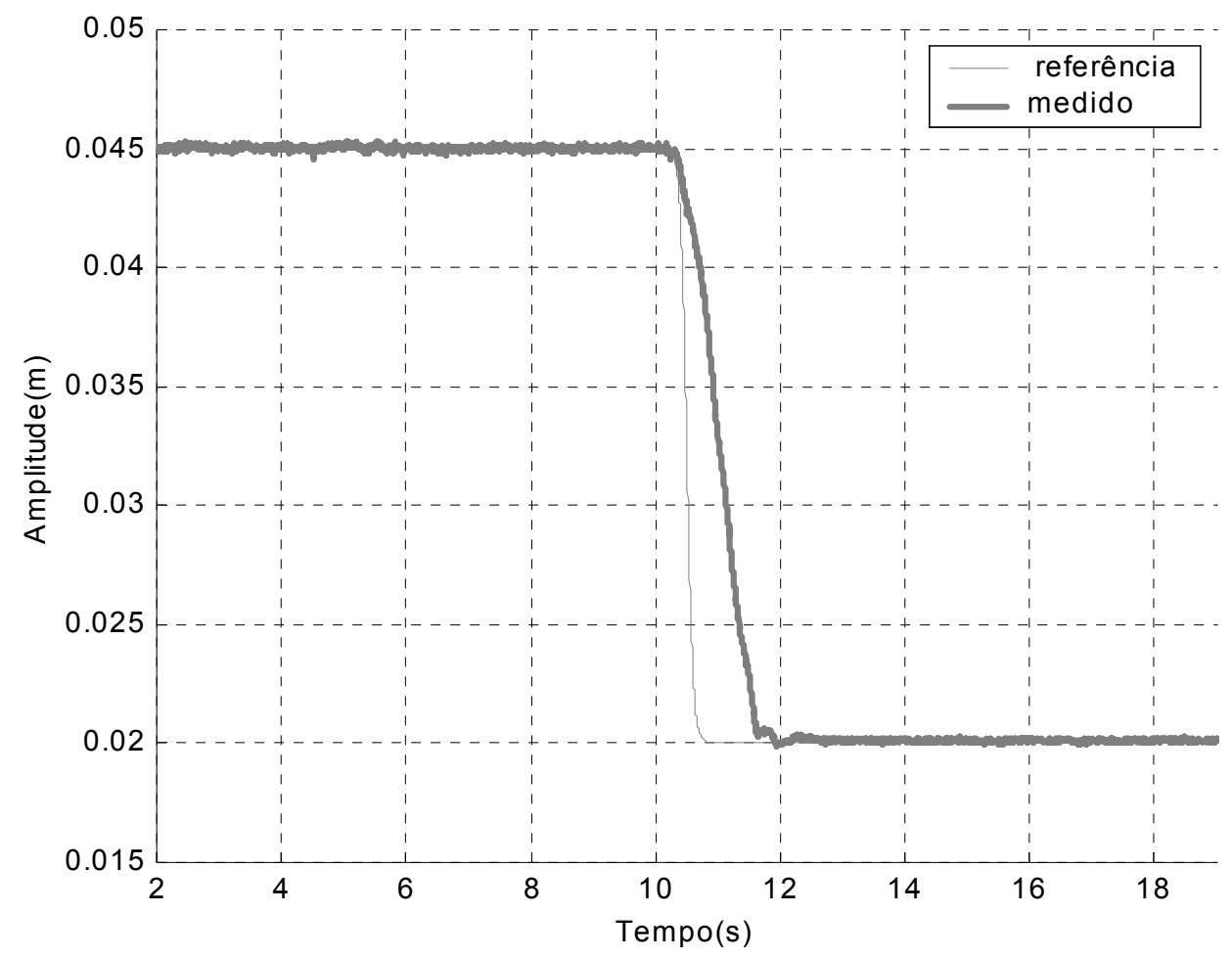

Figura 102 Resposta do atuador SMA degrau suavizado descida com : $\lambda=40 ; \phi=1,6$ e $K_{S M}=64$

Mantendo-se os mesmos parâmetros utilizados para o ensaio em degrau suavizado ( $\lambda=40 ; \phi=1,6$ e $\mathrm{K}_{\mathrm{SM}}=64$ ), os resultados obtidos para os sinais senoidais, com amplitude de $1 \mathrm{~cm}$ (centralizado em $2 \mathrm{~cm}$ ) podem ser visualizados na Figura 103.

Verificou-se que houve um bom acompanhamento do sinal de referência, sendo que para o pior caso para $T=3$ s o sobre-sinal nos picos foram de $3,3 \%$, quando o sistema começa a perder desempenho. A freqüência de corte foi de aproximadamente de $0,66 \mathrm{~Hz}(\mathrm{~T}=1,5 \mathrm{~s})$. 


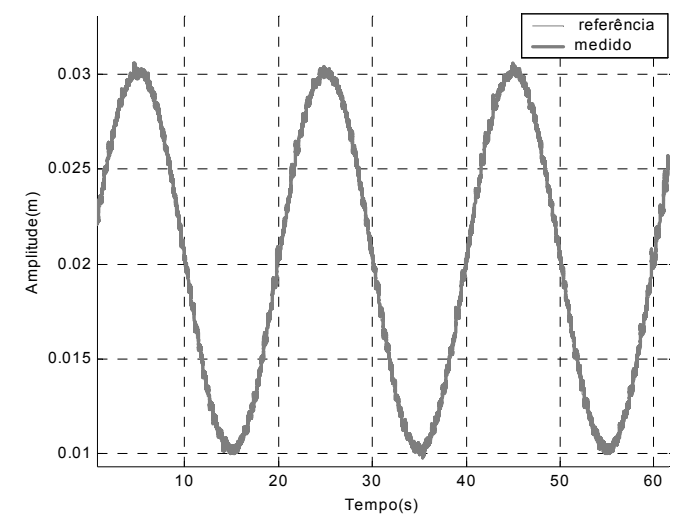

$\mathrm{T}=20 \mathrm{~s}$

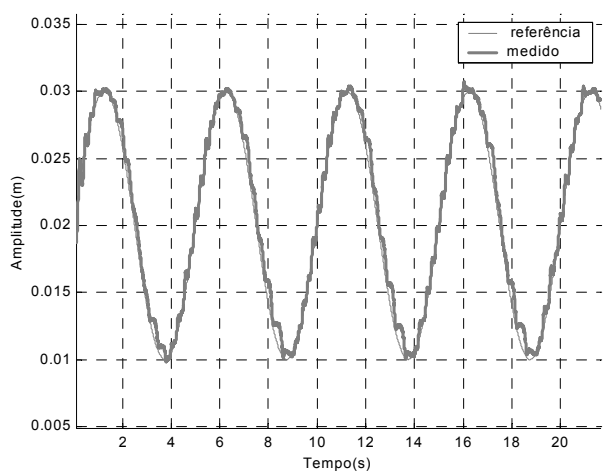

$\mathrm{T}=5 \mathrm{~s}$

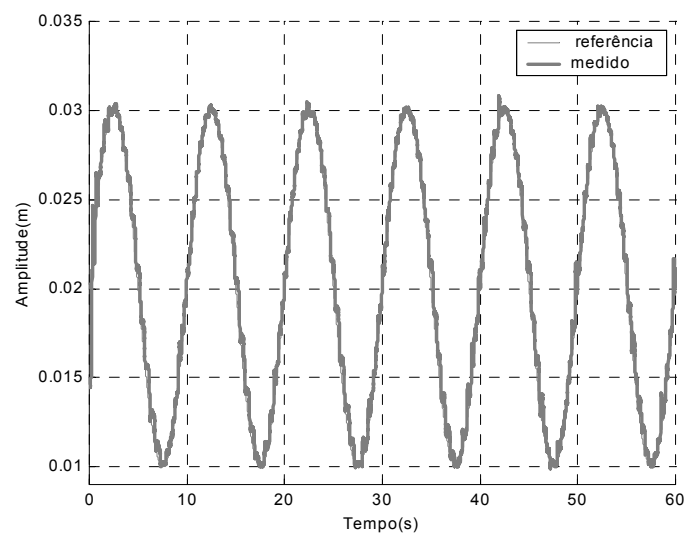

$\mathrm{T}=10 \mathrm{~s}$

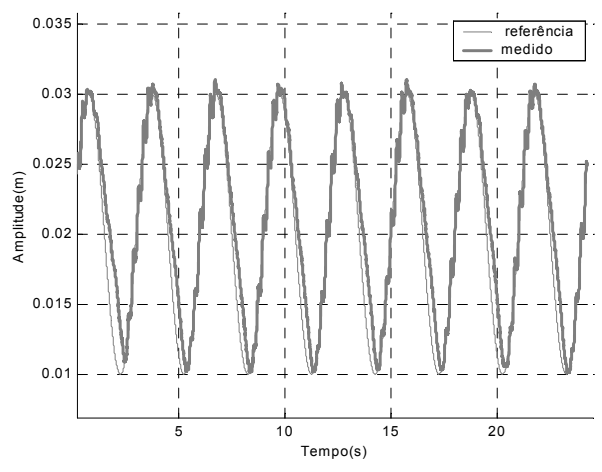

$\mathrm{T}=3 \mathrm{~s}$

Figura 103 Resposta do atuador $\operatorname{com} \lambda=40 ; \phi=1,6$ e $K_{S M}=64$ (sinais referência senoidais $1 \mathrm{~cm}$ )

A Tabela 13 mostra os erros de acompanhamento obtidos com os sinais de referência senoidal obtidos na Figura 103.

Tabela 13 Erro de acompanhamento do controlador SMC para $\lambda=40 ; \phi=1,6$ e $K_{S M}=64$.

\begin{tabular}{|l|l|l|}
\hline $\begin{array}{l}\text { Onda senoidal } \\
\text { Amplitude/Período }\end{array}$ & $\begin{array}{l}\text { Erro } \\
\text { acompanhamento } \\
\Delta \mathrm{cm}\end{array}$ & $\begin{array}{l}\text { Erro } \\
\text { acompanhamento } \\
\mathrm{e}(\%)\end{array}$ \\
\hline $1 \mathrm{~cm} / \mathrm{T}=20 \mathrm{~s}$ & $0,08 \mathrm{~cm}$ & $8 \%$ \\
\hline $1 \mathrm{~cm} / \mathrm{T}=10 \mathrm{~s}$ & $0,13 \mathrm{~cm}$ & $13 \%$ \\
\hline $1 \mathrm{~cm} / \mathrm{T}=5 \mathrm{~s}$ & $0,15 \mathrm{~cm}$ & $15 \%$ \\
\hline $1 \mathrm{~cm} / \mathrm{T}=3 \mathrm{~s}$ & $0,40 \mathrm{~cm}$ & $40 \%$ \\
\hline
\end{tabular}

Verifica-se que o erro de acompanhamento aumenta com o aumento da freqüência . Houve uma melhoria em relação à parametrização anterior (Tabela 10). 


\subsubsection{Reajuste de parâmetros ( $2^{\mathrm{a}}$ iteração)}

Seguindo a mesma lógica descrita anteriormente, novos ensaios foram realizados estimando: $\lambda=38 ; \phi=2$ e $\mathrm{K}_{\mathrm{SM}}=76$.

Aplicou-se o sinal de referência (degrau suavizado) com amplitude $\Delta x d=2,5 \mathrm{~cm}$, com a posição inicial $x i=2 \mathrm{~cm}$, no controlador $S M C$. O resultado obtido é mostrado na Figura 104.

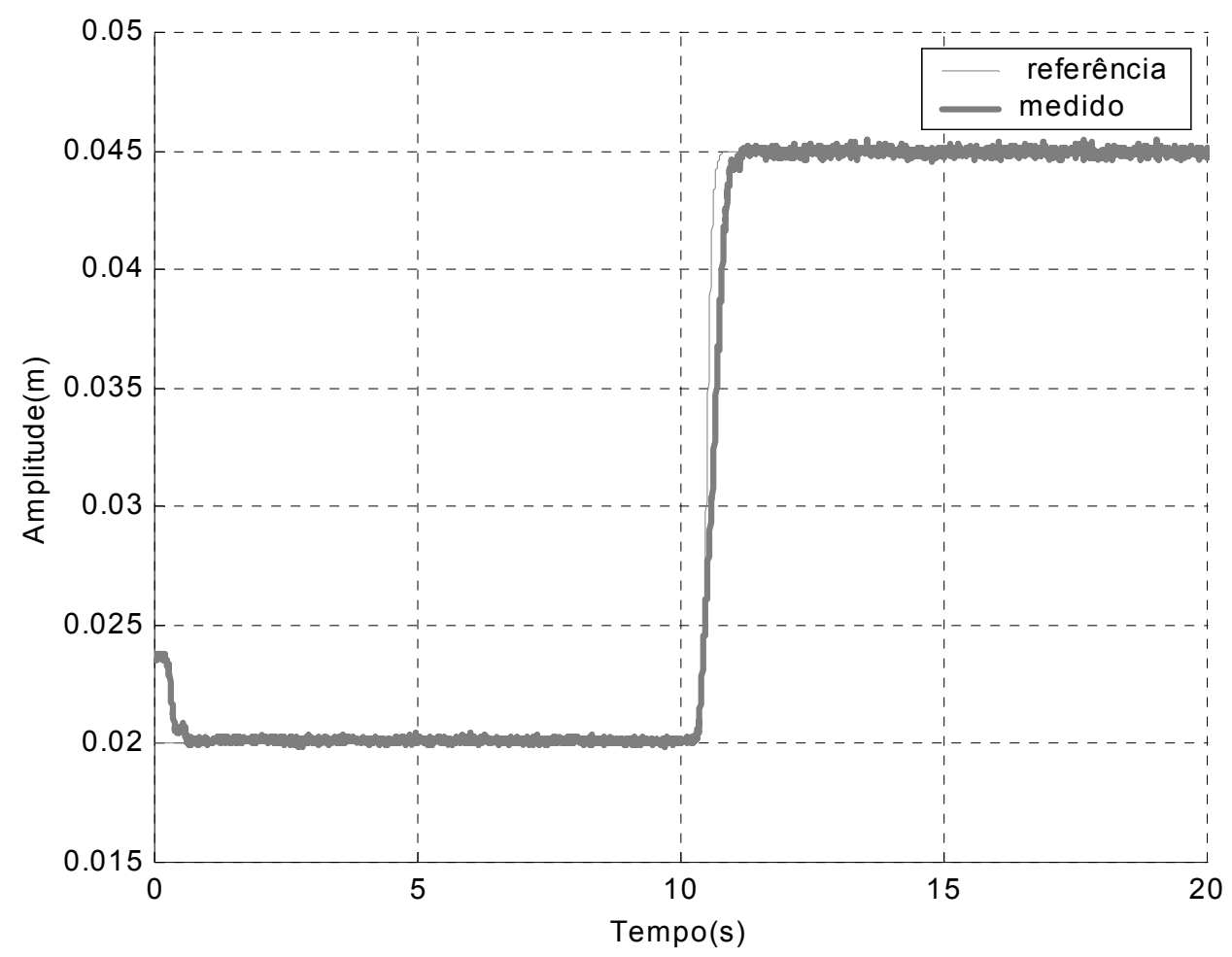

Figura 104 Resposta do atuador SMA degrau suavizado de 2,5cm com : $\lambda=38 ; \phi=2$ e $K_{S M}=76$

Obteve-se um sobre-sinal de 0,8\%, um tempo de acomodação de 0,23s e um erro de acompanhamento de aproximadamente $0,6 \%$, valores estes bem próximos aos obtidos anteriormente.

A resposta da variável s pode ser visualizada conforme mostra Figura 105. Nota-se, como no caso anterior, que a variável s mantém-se dentro da camada limite $\phi$, após os transitórios. 


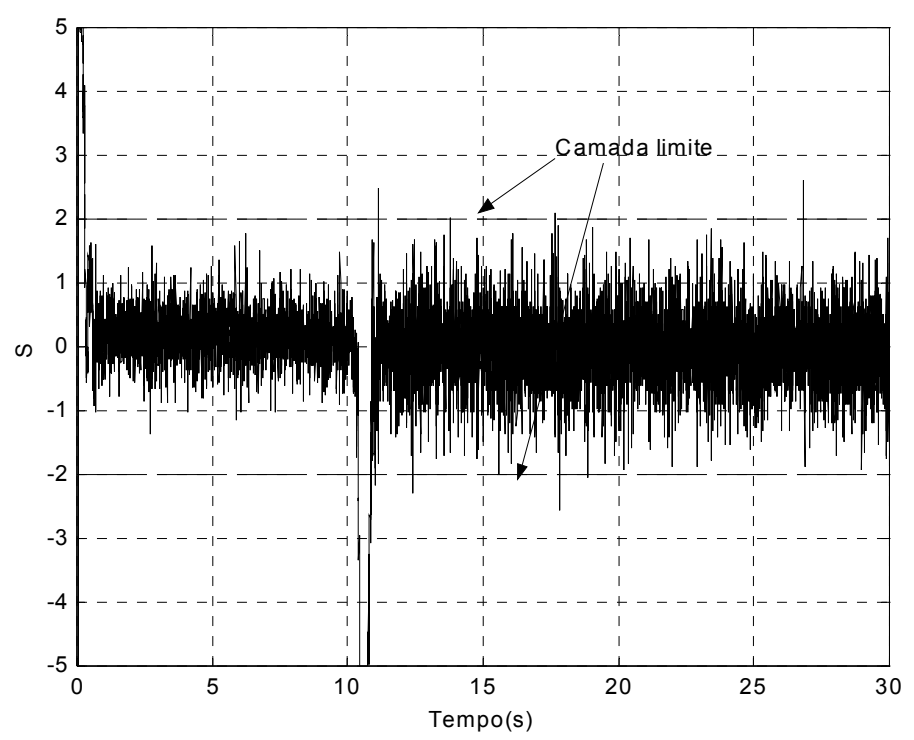

Figura 105 Variável s para: $\lambda=38$; $\phi=2$ e $K_{S M}=76$

Aplicou-se então o sinal de referência (degrau suavizado) de descida com amplitude $\Delta x d=-2,5 \mathrm{~cm}$, com a posição inicial $x i=4,5 \mathrm{~cm}$ para $\lambda=38, \phi=2 ; K_{S M}=76$. $O$ resultado obtido está mostrado na Figura 106.

Obteve-se tempo de acomodação de 0,68s, sobre-sinal máximo de $1 \%$ e um erro de acompanhamento de $0,7 \%$. Verifica-se que houve uma resposta mais lenta que na subida e um sobre-sinal bastante satisfatório.

A Tabela 14 mostra os efeitos dos parâmetros nos ensaios com degrau suavizado de amplitude $2,5 \mathrm{~cm}$ com posição inicial $2 \mathrm{~cm}$.

Tabela 14 Comparação dos efeitos obtidos com os parâmetros de controle

\begin{tabular}{|l|l|l|l|l|l|}
\hline Parâmetros & $\begin{array}{l}\text { Maior erro de } \\
\text { acompanhamento } \\
\text { em regime (\%) }\end{array}$ & $\begin{array}{l}\text { Tempo } \\
\text { acomodação } \\
\text { subida (s) }\end{array}$ & $\begin{array}{l}\text { Tempo } \\
\text { acomodação } \\
\text { descida (s) }\end{array}$ & $\begin{array}{l}\text { Sobre-sinal } \\
\text { Subida (\%) }\end{array}$ & $\begin{array}{l}\text { Sobre-sinal } \\
\text { descida(\%) }\end{array}$ \\
\hline$\lambda=40 ; \phi=0,16 ; s M=250$ & 0,48 & 0,4 & 0,75 & 1,33 & 0 \\
\hline$\lambda=40 ; \phi=1,6 ; K_{S M}=64$ & 0,8 & 0,23 & 0,92 & 0,6 & 0,5 \\
\hline$\lambda=38 ; \phi=2 ; K_{S M}=76$ & 0,6 & 0,23 & 0,68 & 0,8 & 1,0 \\
\hline
\end{tabular}

Pelos resultados obtidos, conclui-se que os parâmetros $\left(\lambda=38 ; \phi=2 ; K_{S M}=76\right)$ levaram a uma ligeira melhora no desempenho geral do controlador SMC em resposta a degrau. 


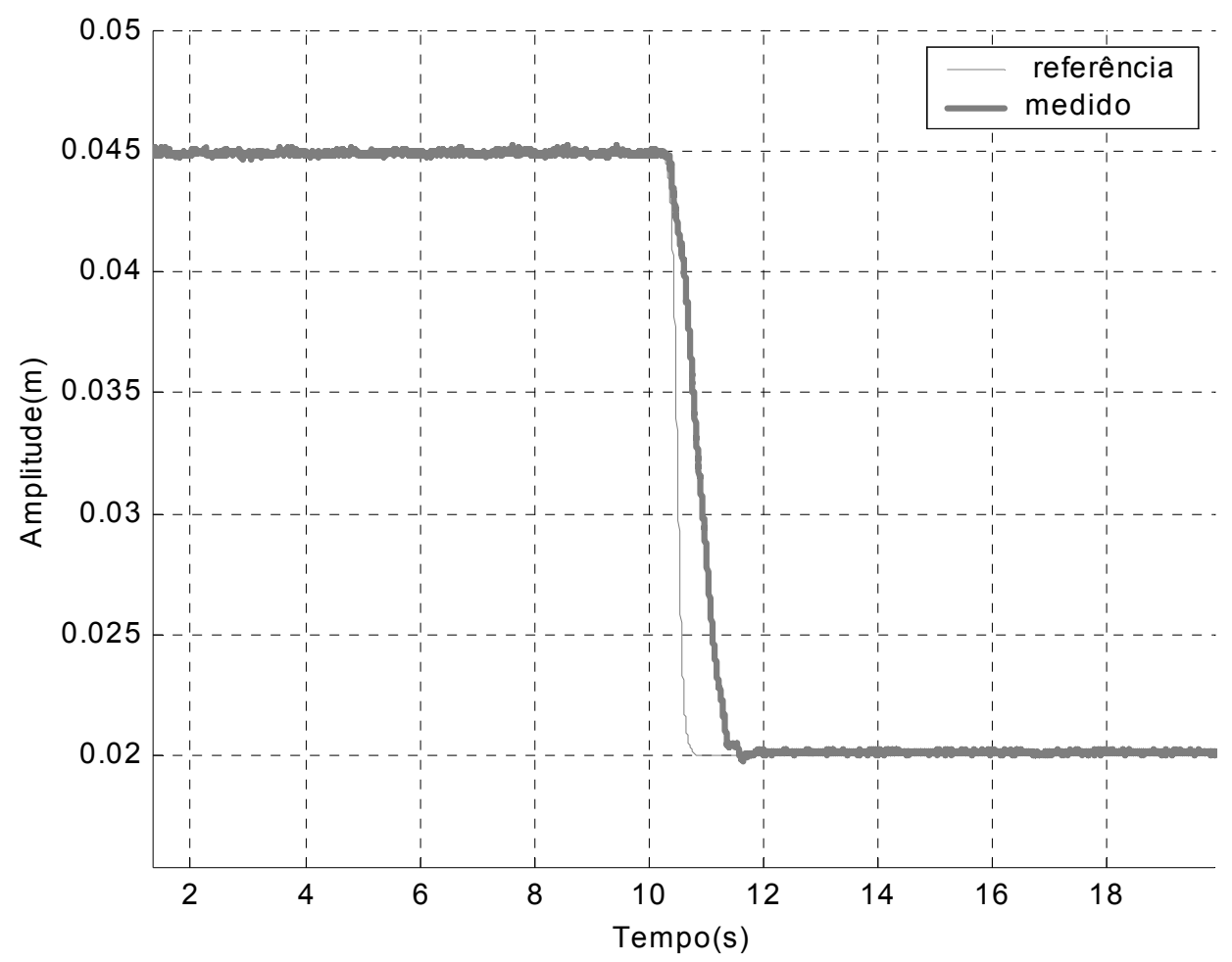

Figura 106 Resposta do atuador SMA degrau suavizado descida com : $\lambda=38$; $\phi=2$ e $K_{S M}=76$

Mantendo-se os mesmos parâmetros utilizados na $2^{a}$ iteração $(\lambda=38 ; \phi=2$ e $\mathrm{K}_{\mathrm{SM}}=76$ ), os resultados obtidos para os sinais senoidais, com amplitude de $1 \mathrm{~cm}$ (centralizado em 2cm) podem ser visualizados na Figura 107.

Verificou-se que houve um bom acompanhamento do sinal de referência, sendo que para o pior caso para $\mathrm{T}=3$ s o sobre-sinal nos picos foram de 1,7\%, quando o sistema começa a perder desempenho. A Tabela 15 mostra os erros de acompanhamento obtidos com os sinais senoidais com amplitude $1 \mathrm{~cm}$

Tabela 15 Erro de acompanhamento do controlador SMC (senóides $1 \mathrm{~cm}$ ) ( $\lambda=38 ; \phi=2$ e $K_{S M}=76$ )

\begin{tabular}{|l|l|l|}
\hline $\begin{array}{l}\text { Onda senoidal } \\
\text { Amplitude/Período }\end{array}$ & $\begin{array}{l}\text { Erro } \\
\text { acompanhamento } \\
\Delta \mathrm{cm}\end{array}$ & $\begin{array}{l}\text { Erro } \\
\text { acompanhamento } \\
\mathrm{e}(\%)\end{array}$ \\
\hline $1 \mathrm{~cm} / \mathrm{T}=20 \mathrm{~s}$ & $0,05 \mathrm{~cm}$ & $5 \%$ \\
\hline $1 \mathrm{~cm} / \mathrm{T}=10 \mathrm{~s}$ & $0,10 \mathrm{~cm}$ & $10 \%$ \\
\hline $1 \mathrm{~cm} / \mathrm{T}=5 \mathrm{~s}$ & $0,15 \mathrm{~cm}$ & $15 \%$ \\
\hline $1 \mathrm{~cm} / \mathrm{T}=3 \mathrm{~s}$ & $0,20 \mathrm{~cm}$ & $20 \%$ \\
\hline
\end{tabular}




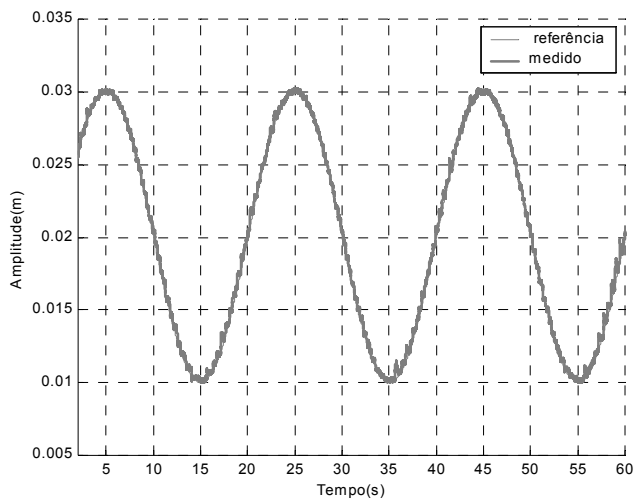

$\mathrm{T}=20 \mathrm{~s}$

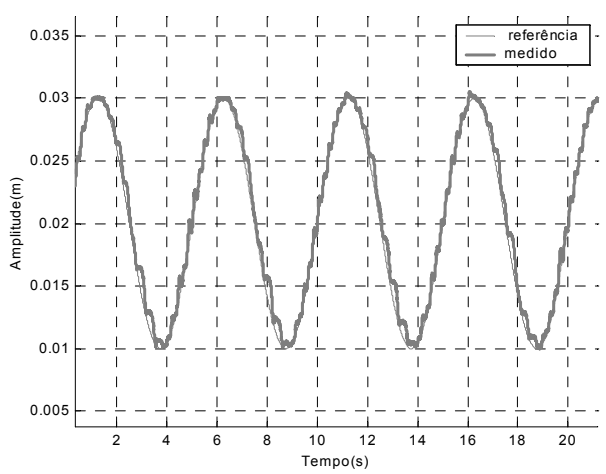

$\mathrm{T}=5 \mathrm{~s}$

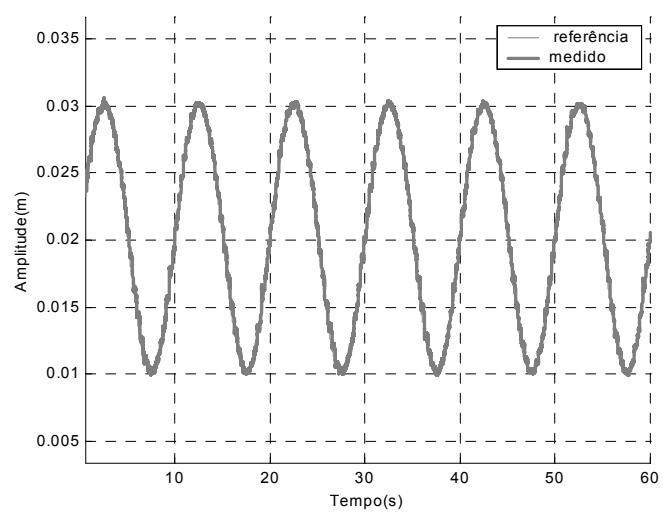

$\mathrm{T}=10 \mathrm{~s}$

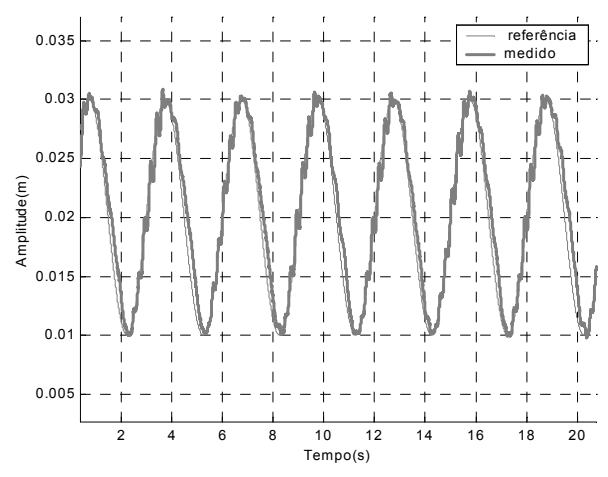

$\mathrm{T}=3 \mathrm{~s}$

Figura 107 Resposta do atuador $\operatorname{com} \lambda=38 ; \phi=2$ e $K_{S M}=76$ (sinais referência senoidais $1 \mathrm{~cm}$ )

Comparando-se os resultados das tabelas Tabela 10, Tabela 13 e a Tabela 15 , verifica-se que houve uma melhora para os sinais senoidais utilizando os parâmetros ( $\lambda=38 ; \phi=2$ e $\mathrm{K}_{\mathrm{SM}}=76$ ).

A largura de faixa obtida para os parâmetros $\lambda=38 ; \phi=2$ e $\mathrm{K}_{\mathrm{SM}}=76$ foi de $0,69 \mathrm{~Hz}$ na qual obteve-se aproximadamente $70,7 \%$ da amplitude do sinal de referência, conforme mostra a Figura 108.

Portanto, tanto na comparação com referência degrau e senoidal, o controlador SMC com $\left(\lambda=38 ; \phi=2\right.$ e $\left.\mathrm{K}_{\mathrm{SM}}=76\right)$ apresentou melhor desempenho. 


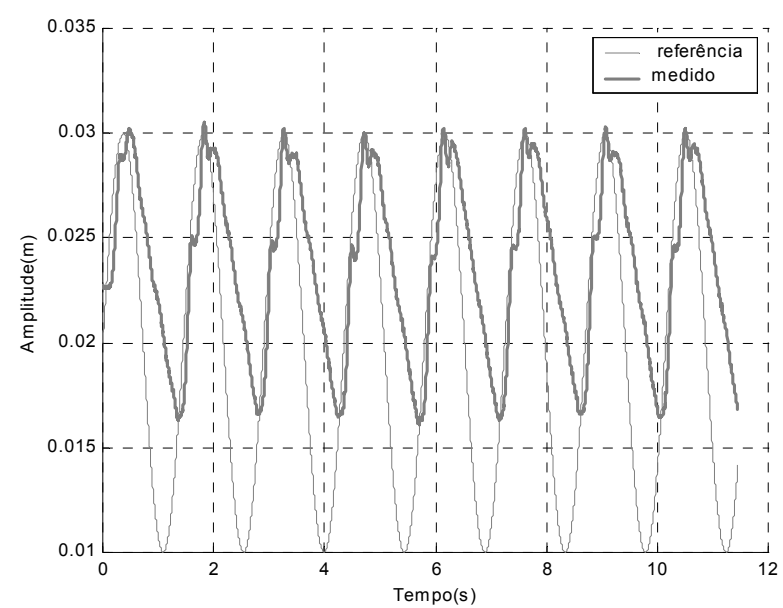

Figura 108 Resposta do controlador SMC com sinal de referência senoidal ( $1 \mathrm{~cm}$ e T=1,45s)

Verificou-se agora o desempenho, com sinais senoidais de amplitude de $2 \mathrm{~cm}$ (centralizado em 2cm). Os resultados são mostrados na Figura 109.

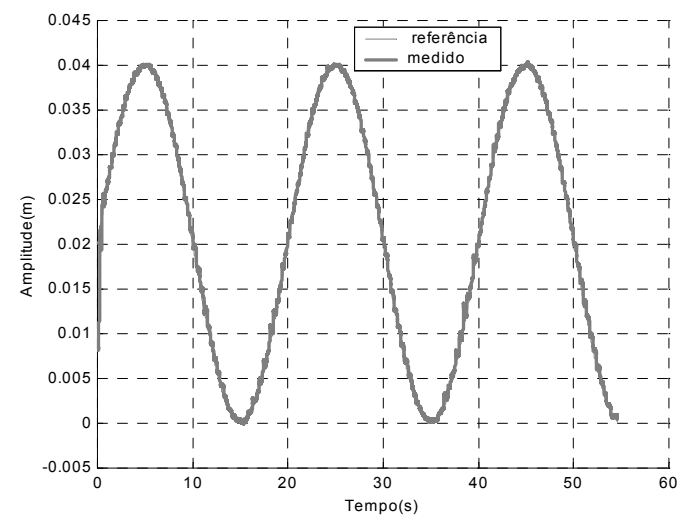

$\mathrm{T}=20 \mathrm{~s}$

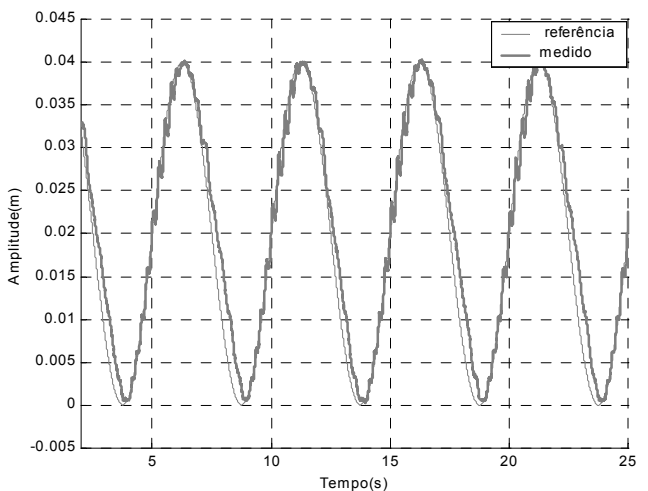

$\mathrm{T}=5 \mathrm{~s}$

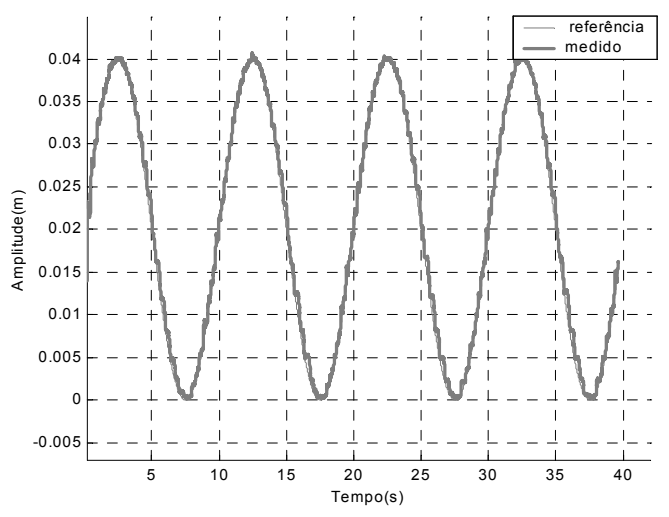

$\mathrm{T}=10 \mathrm{~s}$

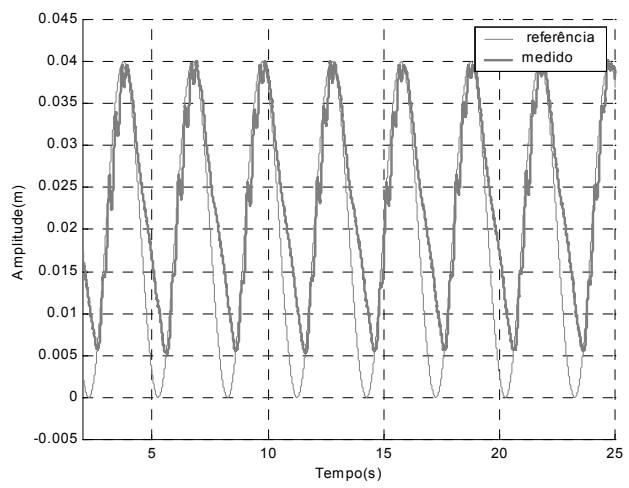

$\mathrm{T}=3 \mathrm{~s}$

Figura 109 Resposta do atuador $\operatorname{com} \lambda=38 ; \phi=2$ e $K_{S M}=76$ (sinais referência senoidais $2 \mathrm{~cm}$ )

A tabela mostra os erro de acompanhamento do controlador SMC para os parâmetros para $\lambda=38 ; \phi=2$ e $\mathrm{K}_{\mathrm{SM}}=76$. 
Tabela 16 Erro de acompanhamento do controlador SMC (senóides $2 \mathrm{~cm}$ ) $\left(\lambda=38 ; \phi=2\right.$ e $K_{S M}=76$ )

\begin{tabular}{|l|l|l|}
\hline $\begin{array}{l}\text { Onda senoidal } \\
\text { Amplitude/Período }\end{array}$ & $\begin{array}{l}\text { Erro } \\
\text { acompanhamento } \\
\Delta \mathrm{cm}\end{array}$ & $\begin{array}{l}\text { Erro } \\
\text { acompanhamento } \\
\mathrm{e}(\%)\end{array}$ \\
\hline $2 \mathrm{~cm} / \mathrm{T}=20 \mathrm{~s}$ & $0,1 \mathrm{~cm}$ & $5 \%$ \\
\hline $2 \mathrm{~cm} / \mathrm{T}=10 \mathrm{~s}$ & $0,2 \mathrm{~cm}$ & $10 \%$ \\
\hline $2 \mathrm{~cm} / \mathrm{T}=5 \mathrm{~s}$ & $0,35 \mathrm{~cm}$ & $17,5 \%$ \\
\hline $2 \mathrm{~cm} / \mathrm{T}=3 \mathrm{~s}$ & $1,4 \mathrm{~cm}$ & $70 \%$ \\
\hline
\end{tabular}

Verifica-se que o sistema perde desempenho com o aumento da freqüência, mesmo assim ficou melhor que os resultados da obtidos na Tabela 10, para as mesmas amplitudes e freqüências

\subsection{Verificação da sensibilidade à distúrbios}

Mantendo-se os parâmetros: $\lambda=38 ; \phi=2$ e $\mathrm{K}_{\mathrm{SM}}=76$, simularam -se dois tipos de distúrbios:

a) aumento e diminuição de $20 \%$ de massa na carga.

b) resfriamento forçado por fluxo de ar no fio de SMA

No primeiro caso adicionou-se uma carga subitamente de 8gf quando o sistema já se encontrava em regime permanente. O resultado está mostrado na Figura 110a e concluiu-se que houve uma queda instantânea de 1,77\% em relação ao sinal de referência e um rápido retorno para a referência em cerca de $0,2 \mathrm{~s}$. No momento da retirada da carga houve um aumento de 0,9\% e um retorno ao sinal de referência em $0,3 \mathrm{~s}$, mostrando que o controle se recupera rapidamente após o distúrbio de carga. O mesmo teste realizado em malha aberta (Figura 110b), com uma corrente constante sobre o fio, e verificou-se um deslocamento de 2,3\%, sem retorno à posição original, confirmando a efetividade do controlador em relação à rejeição de distúrbios deste tipo.

No segundo caso após o sistema ter entrado em regime permanente com um sinal de referência fixo, provocou-se um resfriamento forçado no fio do atuador SMA com um pequeno ventilador, utilizado para refrigerar fontes de microcomputadores. A Figura 111a, mostra o resultado obtido para o distúrbio, onde o sinal decaiu em relação ao sinal de referência para $4 \%$. Este teste, realizado em malha aberta, com 
aplicações e retiradas sucessivas da ventilação, mostram o grande efeito que tal resfriamento provoca no sistema não controlado (Figura 111b).

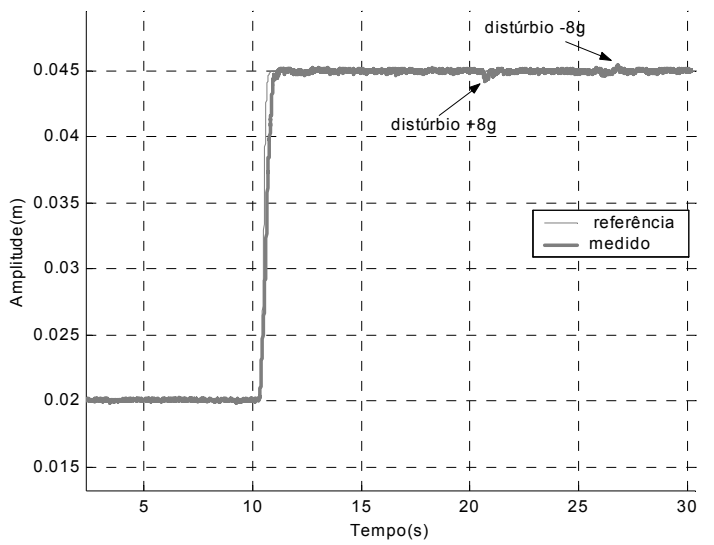

(a)

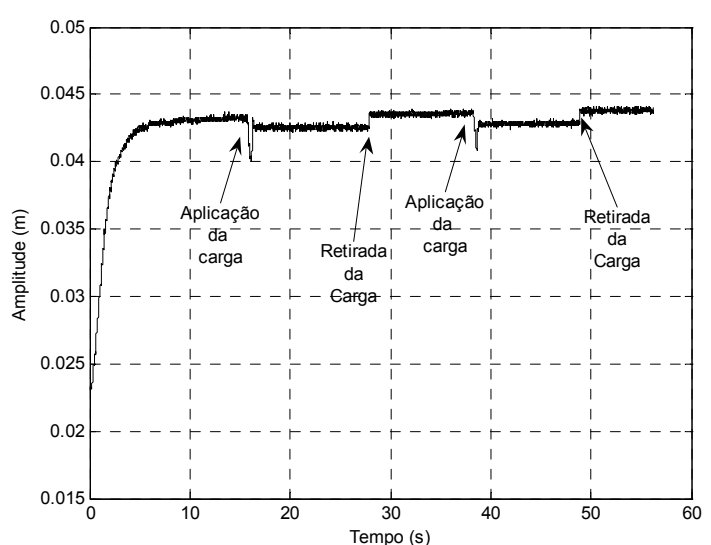

(b)

Figura 110 Sensibilidade à distúrbio de carga $\pm 20 \%$, (a) Malha fechada SMC ( $\lambda=38 ; \phi=2$ e $K_{S M}=$ 76); (b) Malha aberta

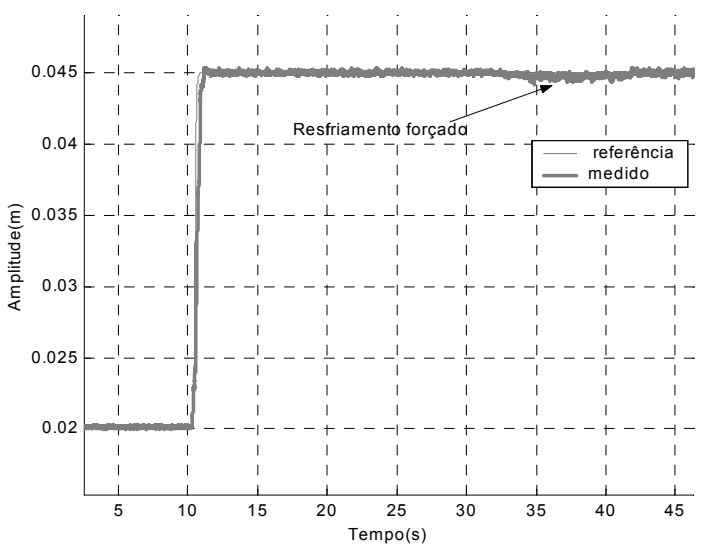

(a)

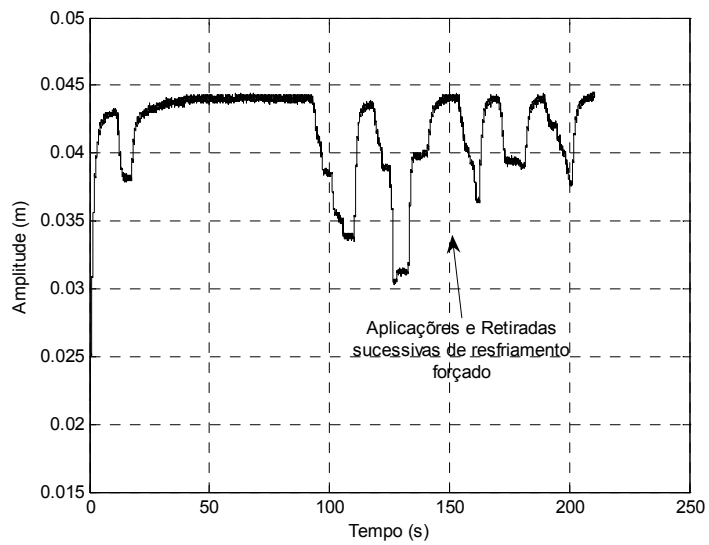

(b)

Figura 111 Sensibilidade à distúrbio por fluxo de ar, (a) Malha fechada SMC $\left(\lambda=38\right.$; $\phi=2$ e $\mathrm{K}_{\mathrm{SM}}=$ 76); (b) Malha aberta

Verifica-se portanto que o controlador por modos deslizantes SMC é um controlador pouco sensível aos distúrbios externos e variações de carga. É portanto, indicado para ser utilizado em atuadores baseados em ligas de memória de forma para as quais as condições ambientais não devem interferir no funcionamento do atuador na ocorrência da variação de tração da carga e variação dos parâmetros térmicos do fio de SMA. 


\section{CONCLUSÕES}

Neste trabalho realizou-se o projeto, implementação, testes e otimização de um atuador mecânico utilizando ligas de memória de forma.

Estes atuadores caracterizam-se por serem leves, compactos e silenciosos, sendo indicados para aplicações de micro-dispositivos. A grande desvantagem reside no fato de serem lentos, possuírem grande histerese e necessitarem de um sistema auxiliar de resfriamento forçado para melhorar seu desempenho dinâmico. Além disso, exigem um complexo sistema de controle para sua implementação prática. Apesar das dificuldades em se fazer o controle, esse tipo de atuador pode ser utilizado em várias aplicações práticas, sendo uma boa alternativa em aplicações onde tamanho, peso e nível de ruído são relevantes.

Foi mostrado o estudo de três casos de atuadores SMAs descritos na literatura, com vários tipos de sistema de refrigeração, confirmando a importância do atuador ser refrigerado a fim de melhorar sua resposta dinâmica.

No atuador desenvolvido no presente trabalho, foi proposto um inovador sistema de refrigeração com pastilha termoelétrica, que sana alguns problemas descritos em outros sistemas de refrigeração, como a existência de partes mecânicas móveis, complexos sistemas de automação e grande consumo de energia. Mostrou-se que este sistema de refrigeração forçada por pastilha termoelétrica é leve, não possui peças móveis e todo controle é realizado eletricamente, o que é uma grande vantagem em termos de facilidade de implementação.

Um modelo matemático simplificado foi implementado, baseado nas teorias obtidas na literatura e nas especificações do fabricante do fio de memória de forma. Os parâmetros do modelo foram ajustados por meio de procedimentos de identificação, e foram feitos ensaios práticos para validar o modelo resultante.

Foram estudadas diversas técnicas de sintonia descritas na literatura para otimizar o desempenho de um controlador PID em conjunto com o atuador SMA em estudo e conclui-se que o método com melhores resultados foi o baseado no critério ITAE, obtendo-se $0,37 \mathrm{~Hz}$ de largura de faixa. Conclui-se que o controlador PID pode ser utilizado de maneira limitada para esse tipo de atuador, uma vez que o 
controlador PID foi desenvolvido para ser utilizado em sistemas lineares e o atuador SMA é um sistema não linear com grande histerese.

Em seguida, apresentou-se de forma sucinta a teoria de controle não linear por modos deslizantes segundo Slotine e Li (1991) e foram feitos testes práticos de dois tipos de controle não linear descritos por Asharafiuon e Elahinia (2002), Elahinia (2004) e comprovando os efeitos de filtragem devido à camada limite.

Finalmente, foi realizado o projeto completo de controle por modos deslizantes acoplado a linearização por realimentação, incluindo o modelo matemático do atuador SMA. Comprovou-se que o controlador SMC obteve desempenho e largura de faixa superior ao controlador PID, alcançando $0,69 \mathrm{~Hz}$ de largura de faixa.

Avaliou-se o desempenho do projeto do controlador SMC quanto à mudança dos parâmetros de controle e os resultados experimentais obtidos mostraram que o controle por modos deslizantes apresenta boa resposta dinâmica mesmo com cálculo parâmetros não ajustados de maneira ótima. Realizou-se uma avaliação da sensibilidade a distúrbios de carga e distúrbios ambientais e verificou-se que o controlador SMC apresentou baixa sensibilidade a tais distúrbios.

Conclui-se, portanto, que o controle por modos deslizantes possui a capacidade de interagir com os parâmetros incertos do modelo e também com os efeitos não lineares do atuador em estudo. 


\section{REFERÊNCIAS}

ASADA, H.H.; MASCARO, S. Wet shape memory alloy actuators. In: INTERNATIONAL CONFERENCE ON ROBOTICS AND AUTOMATION, Taipei, 2003. Proccedings . New York: IEEE, 2003. p. 282-287.

ASHRAFIUON, H.; ELAHINIA, H. M. Nonlinear control of a shape memory alloy actuated manipulator. Jounal of vibration and acoustics. v. 124, p. 566-575, Oct.2002.

DANVIC. Definição de efeito Peltier. Disponível em: <http:// www.efeitopeltier.com.br>. Acesso em: 20 Dec. 2005.

DYNALLOY, INC. Flexinol - Wire specifications. Disponível em: < http:/l www.dynalloy.com>. Acesso em: 20 Dec. 2005.

EDWARDS, C.; SPURGEON, K .S. Sliding mode control: theory and applications London: TAYLOR \& FRANCIS, 1998.

ELAHINIA, H.M. Effect of systemdynamics on shape memory alloy behavior and control. 2004. 176p. Dissertation (Doctor)- Faculty of the Virginia Polytechnic Institute and University. Blacksburg, 2004.

FURUYA, Y.; SHIMADA, H. Shape memory actuator for robotic applications. In:_ Engineering aspect of shape memory alloys. London: ButterworthHeinemann, 1990. p. 338-355.

GORBET, B.R.; RUSSEL, A.R. Improve the response of sma actuators In : INTERNATIONAL CONFERENCE ON ROBOTIC AND AUTOMATION, Nagoya, 1995. Proccedings. New York: IEEE, 1995. p. 2299-2303.

GRANT, D.; HAYWARD, V.; LU, A. Design and comparison of high strain shape memory alloy actuators. In: INTERNATIONAL CONFERENCE ON ROBOTIC AND AUTOMATION. Albuquerque, 1997 . Proccedings. New York: IEEE, 1997. v. 1, p.260-265.

HIROSE, S.; IKUTA, K.; TSUKAMOTO, M. Mathematical model and experimental verification of shape memory alloy for designing micro actuator. In: MICRO ELECTROMECHANICAL SYSTEMS, AN INVESTIGATION OF MICROSTRUCTURES, SENSORS, ACTUATORS, MACHINES, AND ROBOTS, Nara, 1991. Proccedings. New York: IEEE, 1991. p.103-108. 
HODER, K.; SOLC, F.; VASINA, M. Shape memory alloy - Unconventional actuators. In: INTERNATIONAL CONFERENCE ON INDUSTRIAL TECNOLOGY, Maribor, 2003. Proceedings ICIT'03. New York : IEEE, 2003. p. 190-193.

HOLMAN, P.J. Transferencia de calor. México: C.E.C.S.A., 1977.

IMPLASTEC, Termal paste IP300 - characteristics. Disponível em <http://www.implastec.com.br>. Acesso em 20 Jan. 2006.[catálogo].

INCROPERA, P., F; WITT, D.P.D. Fundamentos de transferência de calor e de massa. 4. ed. Rio de Janeiro: LTC, 1998.

MAVROIDIS, C.; PFEIFFER, C.; MOSLEY, M. Conventional actuators, shape memory alloys and electrorheological fluids. |Invited: Chapter in automation, miniature robotcs and sensors for non - destructive testing and evaluation, Y. BarCohen Editor, 1999.|.

OGATA, K. Engenharia de controle moderno. 2. ed. São Paulo: Prentice Hall do Brasil, 1990

RYU, H.,S.; PARK, H., J. Auto-tuning of sliding mode control parameters using fuzzy logic, In: AMERICAN CONTROL CONFERENCE, 2001, Arlington, 2001 Proceeding of the 2001, New York: IEEE, 2001. Vol.1, p.618-623.

SEBORG, D.E.; EDGAR, T.F.; MELLICHAMP, D.A. Process dynamics and control. New York : Wiley, 1989.

SLOTINE, E. J. J.; LI, W. Applied nonlinear control. Englewood Cliffs: Prentice Hall, 1991.

SMITH, A. C.; CORRIPIO, B. A. Principle and practice of automatic process control. 2. ed. New York: Wiley,1997.

TANAKA,Y.; YAMADA, A. A Rotary actuator using shape memory alloy for a Robot, and Analysis of the Response with Load. In: IEEE/RSJ INTERNATIONAL WORKSHOP ON INTELLIGENT ROBOTS AND SYSTEMS, Osaka, 1991. Proceedings IROS '91, New York: IEEE, 1991. p.1163-1168. 
TEXAS A\&M SMART LAB. Definition of shape memory alloy. Disponivel em $:<h$ ttp://smart.tamu.edu/overview/smaintro/simple/definition.html>. Acesso em :18 out. 2004.

UTKIN, V. I. Variable structure systems with sliding modes, Transactions on automatic control, New York: IEEE, Apr.1977. vol.ac-22, p 212 - 222.

ZIEGLER, G. J.; NICHOLS, B. N. Optimum settings for automatic controllers. In: THE AMERICAN SOCIETY OF MECHANICAL ENGINEERS Transactions of the A.S.M.E., New York: ASME, Nov. 1942. p.759-765. 


\section{APÊNDICE A- DESENHOS MECÂNICOS DO ATUADOR SMA}

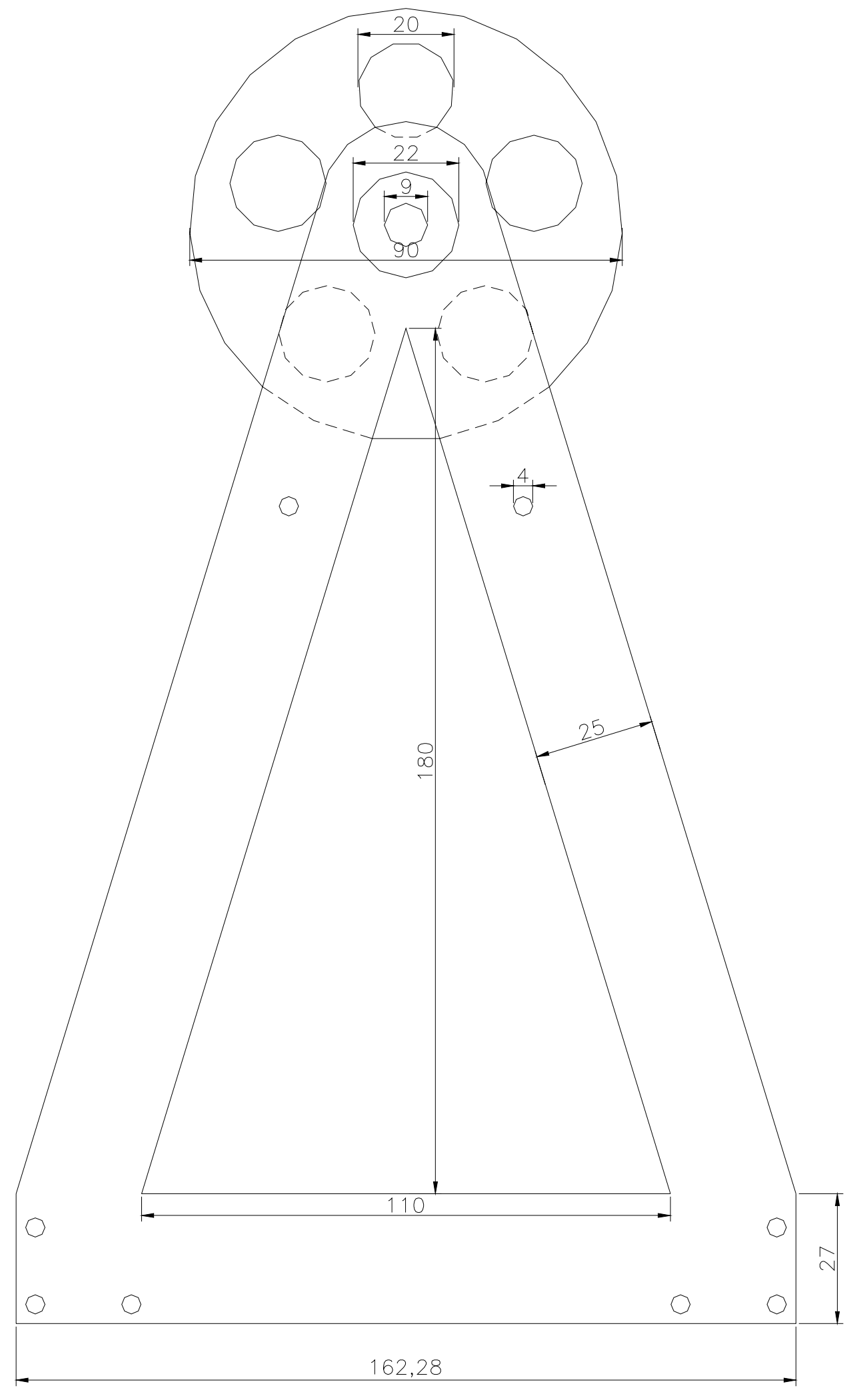

Desenho mecânico do atuador SMA lateral esquerda (medidas em mm) 


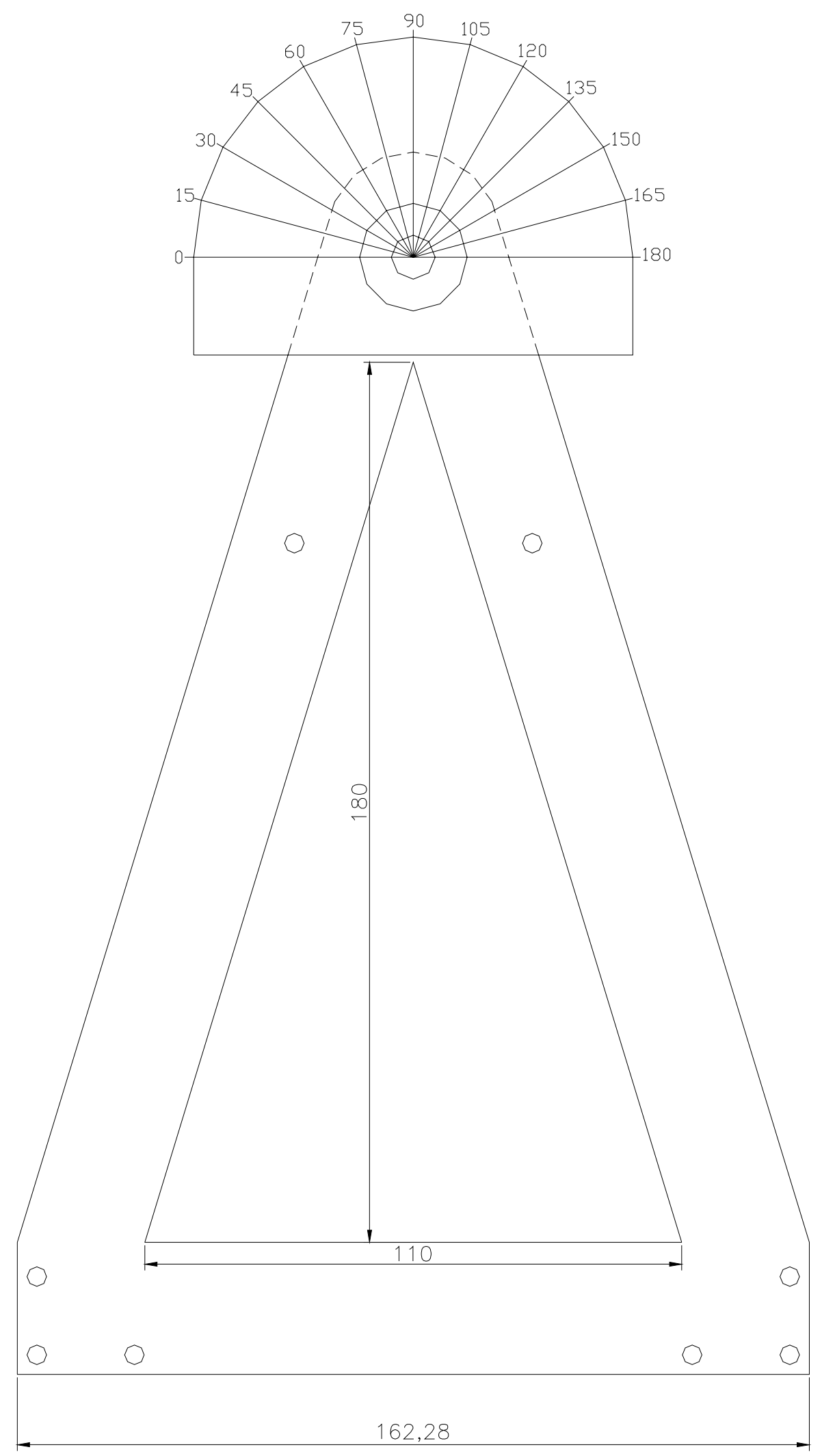

Desenho mecânico do atuador SMA lateral direita (medidas em mm) 


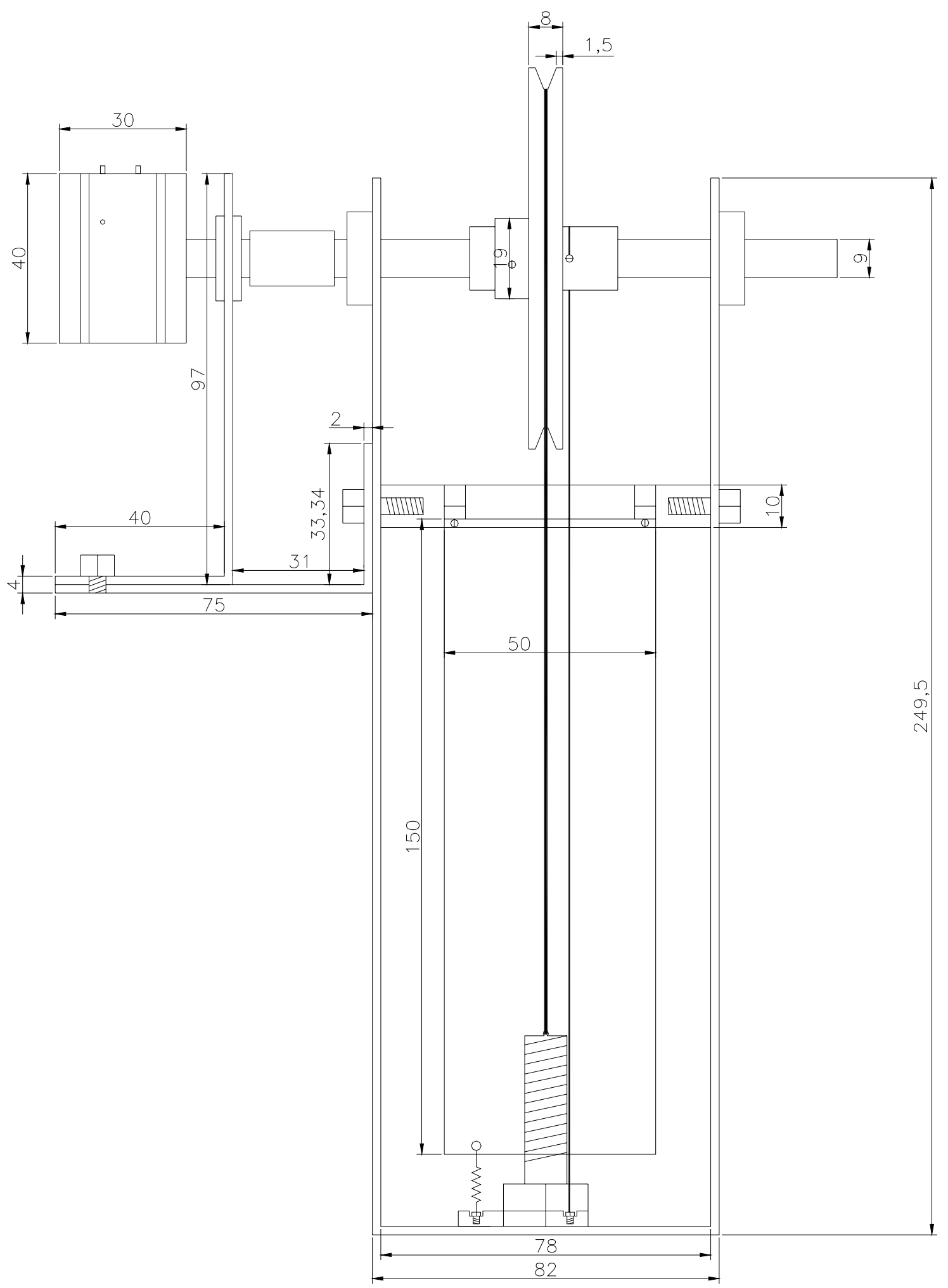

Desenho mecânico do atuador SMA frontal (medidas em mm) 


\section{APÊNDICE B- DETALHES DA PASTILHA TERMOELÉTRICA}

Segundo Danvic (2005), as pastilhas termoelétricas operam segundo o efeito Seebek-Peltier. Sabe-se que há um efeito de aquecimento ou resfriamento quando uma corrente elétrica passa por dois condutores de diferentes tipos de materiais. Uma diferença de potencial elétrico (ddp) é aplicada aos pólos de dois materiais condutores de corrente elétrica com naturezas distintas, que, ao serem unidos na extremidade, faz com que haja a circulação de uma corrente elétrica no circuito criando-se uma diferença de temperatura entre o ponto de união ("junta quente") e os pólos onde estão sendo aplicada a ddp ("junta fria").Essa diferença de temperatura (efeito Seebek-Peltier) fará o calor se movimente de um lado para o outro. Um exemplo típico é o que ocorre em um termopar. A diferença de temperatura entre a junta quente e a junta fria gera uma diferença de potencial (ddp) nos seus terminais. Analogamente se aplicarmos uma tensão nos terminais de um termopar ocorrerá uma diferença de temperatura entre a junta quente e ajunta fria

Esse efeito em condutores metálicos possui valores de pequena intensidade não sendo utilizado na prática como trocador de calor, limitando-se seu uso em sensores de temperatura (ex. termopares). Na Figura 112 mostra-se como ocorre o efeito Seebeck-Peltier.

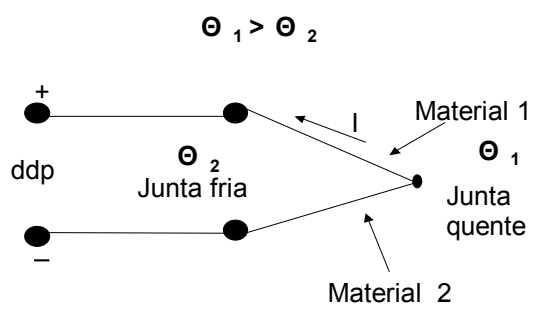

Figura 112 Efeito Seebeck-Peltier $\left(\operatorname{ddp} \alpha \Theta_{1}-\Theta_{2}\right)$

Uma típica pastilha termoelétrica contém uma série de elementos semicondutores do tipo $\mathrm{P}$ e tipo $\mathrm{N}$ agrupados em pares Figura 113, que agirão como condutores de diferentes natureza. 

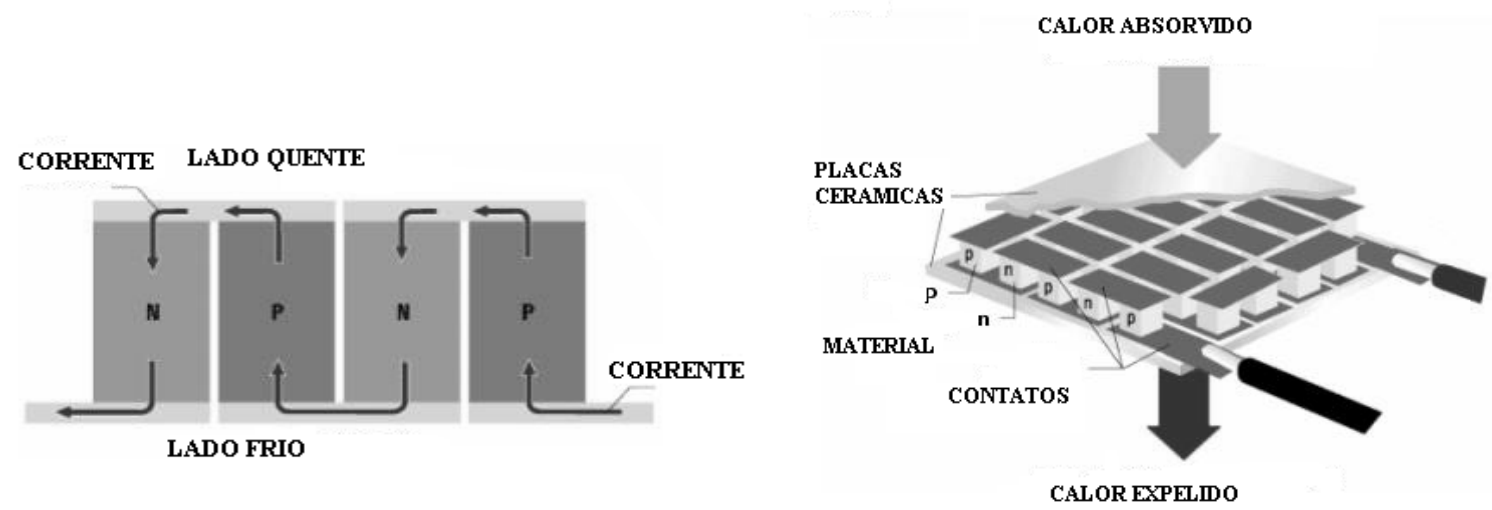

Figura 113 Associação de pastilhas termoelétricas

Esses elementos $(P, N)$ são soldados entre duas placas cerâmicas, eletricamente em série e termicamente em paralelo. Quando uma corrente circula por um ou mais pares de elementos do tipo $\mathrm{P}$ para o tipo $\mathrm{N}$, ocorre uma redução de temperatura da junta ("lado frio"), resultando uma absorção do calor do meio ambiente. Este calor é transferido pela pastilha sendo transportados pelos elétrons e enviados para o outro lado da pastilha ("lado quente"). O fenômeno ocorre quando uma carga muda de um material para outro, na junção, ela emite ou absorve essa diferença na energia causando o efeito Seebeck-Peltier.

A capacidade de bombeamento de calor de um resfriador é proporcional à corrente e o número de elementos tipo $\mathrm{N}$ e tipo $\mathrm{P}$. Logicamente, há um limite para esta capacidade, que ocorre quando o calor bombeado se iguala ao calor gerado internamente por Efeito Joule. Este valor de calor transferido máximo é conhecido como Qmáx. A corrente elétrica associada ao Qmáx é conhecida como Imáx (corrente máxima), e a tensão correspondente como Vmáx (tensão máxima). Se um módulo estiver completamente isolado termicamente do meio ambiente e estiver circulando pela pastilha uma Imáx, produzirá uma diferença máxima de temperatura entre o lado frio e a quente conhecida como dTmáx (diferença máxima de temperatura).

As pastilhas termoelétricas são leves e silenciosas e são recomendadas para resfriar pequenos dispositivos como, por exemplo, microprocessadores. Essas pastilhas proporcionam uma grande precisão de temperatura, uma vez que não possuem peças móveis. Contudo, o efeito Seebeck-Peltier começa a perder sua vantagem para transferência de calor acima de 200W. Apenas em aplicações 
militares ou científicas nas quais, em condições especiais e com associação de várias pastilhas, pode-se obter a transferência de algumas dezenas de KW.

As pastilhas, quando devidamente polarizadas com correntes e tensões nominais, possuem uma baixa manutenção, grande durabilidade e alta confiabilidade. Devido a sua alta precisão, as pastilhas podem ser utilizadas para controle térmico, uma vez que podem também aquecer bastando inverter a corrente que circula nos seus elementos.

Um único módulo pode transferir $125 \mathrm{~W}$ de potência, mas podem-se empilhar ou associá-las de forma a aumentar essa potência. Com uma diferença de temperatura entre o lado quente e o lado frio que não ultrapasse $60^{\circ}$, utiliza-se normalmente uma única pastilha.

As pastilhas possuem, em média, lados de $50 \mathrm{~mm} \times 50 \mathrm{~mm}$. Este é um limite prático pois, devido à grande diferença de temperatura entre o lado quente e o frio, a dilatação e contração causaria fadiga mecânica nos pontos de solda, danificando as ligações elétricas.

As pastilhas trabalham, em geral, com uma tensão de 10,4 V com fator de ripple de 10 a $15 \%$. A corrente nominal é cerca de $4,1 \mathrm{~A}$, resultando numa potência elétrica consumida de 42,64W para fazer a troca de calor.

Deve-se levar em consideração essa potência requerida pela pastilha na implementação de um trocador de calor. Na troca de calor, o lado quente terá a potência retirada do sistema que está sendo resfriado, além dos 42,64W da própria pastilha termoelétrica. Assim torna-se obrigatório a utilização de um dissipador de calor no lado quente e em muitas vezes com ventilador para que a troca de calor seja eficiente e não ocorra a destruição da pastilha, derretendo-se as soldas das junções. A Figura 114 mostra a configuração típica de como pode ser montado o dissipador para operar junto com a pastilha termoelétrica.

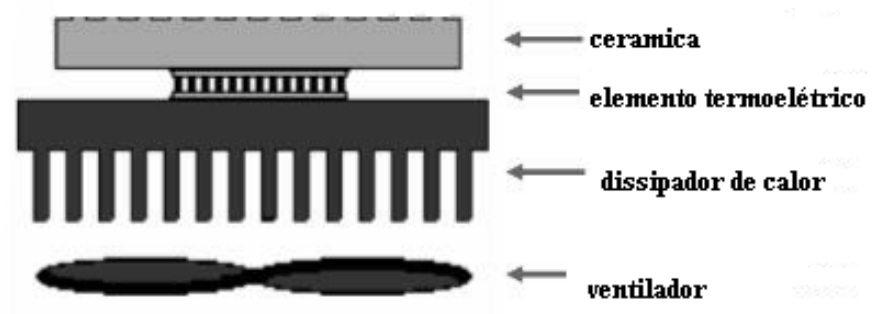

Figura 114 Pastilha termoelétrica com dissipador e ventilador 


\section{APÊNDICE C- DIAGRAMA DO CONDICIONADOR DE SINAIS}

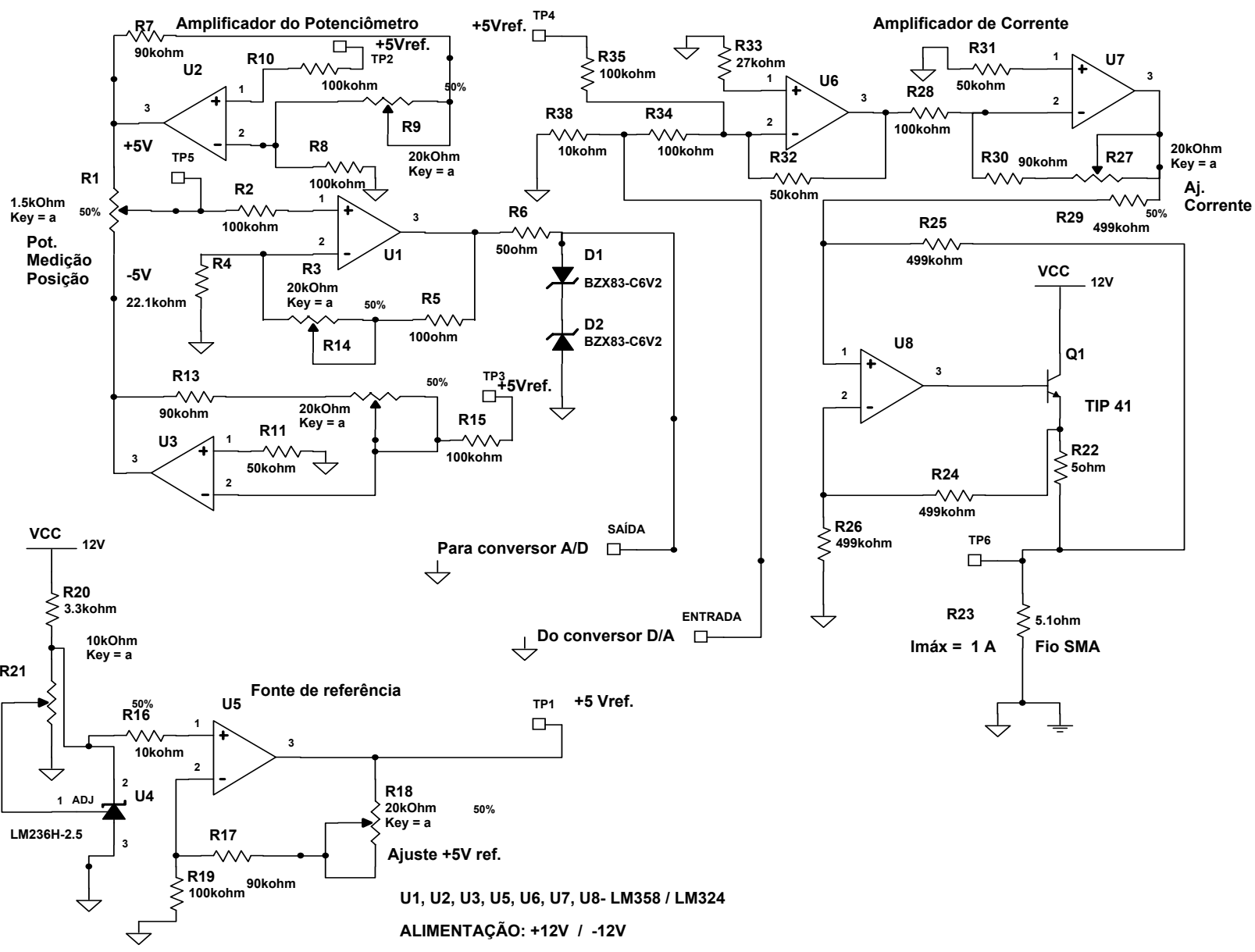

